Universidade de São Paulo

Instituto de Física

\title{
DESENVOLVIMENTO DE UM SISTEMA DE MEDIDAS PARA ESTUDOS DE EFEITOS DE RADIAÇÃO EM DISPOSITIVOS ELETRÔNICOS: METODOLOGIAS E ESTUDOS DE CASOS
}

\author{
Vitor Ângelo Paulino de Aguiar
}

Orientador: Prof. Dr. Nilberto Heder Medina

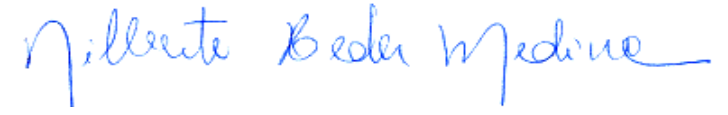

Tese de doutorado apresentada ao Instituto de Física como requisito parcial para a obtenção do título de Doutor em Ciências.

Banca Examinadora:

Prof. Dr. Nilberto Heder Medina - Orientador -IFUSP

Prof. Dr. Vito Roberto Vanin - IFUSP

Prof. Dr. Maurício Moralles - IPEN

Prof. Dr. Maurício Tizziani Pazioanotto - ITA

Prof. Dr. Ênio Frota da Silveira - PUC/RJ 
FICHA CATALOGRÁFICA

Preparada pelo Serviço de Biblioteca e Informação do Instituto de Física da Universidade de São Paulo

Aguiar, Vitor Ângelo Paulino de

Desenvolvimento de um sistema de medidas para estudos de efeitos de radiação em dispositivos eletrônicos: metodologias e estudos de casos. São Paulo, 2019.

Tese (Doutorado) - Universidade de São Paulo. Instituto de Física. Depto. de Física Nuclear.

Orientador: Prof. Dr. Nilberto Heder Medina

Área de Concentração: Física Nuclear Aplicada

Unitermos: 1. Instrumentação(Física); 2. Física nuclear; 3. Dispositivos eletrônicos; 4. Radiação ionizante. 
University of São Paulo

Physics Institute

\title{
DEVELOPMENT OF A MEASUREMENT SYSTEM FOR RESEARCH ON RADIATION EFFECTS ON ELECTRONIC DEVICES: METODOLOGIES AND CASE STUDIES
}

\author{
Vitor Ângelo Paulino de Aguiar
}

Supervisor: Prof. Dr.Nilberto Heder Medina

Thesis submitted to the Physics Institute of the University of São Paulo in partial fulfillment of the requirements for the degree of Doctor of Science.

Examining Committee:

Prof. Dr. Nilberto Heder Medina - Supervisor (IFUSP)

Prof. Dr. Vito Roberto Vanin - IFUSP

Prof. Dr. Maurício Moralles - IPEN

Prof. Dr. Maurício Tizziani Pazioanotto - ITA

Prof. Dr. Ênio Frota da Silveira - PUC/RJ 

Aos meus avós Walter e Waldemarina (in memorian) 
What would you think if I sang out of tune? Would you stand up and walk out on me?

Lend me your ears and I'll sing you a song

And I'll try not to sing out of key

Oh, I get by with a little help from my friends

I get high with a little help from my friends

Gonna try with a little help from my friends

What do I do when my love is away?

(Does it worry you to be alone?)

How do I feel by the end of the day?

(Are you sad because you're on your own?)

No, I get by with a little help from my friends

I get high with a little help from my friends

gonna try with a little help from my friends

Do you need anybody?

I need somebody to love

Could it be anybody?

I want somebody to love

Would you believe in a love at first sight?

Yes, I'm certain that it happens all the time

What do you see when you turn out the light?

I can't tell you, but I know it's mine

Oh, I get by with a little help from my friends

I get high with a little help from my friends

Gonna try with a little help from my friends

Do you need anybody?

I just need someone to love

Could it be anybody?

I want somebody to love

Oh, I get by with a little help from my friends

Gonna try with a little help from my friends

Oh, I get high with a little help from my friends

Yes, I get by with a little help from my friends

With a little help from my friends

John Lennon e Paul McCartney 
"Tente outra vez"

Raul Seixas, orientando seu aluno em Física Experimental 


\section{Agradecimentos}

Agradeço primeiro à minha família, em especial aos meus pais, Edson e Beti, e meu irmão Guilherme pela compreensão e apoio durante o curso de Física e a pósgraduação, nunca me forçando a um "emprego de verdade"e reconhecendo o valor do caminho escolhido. Aos meus avós Walter e Waldemarina (in memorian) pelo apoio incondicional e pelos valores transmitidos enquanto aqui estiveram e que carrego comigo. À Kelme, pelo carinho e companheirismo que têm me dedicado neste último ano.

Agradeço também àqueles que me ajudaram a dar os primeiros passos na pré-carreira acadêmica, professores Max e Colognesi da ETE Lauro Gomes.

Aos amigos do IGc-USP, por toda a experiência que tive com eles e todo apoio e amizade com que sempre me presentearam, em especial ao professor Paulo Giannini, Adriano, Xiwawa, Carlos, Elaine, Daniel, Rodolfo. Ao Isaac, que além de tudo isso durante os anos em que lá estive, ainda ajudou neste trabalho de doutorado com muita disposição. Sem ele, talvez os caminhos trilhados não teriam conduzido a essa tese.

Formar-se na Física é uma experiência dolorosa, mas esse caminho pelas chamas do inferno pode ser muito mais leve se junto com você caminham pessoas especiais. Não teria me formado nunca sem a companhia constante (ou nem tanto) do Danosa, Luiz, Bardo, Al Queda, Mano, Gomes, Hellmann's, Kamika, Ismael, Chaps e Parra, mas melhor do que os diplomas que eles me ajudaram a conseguir foram os inúmeros churrascos, cervejas, pizzas no Basílio, truco na mesa da procrastinação e histórias tão inesquecíveis quanto impublicáveis.

Aos professores do IFUSP: Ribas, por toda ajuda com instrumentação e todos os esclarecimentos sobre poder de freamento; Suaide, pela ajuda com o ROOT; Zwinglio pela ajuda constante com estatística; Manfredo e Zero pelas sugestões; Vito e Márcia pela revisão crítica da qualificação; Beth por emprestar o material da dosimetria sempre que necessário; Marcelo e Marco por trazer o experimento com o SAMPA chip e o detector anular, e a todos os outros professores e colegas do DFN. Aos professores das 
equipes de Física Experimental com os quais tive o privilégio de dividir as disciplinas, por ajudar a me tornar mais capacitado a transmitir o conhecimento. Agradeço também a alguns dos ótimos professores com quem tive aula, pelo conhecimento, inspiração e empolgação que souberam transmitir. Agradeço ainda aos membros da banca examinadora desta tese de doutoramento, professores Vito Vanin (novamente), Maurício Moralles (IPEN), Maurício Pazioanotto (ITA) e Ênio Frota da Silveira (PUC-RJ), pelas correções e sugestões que muito enriqueceram este trabalho.

Aos funcionários do DFN/IFUSP, pois sem eles este trabalho não teria saído do papel. Aos mecânicos Otávio, Edmilson, Pedro, Marcos, Alex, Clineo e Roberto, que trabalharam muito nas dezenas (ou centenas?) de peças mecânicas para confeccionar e modificar, além da montagem destas na canalização e as várias dicas nos projetos. Ao Celso, que ajudou nos projetos das câmaras e projetou o painel de controle de vácuo, além dos testes com leak detector, colagem das peças com vazamento, etc., e ao Luiz Marcos, sempre disposto a compartilhar seu imenso conhecimento de vácuo. Ao João, por transformar meus rabiscos em desenhos mecânicos profissionais. Ao Antônio, por ajudar sempre que necessário na montagem da canalização. Ao nosso chef de catodos Zé Carlos de Abreu, por atender aos pedidos cada vez piores de cadinhos "salada de frutas". Ao Rone, Silvinho, Jorge, Serginho e Márcio, por manterem toda a estrutura do acelerador sempre funcionando apesar de todas as dificuldades que o orçamento impõe. À Wanda e ao Tromba, pelos "trocentos"alvos de ouro preparados durante este trabalho. Aos grandes Messias, Wellington, Vitório, Daniil e Ricardo, que ajudaram a montar os diversos sistemas eletrônicos, como o painel de vácuo, as caixa de controle e leitura de fendas e os outros módulos de apoio. Ao Fábio pela ajuda com os computadores, às secretárias Gilda, Zenaide e Andréia pelo apoio acadêmico e ao grande Sérgio Tanaka pela ajuda com as compras e cotações. Todos estes ajudaram com muita presteza e no desenvolvimento da nova canalização, mas além disso, com muita amizade.

Aos professores da FEI, Marco Antônio Melo, Ricardo Stolf e Renato Giacomini 
e os pós-graduandos Juliano e Felipe, pela proposta de medidas com o 3N163 ainda durante o mestrado e o desenvolvimento da placa de aquisição de dados que gerou os resultados para o transistor e que inspiraram diversos desenvolvimentos subsequentes deste trabalho.

Aos colegas da UFRGS e da PUC-RS, Roger, Paulo, Adria, Fabian e Fernanda pelos vários experimentos que ajudaram na minha formação na área, bem como a aumentar o currículo. Em especial, ao Fábio Benevenuti, que doou a placa com o FPGA e a programou para os experimentos com o dispositivo digital que aparecem nesta tese.

Ao pessoal do Centro de Tecnologia da Informação Renato Archer (CTI), em especial Saulo Finco, por depositar a confiança no meu trabalho e possibilitar minha inserção no Projeto CITAR (além de toda a ajuda institucional possível), Luis Seixas pela ajuda com o PXI e Daniel Lazari pela ajuda na escolha da memória SRAM.

Aos amigos do LAMFI, pelo companheirismo, pelos almoços e subsequentes cafés, pizzas e cervejadas de vez em quando, e falação de besteira de vez em sempre, e por toda a ajuda em diferentes fases do projeto: Renan pela ajuda com alguns dos projetos mecânicos, Alisson por sua imensa paciência em me ensinar e corrigir minhas burradas em LabView, Cléber e Tiago pelas ajudas com análise de dados e RBS e as valiosas discussões, Marquinhos por rodar as análises de RBS e ao Mário.

Aos amigos do DFN que não estão mais entre nós, Renatão, Erich e Jeremias, que contribuiram nas primeiras fases deste trabalho. Aos amigos que estão por aqui, Valdir, Rafael, Paula, Hellen, Vinícius e Oswaldo, seja na ajuda durante os períodos de máquina (que foram muitos), ajudando com programação, raios-X, dúvidas de estatística, ROOT, Latex, Ubuntu e todas essas desgraças de programas, discussões de resultados, revisão do texto e sugestões, além do apoio constante nesses anos de convivência. Agradeço ainda ao David Flechas da Universidade Nacional da Colômbia, pela colaboração nos últimos períodos de máquina e as simulações com GEANT.

Aos amigos do grupo de radiação em dispositivos eletrônicos: Shila, pelo apoio, 
trocas de idéias, ajuda nos períodos de máquina e sugestões e discussões sobre os dados. Fernando Aguirre (versão sóbria do Al Queda) por sua colaboração nos períodos de máquina e Saulo (o preferido do Medina), pela ajuda constante na canalização e nas intermináveis discussões sobre efeitos de radiação.

Ao Conselho Nacional de Desenvolvimento Científico e Tecnológico (CNPq), à Comissão Nacional de Energia Nuclear (CNEN) e ao Instituto de Física, pelo apoio financeiro e institucional. À FAPESP pela verba concedida para a construção da canalização.

Por último, agradeço ao Eduardo por ensinar tanto sobre instrumentação e fazer todos os esforços possíveis para que este trabalho fosse realizado, ao Nemi por ter uma paciência infinita em ajudar a fazer os experimentos funcionarem, discutir dados e ensinar tanta coisa durante meu mestrado e doutorado, e ao Medina, que desde a iniciação científica tem me apoiado, orientado, ensinado e incentivado nesta trajetória.

A todos estes (e peço que me perdoem se esqueci de alguém) meu "muito obrigado". De todos os frutos deste trabalho, o que mais me dá satisfação são as amizades cultivadas no seu decorrer. 


\section{Resumo}

Efeitos causados pela interação da radiação ionizante em dispositivos eletrônicos consistem numa preocupação crescente em diversos segmentos, como as aplicações aeroespaciais e em física de altas energias. Entre os efeitos de radiação induzidos por íons pesados estão os chamados de Efeitos de Eventos Isolados (Single Event Effects - SEE), em que o impacto de um único íon pode ser capaz de gerar um efeito observável, através da elevada deposição de energia e consequente geração de pares elétron-lacuna. O estudo destes efeitos requer um acelerador de partículas capaz de prover feixes uniformes de íons pesados com baixo fluxo. Neste trabalho, desenvolvemos um sistema para produção de feixes de íons pesados para estudar SEE no Acelerador Pelletron 8UD, utilizando as técnicas de desfocalização e espalhamento múltiplo em folhas de ouro. O sistema foi projetado para prover feixes com intensidades entre $10^{2}$ e $10^{5}$ partículas $/ \mathrm{s} / \mathrm{cm}^{2} \mathrm{com}$ uniformidade maior que $90 \%$ numa área circular de diâmetro de 1,5 cm, operando em regime de alto-vácuo. Um manipulador de amostras permite a movimentação do dispositivo sob teste com precisão de $2,5 \mu m$ e um sistema de aquisição de dados dedicado foi desenvolvido, permitindo a automação de medidas. O sistema foi caracterizado com feixes de ${ }^{1} \mathrm{H},{ }^{12} \mathrm{C},{ }^{16} \mathrm{O},{ }^{19} \mathrm{~F},{ }^{28} \mathrm{Si},{ }^{35} \mathrm{Cl}$ e ${ }^{63} \mathrm{Cu}$ a várias energias, apresentando fluxo e uniformidade adequados aos experimentos em diversas configurações de focalização e folhas espalhadoras, e tem sido utilizado por diversos grupos de pesquisa. O novo sistema foi utilizado para estudar o efeito das camadas de isolamento e metalização na coleta de carga e geração de eventos observáveis em um dispositivo analógico e em um dispositivo digital, de modo a estabelecer metodologias de trabalho adequadas para estudos precisos de mecanismos de ocorrência de efeitos de radiação. O dispositivo analógico estudado foi um transistor p-MOS, onde o sinal de corrente induzido pelo impacto de íons diversos foi analisado de modo a obter a seção de choque de eventos e a carga 
gerada, permitindo determinar a espessura da camada de metalização em 1,28(2) $\mu m$, e a camada de coleta de carga dependente do LET e alcance da partícula incidente, variando entre 6,0 e 11,0 $\mu \mathrm{m}$. O dispositivo digital estudado foi uma memória SRAM $28 \mathrm{~nm}$, onde foi observada uma forte dependência da seção de choque de eventos com a penetração do feixe no dispositivo. Associando as camadas de metalização e isolamento a um meio efetivo de interação, obteve-se que toda a área sensível do dispositivo só pode ser excitada, isto é, nela ocorrerem eventos observáveis, para partículas com alcance, no meio efetivo, entre 14 e $20 \mu m$, embora partículas com alcance de até $10 \mu m$ sejam capazes de sensibilizar até $50 \%$ da área ativa do dispositivo.

Palavras-chave: Single-Event-Effects, Espalhamento múltiplo, Instrumentação Nuclear, MOSFET, SRAM 


\begin{abstract}
Effects on electronic devices caused by interactions of ionizing radiation are a main concern in several fields, such as aerospace applications and high-energy physics. Among the heavy-ion induced radiation effects are the Single Event Effects, in which a strike of a single ion can be enough to generate an observable effect, as a result of the high energy deposition and thus electron-hole pairs generation. The study of these effects requires the use of uniform, low-flux particle beams. In this work, we developed a system for production of heavy ion beams for SEE studies at Pelletron 8UD accelerator, through the defocusing and multiple scattering in gold foil techniques. The setup can provide ion beams with intensities ranging from $10^{2}$ e $10^{5}$ particles $/ \mathrm{s} / \mathrm{cm}^{2}$ with uniformity better than $90 \%$ in an circular area of $1.5 \mathrm{~cm}$ diameter, operating under high-vacuum. A sample manipulador allows device under test positioning with a precision of $2.5 \mu \mathrm{m}$, and a dedicated data acquisition system was developed, allowing measurement automation. The system was characterized with ${ }^{1} \mathrm{H},{ }^{12} \mathrm{C},{ }^{16} \mathrm{O},{ }^{19} \mathrm{~F},{ }^{28} \mathrm{Si},{ }^{35} \mathrm{Cl}$ and ${ }^{63} \mathrm{Cu}$ ion beams at several energies, presenting flux and uniformity adequate for SEE studies in many different configurations, and it is being used by several research groups. The new facility was used to study the effect of isolation and metalization layers in charge collection and observable events generation in an analog and in a digital device, in order to establish proper metodologies for precise studies of radiation effects mecanisms. The analog device studied was a p-MOS transitor, from which the heavy-ion impact induced current signal was analised to obtain cross-section and colected charge, allowing to determine metalization layer thickness to be 1.28(2) $\mu \mathrm{m}$, and charge collection dependency on particle LET and range, varying from 6.0 to $11.0 \mu \mathrm{m}$. The digital device studied was a 28nm SRAM memory, where a strong dependency of cross-section with particle range in the device was observed. Associating to the metal and insulating layers an effective
\end{abstract}


medium, it was observed that the complete sensitive area can be excited only by particle with ranges in effective medium between 14 and $20 \mu m$, although particles with ranges up to $10 \mu \mathrm{m}$ are capable of sensibilizing up to $50 \%$ of device's active area.

Keywords: Single-Event-Effects, Multiple Scattering, Nuclear Instrumentation, MOSFET, SRAM 


\section{Lista de Figuras}

i.1 Localização das ocorrências de upsets de memória no satélite UOSAT2 . 3

i.2 Mapa das instalações de irradiação de dispositivos eletrônicos com feixes de íons pesados até $2011 \ldots \ldots$. . . . . . . . . . . . . . 6

1.1 Poder de Freamento Eletrônico ． . . . . . . . . . . . . . . . . 17

2.1 Espalhamento elástico . . . . . . . . . . . . . . . . . . . . 28

2.2 Espalhamento por um potencial . . . . . . . . . . . . . . . . 30

2.3 Distribuição gaussiana do feixe ao passar por uma folha difusora . . . . 37

2.4 Perfis de feixes espalhados em baixa e alta energia . . . . . . . . . . . 41

3.1 Exemplos de plano de fase e elipses de feixe . . . . . . . . . . . . 46

3.2 Desenho esquemático de um quadrupolo magnético . . . . . . . . . . . . 49

3.3 Astigmatismo numa lente quadrupolar, configuração dubleto . . . . . . . 50

3.4 Astigmatismo numa lente quadrupolar, configuração tripleto . . . . . . . 50

4.1 Fonte de íons . . . . . . . . . . . . . . . . . . . . 55

4.2 Esquema do Acelerador . . . . . . . . . . . . . . . . 56

4.3 Carregamento do terminal . . . . . . . . . . . . . 57

4.4 Medida de ressonância magnética . . . . . . . . . . . . . . . . . 60

4.5 Acelerador Pelletron . . . . . . . . . . . . . . . . . . . . . . 62

4.6 Sala Experimental . . . . . . . . . . . . . . . . . . . . 62 
5.1 Plano de fase numa das direções transversais para um feixe de ${ }^{12} C 50 \mathrm{MeV} 64$

5.2 Histograma com as distribuições de posição de partículas nas duas condições . . . . . . . . . . . . . . . . . . . . . . . 64

5.3 Esquema da canalização zero graus contendo a condição de focalização do feixe de ${ }^{16} \mathrm{O}$ a $60 \mathrm{MeV} \ldots \ldots \ldots \ldots \ldots$

5.4 Planos de fase transversais e seções transversais do feixe de ${ }^{16} O$ a 60 $\mathrm{MeV}$ em diversos pontos da canalização . . . . . . . . . . . . . . . . 68

5.5 Esquema de um sistema de 3 câmaras com dois espalhadores. . . . . . . 72

5.6 Uniformidade segundo o método Meyer-Montenegro para distância 4,3 m 72

5.7 Uniformidade segundo o método Meyer-Montenegro para distância 3,0 m 72

5.8 Intensidade segundo o método Meyer-Montenegro para distância 4,3 m . 73

5.9 Intensidade segundo o método Meyer-Montenegro para distância 3,0 m . 73

5.10 Intensidade relativa transmitida à segunda folha . . . . . . . . . . . . 74

5.11 Primeiros cálculos de Monte-Carlo realizados para ${ }^{12} C 50 \mathrm{MeV}$. . . . 76

5.12 Perfis simulados para o feixe de ${ }^{12} C 50 \mathrm{MeV} \ldots \ldots \ldots . \ldots 78$

5.13 Perfis simulados para o feixe de ${ }^{28} \mathrm{Si} 70 \mathrm{MeV} \ldots \ldots . \ldots 79$

5.14 Carbono - desvio-padrão . . . . . . . . . . . . . . . . . . . 81

5.15 Carbono - curtose . . . . . . . . . . . . . . . . . . 81

5.16 Carbono - uniformidade . . . . . . . . . . . . . . . 82

5.17 Carbono - transmitância . . . . . . . . . . . . . . . . . . . . . . 82

5.18 Silício - desvio-padrão . . . . . . . . . . . . . . . . . . 84

5.19 Silício - uniformidade . . . . . . . . . . . . . . . . . . . . . . 84

5.20 Silício - transmitância . . . . . . . . . . . . . . . 85

6.1 Esquema ilustrativo da canalização . . . . . . . . . . . . . . 88

6.2 Estruturas e elementos de manipulação de monitoramento no setor I . . 90

6.3 Câmaras gêmeas . . . . . . . . . . . . . . . . . . . . 91 
6.4 Câmara de irradiação . . . . . . . . . . . . . . . . . . . . . 93

6.5 Sistemas de vácuo . . . . . . . . . . . . . . . . . . . . . 95

6.6 Manipulação de amostras . . . . . . . . . . . . . . . . . . . . . 97

6.7 Programa LabView de movimentação de amostras . . . . . . . . . . . . 98

6.8 Esquema da eletrônica de aquisição . . . . . . . . . . . . . . . . . . . . . 101

6.9 Programa LabView de aquisição de dados . . . . . . . . . . . . . . . . . 102

6.10 Eletrônica de aquisição . . . . . . . . . . . . . . . . . . . . . . . . 102

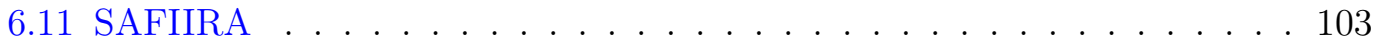

7.1 Sinal de coleta de carga no beam scanner do SAFIIRA . . . . . . . . 106

7.2 Imagem do feixe nos cintiladores . . . . . . . . . . . . . . . 107

7.3 Distribuições de partículas na posição de irradiação para diversas condições de espalhamento do feixe de ${ }^{12} C 35 \mathrm{MeV}$ e segunda folha espalhadora de $649 \mu \mathrm{g} / \mathrm{cm}^{2} \ldots \ldots \ldots \ldots \ldots$. . . . . . . . . . . . . . 108

7.4 Distribuições de partículas na posição de irradiação para diversas condições de espalhamento do feixe de ${ }^{16} O$. . . . . . . . . . . . . . . . . . . 109

7.5 Distribuições de partículas na posição de irradiação para diversas condições de espalhamento do feixe de ${ }^{28}$ Si $47 \mathrm{MeV}$. . . . . . . . . . . . . . . 110

7.6 Distribuições de partículas na posição de irradiação para diversas condições de espalhamento do feixe de ${ }^{19} F 49 \mathrm{MeV}$. . . . . . . . . . . . . . 112

7.7 Distribuições de partículas na posição de irradiação para feixes de ${ }^{1} H 15$ $\mathrm{MeV}$ e ${ }^{63} \mathrm{Cu} 78 \mathrm{MeV} \ldots \ldots \ldots \ldots \ldots \ldots$

7.8 Perfil de contagens no detector anular . . . . . . . . . . . 116

8.1 Estrutura de bandas . . . . . . . . . . . . . . . . . . . . . . . 124

8.2 Diodo . . . . . . . . . . . . . . . . . . . . . . . . . 129

8.3 Representação esquemática de um MOSFET . . . . . . . . . . . . . . . 130

8.4 Fotografia de um n-MOSFET . . . . . . . . . . . . . . . 130 
8.5 Curvas características de um n-MOSFET genérico . . . . . . . . 131

8.6 Fotografia de um circuito flip-flop . . . . . . . . . . . . . . . . . 132

8.7 Desenho esquemático de uma estrutura CMOS . . . . . . . . . . . . 132

8.8 Ilustração da sequência de fabricação de uma estrutura nMOS . . . . . . 133

8.9 Ilustração esquemática de uma estrutura de três níveis de metalização 133

8.10 Eletromicrografia de uma seção transversal de uma estrutura com quatro níveis de metalização . . . . . . . . . . . . . . . . . . . . . . . 134

8.11 Eletromicrografia de uma estrutura com seis níveis de metalização, após corrosão seletiva do material isolante . . . . . . . . . . . . . . . . . . . 134

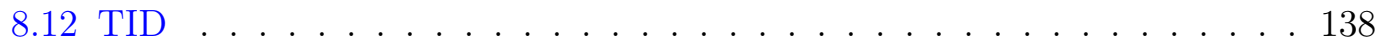

8.13 Defeitos cristalinos . . . . . . . . . . . . . . . . . 139

8.14 Processo de formação do funil . . . . . . . . . . . . . . . . . . . . 143

8.15 Comportamento dos parâmetros elétricos na presença do funil . . . . . . 144

8.17 Forma do pulso SEE . . . . . . . . . . . . . . . . . . . . 146

8.18 Seção de choque SEE em um FPGA . . . . . . . . . . . . . . . . 150

9.1 Simulações de corrente no 3N163 . . . . . . . . . . . . . . . 156

9.2 Esquema elétrico da placa Sensora de Eventos em transistor PMOS 3N163157

9.3 Vista da placa Sensora de Eventos para o transistor PMOS 3N163. . . . 158

9.4 Variação do LET com a penetração em silício para alguns dos feixes utilizados. . . . . . . . . . . . . . . . . . . . . . 159

9.5 Sinais de carga coletada observados no osciloscópio e curvas de ajuste, para feixes de ${ }^{16} \mathrm{O} 42 \mathrm{MeV}$ e ${ }^{63} \mathrm{Cu} 110 \mathrm{MeV} \ldots \ldots \ldots \ldots 1$

9.6 Distribuições de amplitude, largura e carga dos eventos observados para

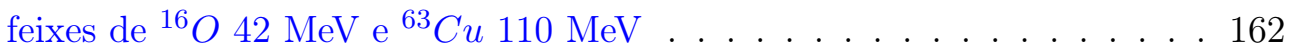

9.7 Distribuições de carga coletada para feixes de ${ }^{28} \mathrm{Si},{ }^{35} \mathrm{Cl},{ }^{48} \mathrm{Ti}$ e ${ }^{63} \mathrm{Cu}$ a $78 \mathrm{MeV} \ldots \ldots \ldots \ldots \ldots \ldots$ 
9.8 Distribuições bidimensionais carga $\mathrm{x}$ amplitude e carga $\mathrm{x}$ largura dos sinais analisados . . . . . . . . . . . . . . . . . . . 164

9.9 Distribuição de larguras de pulso para todos os eventos observados. . . . 165

9.10 Fotomicrografias do p-MOSFET 3N163 em diferentes níveis de aumento 167

9.11 Eletromicrografia e mapeamento do p-MOSFET 3N163 . . . . . . . . . 169

9.12 Microanálise química das quatro estruturas identificadas no p-MOSFET

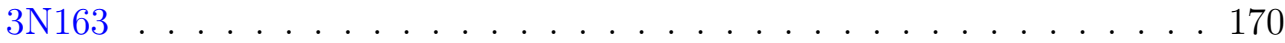

9.13 Simulações da interação do feixe de elétrons em camadas de $1000 \mathrm{~nm}$ e $500 \mathrm{~nm}$ sobre silício em energias de $10 \mathrm{keV}$ e $15 \mathrm{keV}$. . . . . . . . . . 172

9.14 Resíduos reduzidos para a diferença de energia observada nos eventos de íons pesados no p-MOSFET 3N163, simulados utilizando espessura de

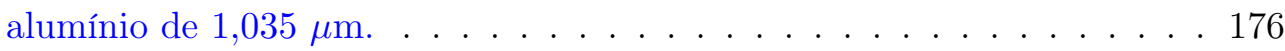

9.15 Ilustração dos casos de coleta completa e incompleta de carga. . . . . . . 177

9.16 Distribuição de $\chi^{2}$ em função da espessura do filme de alumínio simulado.177

9.17 Resíduos reduzidos para a diferença de energia observada nos eventos de íons pesados no p-MOSFET 3N163, simulados utilizando espessura de alumínio de $1,285 \mu \mathrm{m} . \ldots \ldots \ldots$. . . . . . . . . . . . 177

9.18 Resíduos reduzidos para a carga coletada na condição de $\chi^{2}$ mínimo . . 179

9.19 Distribuição de $\chi^{2}$ normalizado em função das espessuras do filme de nitreto de silício e da camada ativa. . . . . . . . . . . . . . . . . . 180

9.20 Relação de linearidade entre a carga e o parâmetro $\kappa$. . . . . . . . . . . 181

9.21 Espessura da região de coleta de carga em função do LET do íon no início da camada sensível. . . . . . . . . . . . . . . . . . . . . . . . . . 182

9.22 Distribuição de $\chi^{2}$ normalizado em função da espessura do filme de nitreto de silício e do valor do parâmetro $k \ldots \ldots$. . . . . . . . . 183

9.23 Resíduos reduzidos para a carga coletada na condição de $\chi^{2}$ mínimo e funil variável com fator $K=8,75 \times 10^{-11} \mathrm{~cm} /$ par . . . . . . . . . . . 184 
9.24 Espessura da região de coleta de carga que minimiza o resíduo em função do LET. . . . . . . . . . . . . . . . . . . . . . . . . . . . . 185

9.25 Seção de choque de eventos no p-MOSFET 3N163 em função do LET do

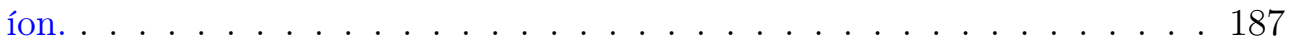

9.26 Áreas de coleta de carga no dispositivo 3N163. . . . . . . . . . . . . 188

10.1 Dispositivo Zynq-7020 . . . . . . . . . . . . . . . . . . . . . . 192

10.2 Desenho representando os diversos materiais e estruturas em dispositivos como o FPGA Zynq-7020. . . . . . . . . . . . . . . . . . . 194

10.3 Eletromicrografia de uma seção transversal do dispositivo Zynq-7020. . . 195

10.4 Seção de choque de SEU em função da energia efetiva no dispositivo no FPGA Zynq-7020. . . . . . . . . . . . . . . . . . . . 198

10.5 Seção de choque de SEU em função do alcance das partículas no FPGA Zynq-7020． . . . . . . . . . . . . . . . . 198

10.6 Ilustração do meio equivalente . . . . . . . . . . . . . . . . . . . . 200

10.7 Seção de choque em função do LET e alcance no meio equivalente. .. . 201

10.8 Seção de choque em função do LET e posição do pico de Bragg no meio equivalente. . . . . . . . . . . . . . . . . . . . 202

10.9 Seção de choque em função do LET para diversos valores de alcance no meio equivalente. . . . . . . . . . . . . . . . . . . . . . . 202

A.1 Funções $g_{1}(\tau)$ e $g_{2}(\tau) \ldots \ldots \ldots . \ldots \ldots . \ldots \ldots \ldots$

A.2 Comparação dos resultados de uniformidade calculados com diferentes aproximações . . . . . . . . . . . . . . . . . . . . . . . . . . 227 


\section{Lista de Tabelas}

5.1 Parâmetros de emitância do feixe após o ME-200 . . . . . . . . . 66

5.2 Parâmetros $x, x^{\prime}, y, y^{\prime}$ obtidos para a emitância dos feixes de ${ }^{12} C,{ }^{16} O,{ }^{28} \mathrm{Si}$

e ${ }^{63} \mathrm{Cu}$ após a simulação de focalização na posição do copo de Faraday. . 68

5.3 Parâmetros de alguns feixes no Pelletron a diferentes energias para escolha do modelo de espalhamento utilizado . . . . . . . . . . . . 70

7.1 Uniformidades calculadas para feixes de ${ }^{16} \mathrm{O}$ a várias energias e segunda folha espalhadora de $649 \mu \mathrm{g} / \mathrm{cm}^{2} \ldots \ldots \ldots \ldots \ldots 11$

7.2 Uniformidades calculadas para feixes de ${ }^{16} \mathrm{O} 42 \mathrm{MeV}$ e segunda folha espalhadora de diversas espessuras . . . . . . . . . . . . . 111

7.3 Uniformidades calculadas para diversos feixes a várias energias e segunda

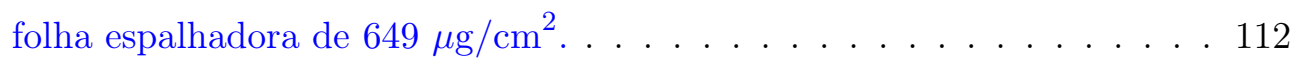

9.1 Feixes e condições de irradiação do MOSFET 3N163 . . . . . . . . . 160

9.2 Parâmetros do ajuste da curva de Weibull à seção de choque total do p-MOSFET 3N163 . . . . . . . . . . . . . . . . . . . 189

10.1 Feixes e condições de irradiação do dispositivo digital . . . . . . . . . . . 197 


\section{Sumário}

$\begin{array}{ll}\text { Introdução } & 1\end{array}$

I Interações da Radiação com a Matéria 13

1 Interações da Radiação Ionizante em Meios Materiais 13

1.1 Conceitos Básicos . . . . . . . . . . . . . . . . . . . . . . 13

1.2 Interações de Íons Pesados . . . . . . . . . . . . . . . . . . . . . 15

1.2.1 Poder de Freamento Eletrônico . . . . . . . . . . . . . . . . 15

1.2.2 Poder de Freamento Nuclear . . . . . . . . . . . . . . . . . 18

1.2.3 Materiais Semicondutores . . . . . . . . . . . . . . . . 23

1.3 Cálculos de Taxa de Deposição de Energia do Íon no Meio . . . . . . . . 25

2 Dinâmica do Espalhamento Elástico $\quad 27$

2.1 Espalhamento Elástico de Duas Partículas . . . . . . . . . . . . . . . . . 27

2.2 Seção de Choque de Espalhamento . . . . . . . . . . . . . . . . . 29

2.3 Espalhamento Múltiplo . . . . . . . . . . . . . . . . . . . . . . . . 32

$\begin{array}{lll}\text { II SAFIIRA } & 43\end{array}$

3 Óptica Iônica $\quad 45$ 
3.1 Parâmetros de definição do feixe de partículas . . . . . . . . . . . . . 45

3.2 Manipulação do espaço de fase . . . . . . . . . . . . . . . . . 47

4 O Acelerador Pelletron $\quad 53$

4.1 Fonte de Íons . . . . . . . . . . . . . . . . . . . . . . . . . 53

4.2 Acelerador . . . . . . . . . . . . . . . . . . . . 55

4.2 .1 Aceleração . . . . . . . . . . . . . . . . . . . 55

$4.2 .2 \quad$ Controle de energia . . . . . . . . . . . . . . . . . 59

5 Projeto do Sistema de Uniformização de Feixes 63

5.1 Óptica ............................... 63

5.1 .1 Desfocalização . . . . . . . . . . . . . . . . 63

5.1.2 Óptica do Acelerador Pelletron e da nova canalização a $0^{\circ}$. . . . 65

5.2 Espalhamento . . . . . . . . . . . . . . . . . . 68

6 Sistema de Feixes Iônicos para Irradiações e Aplicações (SAFIIRA) 87

6.1 Estrutura Física . . . . . . . . . . . . . . . . . . . . 87

6.2 Manipulação e monitoramento de feixe . . . . . . . . . . . . . . . . . . . 89

6.3 Câmaras de espalhamento . . . . . . . . . . . . . . . . . . 91

6.4 Calibração e monitoramento de fluxo . . . . . . . . . . . . . . . . . 93

6.5 Sistema de vácuo . . . . . . . . . . . . . . . . . . . . . . . . . . 94

6.6 Amostras e alvos . . . . . . . . . . . . . . . . . . 96

6.7 Eletrônica e aquisição de dados . . . . . . . . . . . . . . . . . . . . . 99

7 Caracterização do SAFIIRA 105

7.1 Uniformidade do Feixe . . . . . . . . . . . . . . . . . . 105

7.2 Otimização da operação . . . . . . . . . . . . . . . . . . . . 113

7.3 Exemplos de utilização . . . . . . . . . . . . . . . . . . . . 115

7.4 SAFIIRA como estação multi-uso: possibilidades e perspectivas . . . . 117 
7.4 .1 Irradiações diversas . . . . . . . . . . . . . . . . . 117

7.4.2 Análise de materiais . . . . . . . . . . . . . . . . . . . 118

7.4.3 Produção de nêutrons . . . . . . . . . . . . . . . . . . . . 118

III Efeitos de Radiação em Dispositivos Eletrônicos: Influência das Camadas de Passivação e Metalização nos Efeitos Observados 121

8.1 Dispositivos Semicondutores . . . . . . . . . . . . . . . . 123

8.1.1 Estruturas de Dispositivos Semicondutores . . . . . . . . . . . . 128

8.2 Efeitos de Radiação Ionizante em Dispositivos Eletrônicos . . . . . . 136

8.2.1 Dose Ionizante Total (Total Ionizing Dose - TID) . . . . . . . . . 137

8.2.2 Dano por Deslocamento (Displacement Damage - DD) . . . . . 139

8.2.3 Efeitos por Eventos Isolados (Single Event Effects - SEE) . . . . 140

9 Um caso analógico $\quad 155$

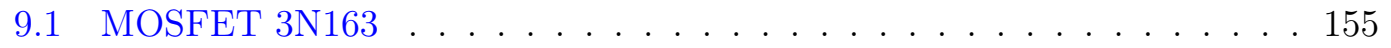

9.2 Ensaios com feixes de íons pesados no SAFIIRA . . . . . . . . . . . 158

9.3 Microscopia eletrônica de varredura . . . . . . . . . . . . . . . . . 166

9.4 Simulações de coleta de carga . . . . . . . . . . . . . . . . . . . . 171

9.5 Resultados e considerações sobre a análise do caso analógico . . . . . . 185

$\begin{array}{ll}10 \mathrm{Um} \text { caso digital } & 191\end{array}$

10.1 FPGA ZYNQ-7020 . . . . . . . . . . . . . . . 191

10.2 Informações estruturais . . . . . . . . . . . . . . . . . . 193

10.3 Ensaios com feixes de íons pesados no SAFIIRA $(2) \ldots \ldots$

10.4 Simulações de LET efetivo . . . . . . . . . . . . . . . . . . . . . . 199

10.5 Resultados e considerações . . . . . . . . . . . . . . . . . 203 


\section{Introdução}

\section{O problema}

Desde a descoberta dos raios X por Röntgen no fim do século XIX as técnicas de física atômica e nuclear encontraram as mais diversas aplicações na ciência básica e áreas como medicina, tecnologia dos materiais, processos industriais, entre outras. No tocante às ciências dos materiais, as técnicas nucleares podem ser utilizadas para promover modificações, estudar estrutura e/ou composição ou mesmo avaliar a resistência dos materiais em ambientes de alta radiação, como por exemplo o ambiente espacial ou áreas experimentais em grandes aceleradores de partículas como o Large Hadron Collider (LHC).

Com o crescente uso de dispositivos eletrônicos em situações críticas de confiabilidade em tais ambientes, principalmente a partir do início da era espacial, tornou-se necessária a caracterização e quantificação dos danos causados pela radiação em tais dispositivos, bem como a avaliação da qualidade dos dados gerados por tais sistemas. Estudos sistemáticos com o objetivo de determinar como a radiação ionizante pode afetar esses dispositivos eletrônicos têm sido realizados desde a década de 1960 tanto pela iniciativa privada quanto por institutos públicos de pesquisa ao redor do mundo $[1,2,3,4,5]$, influenciando diretamente no desenvolvimento de componentes eletrônicos para o uso aeroespacial [6].

O desenvolvimento de grandes aceleradores de partículas com o objetivo de expan- 
dir a fronteira do conhecimento na física e testar predições do Modelo Padrão ainda introduziu novos desafios tecnológicos, como o desenvolvimento de sistemas de detecção mais precisos, velozes e resistentes ao ambiente de elevada radiação produzida em experimentos como, por exemplo, ATLAS, CMS e ALICE do LHC. Ao mesmo tempo, o desenvolvimento de aceleradores de partículas cada vez maiores permitiu, por sua vez, estudar os efeitos de radiação ionizante em dispositivos eletrônicos em outros regimes de fluxo, energia e tipo de radiação.

Para o Brasil, o estudo dos efeitos de radiação em dispositivos eletrônicos e o subsequente desenvolvimento de dispositivos adequados à operação em tais ambientes permite inserções estratégicas no cenário internacional, seja por meio do desenvolvimento de instrumentação tolerante à radiação para o LHC, como feito pelo grupo de pesquisa de instrumentação para física de altas energias do $\operatorname{IFUSP}^{1}$, seja para o desenvolvimento de dispositivos para utilização em satélites nacionais, promovendo assim maior independência tecnológica. No caso brasileiro, a preocupação com tolerância à radiação de componentes de satélites geoestacionários torna-se ainda maior devido à Anomalia Magnética do Atlântico Sul (South Atlantic Anomaly - SAA) [7], uma deformação do campo magnético terrestre que faz com que a intensidade da radiação cósmica seja maior nessa região, conforme ilustrado na figura abaixo, que mostra a maior incidência de upsets de memória no satélite UOSAT2 [8].

\section{Efeitos da Radiação Ionizante em Dispositivos Eletrônicos}

De maneira simplificada, podemos explicar o aparecimento de efeitos de radiação em dispositivos eletrônicos como resultado da deposição de energia no material semicondutor, gerando portadores de carga que podem se acumular em determinadas regiões do dispositivo ou serem transportados pelo campo elétrico aplicado. Esta deposição de energia pode ainda afetar a estrutura do semicondutor, alterando assim suas proprie-

\footnotetext{
${ }^{1}$ HEPIC - High Energy Physics Instrumentation Center
} 


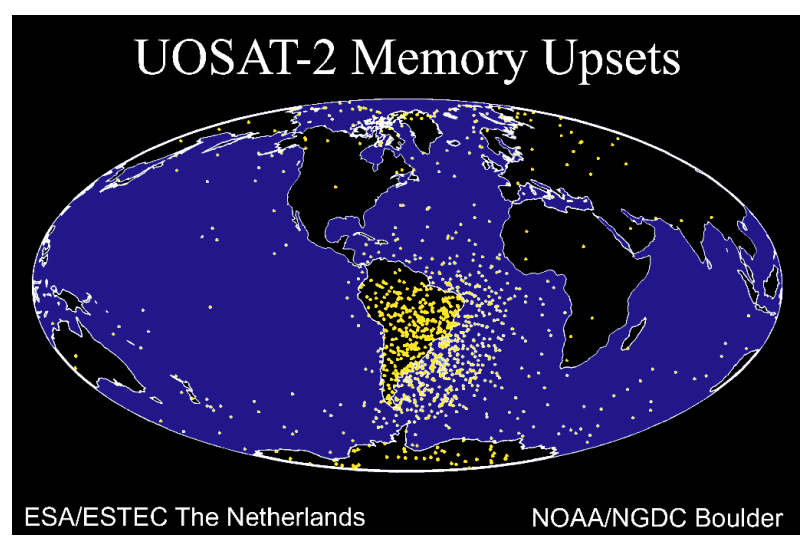

Figura i.1: Localização das ocorrências de upsets de memória no satélite UOSAT2 [8].

dades elétricas.

A evolução das tecnologias de fabricação, que permite a diminuição do tamanho de componentes discretos e maior adensamento de dispositivos em uma só pastilha de silício, contribui também para o maior aparecimento de efeitos de radiação, uma vez que a carga crítica para a mudança de estado de um bit, por exemplo, foi se tornando menor ao longo dos anos [1,3]. Desta forma, os esforços para a eliminação e mitigação (redução ou correção) dos efeitos de radiação sobre dispositivos eletrônicos vêm sendo intensificados, e mesmo efeitos descobertos há muito tempo, como por exemplo o decorrente das contaminações de radionuclídeos alfa-emissores no encapsulamento, ainda são motivo de preocupação, pois continuam a prejudicar dispositivos fabricados com as tecnologias atuais $[3,9]$.

Os efeitos de radiação em dispositivos eletrônicos semicondutores podem ser divididos em três classes principais:

1. Dose Ionizante Total (Total Ionizing Dose - TID): os efeitos de dose ionizante total são efeitos cumulativos causados pela dose depositada por fótons e/ou partículas, como prótons, nêutrons e elétrons. A baixa deposição de energia destas partículas por diferentes processos não produz instantaneamente uma alta geração 
de pares elétron-lacuna que vá afetar o dispositivo, porém produz um efeito de acúmulo de cargas principalmente no óxido de silício, sendo, portanto, mais importante em dispositivos fabricados com a tecnologia Metal-Oxide-Semiconductor $(\mathrm{MOS})^{2}$.

2. Efeitos de Eventos Isolados (Single Event Effects - SEE):São chamados de Efeitos por Eventos Isolados (Single Event Effects) os efeitos em dispositivos eletrônicos causados pela incidência de uma única partícula ionizante, desde que esta partícula seja capaz de gerar uma quantidade de pares elétron-lacuna suficientemente grande para causar perturbações no circuito em operação. Em geral, as partículas causadoras de SEE são os íons pesados, desde partículas alfa [3, 5] até os elementos transurânicos, assim como os múons e píons [5, 10] e os produtos de reações e processos de espalhamento, que podem envolver nêutrons, prótons e partículas sub-nucleares $[4,5,10,11]$. A maior parte dessas radiações é gerada ou oriunda de raios cósmicos, sejam eles primários ou resultado da interação com a atmosfera terrestre gerando os chamados "chuveiros"de partículas [2], porém também são produzidas em grandes quantidades em aceleradores de partículas como o LHC. Prótons e elétrons também podem gerar efeitos de eventos isolados por meio de ionização direta em dispositivos muito sensíveis $[12,13,14]$. A grandeza mais importante neste tipo de estudo é, portanto, a quantidade de energia depositada no volume sensível (onde a carga é coletada - grosso modo, na região do dreno dos transistores), que pode ser representada pelo Linear Energy Transfer - LET, em unidades de $\mathrm{MeV} / \mathrm{mg} / \mathrm{cm}^{2}$ ou $\mathrm{MeV} / \mu \mathrm{m}$ e está relacionado com o stopping power da partícula no meio.

3. Dano por Deslocamento (Displacement Damage - DD): os danos por deslocamento são gerados pela componente não-ionizante da perda de energia por

\footnotetext{
${ }^{2}$ tecnologia de fabricação que isola o contato (metal) da região de porta do transistor através de uma camada de óxido.
} 
partículas como nêutrons, núcleos de recuo, prótons e elétrons de alta energia [15]. Colisões atômicas não-ionizantes levam ao deslocamento de átomos da rede, podendo criar diversos defeitos cristalinos que agem como regiões de acúmulo de carga devido ao efeito de armadilhamento.

\section{A busca pela solução}

Existem três formas básicas de reduzir os efeitos de radiação em dispositivos eletrônicos: a primeira consiste em construir circuitos redundantes e fazer com que a mesma informação seja tratada em dois ou mais circuitos, e as falhas oriundas da radiação são prontamente corrigidas pela lógica do sistema; a segunda forma é construir blindagens para proteger o sistema do ambiente de radiação (devido ao fato de que novas partículas podem ser produzidas na blindagem, este método é pouco usado), e a terceira forma consiste em projetar dispositivos que, por sua própria construção (geometria, parâmetros de operação, etc), sejam mais resistentes à radiação [16, 17]. A escolha entre os três métodos leva em conta o custo e sua aplicabilidade, sendo que, quando possível, diversos desenvolvedores de sistemas buscam a utilização de dispositivos comerciais que possam ser configurados/aplicados de maneira a apresentar a tolerância necessária. Além disso, para determinar a melhor forma de tornar os efeitos de radiação menos prejudiciais, é necessário primeiro conhecer, para um dado dispositivo, quais os efeitos predominantes, sob quais condições eles se manifestam, qual a probabilidade de ocorrência e qual o dano causado. No tocante aos SEE, o estudo requer ainda o conhecimento dos processos de coleta de carga dentro do dispositivo e a influência da energia depositada em regiões não-sensíveis na seção de choque de eventos observada, tornando necessário um conhecimento da estrutura do dispositivo que, no caso de dispositivos comerciais, não é fornecido pelo fabricante.

Até 2011 existiam no mundo todo apenas 21 instalações dedicadas (total ou par- 
cialmente) ao estudo de efeitos de radiação com feixes de íons pesados, sendo que nenhuma se encontrava no hemisfério sul [18], conforme Figura i.2. Dentre as mais importantes, podemos citar os laboratórios de Sandia e Brookhaven (Estados Unidos), Louvain-La-Neuve (Bélgica), Legnaro (Itália), entre outros. Desde então estudos semelhantes também começaram a ser conduzidos no Laboratório Tandar, Argentina [19], e no Laboratório Aberto de Física Nuclear (LAFN), em São Paulo [20, 21, 22].

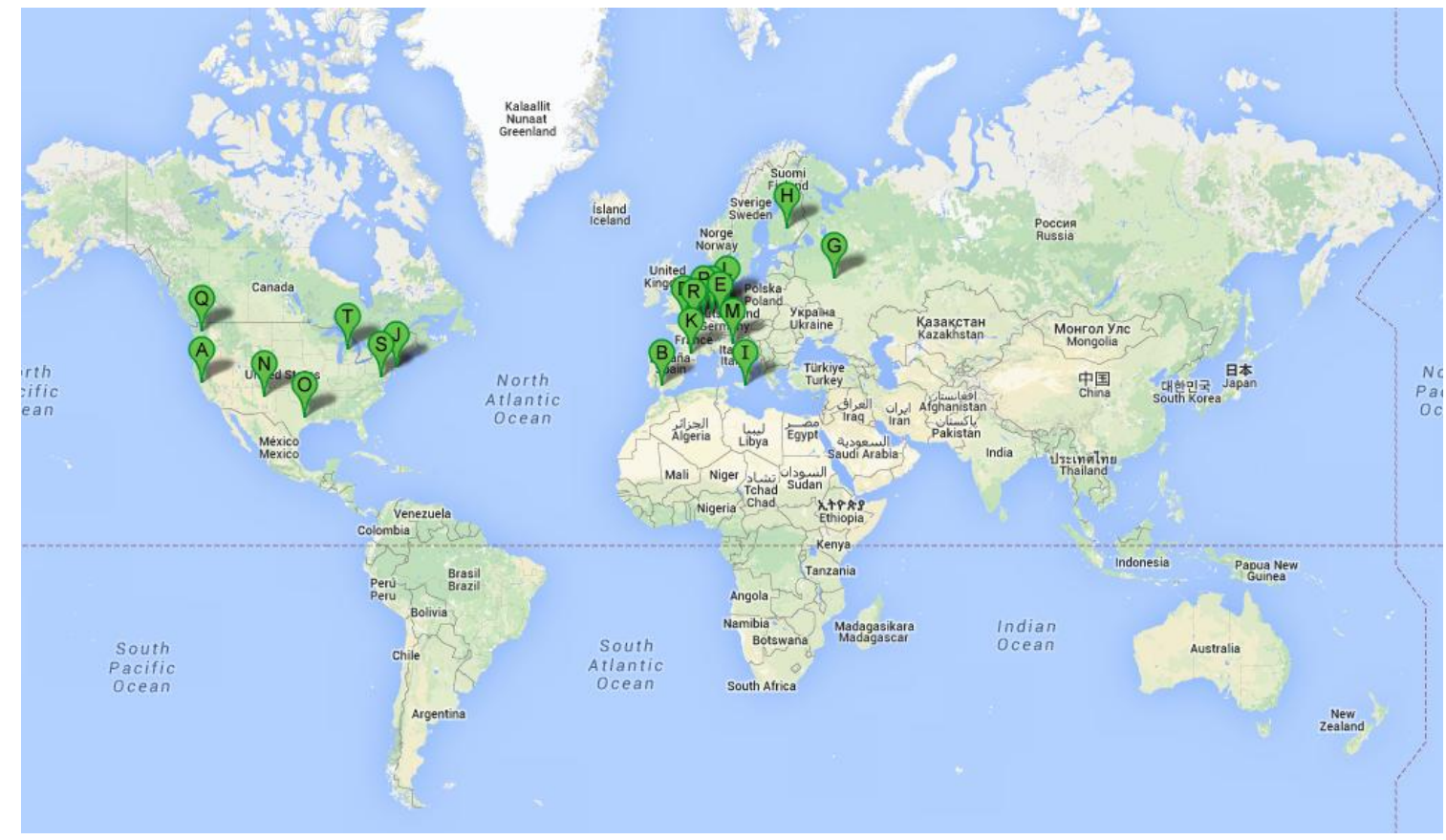

Figura i.2: Localização das instalações de irradiação de dispositivos eletrônicos com feixes de íons pesados até 2011 [18].

Inicialmente, os estudos realizados no LAFN foram feitos numa montagem capaz de gerar os feixes com as características desejadas utilizando a técnica de espalhamento Rutherford, porém de forma não otimizada e dedicada [20]. A necessidade de obter melhores resultados e com maior eficiência mostrou a importância de desenvolver uma nova canalização no LAFN destinada a este tipo de estudo, mas que ao mesmo tempo pudesse ser utilizada como uma estação multi-uso para física aplicada com feixes de 
partículas de até $120 \mathrm{MeV}$.

O Instituto de Física da Universidade de São Paulo (IFUSP) é detentor do único acelerador de íons pesados de grande porte no Brasil, o acelerador eletrostático Pelletron de 8 MV [23], localizado no Laboratório Aberto de Física Nuclear (LAFN), que pode ser utilizado para estudar efeitos de radiação em dispositivos eletrônicos, e também um acelerador Pelletron de 1,7 MV localizado no Laboratório de Análise de Materiais com Feixes Iônicos (LAMFI), utilizado tanto para estudos de efeitos de radiação em componentes eletrônicos quanto para análise e qualificação de materiais. No futuro, com a entrada em funcionamento do Acelerador Linear (LINAC), as energias dos feixes disponíveis no LAFN-USP serão muito maiores, podendo ampliar a faixa de testes e qualificação dos dispositivos eletrônicos, satisfazendo todas as normas exigidas para este tipo de ensaio. Dos 21 laboratórios que fazem qualificação de dispositivos eletrônicos com feixes de íons pesados, atualmente 12 são capazes de operar na faixa de energia obtida com o acelerador Pelletron do LAFN e/ou na faixa de energia obtida com o acelerador LINAC (em construção).

Para fins de teste e qualificação destes microdispositivos, é necessário que a instalação atenda às normas pré-estabelecidas por associações de normas técnicas especializadas, como, por exemplo, as da Agência Espacial Européia (ESA) [24, 25], da Associação Americana para Testes em Materiais (ASTM) [26] e da Associação das Indústrias Eletrônicas (JEDEC) [27], onde as características dos feixes e do sistema de irradiação são apresentadas. Embora não seja obrigatório que tais normas sejam seguidas em estudos acadêmicos, segui-las permite melhor comparação inter-laboratorial dos resultados observados. Por outro lado, estudos fora dos limites recomendados fornecem informações para o estabelecimento de normas de ensaio mais modernas, e, possivelmente, adaptadas às possibilidades e limitações destes ensaios no cenário nacional. Deve-se atentar, todavia, que o acelerador Pelletron do LAFN é um acelerador de pequeno porte comparado a alguns dos utilizados para este tipo de estudo, e na faixa de energia que pode ser 
obtida neste acelerador a perda de energia das partículas nas camadas de metalização e passivação devem ser consideradas, tornando a metodologia de ensaio mais complexa, porém mais rica nas possibilidades de investigação dos mecanismos de coleta de carga em dispositivos eletrônicos.

Os experimentos para verificação de susceptibilidade a SEE com íons pesados devem ser conduzidos de forma a garantir um fluxo uniforme no dispositivo sob ensaio (Device Under Test - DUT) e baixo o suficiente para que seja possível separar eventos distintos e evitar outros tipos de dano ao dispositivo, como por exemplo doses altas demais que possam causar efeitos de TID e sobre-aquecimento. As principais recomendações dessas agências são:

- Área do feixe: deve ser grande o suficiente para cobrir toda a área de interesse. A princípio, a recomendação é de um feixe de 1-2 cm de diâmetro [27].

- Uniformidade: o feixe deve ser uniforme em intensidade dentro de uma tolerância de $10 \%$ na área considerada.

- Fluxo: os fluxos de partículas devem estar compreendidos na faixa de $10^{2}$ e $10^{5}$ íns $/ \mathrm{cm}^{2} / \mathrm{s}$. Tal requisito visa garantir que o dispositivo não seja atingido por mais de um íon durante um ciclo de aquisição de dados.

- Fluência: o fluxo acumulado no tempo deve estar compreendido entre $10^{6} \mathrm{e}$ $10^{8}$ íns $/ \mathrm{cm}^{2}$.

- Eventos: no caso da ocorrência de 100 eventos, o teste pode ser encerrado mesmo sem atingir a fluência mínima [27].

- Alcance: o penetração mínima do feixe deve ser de $30 \mu \mathrm{m}$ em silício. Todavia, este requisito é mais importante para estudos de $\mathrm{SEL}^{3}$ (em que a junção relevante

\footnotetext{
${ }^{3}$ Single-Event Latchup é um efeito potencialmente destrutivo em dispositivos CMOS, e consiste numa alta densidade de corrente parasitária.
} 
está além da camada ativa), sendo que nos demais casos pode-se considerar que o alcance deve apenas ser muito maior que a espessura da camada ativa [26].

- Energia e LET: a energia e o LET do feixe no dispositivo devem ser conhecidos dentro de uma variação máxima de 10\%. O LET pode ser conhecido a partir da energia e de simulações computacionais. Para que o LET não varie mais que 10\%, deve-se garantir que a curva de Bragg na região onde a carga é coletada (camada ativa) forme um platô, condição geralmente satisfeita quando o alcance é muito maior que a espessura da camada ativa.

- Feixes: deve-se realizar o ensaio com diversos feixes, de preferência alguns feixes com o mesmo LET, pois os efeitos podem variar com a espécie iônica. Se possível, deve-se tomar dados até duas vezes o LET de saturação. Do contrário, ao menos $120 \mathrm{MeV} / \mathrm{mg} / \mathrm{cm}^{2}$ é o limite recomendado.

- Amostra: deve ser possível movimentar a amostra dentro da câmara de vácuo, tanto para inclinação do mesmo em relação à incidência do feixe quando irradiação de diferentes áreas.

\section{Propostas do Projeto}

Durante o desenvolvimento do projeto de mestrado, o autor e seus colaboradores foram responsáveis pela implantação de um sistema para irradiação de dispositivos eletrônicos [20, 28], que permitiu as primeiras medidas de SEE com íons pesados no Brasil [29]. Todavia, para satisfazer de forma mais adequada as exigências das normas internacionais [24, 26, 27], melhorar a qualidade dos dados obtidos e ainda abrir novas possibilidades de estudos de efeitos de radiação em dispositivos eletrônicos, como por exemplo utilizando técnicas de mapeamento com microfeixes colimados e de caracterização de estrutura, havia a necessidade da implantação de um novo aparato experimental. 
Tal sistema baseia-se nas técnicas de espalhamento múltiplo e desfocalização, que permite obter feixes uniformes com perda de energia menor e intensidades mais elevadas comparado ao sistema anterior de espalhamento Rutherford, reduzindo o tempo de ensaio e aumentando o alcance das partículas dentro do dispositivo.

Com a utilização do novo sistema, abrem-se as possibilidades de estudos detalhados da influência das camadas de passivação e metalização sobre o dispositivo, essencial para futuros estudos de SEE em aceleradores de partículas de pequeno porte e para a melhor compreesão dos mecanismos de coleta de carga gerada por radiação ionizante. Dois estudos de caso para determinação da influência das camadas das quais o dispositivo sob ensaio é composto são apresentados.

\section{Organização}

Correndo o risco de pecar pelo excesso, o texto desta tese de doutoramento foi elaborado de modo a permitir ao leitor iniciante a compreensão adequada dos assuntos abordados, e foi dividido em três partes . A Parte I consiste na revisão bibliográfica das interações da radiação ionizante em meio materiais, com especial enfoque em íons pesados e nas descrições dos processos de freamento eletrônico e nuclear (Capítulo 1), seguindo-se uma discussão sobre os processos de espalhamento elástico singular e múltiplo (Capítulo 2). Tais temas formam a base dos desenvolvimentos teóricos e experimentais nas seções seguintes. A Parte II é dedicada ao desenvolvimento de um sistema específico para o estudo de efeitos de radiação em dispositivos eletrônicos e outras aplicações, chamado SAFIIRA (Sistema de Feixes Iônicos para IRradiações e Aplicações). Uma introdução aos conceitos de óptica iônica é apresentada no Capítulo 3, e o acelerador de partículas Pelletron é descrito no Capítulo 4. Estes dois capítulos, juntamente com a Parte I, servem de base para os cálculos e simulações descritos na etapa de projeto do novo sistema (Capítulo 5), que por sua vez é descrito no Capítulo 
6, e cuja caracterização é apresentada no Capítulo 7. Na Parte III são detalhados os efeitos de radiação em dispositivos eletrônicos e o problema da determinação da camada sensível (Capítulo 8). O Capítulo 9 apresenta o estudo de caso para um dispositivo analógico, e o Capítulo 10 apresenta o estudo de caso em um dispositivo digital. As conclusões e perspectivas futuras são apresentadas ao final deste trabalho, seguidas das referências bibliográficas e do apêndice com informações complementares. 


\section{Parte I}

\section{Interações da Radiação com a \\ Matéria}




\section{Capítulo 1}

\section{Interações da Radiação Ionizante}

\section{em Meios Materiais}

Neste capítulo são apresentados os fenômenos e conceitos relacionados com a interação de radiação com a matéria, com especial destaque às interações de íons pesados em meios materiais sólidos.

\subsection{Conceitos Básicos}

Podemos separar a classe das radiações ionizantes, isto é, aquelas capazes de gerar ionizações e excitações num meio, em três grupos: fótons (raios X e raios gama), nêutrons e partículas eletricamente carregadas. Tais radiações diferem na forma que depositam energia na matéria, sendo diferentes as consequências ao meio.

- Fótons: os fótons com energia para ionizar um meio material podem interagir por meio de três processos principais: efeito fotoelétrico, onde toda a energia do fóton é transferida a um elétron atômico; efeito Compton, onde apenas uma parte da energia do fóton é transferida a um elétron, havendo portanto um fóton espalhado a um dado ângulo; e produção de pares, em que um fóton de 1,02 MeV dá origem 
a um par elétron-pósitron. As seções de choque de ocorrência de cada um destes efeitos dependem da energia do fóton e do número atômico do elemento. De modo geral, ao atravessar um meio material, a intensidade de um feixe de fótons decai de forma exponencial com o aumento da espessura do meio [30, 31, 32].

- Nêutrons: os nêutrons são partículas indiretamente ionizantes, uma vez que, por não possuírem carga elétrica, não interagem com os elétrons. Para gerar ionização, um nêutron deve interagir com o núcleo de um átomo do meio e, por espalhamento (elástico ou inelástico) produzir um núcleo de recuo que provocará ionizações, ou provocar uma reação nuclear cujos produtos irão produzir as ionizações no meio $[30,31,32]$.

- Partículas Carregadas: por possuírem carga elétrica, interagem muito facilmente nos meios materiais, seja com o campo elétrico nuclear, seja com a nuvem eletrônica (mais provável). As partículas carregadas perdem energia de maneira quase contínua ao longo do meio material, interagindo com praticamente cada átomo no caminho e transferindo pequenas porções de energia. O elevado número de interações envolvidas e a natureza probabilística destas torna este um processo estocástico, de modo que apenas valores médios de transferência de energia podem ser calculados. À perda média de energia por unidade de comprimento de trajetória dá-se o nome de stopping power, ou poder de freamento. No caso de partículas leves (elétrons e pósitrons), a perda de energia ocorre também por meio de irradiação (bremsstrahlung), contribuição irrisória no caso de particulas pesadas de baixa energia. A perda gradual de energia das partículas carregadas dá origem a um alcance máximo destas, cujas variáveis são a energia e carga do íon e o número atômico do meio, quando se tratar de partículas carregadas pesadas. Convém mencionar que elétrons sofrem grandes desvios de trajetórias nas interações, ao passo que íons pesados sofrem pouco desvio [30, 31, 32]. 
O estudo de efeitos de radiação ionizante em dispositivos eletrônicos passa pelo conhecimento detalhado destas interações. Nas próximas seções será dado maior detalhamento às interações de íons pesados (partículas carregadas) por ser este um ponto fundamental dos próximos desenvolvimentos neste trabalho.

\subsection{Interações de Íons Pesados}

Um meio material é composto por um número muito grande de átomos $\left(\sim 10^{23}\right)$, que podem estar dispostos em arranjos cristalinos ou de maneira amorfa. Uma partícula qualquer, ao penetrar neste meio material, poderá interagir com vários destes átomos, sendo que, quanto maior o percurso percorrido dentro do meio material, maior será o número de interações sofridas, em média. Este caráter estocástico das interações torna muito difícil de prever a energia perdida por um íon ao atravessar um meio material, ou mesmo estimar seu alcance dentro deste. Diversos esforços foram feitos desde o início do século XX por Bohr, Bethe, Bloch, Lindhard, entre outros, para desenvolver uma teoria abrangente para o poder de freamento, até avanços mais recentes com as tabulações e parametrizações semi-empíricas de Northcliff e Schilling e de Ziegler, Biersack e Littmark ([33]). O poder de freamento pode ser dividido em duas componentes: eletrônico e nuclear.

\subsubsection{Poder de Freamento Eletrônico}

O poder de freamento eletrônico está relacionado a íons incidentes com velocidades maiores do que a velocidade média dos elétrons atômicos do meio (velocidade de Bohr, $\left.v_{0}=c / 137\right)$, e é a componente dominante do processo de perda de energia de partículas carregadas aceleradas em meios materiais. A interação do íon com os elétrons atômicos do meio pode provocar excitações (com posterior emissão de raios X ou elétrons Auger) quando o parâmetro de impacto é alto (colisão "suave"ou periférica) ou ionizações, 
quando o parâmetro de impacto é baixo (colisão "dura"ou frontal) ([30]). Quando da ocorrência de ionizações, os elétrons ejetados podem possuir energia suficiente para deslocar-se a uma energia apreciável da trajetória inicial da partícula, depositando grande quantidade de energia fora da trajetória desta, sendo estes elétrons chamados de raios delta $(\delta)([31])$. Se a velocidade do íon é grande comparada à dos elétrons atômicos, podemos calcular o poder de freamento pela Teoria de Bethe-Bloch ([34]), na qual a colisão é tratada no contexto da mecânica quântica com o uso da primeira aproximação de Born ([35]). Com a adição de correções para levar em conta efeitos relativísticos, as diferentes velocidades dos elétrons do meio e a polarização dos átomos com a passagem da partícula carregada, temos a expressão completa de Bethe-BlochFano [33, 34, 36], apresentada na Equação 1.1 e que descreve a região III da Figura 1.1.

$$
\frac{d E}{\rho d x}=\frac{4 \pi N Z_{2} Z_{1}^{* 2} e^{4}}{m_{e} v^{2}}\left[\ln \left(\frac{2 m_{e} v^{2}}{\langle I\rangle}\right)+\frac{C(v)}{Z_{2}}+\frac{v^{2}}{c^{2}}-\ln \left(1-\frac{v^{2}}{c^{2}}\right)-\delta\right]
$$

onde $\langle I\rangle$ é a energia média de ionização, $\delta$ é a correção de polarização, $C(v) / Z_{2}$ é a correção de camadas, $m_{e}$ é massa do elétron, $Z_{2}$ o número atômico dos átomos constituntes do meio e $Z_{1}^{*}$ a carga efetiva do íon em trânsito. Em velocidades nãorelativísticas, a expressão se reduz a uma relação aproximada do tipo 1/E. A presença de uma "carga efetiva"na formulação de Bethe-Bloch-Fano implica que o poder de freamento é função da carga e velocidade do íon e do meio freador, de modo que a natureza do íon em questão, representada apenas por meio da carga na equação, constitui um fator de escala. Desta forma, pode-se relacionar o freamento de íons pesados neste regime de velocidades com o de um íon mais leve (prótons, em geral), usando um fator de escala inversamente proporcional ao quadrado da carga efetiva $[36,37]$. 


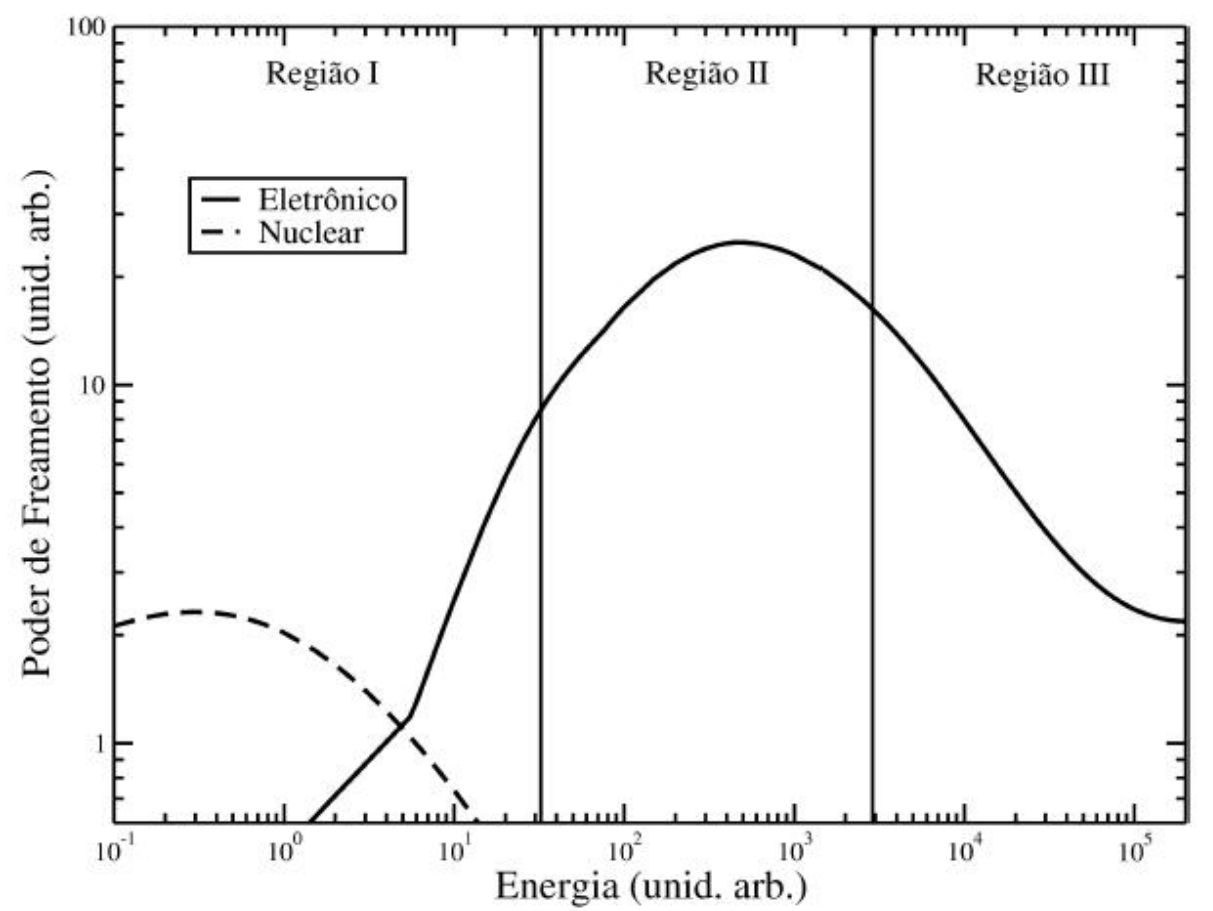

Figura 1.1: Dependência do poder de freamento eletrônico e nuclear com a energia (reproduzida de [33]). A região III é bem descrita pela Eq. 1.1, ao passo que as regiões I e II são apenas aproximadamente descritas pelos modelos mecânico-estatísticos.

Quando a velocidade do íon é baixa (comparável ou menor do que as velocidades orbitais dos elétrons), as teorias existentes apresentam concordância apenas qualitativa com a experiência em muitos casos. Usualmente, tais modelos baseiam-se numa descrição mecânico-estatística da eletrosfera, considerando esta como um gás de elétrons livres com densidade dada pelo modelo de Thomas-Fermi (em algumas formulações, o modelo é de Hartree-Fock) [33, 36]. No caso dos íons pesados, a captura de elétrons do meio modifica a carga efetiva do íon, alterando sua interação com o gás de elétrons, num processo dinâmico onde a perda de energia é bastante acentuada, a que chamamos de pico de Bragg (região II da Figura 1.1).

As limitações dos modelos teóricos levaram ao desevolvimento de parametrizações semi-empíricas que se mostram muito úteis nos cálculos de poder de freamento, perdas 
de energia, etc., com objetivo prático nos experimentos de Física Nuclear. A parametrização mais usada atualmente é aquela proposta por Ziegler, Biersack e Littmark (ZBL) [37], e baseia-se num conjunto amplo de dados experimentais. Para o freamento a velocidades altas, utiliza-se o escalonamento com o freamento de prótons, enquanto que a baixas e médias velocidades utiliza-se o modelo estatístico, com fatores de correção determinados a partir dos dados experimentais. Mesmo empregando os modelos semi-empíricos, os desvios entre o cálculo e o valor experimental podem ser grandes em determinadas combinações alvo-íon-energia [33, 36, 38, 39], e tais desvios são maiores quando o alvo é composto por mais de uma espécie atômica. Neste caso, a regra de Bragg estabelece que devemos fazer uma ponderação dos poderes de freamento de cada espécie, de acordo com a proporção em massa de cada uma no composto, e são desprezados os efeitos das ligações químicas, especialmente importantes no caso de compostos contendo $\mathrm{H}, \mathrm{C}, \mathrm{N}, \mathrm{O}, \mathrm{F}, \mathrm{S}$ e $\mathrm{Cl}[36,37]$. A regra de Bragg ainda desconsidera que para vários elementos, como $\mathrm{O}$ e $\mathrm{H}$, os poderes de freamento são medidos em fase gasosa.

\subsubsection{Poder de Freamento Nuclear}

O processo de freamento nuclear ocorre por meio das colisões elásticas do íon incidente com os átomos do meio. A dinâmica do freamento nuclear é a mesma do espalhamento $^{1}$ de uma partícula por um potencial central da forma $1 / \mathrm{r}$, que no limite de energias mais altas reduz-se à fórmula de Rutherford [37], que será discutida no capítulo 2. A seção de choque de espalhamento elástico possui uma dependência inversa da energia, de forma que a dominância deste processo no freamento das partículas carregadas ocorre apenas em energias baixas.

A cinemática do espalhamento, que pode ser facilmente resolvida utilizando-se a formulação lagrangeana, permite determinar o ângulo de espalhamento de uma partícula e a energia transferida na colisão, no referencial de centro-de-massa (CM) [37]:

\footnotetext{
${ }^{1}$ Tanto no formalismo clássico quanto no formalismo quântico.
} 


$$
\begin{gathered}
\theta=\pi-2 \int_{r_{\text {min }}}^{\infty} \frac{b d r}{r^{2}\left[1-\frac{U(r)}{E_{c}}-\frac{b^{2}}{r^{2}}\right]} \\
T=\frac{4 E_{0} M_{1} M_{2}}{\left(M_{1} M_{2}\right)^{2}} \operatorname{sen}^{2}\left(\frac{\theta}{2}\right)
\end{gathered}
$$

onde $\theta$ é o ângulo de espalhamento no CM, b o parâmetro de impacto, U(r) o potencial, $E_{0}$ a anergia cinética, $\mathrm{r}$ a posição de interação, T a energia transferida e $M_{1,2}$ as massas do projétil e do alvo.

Quando a velocidade do íon é superior à dos elétrons atômicos do meio e o parâmetro de impacto é tal que não ocorre a interpenetração das nuvens eletrônicas, podemos assumir o potencial de interação como sendo coulombiano entre os dois núcleos. Quando a velocidade do íon é menor que a velocidade de um elétron orbital, ocorre a blindagem do potencial, e com uma distância de aproximação menor ocorrem os efeitos de interações elétron-elétron e exclusão de Pauli. Numa primeira aproximação, pode-se utilizar o modelo semi-clássico de Bohr para calcular a velocidade de um elétron orbital. No caso do orbital $\mathrm{s}(\mathrm{n}=1)$ no átomo de ouro $(\mathrm{Z}=79)$, por exemplo, igualando as energias potencial e cinética e utilizando a quantização do momento angular, temos:

$$
v=\frac{1}{4 \pi \epsilon_{0}} \frac{Z e^{2}}{n \hbar} \simeq 1,72 \times 10^{8} \mathrm{~m} / \mathrm{s}
$$

que corresponde a aproximadamente $60 \%$ da velocidade da luz.

A simetria esférica do problema permite a redução do problema de dois corpos ao problema de um corpo e um potencial no referencial de centro de massa. Tal potencial é chamado de potencial interatômico, e, via de regra, são consideradas as interações núcleo-núcleo, núcleo-elétron sobre todas as combinações, elétron-elétron (também sobre todas as combinações) e potencial devido à promoção de elétrons devido ao princípio da exclusão de Pauli [33, 37]. Existem diversas maneiras de calcular os potenciais inte- 
ratômicos: aproximando por um potencial do tipo coulombiano blindado, construindo modelos empíricos com base em dados, resolvendo a complexa interação utilizandose todas as ferramentas da mecânica quântica através do método de Hartree-Fock ou utilizando-se modelos semi-clássicos que levam em conta efeitos quânticos numa nuvem eletrônica suposta um gás de elétrons livres [37]. No caso da utilização do método de Hartree-Fock, deve-se ainda levar em conta a diferença da distribuição eletrônica dos átomos-alvo por estarem estes num sólido, interagindo, portanto, com os átomos vizinhos.

O potencial interatômico blindado é baseado, em geral, nos modelos estatísticos do átomo, como por exemplo o modelo de Thomas-Fermi. O potencial blindado é dado então pelo potencial atômico (ou interatômico) multiplicado por uma função de blindagem $\phi$, que depende da posição onde o potencial é medido e do comprimento de blindagem $a[36,37]$ :

$$
U(r)=\frac{Z_{1} Z_{2} e^{2}}{r} \phi\left(\frac{r}{a}\right) \quad \phi(0)=1 \quad \phi(\infty)=0
$$

A forma mais simples para a função de blindagem é a de Bohr, em que $\phi\left(\frac{r}{a}\right)=e^{-\frac{r}{a_{0}}}$, onde $a=a_{0}=0,529 \times 10^{-10} \mathrm{~m}$ é o raio de Bohr . Todavia, outros autores propuseram diferentes valores para o comprimento de blindagem, como o de Thomas-Fermi (Equação 1.6) e sua generalização para o potencial interatômico feita por Lindhard (Equação 1.7) ([33, 36, 37]). Além disso, propostas diferentes da simples função exponencial de Bohr foram feitas por diversos autores, consistindo em geral de somatórias de funções exponenciais da mesma razão $x=\frac{r}{a}$. Destas formulações, as que melhor descrevem os dados experimentais são as descrições de Molière e Lenz-Jensen, porém, mesmo assim, com sérias divergências para certas combinações íon-átomo e para determinados valores de raio de interação [37], tornando-as de utilização limitada na previsão de espalhamento e/ou freamento. 


$$
\begin{gathered}
a_{T F}=\frac{0,8853 a_{0}}{Z^{1 / 3}} \\
a_{L}=\frac{0,8853 a_{0}}{\left(Z_{1}^{2 / 3}+Z_{2}^{2 / 3}\right)^{1 / 2}}
\end{gathered}
$$

As divergências nas descrições dos potenciais interatômicos por esses modelos com os dados experimentais e com a descrição mais precisa (porém computacionalmente mais difícil) do método de Hartree-Fock para o átomo num sólido levaram à parametrização semi-empírica de Ziegler, Biersack e Littmark (ZBL) ([33, 37]). Ziegler e colaboradores fizeram uma sistemática do potencial interatômico utilizando o método de Hartree-Fock para 522 pares íon-átomo, de onde obtiveram uma descrição média da blindagem interatômica (Equação 1.8), e, portanto, do potencial, a que chamaram de potencial universal (também dada por uma soma de exponenciais), com comprimento de blindagem dado pela Equação 1.9:

$$
\begin{gathered}
\Phi_{U}=0,1818 e^{-3,2 x}+0,5099 e^{-0,9423 x}+0,2802 e^{-0,4028 x}+0,2817 e^{-0,2016 x} \\
a_{U}=\frac{0,8853 a_{0}}{\left(Z_{1}^{0,23}+Z_{2}^{0,23}\right)}
\end{gathered}
$$

A utilização da função de blindagem proposta por Ziegler et al. permite reescrever a integral de espalhamento 1.2, substituindo o potencial pela função de blindagem:

$$
\theta=\pi-2 \int_{x_{0}}^{\infty} \frac{b^{\prime} d x}{x^{2}\left[1-\frac{\phi(x)}{x \epsilon}-\frac{b^{\prime 2}}{x^{2}}\right]^{1 / 2}}
$$

onde: 


$$
\epsilon=\frac{a_{U} E_{C}}{Z_{1} Z_{2} e^{2}}=\frac{a_{U} M_{2} E_{0}}{Z_{1} Z_{2} e^{2}\left(M_{1}+M_{2}\right)}
$$

é a energia reduzida de Lindhard $([37,40])$ e $b^{\prime}=b / a$ é uma mudança de variáveis no parâmetro de impacto.

Se no caso do espalhamento sem blindagem a integral pode ser resolvida analiticamente, isto não é possível com a função de blindagem. A passagem da partícula pelo meio pode então ser descrita através de uma equação de transporte, solução buscada por Lindhard et al. [37] ou calculando as várias interações usando método de Monte Carlo, quando o tempo levado no método de solução (numérica) é crucial. Vários métodos envolvendo aproximações existem para resolvê-la, porém a "fórmula mágica"(Equação 1.12) desenvolvida por Biersack e Haggmark [37] mostrou-se uma solução adequada e é a solução utilizada no programa SRIM, permitindo prever o ângulo em cada espalhamento e, portanto, a energia transferida em cada colisão.

$$
\cos \frac{\theta}{2}=\frac{b+\rho+\delta}{r_{0}+\rho} \quad \rho=\frac{-2\left(E_{C}-V\left(r_{0}\right)\right)}{V^{\prime}\left(r_{0}\right)}
$$

onde $b$ é o parâmetro de impacto, $r_{0}$ é a distância de máxima aproximação, $\delta$ um parâmetro ajustado pelos autores para reproduzir os dados, $E_{C}$ a energia no referencial de centro-de-massa, $V(r)$ o potencial interatômico e $V^{\prime}(r)$ sua derivada espacial.

Uma vez que no freamento nuclear ocorre o espalhamento entre partículas de massas comparáveis, este é o processo responsável por desvios angulares apreciáveis, diferentemente do processo de freamento eletrônico onde a mudança de direção do íon incidente é desprezível, acarretando num straggling angular (lateral) e em alcance das partículas, somando-se ao straggling em energia causado pelos processos de freamento eletrônico [36]. Tal efeito faz com que o microvolume no qual a energia é depositada no final da trajetória de um feixe de partículas seja maior. Utilizando as equações descritas, o programa TRIM [37] calcula as perdas de energia de partículas atravessando sólidos 
bem como os desvios angulares sofridos. As perdas de energia são fundamentais para determinar o LET incidente de uma partícula num material irradiado, e as deflexões serão utilizadas no cálculo do espalhamento múltiplo nos próximos capítulos.

O espalhamento entre massas comparáveis também origina um recuo, isto é, um átomo do meio sendo deslocado de sua posição original, podendo também depositar energia no meio [37]. Quando o recuo ocorre em baixas velocidades, sua perda de energia é classificada como Perda de Energia Não-Ionizante (Non-Ionizing Energy Loss - NIEL)[10], que tem papel importante na formação de danos permanentes na rede cristalina, porém não cria pares elétron-lacuna em materiais semicondutores.

Além dos processos mencionados, um íon ainda pode perder energia por meio de reações nucleares (espalhamento inelásticos, fusão, transferência, etc.) [30], caso em que os produtos do processo (fótons, nêutrons ou partículas carregadas) também irão depositar sua energia no meio através dos mesmos mecanismos já descritos.

\subsubsection{Materiais Semicondutores}

Um íon pesado, ao penetrar em um meio material, deposita energia neste ao longo de toda a sua trajetória, gerando ionizações, excitações, e danos estruturais ao material, como quebras moleculares e deslocamentos atômicos. Tal trajetória é chamada de traço da partícula no meio. Este traço é uma região que pode ser instável eletronicamente (quimicamente), caso as ionizações tenham sido responsáveis pela quebra de ligações químicas, como pode ocorrer, por exemplo, se um íon com energia suficientemente alta quebrar ligações ao atravessar uma camada de óxido de silício. Tal instabilidade eletrônica, entretanto, só ocorre em materiais dielétricos e semicondutores com alta largura da banda proibida (bandgap) [32], uma vez que nos materiais condutores o desequilíbrio eletrônico é prontamente corrigido devido aos efeitos da "nuvem eletrônica".

Caso a transferência de energia na colisão do íon com um elétron atômico tenha transferido mais energia do que a energia de ligação do elétron, os elétrons serão ejetados 
numa dada direção e terão um percurso dentro do meio antes de serem capturados por um átomo. Estes elétrons, aos quais chamamos de raios $\delta$ e cuja energia pode chegar a dezenas de $\mathrm{MeV}$ [41], depositarão energia ao longo de sua trajetória, contribuindo para uma distribuição da dose em um volume centrado na trajetória do íon. Ao longo da trajetória do íon inicial estará a maior parte do dano gerado (quebras moleculares) e deposição de energia, que será distribuída de maneira não-uniforme pelo raio do traço, da ordem de até centenas de nanômetros $[42,43]$. Raios $\delta$ de energia mais alta podem depositar energia a distâncias ainda maiores da trajetória do íon.

Semicondutores são materiais com propriedades intermediárias entre as dos isolantes e as dos condutores, e nestes o arranjo dos átomos e suas características eletrônicas levam à formação de bandas de valência e de condução com uma diferença de energia pequena entre elas (banda proibida), de modo que as excitações podem promover um elétron à banda de condução ou a um dos estados "armadilhas", isto é, estados permitidos dentro da banda proibida, dos quais os elétrons podem ser liberados por efeitos térmicos ou por meio de radiação [32]. Os recuos de átomos da rede cristalina através dos processos de freamento nuclear criam falhas na periodicidade da rede (defeitos cristalinos), contribuindo para a criação de novos estados armadilhas, ou seja, zonas de concentração de cargas.

Independentemente se o elétron foi promovido à banda de condução ou a um dos estados armadilha, cria-se uma lacuna na banda de valência, que atua como portador de carga positiva, cabendo ao elétron na banda de condução o papel de portador de carga negativa, enquanto elétrons armadilhados não atuam como portadores. Pode ainda ocorrer armadilhamento de lacunas, caso em que estas também deixam de participar da condução elétrica.

A promoção de elétrons à banda de condução depende da quantidade de energia depositada pela partícula na colisão e do tipo de material semicondutor, isto é, da largura da banda proibida (bandgap). No caso do silício, por exemplo, o bandgap é de 
$1,12 \mathrm{eV}$ a $300 \mathrm{~K}$, e a energia para a criação de um par elétron-lacuna é da ordem de três vezes este valor $(\sim 3,6 \mathrm{eV})$ [44], pois além da transferência de energia deve ocorrer transferência de momento linear. Caso uma partícula deposite uma energia de $50 \mathrm{MeV}$ no silício serão gerados cerca de 14 milhões de pares elétron-lacuna, além de possíveis pares gerados por raios $\delta$. Tal situação pode modificar-se na presença de um campo elétrico, quando os pares gerados podem produzir novas ionizações devido à aceleração produzida pelo campo.

Existem ainda algumas particularidades envolvendo a estrutura cristalina do silício: o poder de freamento é, em geral, calculado para íons penetrando no material em direções aleatórias (ou considerando o material como amorfo). Tal suposição assume que as interações são completamente aleatórias. Todavia, em sólidos cristalinos (monocristais, especialmente), pode ocorrer que os íons incidam sobre um plano cristalino específico, direção na qual a força coulombiana é tal que permite a passagem dos íons sem interagir com os elétrons mais ligados [45], o que diminui o poder de freamento e, portanto, a deposição de energia no meio por unidade de comprimento (ou volume), com a consequência de menor geração de portadores de carga no semicondutor. Tal fenômeno, conhecido como channeling, não foi levado em conta nos cálculos deste trabalho.

\subsection{Cálculos de Taxa de Deposição de Energia do Íon no Meio}

Para o estudo de efeitos de íons pesados acelerados em sistemas eletrônicos devemos conhecer a taxa de deposição de energia do íon no meio para avaliar a geração de pares elétron-lacuna. Enquanto o poder de freamento é a perda de energia por unidade de trajetória do íon no meio, definimos o Linear Energy Transfer (LET) como a quantidade de energia depositada por unidade de percurso do íon no meio. Em primeira aproximação, a energia depositada no meio é aquela perdida pelo íon, porém duas observações 
devem ser feitas:

- O LET é uma quantidade definida localmente, de modo que, dada uma energia de corte $\Delta$, raios $\delta$ com energia superior a esta não são contabilizados na energia depositada no microvolume considerado, havendo portanto uma diferença entre o valor de LET e o de stopping power (stopping power restrito) ([30],[31]).

- É muito difícil realizar os cálculos de LET com valores de corte, sendo para isto necessárias simulações de Monte Carlo envolvendo os raios $\delta$, sendo ainda difícil prever em quais condições cada valor de energia de corte será válido, pois esperase que o valor assumido represente uma deposição de energia tão distante que não influencie o estudo em questão, hipótese pouco provável ao se tratar de um semicondutor polarizado no qual nem mesmo se pode saber em que posição os íons o estão atingindo.

Desta forma, neste trabalho os cálculos de LET foram feitos considerando-se $\Delta=\infty$, situação em que o LET é numericamente igual ao poder de freamento do íon no meio.

Os cálculos foram realizados por meio dos softwares SRIM/TRIM [37], que utilizam as parametrizações semi-empíricas ZBL para os cálculos de poder de freamento, além de simulações de Monte Carlo para vários íons que permitem a visualização direta da curva de Bragg. 


\section{Capítulo 2}

\section{Dinâmica do Espalhamento Elástico}

Neste capítulo são apresentados os conceitos básicos de espalhamento elástico de partículas aceleradas. Será tratado apenas o caso em que as interações entre projétil e alvo são eletromagnéticas, desprezando portanto as interações nucleares. Uma descrição da cinemática de colisões e do espalhamento Rutherford é feita, servindo de base à discussão do espalhamento múltiplo por potenciais blindados.

\subsection{Espalhamento Elástico de Duas Partículas}

Quando duas partículas interagem sem haver mudança de energia interna destas partículas, conservando-se portanto energia e momento linear, chamamos este processo de espalhamento elástico. De modo geral, assumindo que as partículas iniciais possuem massas $M_{1}$ (com energia $E_{1}$ ) e $M_{2}$ e as partículas após a interação (colisão) possuem massas $M_{3}$ e $M_{4}$, com energias $E_{3}$ e $E_{4}$, respectivamente, a conservação de energia (no referencial de laboratório, com a partícula 2 inicialmente em repouso) é dada por:

$$
M_{2} c^{2}+E_{1}+M_{1} c^{2}=E_{3}+M_{3} c^{2}+E_{4}+M_{4} c^{2}
$$

sendo que $M_{i} c^{2}$ corresponde à energia relativística de repouso da partícula $i$. Segue 
que:

$$
E_{1}+\left(M_{1}+M_{2}-M_{3}-M_{4}\right) c^{2}=E_{3}+E_{4}
$$

em que o segundo termo do lado esquerdo é chamado de $Q$ da reação e reflete a mudança da energia de centro de massa do sistema. No caso do espalhamento elástico, $Q=0$, de modo que $E_{1}=E_{1}^{\prime}+E_{2}^{\prime}$, onde o sobrescrito indica o estado após o espalhamento e as partículas iniciais e finais são as mesmas, ou seja, não há reação nem processos inelásticos. Quanto à conservação de momento, considerando que a colisão ocorra com um parâmetro de impacto $b \neq 0$, haverá um ângulo de espalhamento entre as partículas, conforme a Figura 2.1:

Sistema do

\section{Laboratório}

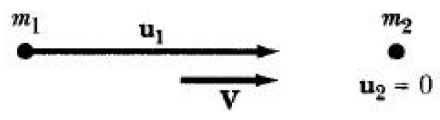

(a) Condição Inicial

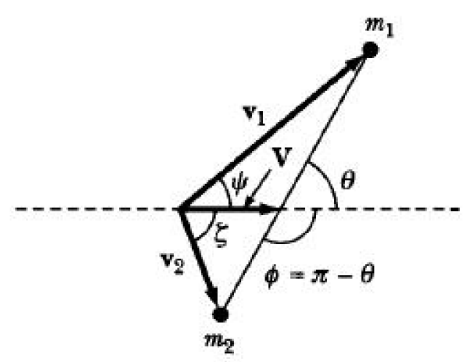

(c) Condição Final

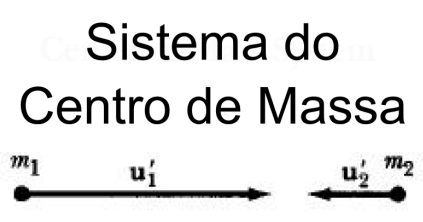

(b) Condição Inicial

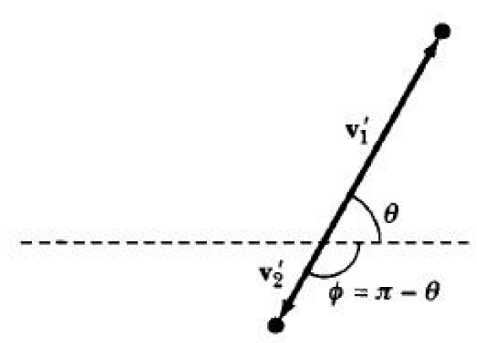

(d) Condição Final

Figura 2.1: Espalhamento de duas partículas, nos referenciais de laboratório e centrode-massa(adaptada de [46]).

De modo que a conservação de momento nos garante: 


$$
\begin{gathered}
\vec{p}_{1}={\overrightarrow{p_{1}}}^{\prime}+{\overrightarrow{p_{2}}}^{\prime} \\
p_{1}=p_{1}^{\prime} \cos \theta+p_{2}^{\prime} \cos \phi \\
p_{1}^{\prime} \operatorname{sen} \theta=p_{2}^{\prime} \operatorname{sen} \phi
\end{gathered}
$$

O desenvolvimento dessas equações se reduz a um sistema simples, no caso não relativístico, de quatro incógnitas e três equações, cuja solução para a energia da partícula incidente após o espalhamento é dada por:

$$
\frac{E_{1}^{\prime}}{E_{1}}=\frac{M_{1}^{2}}{\left(M_{1}+M_{2}\right)^{2}}\left[\cos \theta+\sqrt{\frac{M_{2}^{2}}{M_{1}^{2}}-\operatorname{sen}^{2} \theta}\right]^{2}
$$

Da equação 2.4 podemos observar que para determinadas relações $M_{2}^{2} / M_{1}^{2}$ existe um ângulo máximo a partir do qual o sistema não possui solução. Tal situação é a de ocorrência de cinemática inversa, isto é, projétil mais pesado que o alvo.

\subsection{Seção de Choque de Espalhamento}

Se uma partícula em movimento colide com uma partícula em repouso e esta colisão possui um certo parâmetro de impacto $b$, é possível saber o ângulo de espalhamento. Num experimento de Física Nuclear, devido ao tamanho infinitesimal dos núcleos e o elevado número de partículas envolvidas, não é possível conhecer os parâmetros de impacto, então utiliza-se a grandeza chamada de seção de choque, definida como sendo a razão entre a taxa de eventos (partículas espalhadas), num dado ângulo, e a taxa de partículas incidentes, do ângulo sólido compreendido e do número de elementos espalhadores por unidade de área. Ao conter essa dependência entre o número de partículas espalhadas e incidentes, podemos entender a seção de choque como a probabilidade de observar uma partícula espalhada a um dado ângulo. Uma vez que a probabilidade de 
observação das partículas depende do ângulo sólido ${ }^{1}$ do centro espalhador à região de observação, define-se a seção de choque diferencial como:

$$
\sigma(\theta)=\frac{d \sigma}{d \Omega} \quad\left[\frac{a ́ r e a}{\text { esterradiano }}\right]
$$

O cálculo da seção de choque para um potencial é feito atribuindo à partícula incidente a massa reduzida do sistema

$$
\mu=\frac{m_{1} m_{2}}{m_{1}+m_{2}}
$$

sendo espalhada por um centro de força (Figura 2.2).

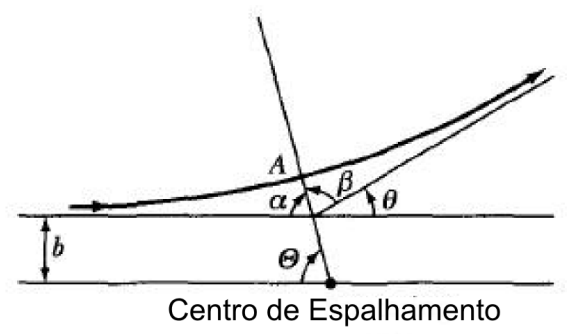

Figura 2.2: Espalhamento de uma partícula com massa reduzida $\mu$ por um potencial (adaptada de [46])

Definindo $r$ como a coordenada relativa entre a partícula e o centro espalhador e $U(r)$ o potencial, o momento angular é dado por $L=\mu r^{2} \dot{\Theta}$, de modo que a energia total é dada por:

$$
E=\frac{1}{2} \mu \dot{r}^{2}+\frac{L^{2}}{2 \mu r^{2}}+U(r)
$$

Usando a formulação lagrangeana [46, 47], obtemos a integral do espalhamento mencionada anteriormente (Equação 1.2):

\footnotetext{
${ }^{1} \Omega=\frac{A}{d^{2}}$, onde $A$ é a área e $d$ a distância, numa aproximação de $d>>\sqrt{A}$
} 


$$
\Theta=\int_{\infty}^{r_{\min }} \frac{b d r}{r^{2} \sqrt{1-\frac{U(r)}{E_{C}}-\frac{b^{2}}{r^{2}}}}
$$

No limite de energia alta o suficiente para a blindagem eletrônica ser considerada desprezível e assumindo que não haja interação nuclear, o campo elétrico do núcleo é o único responsável pelo espalhamento, isto é:

$$
U(r)=\frac{Z_{1} Z_{2} e^{2}}{r}
$$

De modo que, $\operatorname{com} \theta=\pi-2 \Theta$ resulta como solução da integral:

$$
\frac{d \sigma}{d \Omega}=\left(\frac{Z_{1} Z_{2} e^{2}}{4 E}\right)^{2} \frac{1}{\operatorname{sen}^{4}\left(\frac{\theta}{2}\right)}
$$

Esta é a seção de choque de espalhamento Rutherford no referencial do centrode-massa, derivada por E. Rutherford em 1911 [46], e nos permite calcular a taxa de partículas num dado ângulo conhecendo-se a energia do feixe e número atômico do feixe e do alvo. Esta função diverge em $\theta=0$, pois corresponde a um parâmetro de impacto tendendo ao infinito [48]. Este cálculo ignora possíveis efeitos de espalhamento múltiplo, sendo, portanto, válida apenas em casos onde este é desprezível. Como veremos, entretanto, baixos ângulos de espalhamento possuem interesse na obtenção de feixes uniformes. A seção de choque possui unidade de área, sendo usado, em geral, o barn (1 barn $\left.=10^{-24} \mathrm{~cm}^{2}\right)$.

O cálculo da seção de choque a partir de dados experimentais é feito considerandose o número de núcleos espalhadores por $\mathrm{cm}^{2}$ no alvo $\left(N_{\text {alvo }}\right)$, o número de eventos observados $\left(N_{\text {contagens }}\right)$, o número de partículas do feixe por segundo $\left(N_{\text {feixe }}\right)$, o ângulo sólido $\Delta \Omega$ compreendido pelo detector e o jacobiano (razão entre os ângulos sólidos nos sistemas de laboratório e de centro-de-massa), sendo dada por: 


$$
\frac{d \sigma}{d \Omega}=\frac{N_{\text {contagens }} J_{\text {acobiano }}}{N_{\text {feixe }} N_{\text {alvo }} \Delta \Omega}
$$

O jacobiano pode ser expresso por [49]:

$$
\frac{\left(1+X^{2}+2 X \cos \left(\theta_{e s p}^{C M}\right)\right)^{3 / 2}}{\left(1+X \cos \left(\theta_{e s p}^{C M}\right)\right)}
$$

onde $\theta_{e s p}^{C M}$ é o ângulo de espalhamento no referencial do centro de massa e X é dado por

$$
X=\sqrt{\frac{m_{\text {ion }}^{2} E_{\text {inicial }}}{m_{\text {alvo }}^{2}\left(E_{\text {inicial }}+Q\right)}}
$$

onde $E_{\text {inicial }}$ é a energia do íon incidente e $m_{\text {ion,alvo }}$ referem-se às massas do íon incidente e do alvo, respectivamente.

\subsection{Espalhamento Múltiplo}

Como será visto adiante, uma das técnicas de obtenção de feixe uniforme existentes é a técnica de espalhamento múltiplo das partículas carregadas em alvos finos. Este processo possui algumas particularidades com relação ao espalhamento considerado até o momento.

O processo de espalhamento múltiplo ocorre quando as partículas aceleradas sofrem uma série de sucessivos espalhamentos semelhantes (mesmo tipo de potencial) que sejam estatisticamente independentes, desprezando, em primeira aproximação, os efeitos de interferência e difração [50]. O espalhamento em ângulos pequenos é predominante para potenciais do tipo coulombiano, o que contribuiu para o rápido desenvolvimento das teorias de espalhamento múltiplo de partículas carregadas pesadas. O tratamento teórico para o espalhamento múltiplo pode ser feito através de uma equação de transporte, da soma individual de espalhamentos, de aproximações gaussianas, até a obtenção da 
distribuição através de métodos de Monte-Carlo ([37, 50]). Algumas dessas formulações serão detalhadas a seguir.

No capítulo 1 algumas limitações da utilização do potencial coulombiano para o espalhamento já foram mencionadas, com ênfase na blindagem do potencial. Conforme a Equação 2.9, pode-se notar que espalhamentos em ângulos baixos possuem maior probabilidade de ocorrência, correspondentes a parâmetros de impacto maiores (colisão distante). Colisões distantes tornam o íon incidente mais blindado em relação ao potencial coulombiano do núcleo, situação agravada quando a velocidade do íon é inferior à dos elétrons atômicos (vide Equação 1.4). Outras contribuições a serem incluídas no cálculo são os efeitos relativísticos e de spin em ordens superiores da aproximação de Born, espalhamento por elétrons atômicos, tamanho finito do núcleo, recuo, estrutura cristalina do espalhador, polarização, entre outras [50], porém os efeitos mais importantes resumem-se à blindagem do potencial e à validade da aproximação de Born.

A primeira aproximação de Born é um procedimento utilizado para tratar o espalhamento de partículas no contexto da mecânica quântica, onde a partícula incidente é tratada matematicamente como uma onda plana incidente e a descrição após o espalhamento é feita considerando-se uma onda esférica [35]. Um teste de validade da primeira aproximação de Born é o chamado parâmetro de Born, $\alpha$, definido como a razão entre o raio de colisão (metade do parâmetro de impacto) e o comprimento de onda de De Broglie da partícula incidente. Essa razão indica a validade da aproximação quando seu valor é pequeno $[50,51]$.

$$
\alpha=\frac{Z_{1} Z_{2} e^{2}}{\hbar v} \approx \frac{Z_{1} Z_{2}}{137 \beta}
$$

onde $Z_{1}, Z_{2}$ são os números atômicos dos elementos envolvidos, e é a carga do elétron, $\hbar$ é a constante de Planck dividida por $2 \pi, v$ é a velocidade da partícula incidente e $\beta$ é a razão entre $v$ e a velocidade da luz. 
Associando ao feixe uma função distribuição de posição, os métodos de cálculo de espalhamento múltiplo visam determinar a distribuição emergente (angular ou projetada) $F(\theta, \phi, t)$, onde $\theta, \phi$ são respectivamente os ângulos polar e azimutal e $t$ a espessura da folha espalhadora, dada uma distribuição inicial, normalmente considerada uma distribuição delta de Dirac [50], e a distribuição de probabilidade de ocorrência de um espalhamento único numa lâmina $d t$ de material $(\mathrm{W})$.

$$
W(\theta, t) d t=N(t) d \sigma(\theta, t) d t
$$

onde $\mathrm{N}(\mathrm{t})$ é o número de elementos espalhadores por unidade de volume e $\sigma(\theta, t)$ é a seção de choque de espalhamento simples (Equação 2.9).

A principal característica do espalhamento múltiplo é de que a função distribuição para cada espalhamento é independente, de modo que as distribuições para diferentes espalhamentos podem ser combinadas através de uma integral de convolução, que nos dá a probabilidade de ocorrência de um ângulo de espalhamento igual à soma dos ângulos individuais, como a expressão 2.14 mostra para o caso de espalhamento duplo:

$$
F(\theta) d \theta=d \theta \int_{-\infty}^{\infty} d \theta_{1} F_{1}\left(\theta_{1}\right) F_{2}\left(\theta-\theta_{1}\right)
$$

Este tratamento através de distribuições parciais é útil para se obter como resultado a distribuição final esperada. O mesmo raciocínio pode ser aplicado para se calcular a probabilidade de $N$ espalhamentos resultando num espalhamento total igual a $\theta_{\text {final }}$, onde multiplicamos as probabilidades $W$ individuais. A dependência da função $W$ com o ângulo para ângulos pequenos é resultado da estrutura da blindagem. Todavia, partículas não polarizadas sofrem o espalhamento de tal forma que tais detalhes são correções menores, importando apenas a estrutura básica da blindagem, caso em que a forma exponencial é suficiente [37, 50].

O método acima, chamado de método da soma, permite obter a distribuição espe- 
rada, porém apresenta dificuldades de cálculo devido às várias convoluções envolvidas. Outros métodos foram desenvolvidos, como o da aproximação gaussiana para a distribuição, método este que prediz incorretamente as caudas da distribuição [50]. A teoria de espalhamento múltiplo mais aceita foi proposta por Molière, que deduziu a forma da distribuição para valores pequenos de $\alpha$, com posteriores tentativas frustradas de contemplar valores maiores de $\alpha$ (Equação 2.12) e de ângulo. A teoria de Molière parte da utilização de um potencial blindado e considera que haja um ângulo mínimo de espalhamento devido à presença da blindagem. Utilizando a primeira aproximação de Born, Molière deduz o desvio de fase da onda incidente devido a um único espalhamento e usa o método de convolução para obter o desvio total [50, 52]. A distribuição deduzida por Molière pode ser representada por [52]:

$$
\begin{gathered}
F(\theta) d \theta=\left(d \theta / \theta_{1}^{2}\right) \int_{0}^{\theta_{1} / \theta_{a}} J_{0}\left(y \theta / \theta_{1}\right) y e^{\left[0,25 y^{2}\left(\ln 0,25 y^{2}-b\right)\right]} d y \\
\theta_{1}=\left[0,1569 \frac{Z_{2}\left(Z_{2}+1\right) Z_{1}^{2} t}{A p v}\right]^{1 / 2} \\
\theta_{1} / \theta_{a}=\left[\frac{7821 Z_{2}^{1 / 3}\left(Z_{2}+1\right) Z_{1}^{2} t}{\beta^{2} A+1,78.10^{-4} Z_{1}^{2} Z_{2}^{2} A}\right]^{1 / 2} \\
b=\ln \left(\frac{\theta_{1}^{2}}{\theta_{a}^{2}}\right)-0,1544
\end{gathered}
$$

onde $J_{0}$ é a função de Bessel de ordem zero, $Z_{1,2}$ são os números atômicos do íon incidente e do alvo, respectivamente, $t$ é a espessura do alvo em $\mathrm{g} / \mathrm{cm}^{2}, A$ a massa atômica do alvo, $p v$ o momento multiplicado pela velocidade da partícula incidente, $\beta$ a razão $\frac{v}{c}, \theta_{1}$ o ângulo acima do qual, na média, a partícula sofre apenas uma colisão ao atravessar a folha e $\theta_{a}$ o ângulo crítico, abaixo do qual todo o espalhamento é suprimido devido à blindagem do potencial [52]. Podemos observar que a teoria de 
Molière depende apenas do parâmetro $\theta_{a}$, que pode ser calculado utilizando o modelo estatístico do átomo ou pelo método de Hartree-Fock.

Embora a teoria de Molière seja um dos principais métodos de descrição do espalhamento múltiplo, este método possui algumas falhas no tocante ao regime de energias baixas $(\alpha>1)$, onde algumas aproximações feitas não são válidas ${ }^{2}$, e por desconsiderar a variação da energia da partícula ao atravessar a folha espalhadora $[50,51,52,53]$. Meyer reescreve o parâmetro de Born e demonstra que a validade da teoria de Molière se dá em valores de energia tais que [51, 53]:

$$
E(k e V)>25 A_{1} Z_{1}^{2} Z_{2}^{2}
$$

No caso contrário, isto é, em energias menores do que o valor da expressão 2.19, o espalhamento múltiplo pode ser tratado classicamente, utilizando um potencial blindado do tipo representado na Equação 1.5. Lindhard et al. demonstraram que a seção de choque de espalhamento simples pode ser aproximada para uma dependência de apenas um parâmetro $\eta=\epsilon \operatorname{sen}(\theta / 2)$, onde $\epsilon$ é a energia reduzida de Lindhard (Equação 1.11), e uma função $f(\eta)$ tabelada. Para uma partícula atravessando um meio onde sofrerá uma média de $\bar{n}=\pi r_{0}^{2} N t$ colisões, onde $N t$ é o número de átomos espalhadores por unidade de área e $r_{0}$ o raio entre átomos no empacotamento do material ${ }^{3}$, Meyer deduz que a distribuição de partículas espalhadas é dada por [51, 53]:

$$
\begin{gathered}
F(\bar{\theta})=\frac{\epsilon^{2}}{8}\left(\frac{A_{1}+A_{2}}{A_{2}}\right)^{2}\left[f_{1}(\tau, \bar{\theta})-\frac{a^{2}}{r_{0}^{2}} f_{2}(\tau, \bar{\theta})\right] \\
\bar{\theta}=\frac{\epsilon}{2}\left(\frac{A_{1}+A_{2}}{A_{2}}\right) \theta
\end{gathered}
$$

\footnotetext{
${ }^{2} \mathrm{O}$ detalhamento das aproximações encontra-se fora do escopo deste trabalho. O leitor interessado pode consultar [51].

${ }^{3} r_{0}=0,562 N^{-1 / 3}$ para a rede cristalina cúbica de face centrada, como do ouro. $N$ é o número de coordenação da rede, igual a 12 no caso do ouro.
} 
onde $a$ é o comprimento de blindagem e $f_{1,2}$ são funções tabeladas por Meyer em função de $\tau=\pi a^{2} N t$. Esta formulação reproduz melhor os dados de espalhamento múltiplo de íons pesados em energias baixas, conforme [53]. A teoria de Meyer foi utilizada por Montenegro [54] para construir um sistema de uniformização de feixes de prótons. Montenegro parte de um feixe incidente com distribuição gaussiana de desvio-padrão $\Delta$ que, após passar por um colimador de diâmetro D, é espalhado pelo alvo. Definindo a variação espacial de intensidade do feixe como a diferença entre a probabilidades máxima, $P_{\max }$, e mínima, $P_{\min }$ probabilidade de se encontrar uma partícula naquele ponto da distribuição [54]:

$$
\epsilon_{f}=\frac{P_{\max }-P_{\min }}{2<P>}=\tanh \left(\frac{D}{4 \Delta}\right)
$$

onde $\langle P\rangle$ é a probabilidade média. Assumindo o plano de medição a uma distância $R>\Delta$, o ângulo de espalhamento para o qual a distribuição possui metade da intensidade no plano de medição é dado por:

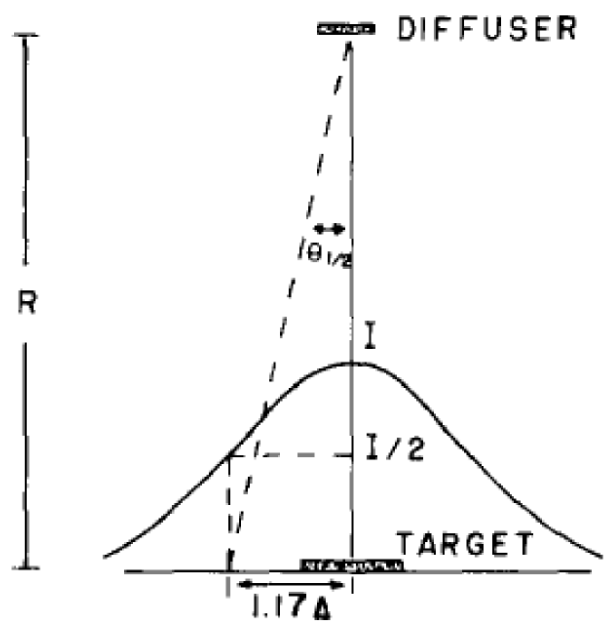

Figura 2.3: Distribuição gaussiana do feixe ao passar por uma folha difusora [54]. 


$$
\theta_{1 / 2}=\frac{1,17 \Delta}{R}
$$

que resulta:

$$
\epsilon_{f}=\tanh \left(\left(\frac{1,17 D}{4 R \theta_{1 / 2}}\right)^{2}\right)
$$

Montenegro reduziu a expressão de Meyer para o caso de prótons. Fazendo o desenvolvimento completo para qualquer íon, obtemos para $\theta_{1 / 2}$ :

$$
\theta_{1 / 2}=6,15 \times 10^{-5} \frac{Z_{1} Z_{2}\left(Z_{1}^{2 / 3}+Z_{2}^{2 / 3}\right)^{1 / 2}}{E} g(\tau) \quad ; \quad \tau=\frac{41,45}{A\left(Z_{1}^{2 / 3}+Z_{2}\right)^{2 / 3}} t
$$

onde $\mathrm{E}$ é a energia em $\mathrm{MeV}, Z_{1,2}$ são os números atômicos do projétil e do alvo, respectivamente, A é a massa atômica do alvo, t a espessura do alvo em $\mu \mathrm{g} / \mathrm{cm}^{2}$ e $g(\tau)$ é uma função tabelada por Meyer. Das expressões 2.24 e 2.25 resulta:

$$
\epsilon_{f}=\tanh \left(\frac{2,26 \times 10^{7}}{Z_{1}^{2} Z_{2}^{2}\left(Z_{1}^{2 / 3}+Z_{2}^{2 / 3}\right) g(\tau)^{2}}(D E / R)^{2}\right)
$$

Esta expressão foi utilizada como base para a construção de sistemas de difusão e uniformização de feixes de prótons e carbono em $[54,55,56]$, com bons resultados. Ao aplicar este método, entretanto, deve-se ter em mente que existem simplificações na expressão de $\theta_{1 / 2}$ original, que na definição de comprimento de blindagem é utilizado o valor de Lindhard (Equação 1.7), além de depender de funções tabeladas. A dedução da fórmula geral e uma discussão mais completa é apresentada no Apêndice A.

De acordo com [54], a uniformidade ainda guarda relação com a intensidade do feixe incidindo sobre o espalhador $\left(I_{0}\right)$ e sobre a posição de medida $(I)$, conforme a Equação 2.27, que permite obter a redução relativa de intensidade após o espalhamento. 


$$
\epsilon_{f}=\frac{I}{2 I_{0}-I} \Longrightarrow \frac{I}{I_{0}}=\frac{2 \epsilon_{f}}{1+\epsilon_{f}}
$$

Conforme [50], as técnicas de Monte Carlo são úteis para se determinar não apenas a distribuição emergente, mas também outros parâmetros como a perda de energia do feixe incidente sobre o espalhador, informação importante quando se utilizam espalhadores como ouro em aceleradores de partículas de baixa energia. No caso de estudos envolvendo radiobiologia, a variação na energia do feixe é menos crítica do que em estudos de efeitos de radiação em dispositivos eletrônicos, onde a penetração do feixe deve ser alta. Além disso, ao utilizar técnicas de Monte Carlo, pode-se simular o espalhamento utilizando o potencial universal (Equação 1.8), reproduzindo melhor a situação dos potenciais interatômicos para diversos pares íon-átomo. Métodos de Monte Carlo, todavia, possuem a desvantagem do elevado tempo computacional necessário, que por sua vez é dependente do método utilizado para resolver a integral de espalhamento (Equação 1.10).

Através dos métodos de Monte Carlo pode-se simular as colisões estatisticamente independentes de cada partícula com cada átomo espalhador no percurso dentro do material. Devido à natureza estocástica dos eventos de colisão, a probabilidade $\mathrm{W}$ de que uma partícula sofra $n$ colisões segue uma distribuição de Poisson (Equação 2.28), onde $\bar{n}$ é o número médio de colisões, dado por $\bar{n}=\pi r_{0}^{2} N t$, definido anteriormente. Ziegler et al. mostram o exemplo para o caso de uma partícula sofrendo em média 1,5 colisões ao atravessar o meio, caso em que, do número de partículas simuladas, espera-se que cerca de $22 \%$ não sofram nenhuma colisão, $33 \%$ uma colisão, $25 \%$ duas colisões e assim por diante. Quando mais de uma colisão ocorre, a convolução dos desvios (Equação 2.14) é feita. Ao passo que as simulações de Monte Carlo calculam cada espalhamento individualmente, e, portanto, podem considerar qualquer número de colisões, a natureza estatística das teorias de Molière e Meyer as torna imprecisas se 
o número médio de colisões for menor que 10-20 [52]

$$
W(n)=\frac{(\bar{n})^{n}}{n !} e^{-\bar{n}}
$$

O programa TRIM [37] é uma das principais ferramentas que se baseia no método de Monte Carlo para se calcular o freamento e espalhamento de íons acelerados em meios materiais para íons com energia variando entre $0,1 \mathrm{keV} / \mathrm{u}$ a vários $\mathrm{MeV} / \mathrm{u}$. A resolução da integral de espalhamento se dá através da "fórmula mágica"(Equação 1.12) desenvolvida por Biersack et al. [37], reduzindo o tempo de cálculo para cada espalhamento. O potencial de blindagem utilizado é o potencial universal (Equação 1.8) com comprimento de blindagem apresentado na Equação 1.9, reproduzindo, portanto, com razoável acurácia o potencial interatômico da maior parte dos pares íon-átomo. Uma das principais vantagens reside ainda na representação adequada de uma faixa ampla de energias por este método [37, 40]. Para valores elevados de energia reduzida, $\epsilon>10$ (Equação 1.11, com $E$ em keV), a distinção entre os potenciais coulombiano puro e coulombiano blindado é pequena, caso em que a integração direta é mais rápida que a utilização da "fórmula mágica". No caso de $\epsilon=10$ e altos parâmetros de impacto, isto é, a condição de espalhamento múltiplo, as diferenças tornam-se mais significativas [37]. Biersack [40] claramente distingue que devem ser tratados como íons de alta energia os casos de $\epsilon>>1$, onde os efeitos de espalhamento múltiplo produzem um pico central na distribuição que possui caudas relativas ao espalhamento simples; íons com energia baixa, $\epsilon \leq 1$, podem sofrer grandes desvios angulares e trasferir quantidades maiores de energia com maior probabilidade. Casos com energia intermediária experimentam todos estes efeitos. A Figura 2.4 ilustra o perfil do feixe espalhado em baixa energia (esquerda) e alta energia (direita), onde se distingue o perfil de espalhamento múltiplo (1) e espalhamento simples (2).

A eficiência computacional é aumentada através da definição de "caminho de vôo 
livre", definida como a menor distância que o íon deve percorrer antes de sofrer, estatisticamente, uma deflexão apreciável. Este valor varia com a energia do íon (e, portanto, durante seu percurso no material) e pode ser tão pequeno quanto alguns décimos de grau. O programa TRIM combina colisões que produzem um deflexão menor que o mínimo numa única colisão com o valor mínimo.

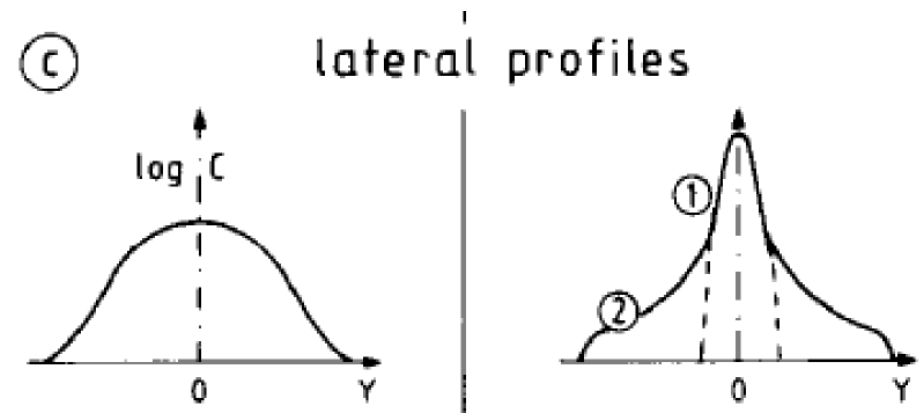

Figura 2.4: Perfis de feixes espalhados em baixa energia (esquerda) e alta energia (direita), onde se distingue o perfil de espalhamento múltiplo (1) e espalhamento simples (2) (reproduzido de [40]).

Por último, os métodos apresentados tratam a distribuição inicial de partículas como sendo do tipo delta de Dirac, uniforme ou gaussiana, situações que não refletem adequadamente o feixe de partículas obtido num acelerador de partículas, que possui uma distribuição espacial mais complexa e uma distribuição de ângulos de divergência. Para levar em conta estes efeitos, a distribuição de entrada para o cálculo do espalhamento deve conter as informações do espaço de fase do feixe de partículas, tema que será tratado a seguir. 
Parte II

SAFIIRA 


\section{Capítulo 3}

\section{Óptica Iônica}

Para simular a situação real do espalhamento múltiplo de partículas aceleradas, deve-se ter como entrada dos cálculos uma distribuição de partículas com as características de um feixe real de um acelerador, ao contrário das distribuições uniformes e/ou gaussianas das teorias apresentadas previamente, que em todos os casos eram caracterizadas por apenas uma direção de propagação. Neste capítulo serão apresentados os principais conceitos de óptica iônica de primeira ordem utilizados neste trabalho.

\subsection{Parâmetros de definição do feixe de partículas}

Um feixe de partículas num acelerador é caracterizado inicialmente por sua espécie atômica, energia, corrente ou intensidade, estrutura temporal ${ }^{1}$ e emitância ${ }^{2}$. No caso de feixes contínuos, a estrutura temporal não é um parâmetro relevante. A energia do feixe é determinada pelos elementos aceleradores e determina a emitância longitudinal do feixe. A intensidade pode ser medida em partículas por segundo ou corrente, sendo que as duas quantidades estão relacionadas através do estado de carga das partículas.

\footnotetext{
${ }^{1}$ Variação da intensidade do feixe com o tempo.

${ }^{2}$ Área no espaço de fase da dimensão correspondente. No caso da emitância transversal, está relacionada ao tamanho e divergência do feixe nos dois eixos transversais à direção de propagação; a emitância longitudinal está relacionada à energia e à dispersão em energia do feixe
} 
(a)

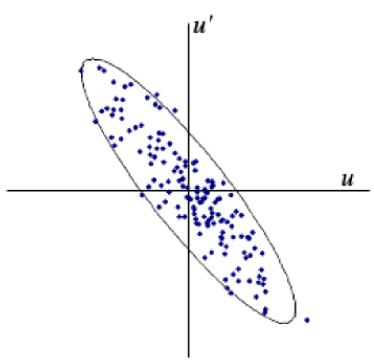

(b)

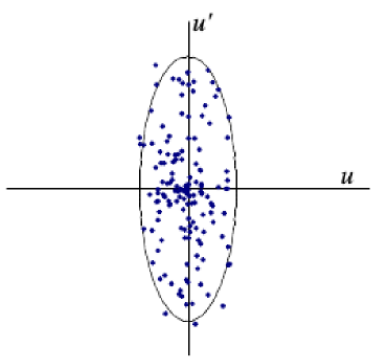

(c)

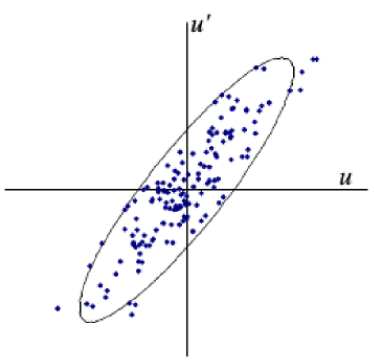

Figura 3.1: Exemplos de plano de fase e elipses de feixe: (a)Feixe convergente. (b) cintura de feixe (ponto focal). (c) feixe divergente. (retirado de [59])

Para um feixe com energia $E$ e momento $p_{0}$ na direção de propagação $(\mathrm{z}), \operatorname{com} E=\frac{p_{0}^{2}}{2 m}$, onde $m$ é massa da partícula, temos que um feixe com uma pequena divergência possui momento nas direções transversais (x e y) dados por:

$$
p_{x}=p_{0} \operatorname{sen}\left(x^{\prime}\right) \approx p_{0} x^{\prime} ; \quad p_{y}=p_{0} \operatorname{sen}\left(y^{\prime}\right) \approx p_{0} y^{\prime}
$$

onde os $x^{\prime}, y^{\prime}$ são os ângulos entre as duas direções transversais e a direção de propagação e as simplificações são resultado da aproximação paraxial (pequenos ângulos de divergência). Exceto nas etapas onde o momento $p_{0}$ se altera, o espaço de fase hexadimensional $\left(x, p_{x}, y, p_{y}, z, p_{0}\right)$ pode ser representado por $\left(x, x^{\prime}, y, y^{\prime}, z, \Delta p / p_{0}\right)$, onde temos três planos de fase independentes $[57,58,59]$, sendo que, nesta aproximação, os acoplamentos entre coordenadas são desprezados. A Figura 3.1 [59] ilustra a representação de uma distribuição de partículas num plano de fase transversal, bem como a elipse de feixe, região que concentra 95\% das partículas do feixe. Podemos então definir emitância $\epsilon_{\text {feixe }}$ como sendo a área da elipse dividida por $\pi$, em unidades de mm.mrad. A forma e a orientação da elipse de feixe nos dão informações sobre a divergência do feixe, distribuição espacial e evolução através de elementos do acelerador [59].

De acordo com o Teorema de Liouville [46], a emitância, isto é, a área no espaço 
de fase e, portanto, o fluxo de partículas, permanece constante na presença de forças conservativas. Isto não é real quando existem elementos que atuam através de forças não-conservativas ou que delimitam o feixe, como folhas espalhadoras ou colimadores [57, 58]; colimadores, em especial, são elementos que definem nova emitância para um feixe de partículas. Na presença apenas de forças conservativas, o plano de fase para uma coordenada transversal permite conhecer o comportamento do feixe na região: elipse com inclinação negativa ((a) na Figura 3.1) representam um feixe convergente; elipse sem inclinação ((b) na Figura 3.1) representam um feixe no ponto focal (cintura) e elipse com inclinação positiva ((c) na Figura 3.1) representam um feixe divergente. Num espaço livre de campos (espaço de deriva ou drift space), a elipse rotaciona no sentido horário ao longo da trajetória, além de tornar-se mais alongada no sentido de manter divergência constante e dimensão crescente [58, 59].

\subsection{Manipulação do espaço de fase}

A manipulação do espaço de fase, isto é, a modificação das trajetórias das partículas, dá-se através de campos elétricos e magnéticos. A característica proporcional à velocidade da força de Lorentz (Equação 3.2), onde $\vec{F}$ é a força de Lorentz, $q$ a carga da partícula, $\vec{E}$ o valor do campo elétrico, $\vec{v}$ a velocidade da partícula e $\vec{B}$ o valor do campo magnético, faz com que os campos elétricos sejam mais eficientes para íons de baixa energia (em geral na focalização após a fonte de íons) e os campos magnéticos sejam mais eficientes no regime de velocidades altas [57].

$$
\vec{F}=q(\vec{E}+\vec{v} \times \vec{B})
$$

Dados os parâmetros $x, x^{\prime}, y, y^{\prime}$ que caracterizam a emitância transversal do feixe, sua evolução ao longo da trajetória pode ser determinada através da resolução do sistema linear levando em consideração as forças atuantes. Por exemplo, tomando como 
$z=0$ a origem do sistema de coordenadas, temos para o espaço de deriva:

$$
x(z)=x(0)+z x^{\prime}(0) \quad x^{\prime}(z)=x^{\prime}(0)
$$

À medida que mais elementos são adicionados ao percurso óptico do feixe de partículas, a resolução do sistema se torna mais complicada, de modo que a utilização do método matricial permite simplificar as operações envolvidas. Utilizando o método matricial, escrevemos para o espaço de deriva:

$$
\left(\begin{array}{l}
x(z) \\
x^{\prime}(z)
\end{array}\right)=\left(\begin{array}{ll}
\alpha_{11} & \alpha_{12} \\
\alpha_{21} & \alpha_{22}
\end{array}\right) \quad\left(\begin{array}{l}
x(0) \\
x^{\prime}(0)
\end{array}\right)=\left(\begin{array}{ll}
1 & z \\
0 & 1
\end{array}\right)\left(\begin{array}{l}
x(0) \\
x^{\prime}(0)
\end{array}\right)
$$

A representação matricial permite que o cálculo do transporte de feixe através de um acelerador seja feito através da multiplicação de matrizes, cada uma representando um elemento óptico e respeitando a não-comutatividade da multiplicação de matrizes. De forma geral, para o plano transversal, podemos generalizar:

$$
\left.\left(\begin{array}{l}
x(z) \\
x^{\prime}(z) \\
y(z) \\
y^{\prime}(z)
\end{array}\right)=\left(\begin{array}{cccc}
\alpha_{11} & \alpha_{12} & 0 & 0 \\
\alpha_{21} & \alpha_{22} & 0 & 0 \\
0 & 0 & \alpha_{33} & \alpha_{34} \\
0 & 0 & \alpha_{43} & \alpha_{44}
\end{array}\right) \quad \begin{array}{c}
x(0) \\
x^{\prime}(0) \\
y(0) \\
y^{\prime}(0)
\end{array}\right)
$$

onde os elementos de matriz iguais a zero na Equação 3.5 podem ser diferentes de zero no caso de elementos ópticos que acoplem as coordenadas ${ }^{3}$. Elementos que afetam a distribuição de energias (cromaticidade) do feixe, como dipolos magnéticos, exigem a introdução de mais uma dimensão na matriz 3.5.

Dentre os vários elementos focalizadores no acelerador Pelletron, os mais utilizados na região de interesse neste trabalho são os quadrupolos magnéticos, nas configurações dubleto e tripleto. Os quadrupolos magnéticos consistem de quatro pólos dispostos a

\footnotetext{
${ }^{3}$ Um desses elementos ópticos que acoplam as coordenadas é o solenóide [59]
} 
$90^{\circ}$ entre si, com polaridade do campo alternada. A orientação é rotacionada de $45^{\circ}$ em relação ao sistema de coordenadas do feixe, de modo a ter força resultante nas direções transversais à propagação. O campo quadrupolar possui as linhas de campo hiperbólicas e tem a característica de ser focalizador numa direção e desfocalizador na direção perpendicular $[57,59,60]$, de modo que as configurações utilizadas para conseguir um efeito focalizador nas duas direções são as de dubleto (Figura 3.2 [60]) e tripleto.

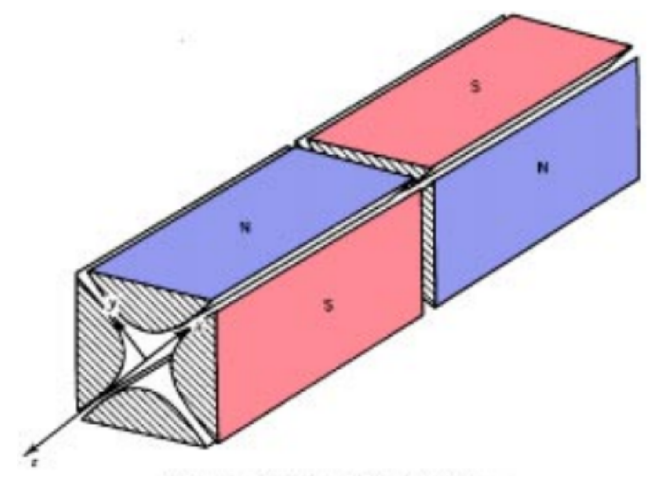

Figura 3.2: Desenho esquemático de um quadrupolo magnético. No caso do acelerador Pelletron, os quadrupolos são rotacionados $45^{\circ}$ de maneira a produzir efeito nas direções vertical e horizontal. (reproduzido de [60])

A característica de focalizar o feixe numa direção e desfocalizar na outra faz com que, mesmo na configuração dubleto, o valor do campo seja diferente para cada quadrupolo de modo a diminuir o astigmatismo do sistema (Figura 3.3 [60]); resultados melhores no tocante ao astigmatismo são obtidos com a configuração de tripleto (Figura 3.4 [60]), onde o primeiro e o terceiro quadrupolos são excitados em conjunto (mesmo valor de campo) e é ajustado o valor absoluto deste campo e sua relação com o campo do quadrupolo central. Na configuração dubleto, os dois quadrupolos possuem o mesmo comprimento; no caso do tripleto, o quadrupolo central possui o dobro do comprimento dos quadrupolos das extremidades. 

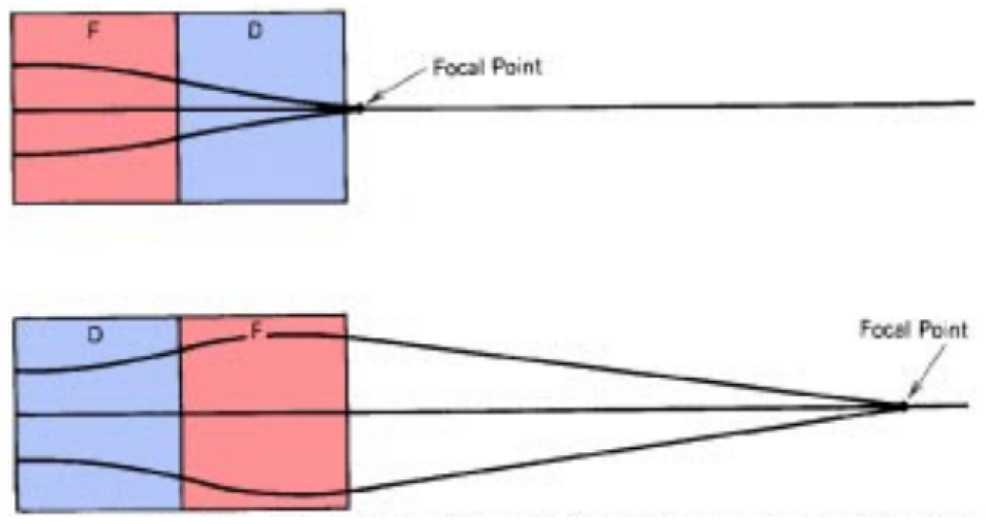

Figura 3.3: Astigmatismo numa lente quadrupolar, configuração dubleto, ilustrando órbitas de partículas inicialmente paralelas ao eixo projetadas nos planos x e y. (retirado de $[60])$
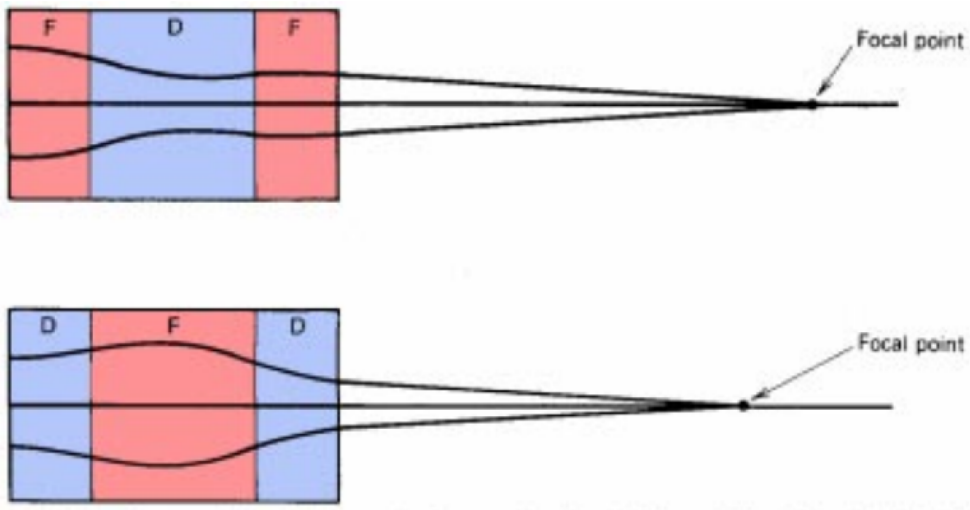

Figura 3.4: Astigmatismo numa lente quadrupolar, configuração tripleto, ilustrando órbitas de partículas inicialmente paralelas ao eixo projetadas nos planos x e y. (retirado de [60])

A matriz de transporte para um quadrupolo configurado como desfocalizador no eixo x focalizador no eixo y é dada por [57]: 


$$
\left(\begin{array}{c}
x(z) \\
x^{\prime}(z) \\
y(z) \\
y^{\prime}(z)
\end{array}\right)=\left(\begin{array}{cccc}
\cosh (k l) & (1 / k) \operatorname{senh}(k l) & 0 & 0 \\
k \operatorname{senh}(k l) & \cosh (k l) & 0 & 0 \\
0 & 0 & \cos (k l) & (1 / k) \operatorname{sen}(k l) \\
0 & 0 & -k \operatorname{sen}(k l) & \cos (k l)
\end{array}\right)\left(\begin{array}{c}
x(0) \\
x^{\prime}(0) \\
y(0) \\
y^{\prime}(0)
\end{array}\right)
$$

onde l é o comprimento do quadrupolo e $k^{2}=\frac{q G_{B}}{\sqrt{2 m E}}$, em que E é a energia do feixe, $\mathrm{m}$ sua massa, q sua carga e $G_{B}$ o gradiente do campo magnético. A configuração dubleto então é obtida através da multiplicação da matriz do quadrupolo com essa configuração pela matriz de deriva (Equação 3.4) por outra matriz de quadrupolo com os eixos de focalização e desfocalização invertidos.

Tendo por base a óptica do acelerador Pelletron, pode-se então calcular o feixe de entrada na canalização projetada e qual a forma do feixe incidindo na primeira folha espalhadora, de modo a obter a distribuição de partículas na posição de irradiação. No próximo capítulo será descrito o acelerador Pelletron. 


\section{Capítulo 4}

\section{O Acelerador Pelletron}

Todo o projeto da canalização dedicada à física aplicada no LAFN-USP e sua posterior utilização dependem das características dos feixes obtidos com o acelerador Pelletron. Neste capítulo, será feita a descrição do acelerador.

O Acelerador Pelletron 8UD é em acelerador eletrostático tipo Tandem, em que um íon ou molécula ionizada com carga negativa é acelerado por uma diferença de potencial positiva até uma região de trocas de carga, passando a ser novamente acelerada após a troca de cargas. Veremos em detalhes este mecanismo adiante.

\subsection{Fonte de Î́ons}

A geração de feixes iônicos com carga negativa pode ser feita de diversas formas, como por exemplo por meio de fontes de plasma ou fontes de sputtering. No caso do Acelerador Pelletron 8UD, usa-se uma fonte MC-SNICS (Multi-Cathode Source of Negative Ions by Cesium Sputtering), produzida pela NEC (National Electrostatics Corporation). Neste tipo de fonte de íons, um forno contendo césio é aquecido a cerca de $120^{\circ} \mathrm{C}$ por meio de uma resistência elétrica, produzindo vapor de césio metálico no interior da fonte de íons. Parte desse vapor ioniza-se ao entrar em contato com o ionizador, 
que consiste de uma superfície de tântalo de formato cônico, aquecida a 1000-1200 ${ }^{\circ} \mathrm{C}$, produzindo íons $\mathrm{Cs}^{+}$. A utilização de tântalo como material do ionizador é devida à sua alta função trabalho [61]. Estes íons carregados positivamente são então atraídos por um potencial negativo de $5 \mathrm{kV}$, aplicado ao cátodo. O cátodo consiste de um cadinho de aço que comporta em seu centro o material (em pó) do qual serão extraídos os íons, sendo que um único cátodo pode conter mais de uma espécie atômica de modo a prover diferentes feixes. A fonte de íons comporta até 32 cátodos diferentes, donde vem o nome multi-catodo. O feixe positivo de Cs, ao ir de encontro ao cátodo, não apenas se deposita neste, criando uma camada muito fina em sua superfície, mas também provoca sputtering no material, isto é, arranca átomos do material, ejetando-os. Neste processo de sputtering, os átomos arrancados passam através da fina camada de césio depositada sobre a superfície. Devido à sua alta eletropositividade, ocorre o fenômeno de ionização superficial [61], produzindo os íons negativos (carga -e) que são repelidos e, portanto, acelerados pelo potencial positivo de $10 \mathrm{kV}$ aplicado ao extrator, passando então através de uma abertura no ionizador. Um esquema do processo pode ser visto na Figura 4.1. Após a passagem pelo extrator, o feixe negativo é acelerado por uma tensão de até $90 \mathrm{kV}$ [62], além de focalizado por um dubleto de quadrupolos eletrostáticos e direcionado por meio de dois pares de trimmers eletrostáticos em direção ao primeiro eletroímã seletor, descrito na próxima seção juntamente com o acelerador de partículas e os sistemas de controle de energia. A Figura 4.2 mostra um esquema dos elementos do acelerador. 


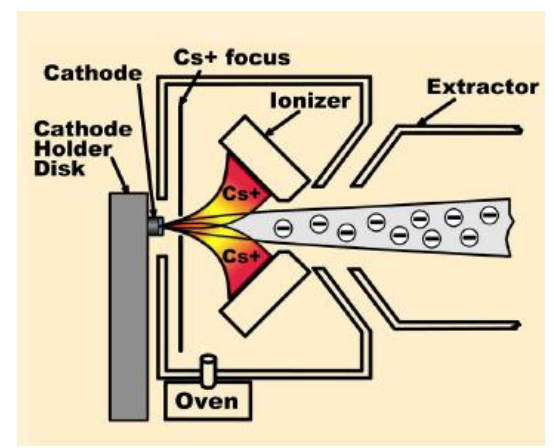

Figura 4.1: Esquema simplificado do processo de extração de feixes negativos (extraído de [62]

\subsection{Acelerador}

Após a produção na fonte de íons, o feixe passa através do eletroíma ME-20, onde 20 significa a máxima razão $m E / q^{2}(u \times M e V)$ das partículas que o eletroímã consegue defletir em $90^{\circ}$. A deflexão em $90^{\circ}$ é responsável pela seleção de massa dos íons de interesse, uma vez que o campo magnético é ajustado de forma que só sejam defletidos com trajetória central os íons com rigidez magnética

$$
B \rho=\frac{m v}{q}
$$

onde $m, v$ e $q$ são respectivamente a massa, a velocidade e a carga do íon, e $\rho$ é o raio da trajetória.

\subsubsection{Aceleração}

Após a seleção de massas, o feixe entra no acelerador propriamente dito. O acelerador consiste de colunas com divisores resistivos e anéis metálicos para a distribuição uniforme de campo elétrico com gradiente de aproximadamente $1 \mathrm{MV} / \mathrm{m}$. No centro do acelerador está o tubo acelerador, feito de alumina com anéis de titânio também 


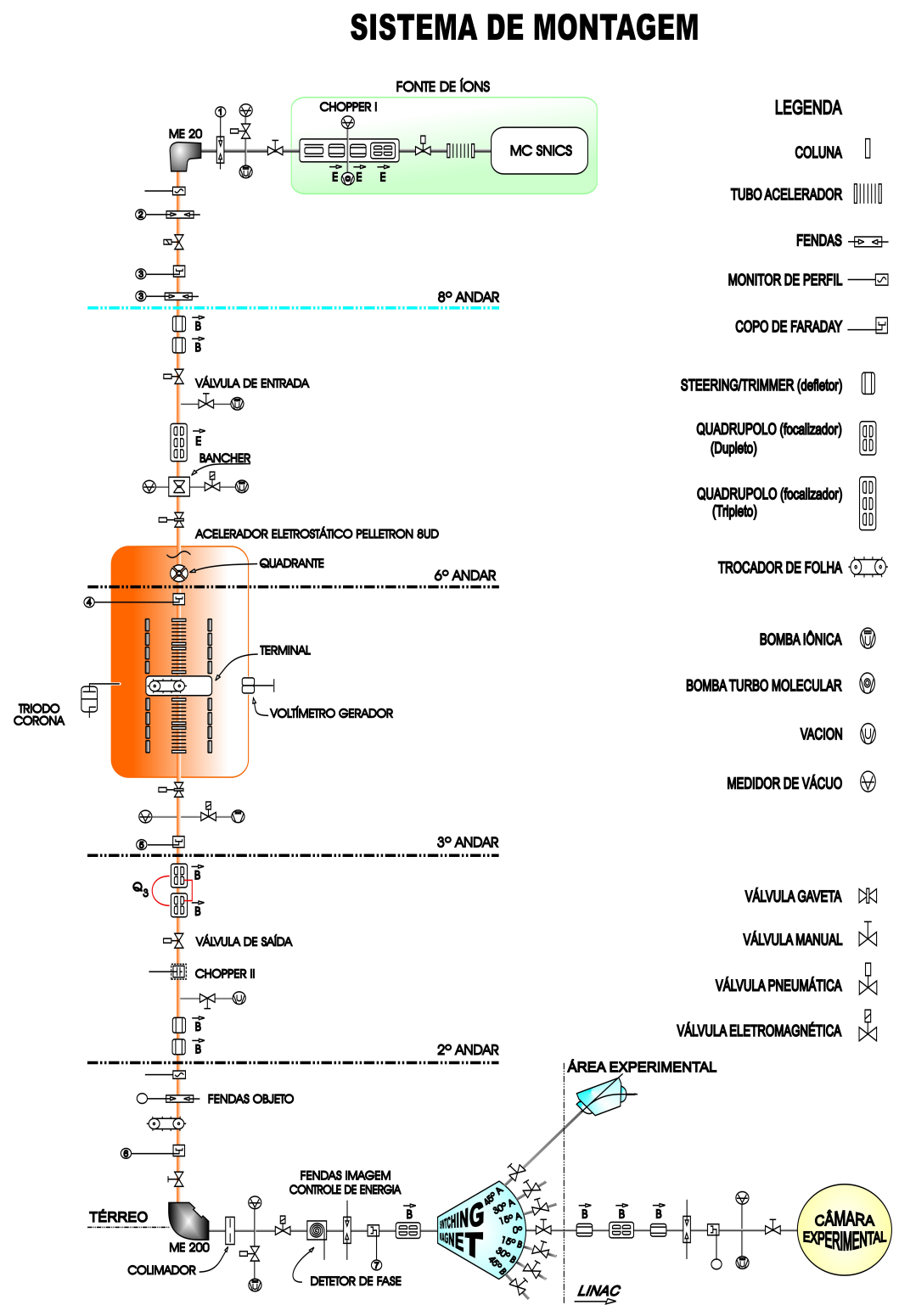

Figura 4.2: Diagrama geral do acelerador Pelletron com todos os elementos ópticos (cortesia de João Carlos Terassi). 
utilizados para a montagem de divisores resistivos. Aproximadamente à meia altura do tanque acelerador está o terminal, onde a tensão de aceleração (positiva de até $8 \mathrm{MV}$ ) é aplicada [23, 63]. O carregamento do terminal é feito por meio de duas correntes com cilindros metálicos (pellets) isolados por conexões de nylon. O carregamento dos pellets com carga positiva é feito com auxílio de um sistema de indução elétrica, assim como a transferência desta carga ao terminal. Neste sistema, um indutor na base do tanque carrega positivamente o pellet (que transfere elétrons à polia) através de uma alta tensão negativa, e no terminal o mesmo processo ocorre com tensão inversa. Ao voltar para a base, a corrente ainda encontra outro indutor com polaridade invertida, aumentando assim a corrente total de carga e a eficiência do sistema. Através dos divisores resistivos ocorre o descarregamento do terminal, razão pela qual as correntes de carga devem ser mantidas ligadas. O sistema de carregamento é ilustrado na Figura 4.3. Embora o interior do tubo acelerador fique em alto-vácuo $\left(\sim 10^{-8}\right.$ Torr $)$ para a passagem do feixe, todo o ambiente dentro do tanque é imerso em hexafluoreto de enxofre, um gás altamente isolante, a uma pressão de 4 a 6 atm.

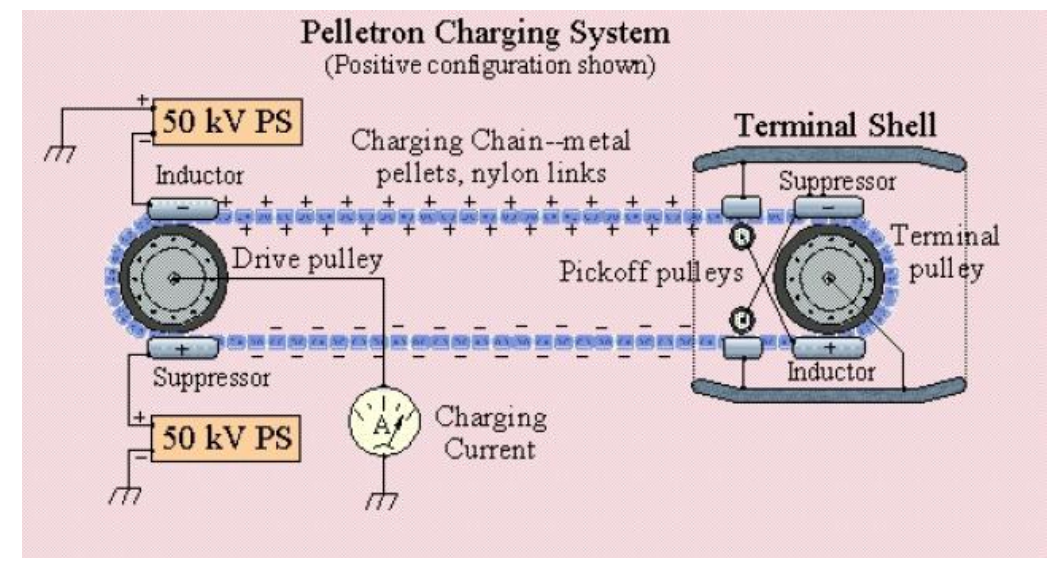

Figura 4.3: Esquema simplificado do processo de carregamento do terminal em um acelerador Pelletron (extraído de [64]).

Na região do terminal existem 3 dispositivos:

- voltímetro gerador: consiste em um sistema que infere a tensão no terminal através 
de um capacitor de área variável, cuja tensão é a própria tensão do terminal, servindo para fazer o controle grosseiro de energia. Neste sistema, uma das placas do capacitor (a outra é o próprio terminal) tem sua área alterada através de um rotor que esconde esta placa da atuação do campo. Sendo esta placa aterrada, ocorre a variação da corrente lida de acordo com a velocidade do rotor e a tensão no terminal. A leitura do voltímetro gerador controla os indutores de carga de modo a manter a tensão do acelerador constante;

- carretel de folhas de carbono: as folhas de carbono são responsáveis pela troca de carga do feixe e ganho maior de energia em aceleradores do tipo tandem em relação aos aceleradores de Van de Graaff de um estágio. Como as folhas possuem uma vida útil que pode ser curta, dependendo do feixe utilizado [28], 80 folhas são montadas em um carretel que pode ser controlado a partir da sala de controle. As folhas de carbono utilizadas no LAFN possuem espessura de cerca de $\sim 5 \mu \mathrm{g} / \mathrm{cm}^{2}$;

- agulha de tríodo: um sistema de 3 agulhas cuja posição dentro do tanque pode ser modificada de modo a possibilitar maior controle de tensão do acelerador. Devido ao intenso campo elétrico causado pela tensão do terminal e as pontas das agulhas, se estabelece uma corrente de Corona, ou seja, um fluxo de carga através do gás que faz a regulagem fina de tensão no terminal. A leitura da corrente das fendas de controle (seção 4.2.2) altera a tensão na grade da válvula tríodo, modificando assim a corrente de Corona estabelecida de modo a manter a tensão do terminal no valor estabelecido [49].

A distribuição de tensão no acelerador é feita de tal forma que os extremos estejam aterrados e o terminal na tensão de operação. Desta forma, ao entrarem no acelerador, as partículas do feixe (com carga -e) são aceleradas até o terminal, ganhando portanto uma energia

$$
E_{1}=V e
$$


onde $V$ é a tensão no terminal. Neste ponto está localizada a folha de carbono, fazendo com que o feixe inicialmente negativo perca elétrons, tornando-se positivo. A troca de cargas faz com que no segundo estágio do acelerador o feixe ganhe energia

$$
E_{2}=q V e
$$

onde $q$ é o estado de carga positivo gerada (em unidades de carga elementar), de modo que a energia total, incluindo a contribuição de $90 \mathrm{keV}$ da fonte de íons, passa a ser:

$$
E(M e V)=0,09+(1+q) V e
$$

\subsubsection{Controle de energia}

Após a saída do acelerador, o feixe deve passar por um segundo eletroíma analisador (equação 4.1), uma vez que a distribuição de estados de carga reflete-se em uma distribuição discreta de energia. No ME-200, eletroíma com relação $m E / q^{2}(u \times M e V)$ máxima 200, um campo magnético de valor bem definido é necessário para se conhecer a energia do feixe com a precisão necessária.

O sistema analisador de campo magnético é localizado dentro do entreferro do imã, próximo à trajetória das partículas e, portanto, imerso no campo magnético da ordem de 1 Tesla. Ele é formado por uma ponte R-L, sendo que dentro do núcleo de uma das indutâncias há uma amostra de água (Figura 4.4). Dado que o momento magnético do átomo de oxigênio na molécula de água é nulo, pode-se considerar que apenas o momento magnético dos prótons influencia no desbalanceamento da ponte R-L. Aplicando aos extremos da ponte uma tensão alternada $V=V_{0} \cos (\omega t)$, pode-se observar uma mudança no valor de tensão lido (parte central da ponte na Figura 4.4) proporcional à variação do momento magnético total no sentido do campo. Quando a frequência é ajustada para $\omega=\omega_{L}$, sendo $\omega_{L}$ a frequência de precessão do próton no campo mag- 
nético externo (frequência de Larmor), ocorre a inversão da orientação dos dipolos no campo magnético, fazendo com que a mudança no valor de tensão lido seja máximo. A frequência de Larmor pode ser calculada com exatidão para as condições da sonda, e podemos relacionar a energia do feixe com a frequência por meio da equação [65]:

$$
E=M u\left[\left(1+2 \frac{Z^{2} f^{2} k}{(M u)^{2}}\right)^{1 / 2}-1\right] M e V
$$

em que $M$ é o número de massa do íon, $u$ é a unidade de massa atômica em $\mathrm{MeV}$ $(\mathrm{u}=931,478 \mathrm{MeV}), k$ é a constante de calibração do eletroímã e $f$ é a frequência de ressonância. A constante de calibração foi obtida a partir de medidas de limiares de produção de nêutrons em reações conhecidas e seu valor é $k=(42,871 \pm 0,023) \mathrm{MeVu} / \mathrm{MHz} \mathrm{z}^{2}$ [65, 66], de modo que a energia do feixe pode ser conhecida a partir do ajuste da frequência de modo a obter a máxima tensão lida pela sonda (ressonância).

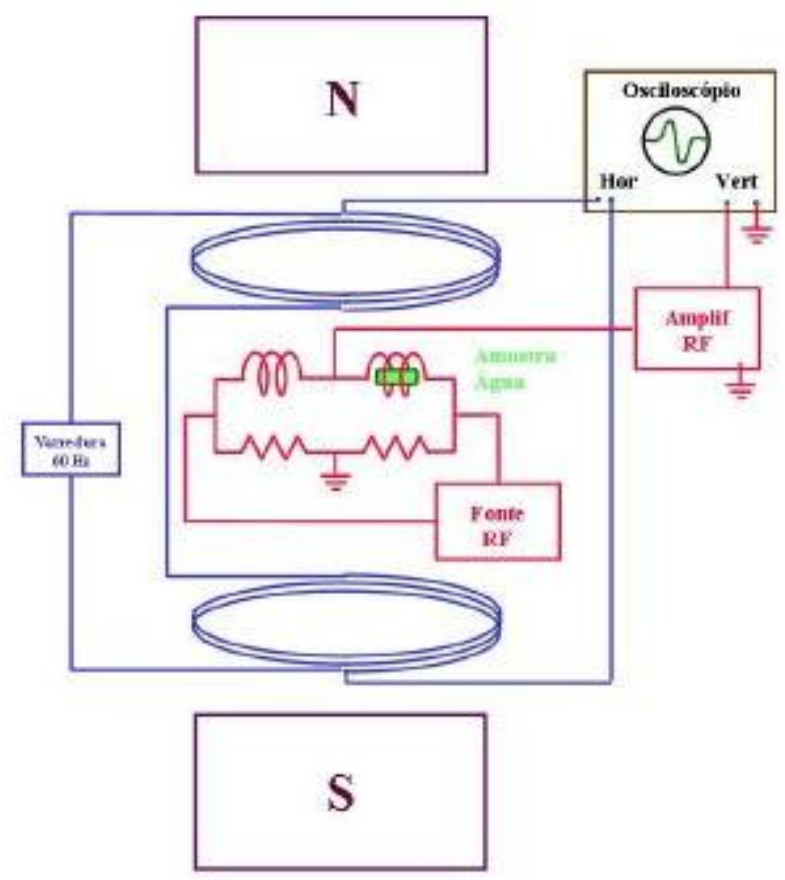

Figura 4.4: Esquema simplificado do processo de medida da frequência de ressonância magnética (cortesia de Nemitala Added). 
Após a passagem pelo eletroímã analisador, o feixe deve passar entre duas fendas que são usadas para fazer o controle fino da energia do acelerador. Caso a energia do feixe esteja abaixo do esperado pela frequência de ressonância, que mantém o controle do campo magnético, a curvatura gerada no feixe é maior do que $90^{\circ}$ e o sinal elétrico (corrente de feixe) lido na fenda superior é maior que na inferior. Um circuito faz a comparação destes dois sinais e controla a corrente de tríodo de modo a corrigir a energia, atuando de modo idêntico para o caso de energia superior ao ajustado. A abertura das fendas de controle também determina a resolução em energia do espectrômetro, $R=\Delta E / E=b / 2 \rho$, onde $b$ representa a abertura total das fendas de controle e $\rho$ o raio central da trajetória (50" para o ME-200). Em condições usuais, a abertura total das fendas é mantida em 50 mils $^{1}$, resultando numa resolução máxima de aproximadamente $0,05 \%$.

O tubo acelerador atua na emitância longitudinal e transversal do feixe [61], e o ME200, devido ao ângulo de curvatura de sua face de saída, também atua na focalização do feixe. No caso, as fendas de controle correspondem ao ponto imagem do ponto objeto anterior ao ME-200.

Após as fendas, o feixe passa por um último eletroímã (Switching Magnet), cuja função é defletí-lo para uma das 7 canalizações disponíveis no Acelerador Pelletron. A Figura 4.5 mostra uma visão geral do prédio do acelerador e a Figura 4.6 dá destaque à área experimental. No caso da canalização construída, por ser localizada a zero graus, a utilização do Switching Magnet não seria necessária; todavia, normalmente é preciso induzir um pequeno campo no ímã para compensar o campo residual (histerese) da utilização anterior em outras linhas, conforme será visto adiante.

\footnotetext{
${ }^{1}$ Milésimos de polegada
} 


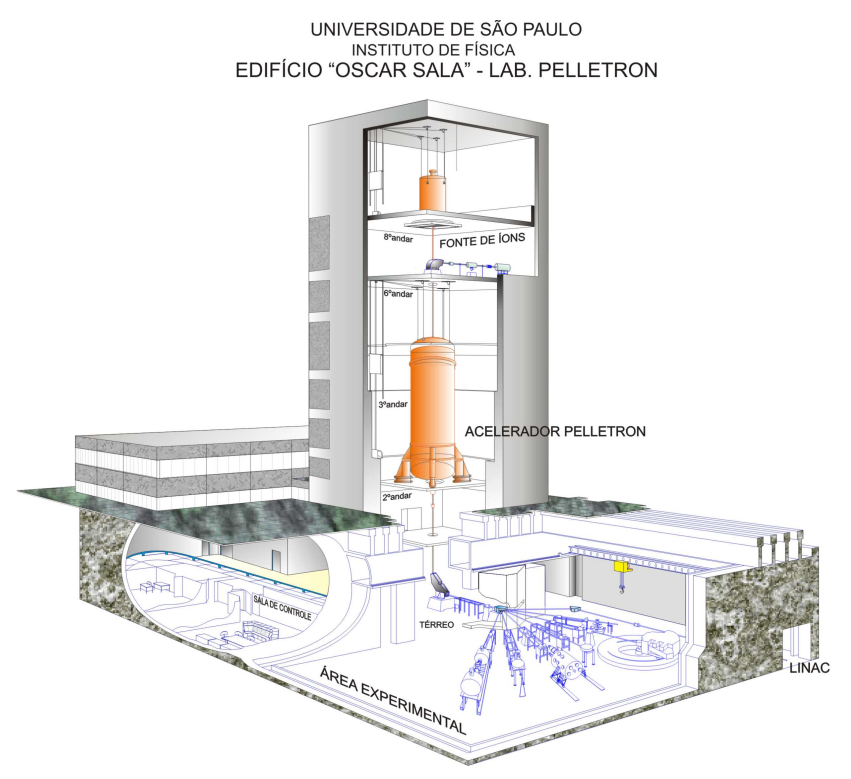

Figura 4.5: Visão geral do Acelerador Pelletron (cortesia de João Carlos Terassi).

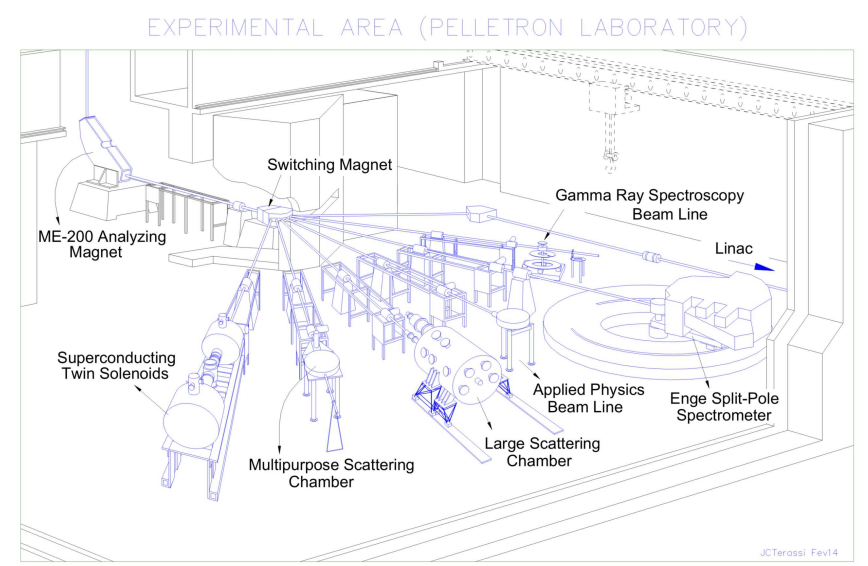

Figura 4.6: Detalhe da sala experimental, onde a canalização de que este trabalho trata é a canalização zero graus (Applied Physics Beam Line) (cortesia de João Carlos Terassi). 


\section{Capítulo 5}

\section{Projeto do Sistema de}

\section{Uniformização de Feixes}

Com base nas teorias de interação de íons acelerados em sólidos, espalhamento múltiplo, óptica iônica e nas características do acelerador Pelletron, foi possível projetar um sistema para uniformização do feixe que combina a desfocalização do feixe com espalhamento múltiplo para obter os resultados desejados, isto é, feixes uniformes de baixa intensidade. Os detalhes dos cálculos e procedimentos adotados são descritos a seguir.

\section{1 Óptica}

\subsubsection{Desfocalização}

Um dos métodos que pode ser utizado para promover a uniformização do feixe é a desfocalização [55, 56, 67], que consiste na focalização do feixe em outro ponto, muito anterior ou posterior, em relação à amostra sob irradiação. Dada uma distribuição de partículas com emitância $\epsilon_{f e i x e}$, se a focalização é feita num ponto próximo ao 
quadrupolo a figura de emitância será modificada para uma figura de pequena extensão $x, y$ e elevada divergência $x^{\prime}, y^{\prime}$ (Figura 5.1a).

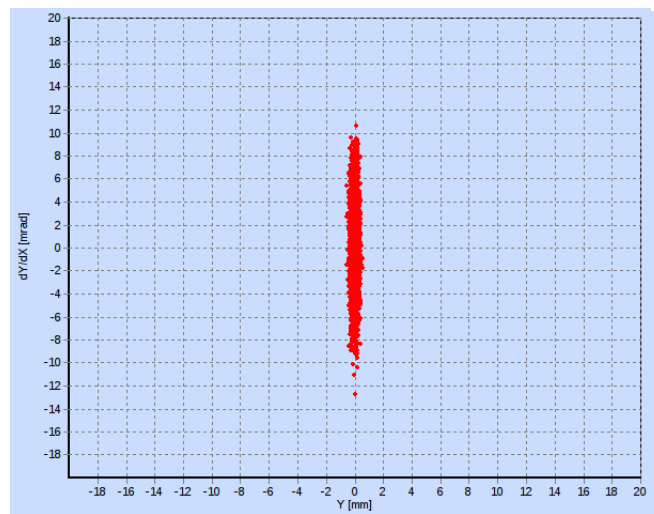

(a)

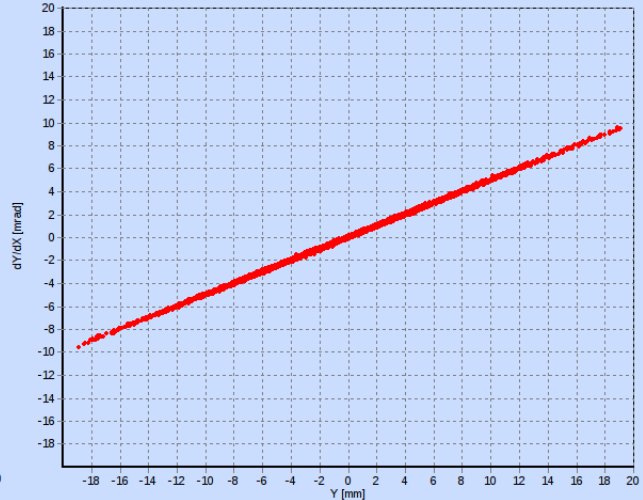

(b)

Figura 5.1: Plano de fase numa das direções transversais para um feixe de ${ }^{12} C 50 \mathrm{MeV}$. (a) No plano focal.(b) Após deriva de 2 metros.

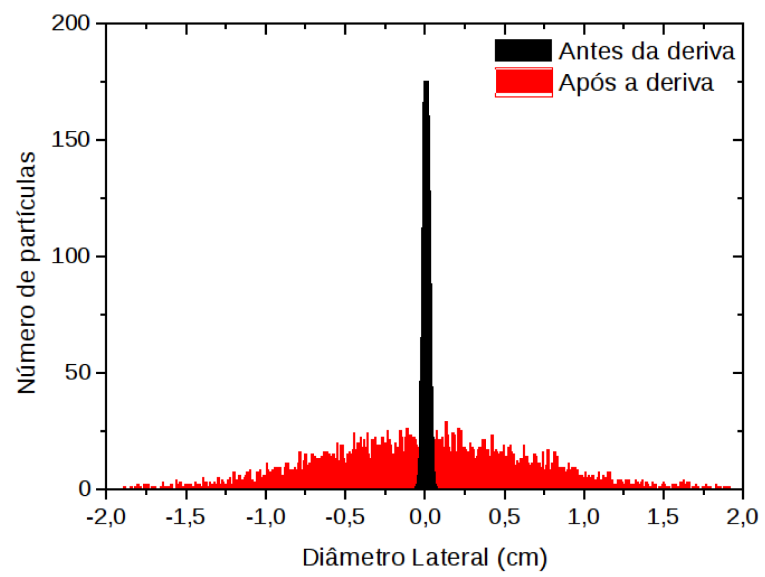

Figura 5.2: Histograma com as distribuições de posição de partículas em duas condições, antes e depois da deriva, ilustrando a utilização da técnica de desfocalização na uniformização e diminuição de intensidade do feixe.

O transporte da distribuição com tal emitância através de um espaço de deriva implica no alargamento da distribuição de acordo com a Equação 3.3, promovendo o aumento da largura total do feixe (vide Figura 5.1b) e, numa determinada área 
central, levando a dois efeitos: diminuição do fluxo e aumento da uniformidade (platô da distribuição gaussiana), conforme pode ser visto na Figura 5.2. As figuras a seguir foram geradas por meio do programa de simulação $S^{3} M$ [68], o qual detalharemos adiante, gerando uma distribuição gaussiana de 5000 íons de ${ }^{12} \mathrm{C}$ a $50 \mathrm{MeV}$, com dimensão transversal horizontal de 1,54 mm e divergência de 32,5 mrad (ponto focal), e a mesma distribuição após uma deriva de 2 metros.

\subsection{2 Óptica do Acelerador Pelletron e da nova canalização a $0^{\circ}$}

A base para a simulação da óptica da canalização zero grau do acelerador Pelletron parte da emitância do feixe após o eletroíma analisador ME-200. Para calcular esta emitância, foi utilizado o programa OPTICA [57], um programa baseado no programa OPTRYK da Universidade de Oxford e adaptado pelo professor J.C. Acquadro. Este programa faz a simulação (em primeira ordem) dos elementos ópticos considerando uma distribuição uniforme de partículas com a emitância definida pela geometria da fonte de íons ${ }^{1}$. Apesar de ser de difícil utilização, este programa foi utilizado nesta primeira parte do cálculo por já conter os dados de entrada com todos os elementos ópticos do acelerador Pelletron, a saber: fonte de íons, tubo de pré-aceleração, dubleto eletrostático, fenda objeto do eletroíma ME-20, dipolo ME-20, fenda imagem do ME20, tripleto eletrostático, tubo acelerador (entrada), folha de stripper, tubo acelerador (saída), tripleto de quadrupolos magnéticos, fenda objeto do ME-200, dipolo ME-200 e fenda imagem do ME-200 conforme pode ser visto na Figura 4.2. O dubleto de quadrupolos magnéticos antes do Switching Magnet não foi considerado nos cálculos pois, estando no mesmo alinhamento do quadrupolo da canalização zero graus, a utilização deste quadrupolo aumentaria o número de graus de liberdade do sistema dificultando a obtenção de uma emitância de entrada para os cálculos posteriores, tendo em vista que o objetivo é simular a emitância obtida com a focalização de maior divergência

\footnotetext{
${ }^{1}$ No caso deste programa, a distribuição de contém mil partículas
} 
possível no copo de Faraday da canalização; todavia, este quadrupolo mantém-se como elemento focalizador na linha de feixe, auxiliando em condições diferentes de trabalho que serão discutidas adiante.

Mesmo possuindo as mesmas características na fonte de íons, diferentes feixes ou energias irão possuir diferentes emitâncias após a passagem por todos os elementos ópticos, além da dependência da própria condição de passagem do feixe, que pode variar devido aos diferentes usuários do acelerador. Desta forma, o programa OPTICA foi utilizado para obter a emitância no ponto imagem do ME-200 para um feixe de ${ }^{16} \mathrm{O}$ com energia de $64 \mathrm{MeV}$. Esta emitância foi tomada como sendo uma representante aproximada das emitâncias obtidas com outros feixes, uma vez que a própria configuração das fendas objeto e imagem do ME-200 limita bastante as variações na emitância do feixe de saída. Os valores obtidos são mostrados na Tabela 5.1.

Tabela 5.1: Parâmetros de emitância do feixe após o ME-200. Valores obtidos com o programa OPTICA e calculados para o acelerador Pelletron com feixe de ${ }^{16} \mathrm{O}$ com energia de $64 \mathrm{MeV}$. Os valores referem-se à extensão total $x, y$ nas direções horizontal e vertical, respectivamente, e aberturas angulares totais $x^{\prime}, y^{\prime}$.

\begin{tabular}{cc}
\hline $\mathrm{x}(\mathrm{mm})$ & 2,56 \\
$\mathrm{x}$ (mrad) & 4,32 \\
$\mathrm{y}(\mathrm{mm})$ & 2,50 \\
$\mathrm{y}^{\prime}(\mathrm{mrad})$ & 4,56 \\
\hline
\end{tabular}

Esta configuração básica do feixe após o ME-200 serviu de base para obter as configurações de focalização dos feixes no copo de Faraday da nova canalização. A nova canalização foi instalada no lugar da antiga canalização a zero graus do acelerador Pelletron, mantendo-se o dubleto de quadrupolos fixo na posição em que se encontrava, bem como a bomba órbitron, responsável pelo alto-vácuo. Mediu-se então a distância da fenda imagem do ME-200 até o quadrupolo e deste até o ponto (aproximado) onde viria a se encontrar o novo copo de Faraday, com valores respectivamente de 10,17(5) 
$\mathrm{m}$ e 2,31(5) $\mathrm{m}$. Com base nestes valores, procedeu-se ao transporte de feixe pelo método matricial de modo a verificar se o dubleto de quadrupolos era capaz de focalizar os feixes nesta pequena distância e, caso possível, qual a emitância obtida. Estes cálculos foram feitos com o programa PBO-Lab [69], um programa de óptica iônica que utiliza o método matricial para calcular os envelopes de feixe e emitâncias através de canalizações de aceleradores. A montagem completa da linha é ilustrada na Figura 5.3 juntamente aos envelopes de feixe para o caso do feixe de ${ }^{16} O 60 \mathrm{MeV}$, onde foram posicionados o dubleto de quadrupolos, o copo de Faraday, os colimadores e as folhas espalhadoras utilizadas na segunda parte do cálculo, e a Figura 5.4 ilustra as elipses de feixe para os planos horizontal (vermelho) e vertical (azul) bem como a seção transversal do feixe em diversos pontos diferentes da linha nesta simulação. Com base na emitância inicial, quatro feixes foram simulados, sendo que para cada feixe as correntes em cada quadrupolo foram alteradas no programa até obter a focalização na posição do copo de Faraday e menor astigmatismo possível. A Tabela 5.2 mostra os valores de emitância obtidos.

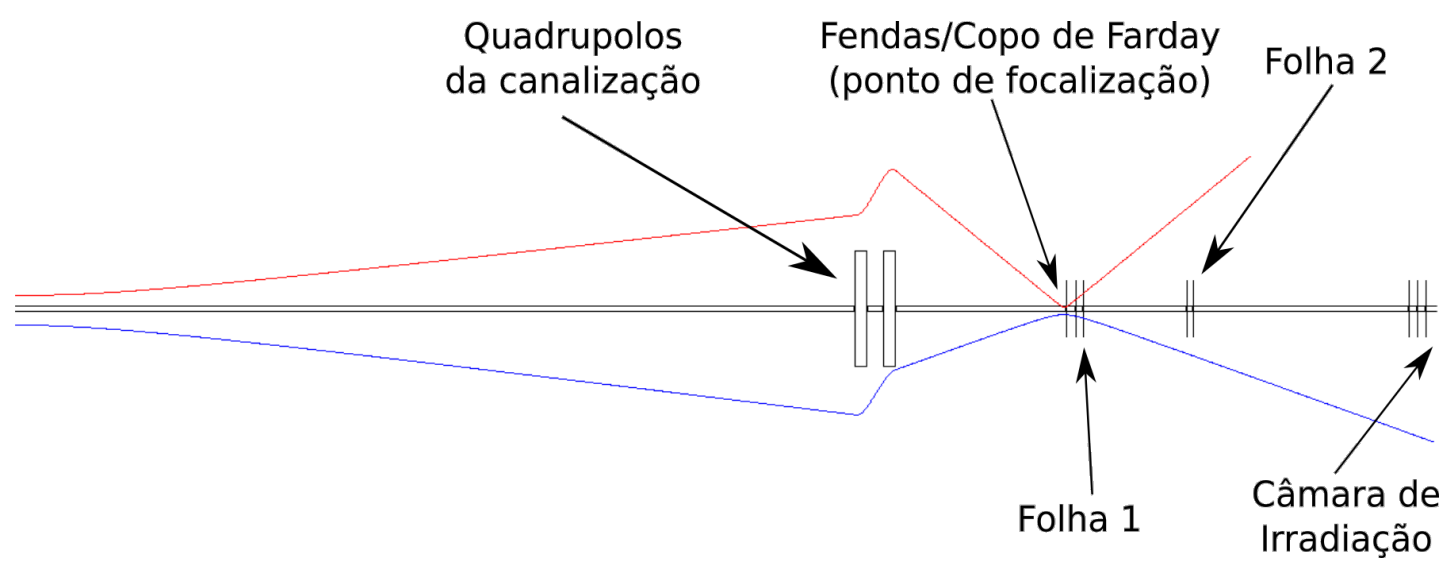

Figura 5.3: Esquema da canalização zero graus contendo a condição de focalização do feixe de ${ }^{16} \mathrm{O}$ a $60 \mathrm{MeV}$. Em vermelho é mostrado o envelope na direção horizontal e em azul o envelope na direção vertical. 


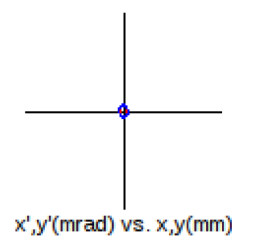

(a)

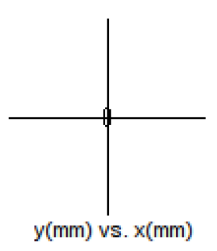

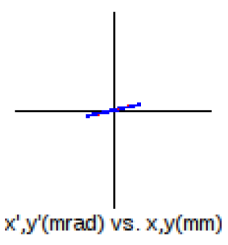

(b)

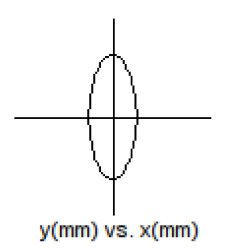

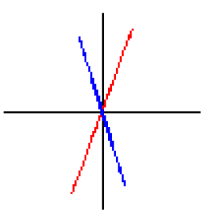

(c)

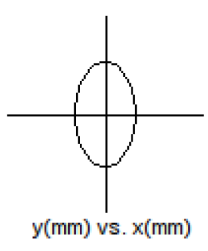

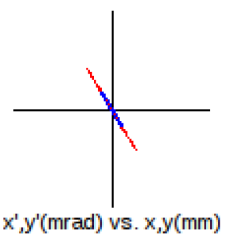

(d)

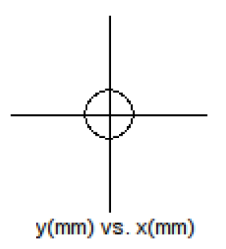

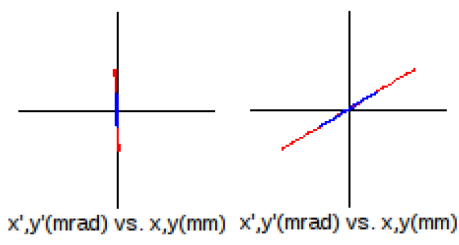

(e)

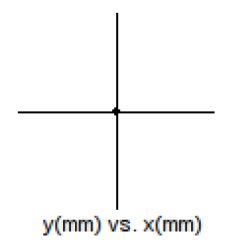

(f)

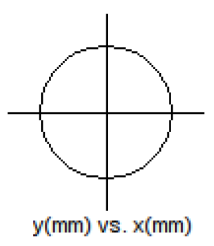

Figura 5.4: Planos de fase horizontal (vermelho) e vertical (azul) e seções transversais do feixe de ${ }^{16} \mathrm{O}$ a $60 \mathrm{MeV}$ em diversos pontos da canalização. Escala dos planos de fase: vertical $= \pm 65 \mathrm{~mm}$, horizontal $= \pm 30 \mathrm{mrad}$. (a) feixe inicial obtido a partir do OPTICA. (b) situação antes de chegar ao quadrupolo. (c) durante a focalização no quadrupolo. (d) após o quadrupolo. (e) próximo ao ponto focal. (f) após a deriva.

Tabela 5.2: Parâmetros $x, x^{\prime}, y, y^{\prime}$ obtidos para a emitância dos feixes de ${ }^{12} C,{ }^{16} O,{ }^{28} \mathrm{Si}$ e ${ }^{63} \mathrm{Cu}$ após a simulação de focalização na posição do copo de Faraday.

\begin{tabular}{ccccccc}
\hline Íon & Energia $(\mathrm{MeV})$ & $\mathrm{Q}$ & $\mathrm{x}(\mathrm{mm})$ & $\mathrm{x}^{\prime}(\mathrm{mrad})$ & $\mathrm{y}(\mathrm{mm})$ & $\mathrm{y}^{\prime}(\mathrm{mrad})$ \\
\hline${ }^{12} \mathrm{C}$ & 50 & $6+$ & 0,36 & 32,5 & 0,88 & 13,0 \\
${ }^{16} \mathrm{O}$ & 60 & $7+$ & 0,36 & 32,1 & 0,88 & 13,0 \\
${ }^{28} \mathrm{Si}$ & 70 & $8+$ & 0,34 & 31,6 & 0,86 & 13,1 \\
${ }^{63} \mathrm{Cu}$ & 80 & $10+$ & 0,36 & 32,3 & 0,88 & 13,0 \\
\hline
\end{tabular}

\subsection{Espalhamento}

A utilização de folhas espalhadoras em conjunto com a desfocalização permite obter feixes mais uniformes $[55,56]$ ao custo da perda de energia das partículas na folha espalhadora. Entretanto, este método possibilita a utilização de um detector monitor após uma das folhas, que, após calibração com a intensidade de feixe na região de 
irradiação, permite determinar o fluxo de partículas na área irradiada. Desta forma, optou-se por um sistema híbrido que permita operar tanto na condição de desfocalização quanto na condição de espalhamento múltiplo, além de combinações desses métodos. No caso do acelerador Pelletron, devido à baixa energia disponível, deve ser feita a avaliação cuidadosa de quando a perda de energia é aceitável e quando deve-se utilizar apenas a técnica de desfocalização. A escolha das folhas espalhadoras deve ser feita de modo a ter baixa contagem de íons de recuo da folha na região de irradiação, baixa (ou inexistente) quantidade de reações nucleares dos íons com os núcleos da folha, capacidade de produzir folhas numa larga gama de espessuras e obter folhas autoportantes com alta durabilidade. Estes fatores levaram à escolha de folhas de ouro como elementos espalhadores. Conforme explicado no Capítulo 2, deve-se escolher dentre os vários métodos para se calcular as distribuições emergentes de uma folha espalhadora, com base em alguns parâmetros que indicam a validade da primeira aproximação de Born. A Tabela 5.3 mostra os valores de $\alpha$ (Equação 2.12) e da energia crítica de Meyer (Equação 2.19), sendo que para o caso de $\alpha<1$ ou $E>E_{\text {crit }}$ utiliza-se a teoria de Molière e no caso contrário pode-se utilizar a teoria clássica de Meyer.

A utilização dos modelos estatísticos depende ainda do número médio esperado de colisões sofridas por um íon ao atravessar a folha espalhadora ser maior que $\sim 20$, que podemos calcular utilizando a expressão $\bar{n}=\pi r_{0}^{2} N t$, definida no Capítulo 2. Dado que, para um alvo de ouro, o número médio de colisões varia com a espessura do alvo $t\left(\mathrm{em} \mathrm{mg} / \mathrm{cm}^{2}\right)$ linearmente da forma $\bar{n}=58 t$, tem-se que a condição é satisfeita para espessuras de alvo maiores que $\sim 0,3 \mathrm{mg} / \mathrm{cm}^{2} 2$.

Conforme pode ser observado, para todos os feixes considerados na faixa de operação do acelerador Pelletron, o modelo teórico mais adequado para a descrição do espalha-

\footnotetext{
${ }^{2}$ Existe uma distinção entre o espalhamento múltiplo, onde o número médio de colisões é maior que 20, e o espalhamento plural, em que o número médio de colisões é entre 2 e 20 . No desenvolvimento de sua teoria, Meyer realiza uma aproximação na resolução da distribuição emergente, aproximação esta que restringe o número médio de colisões a ser maior que 5, correspondendo a alvos de ouro de aproximadamente $0,1 \mathrm{mg} / \mathrm{cm}^{2}$. Alvos mais finos geram uma discrepância entre o cálculo exato e o aproximado de cerca de $8 \%$ [51].
} 
Tabela 5.3: Parâmetros de alguns feixes no Pelletron a diferentes energias para escolha do modelo de espalhamento utilizado.

\begin{tabular}{cccccccc}
\hline Íon & $\mathrm{Z}$ & $\mathrm{A}$ & Energia $(\mathrm{MeV})$ & $\epsilon$ & $\beta$ & $\alpha$ & $E_{\text {crit }}(\mathrm{MeV})$ \\
\hline${ }^{1} \mathrm{H}$ & 1 & 1 & 10 & 1,10 & 0,146 & 4,0 & 156 \\
${ }^{1} \mathrm{H}$ & 1 & 1 & 15 & 1,64 & 0,179 & 3,2 & 156 \\
${ }^{6} \mathrm{Li}$ & 3 & 6 & 20 & 0,66 & 0,084 & 20,5 & $8 \times 10^{3}$ \\
${ }^{6} \mathrm{Li}$ & 3 & 6 & 30 & 0,99 & 0,103 & 16,8 & $8 \times 10^{3}$ \\
${ }^{12} \mathrm{C}$ & 6 & 12 & 40 & 0,61 & 0,084 & 41,1 & $67 \times 10^{3}$ \\
${ }^{12} \mathrm{C}$ & 6 & 12 & 52 & 0,79 & 0,096 & 36,0 & $67 \times 10^{3}$ \\
${ }^{16} \mathrm{O}$ & 8 & 16 & 42 & 0,46 & 0,075 & 61,7 & $159 \times 10^{3}$ \\
${ }^{16} \mathrm{O}$ & 8 & 16 & 68 & 0,74 & 0,095 & 48,5 & $159 \times 10^{3}$ \\
${ }^{28} \mathrm{Si}$ & 14 & 28 & 60 & 0,34 & 0,068 & 119,5 & $856 \times 10^{3}$ \\
${ }^{28} \mathrm{Si}$ & 14 & 28 & 80 & 0,45 & 0,078 & 103,5 & $856 \times 10^{3}$ \\
${ }^{35} \mathrm{Cl}$ & 17 & 35 & 65 & 0,29 & 0,063 & 155,9 & $1 \times 10^{6}$ \\
${ }^{35} \mathrm{Cl}$ & 17 & 35 & 85 & 0,38 & 0,072 & 136,3 & $1 \times 10^{6}$ \\
${ }^{63} \mathrm{Cu}$ & 29 & 63 & 70 & 0,15 & 0,049 & 343,8 & $8 \times 10^{6}$ \\
${ }^{63} \mathrm{Cu}$ & 29 & 63 & 90 & 0,20 & 0,055 & 303,2 & $8 \times 10^{6}$ \\
\hline
\end{tabular}

mento múltiplo é o modelo de Meyer, que por sua vez utiliza o modelo de blindagem de Lindhard, desde que os alvos espalhadores sejam mais grossos que $300 \mu \mathrm{g} / \mathrm{cm}^{2}$. Ainda se verifica na Tabela 5.3 que o parâmetro $\beta$ relativístico para os feixes considerados é muito inferior ao dos primeiros elétrons atômicos do ouro (Capítulo 1), indicando a importância de se considerar o efeito da blindagem eletrônica no caso da utilização destes alvos. Diante das discrepâncias dos potenciais para certos pares íon-átomo e da distribuição inicial considerada, optou-se por utilizar o método de Monte Carlo, conforme descrito no Capítulo 2, valendo-se da blindagem e do potencial universal (Equações 1.9 e 1.8) por sua melhor descrição média dos eventos e também por levar em conta a perda de energia das partículas no alvo (que deve ser considerada), além de não depender de funções tabeladas e poder operar com qualquer número de partículas e colisões. A opção pela utilização do programa TRIM foi feita de acordo com a praticidade de cálculo, a forma de entrada de dados, que permite a utilização de qualquer distribuição 
de partículas, incluindo divergência, e a forma como os dados de saída são acessados. $\mathrm{Na}$ Tabela 5.3 são ainda indicados os valores $\epsilon$ (Equação 1.11) de energia reduzida de Lindhard utilizando o comprimento de blindagem $a_{U}$ (Equação 1.9), indicando que, ao utilizar o código TRIM, baseado no método de Monte Carlo, a maioria das combinações íon-energia com o alvo de ouro possuem forte dependência com a forma da função blindagem e, portanto, devem levá-la em conta através da "fórmula mágica"[37, 40].

Antes de simular o espalhamento do feixe nas folhas, é necessário conhecer o tamanho e divergência deste antes da interação, o que passa por determinar a posição das folhas espalhadoras. A teoria de Meyer-Montenegro faz apenas a previsão para o espalhamento em uma folha, porém alguns autores a utilizaram em sistemas com duas folhas espalhadoras para obter melhores resultados [55, 56], utilizando-se colimadores antes do espalhamento para diminuir o fluxo de partículas. A determinação da posição das folhas espalhadoras não pode ser feita apenas com critérios de óptica iônica, mas também com base nas possibilidades de construção. Em primeira aproximação, a posição da primeira folha pode ser determinada a partir da distância mínima após o copo de Faraday que permita a instalação, e a segunda folha pode ser posicionada à maior distância possível da posição de irradiação, delimitada pelo espaço disponível na sala experimental. Um esquema da montagem é mostrado na Figura 5.5. Utilizando a formulação de Montenegro (Equações 2.22 a 2.26) e tomando como distância aproximada entre a primeira folha espalhadora e o ponto de irradiação como sendo de 4,3 metros e entre a segunda folha e a câmara de irradiação como sendo de 3,0 metros, obtemos os gráficos das Figuras 5.6 e 5.7. As Figuras 5.8 e 5.9 apresentam a queda relativa de intensidade do feixe na mesma área de irradiação em função da espessura da folha, tendo em vista que o objetivo da montagem consiste em não apenas aumentar a área e uniformidade do feixe, mas também reduzir a intensidade de aproximadamente $10^{10}$ partículas por segundo numa área de cerca de $3 \mathrm{~mm}$ para $10^{2}-10^{5}$ partículas $/ \mathrm{s} / \mathrm{cm}^{2}$. 


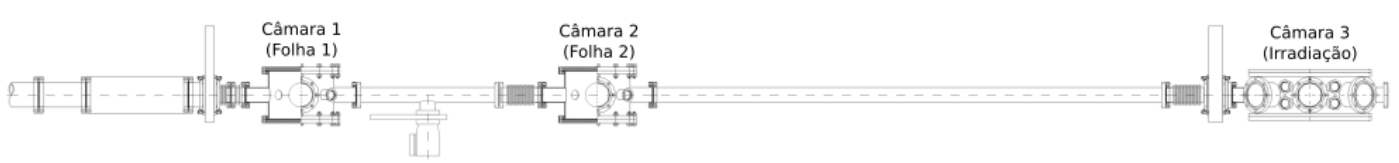

Figura 5.5: Esquema de um sistema de 3 câmaras com dois espalhadores.

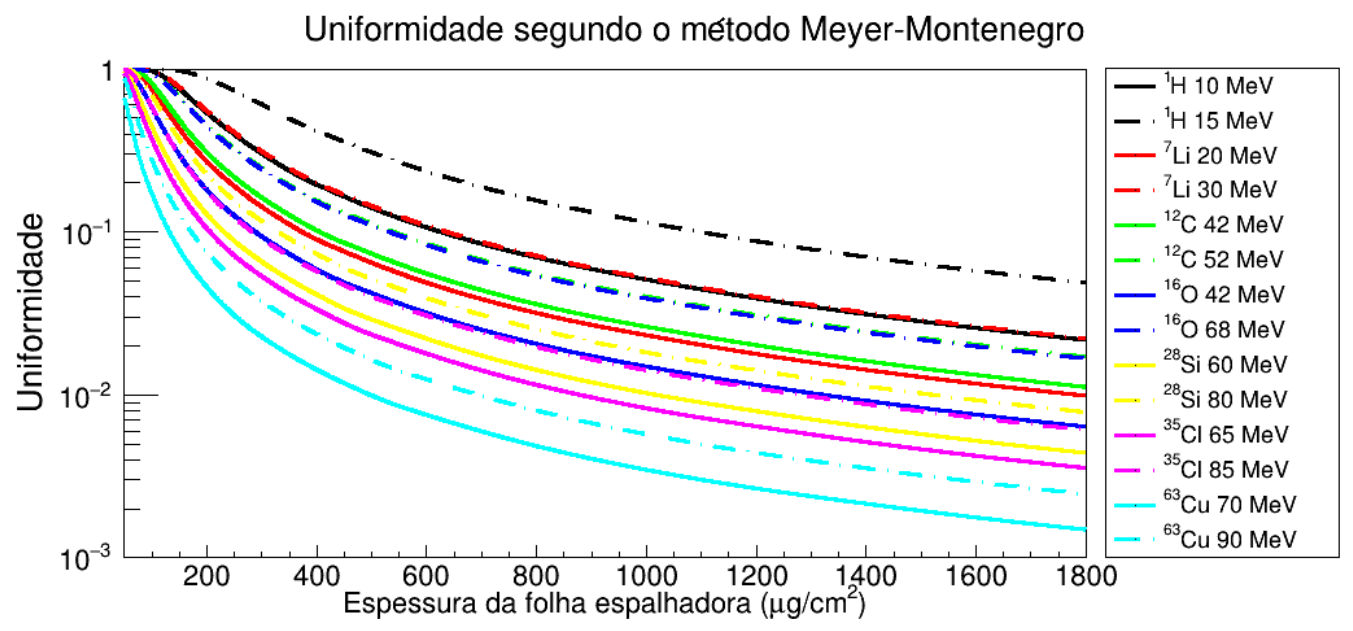

Figura 5.6: Uniformidade $\epsilon_{\text {feixe }}$ segundo o método Meyer-Montenegro para distância 4,3 m em função da espessura da folha de ouro usada como espalhador. Valores de uniformidade menores que 0,1 cumprem os requisitos das normas de irradiação.

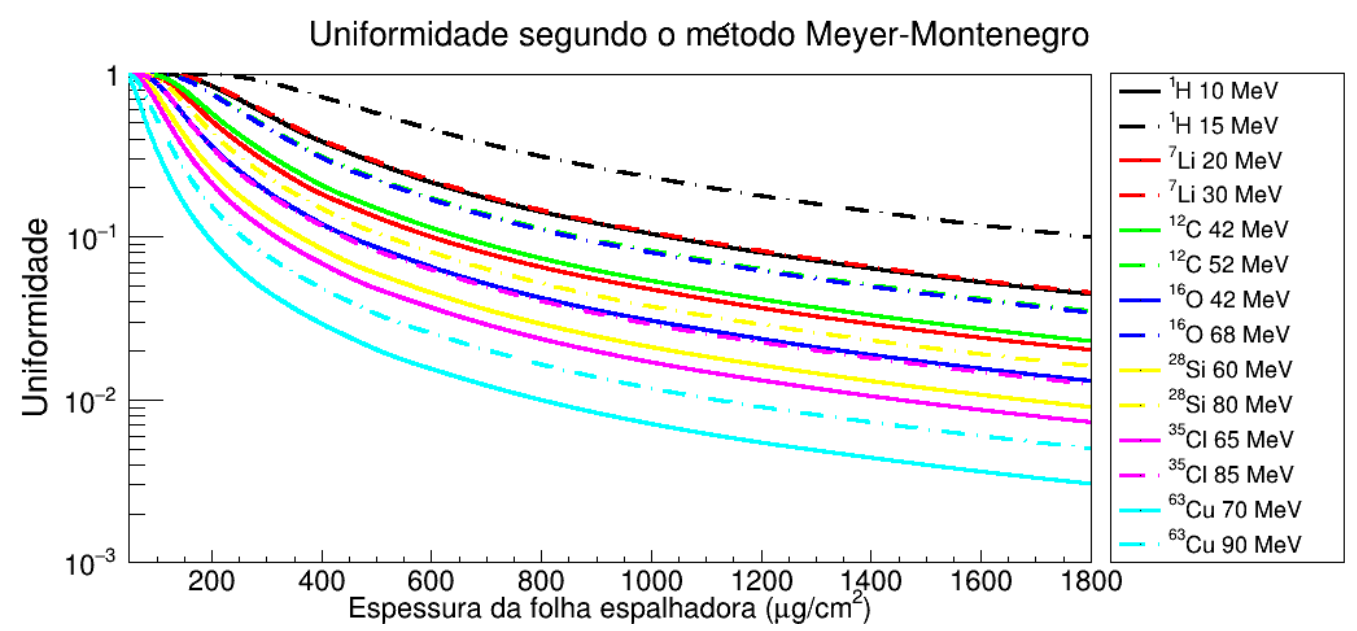

Figura 5.7: Uniformidade $\epsilon_{\text {feixe }}$ segundo o método Meyer-Montenegro para distância 3,0 m em função da espessura da folha de ouro usada como espalhador. Valores de uniformidade menores que 0,1 cumprem os requisitos das normas de irradiação. 


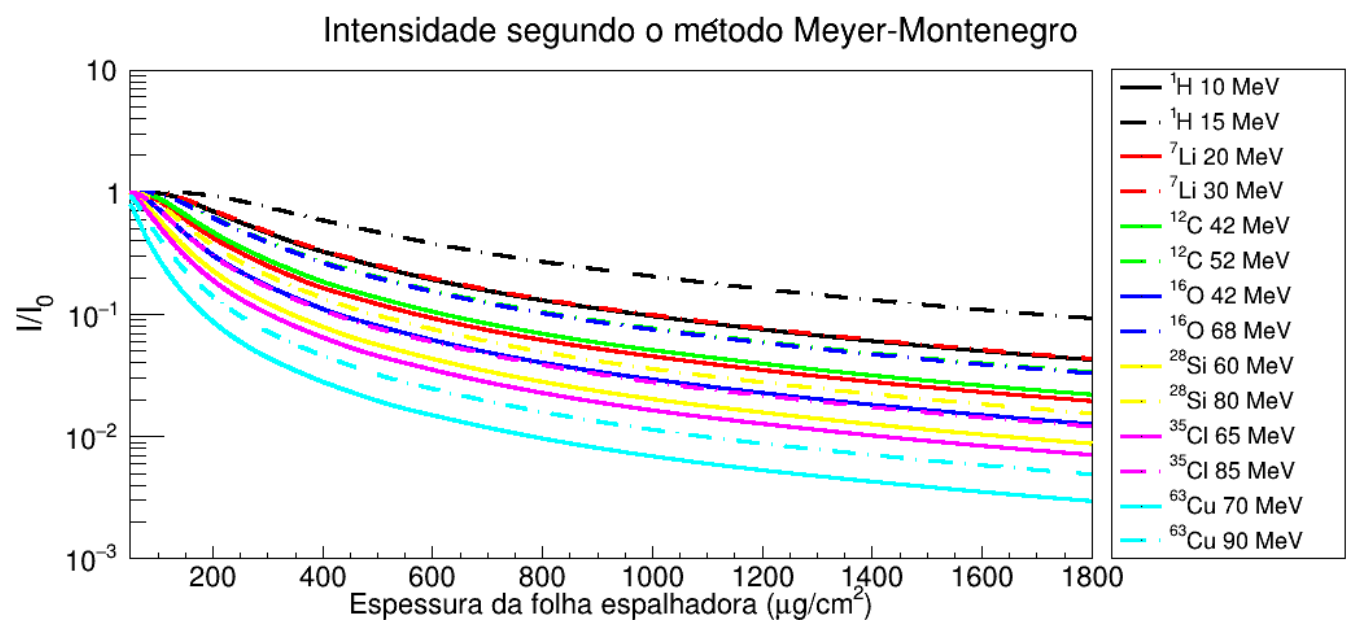

Figura 5.8: Intensidade relativa segundo o método Meyer-Montenegro para distância 4,3 m em função da espessura da folha de ouro usada como espalhador.

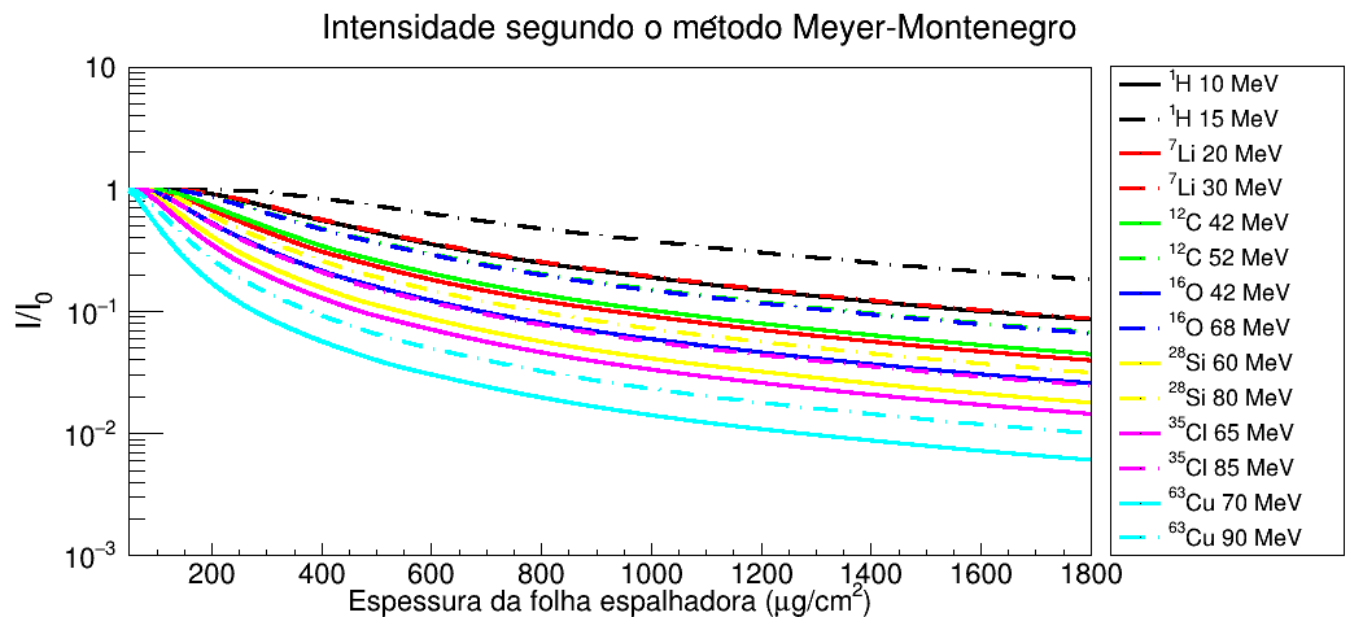

Figura 5.9: Intensidade relativa segundo o método Meyer-Montenegro para distância 3,0 m em função da espessura da folha de ouro usada como espalhador.

Os gráficos indicam que, à distância de 4,3 m, folhas mais espessas que $\sim 700 \mu \mathrm{g} / \mathrm{cm}^{2}$ são suficientes para prover feixes com uniformidade adequada; no caso da distância de $3,0 \mathrm{~m}$, folhas mais grossas que $\sim 1,0 \mathrm{mg} / \mathrm{cm}^{2}$ são necessárias. No caso de prótons, apenas com folhas muito mais grossas pode-se obter a uniformidade ideal. No tocante à intensidade, observa-se uma redução do número de partículas por um fator 2 até, no máximo, um fator 200, insuficiente, portanto, para reduzir o feixe de cerca de $10^{10}$ 
partículas/s para o fluxo desejado. Utilizando-se duas folhas espalhadoras com um colimador antes da segunda folha, obtém-se que a intensidade relativa transmitida da folha 1 à folha 2 também cai por um fator que varia de 2 a 200 (Figura 5.10), dependendo da espessura da folha. Combinando com a segunda folha espalhadora, pode-se obter uma redução na intensidade do feixe de até 40.000 vezes, o que ainda representa um feixe intenso para os experimentos de irradiação de dispositivos eletrônicos. Dessa maneira, deve-se utilizar a desfocalização em conjunto com as folhas espalhadoras, que devem então ser escolhidas de modo a priorizar a uniformidade do feixe, com efeito secundário sobre a intensidade. Os parâmetros usados para os cálculos com o método Meyer-Montenegro foram base para o cálculo utilizando o método de Monte Carlo.

Intensidade na segunda folha, segundo o método Meyer-Montenegro

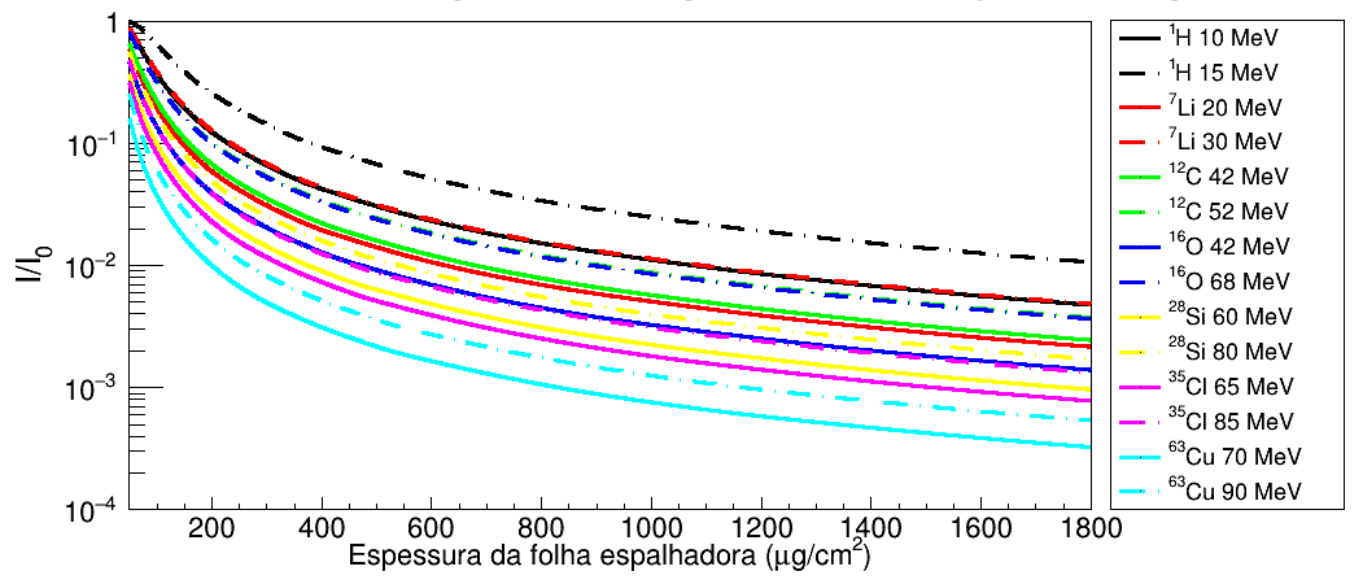

Figura 5.10: Intensidade relativa transmitida à segunda folha, de acordo com o método Meyer-Montenegro, considerando distância de 1,3 m entre folhas e colimador de 1,5 mm antes da folha 2 .

O método de Monte Carlo foi utilizado como alternativa ao método Meyer-Montenegro por levar em conta diversos efeitos desconsiderados no primeiro, principalmente a perda de energia das partículas e a possibilidade de tratar mais de uma folha espalhadora e números pequenos de colisões. Com base nas emitâncias obtidas no cálculo da óptica (Tabela 5.2), foram geradas distribuições de partículas para serem usadas como entrada no software TRIM. As distribuições foram geradas utilizando o software $S^{3} M$ 
pois este gera arquivos contendo as posições iniciais e vetores velocidade das partículas no formato de entrada do código TRIM. As distribuições geradas têm a forma gaussiana tanto para a posição quanto para a divergência, com desvio padrão de $10 \%$ em ambos os casos. A variação na energia foi suposta como sendo de $1 \%^{3}$ e o número de partículas considerado foi de $5 \times 10^{6}$. Procedeu-se então ao transporte do feixe da posição de focalização onde a distribuição foi gerada até a primeira folha, passando por um colimador de forma a diminuir a quantidade de partículas. Este cálculo foi feito através de uma rotina em ROOT [70], que calculava o transporte de cada partícula simulada, com suas respectivas posições e ângulos de divergências, utilizando a matriz de deriva (Equação 3.4). Na posição do colimador (1,5 mm), o código eliminava todas as partículas com posição radial maior que o raio do colimador, continuando então o transporte até a folha espalhadora.

O efeito da folha espalhadora foi avaliado usando a distribuição transportada como entrada no programa TRIM, que, segundo metodologia explicada no capítulo 1, produziu um arquivo de saída contendo as posições e vetores velocidades para cada uma das partículas de entrada (quando não havia freamento completo dentro do próprio alvo). Este arquivo foi utilizado então novamente na rotina de transporte, seja para transportar a distribuição diretamente até a região de irradiação ou até a segunda folha espalhadora. No caso do transporte até a segunda folha, mais uma etapa de cálculo no TRIM e na rotina de transporte eram necessários.

As primeiras simulações foram feitas para os feixes e emitâncias listados na Tabela 5.2 e alvos de ouro com espessuras variando entre 0,7 e $3,5 \mathrm{mg} / \mathrm{cm}^{2}$. Devido à impossibilidade do TRIM simular mais que $10^{6}$ partículas, observou-se que, após a colimação, espalhamento em uma folha e subsequente transporte do feixe a intensidade do feixe no plano de irradiação era muito baixa, insuficiente para uma análise estatística adequada. Observou-se também que a perda de energia para os feixes mais pesados e algumas

\footnotetext{
${ }^{3}$ Superior à precisão que pode ser alcançada com o ME-200, porém uma dispersão maior da energia inicial pode ajudar a reproduzir efeitos de não-uniformidade das folhas espalhadoras.
} 
combinações de alvos era proibitiva para o tipo de experimento a que a canalização se destinaria, de modo que novas simulações foram feitas em diferentes condições. A Figura 5.11 mostra o gráfico do perfil do feixe de ${ }^{12} C 50 \mathrm{MeV}$ na posição de irradiação, para a combinação de uma folha de $0,7 \mathrm{mg} / \mathrm{cm}^{2}$ e uma folha de $3,5 \mathrm{mg} / \mathrm{cm}^{2}$.

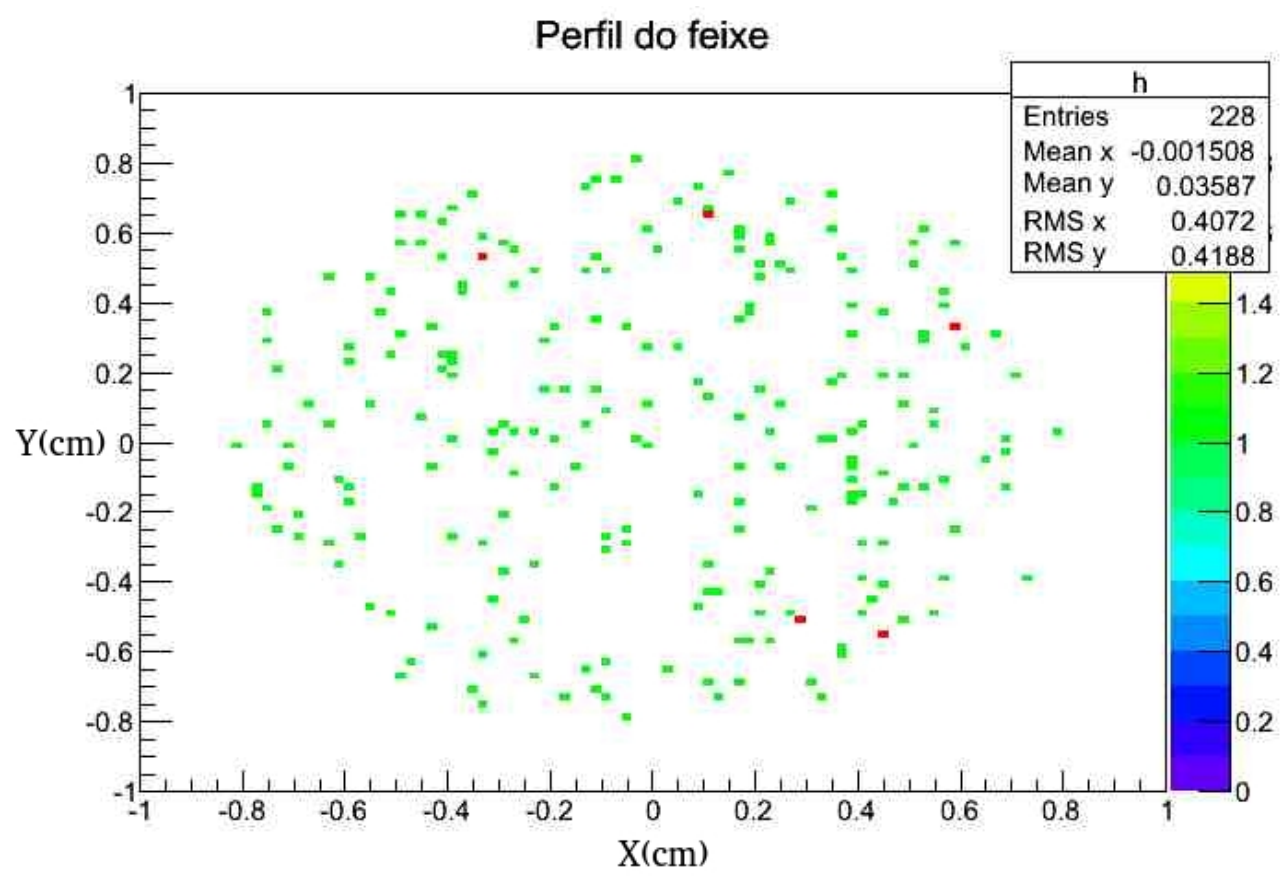

Figura 5.11: Perfil do feixe simulado de ${ }^{12} C 50 \mathrm{MeV}$ na posição de irradiação, para a combinação de uma folha de $0,7 \mathrm{mg} / \mathrm{cm}^{2}$ e uma folha de $3,5 \mathrm{mg} / \mathrm{cm}^{2}$ e considerando-se um total $10^{6}$ partículas.

Os resultados obtidos nas primeiras simulações mostraram que era necessário aumentar o número de partículas a serem consideradas, apesar da limitação do TRIM, e escolher apenas combinações de folhas espalhadoras que resultem numa perda de energia máxima de 20\%. As simulações seguintes foram então realizadas para os feixes de carbono e silício com as configurações iniciais apresentadas na Tabela 5.2 e as combinações de folhas espalhadoras com os seguintes valores de espessura: 0,0 (sem folha); $0,1 \mathrm{mg} / \mathrm{cm}^{2} ; 0,5 \mathrm{mg} / \mathrm{cm}^{2} ; 1,0 \mathrm{mg} / \mathrm{cm}^{2} ; 1,5 \mathrm{mg} / \mathrm{cm}^{2}$ e $2,0 \mathrm{mg} / \mathrm{cm}^{2}$. Para evitar a diminuição da intensidade no plano de irradiação e nas etapas de espalhamento, após 
o transporte do feixe até as folhas espalhadoras suas características eram analisadas, isto é, emitância e energia; gerava-se então um novo feixe com as mesmas características, porém com total de $10^{6}$ partículas a cada etapa. Desta forma, pôde-se obter uma distribuição adequada de partículas no plano de irradiação, e através das transmissões parciais em cada trecho foi possível determinar o fator de atenuação total. Na ausência de folha espalhadora, o respectivo colimador era também excluído das simulações. A Figura 5.12 mostra os resultados de perfil do feixe de carbono na posição de irradiação para seis condições diferentes, e a Figura 5.13 mostra os resultados para feixe de silício, com as intensidades relativas a $10^{6}$ partículas.

Conforme pode ser observado, a não utilização de folhas espalhadoras origina uma distribuição de partículas com diferentes larguras ao longo dos eixos x e y, refletindo o astigmatismo do feixe após a focalização inicial. A utilização de uma folha espalhadora na posição 1 e ausência de colimadores e espalhadores em seguida fornece bons resultados, embora não reduza o suficiente a intensidade do feixe, como se verá a seguir. Observa-se também que há uma pequena melhora na uniformidade do feixe para a utilização de duas folhas espalhadoras, porém a melhor alternativa é utilizar folhas mais grossas no caso da utilização da segunda câmara.

O primeiro passo na análise das distribuições obtidas foi verificar a indepedência da forma do feixe em cada direção através do coeficiente de correlação, da ordem de $10^{-3}$ para todas as 70 distribuições obtidas, o que permitiu considerar que as duas direções não possuíam dependência entre si. A análise das distribuições obtidas foi feita por meio de 4 parâmetros: desvio-padrão, curtose, uniformidade e integral. O desvio-padrão, em cm, foi calculado a partir dos dados nas duas direções e, diante da compatibilidade dos valores nas duas direções para todas as distribuições, a cada condição foi atribuído um valor médio de desvio-padrão dado pela médias dos desviospadrões nas direções X e Y, respectivamente. A incerteza para os valores obtidos de desvio padrão foi, em média, de $0,1 \%$. A curtose é um parâmetro estatístico que mede 


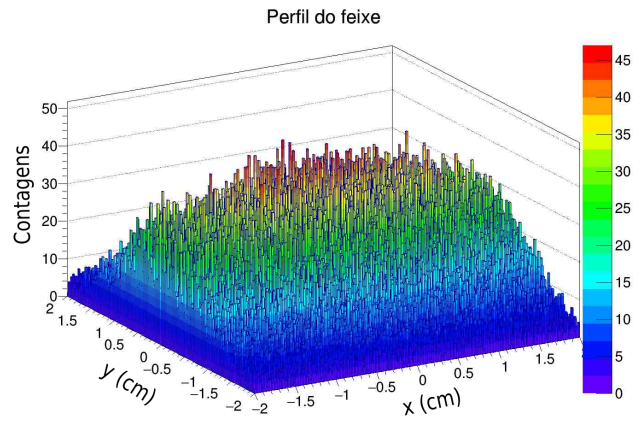

(a) $0,0-0,0$

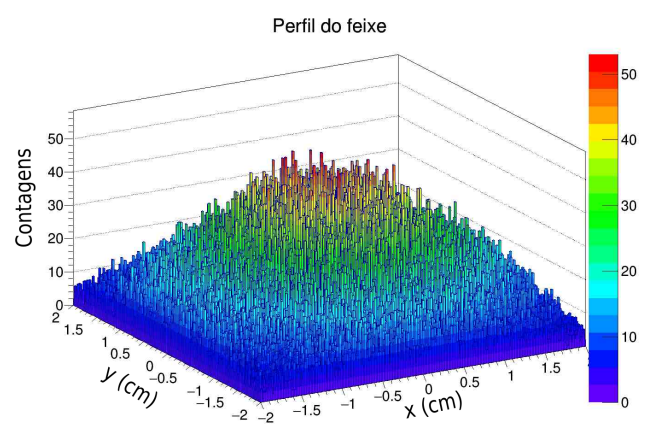

(c) $0,5-0,0$

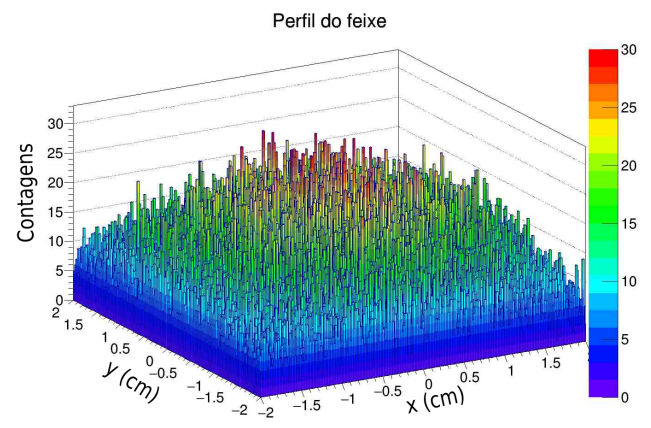

(e) $0,5-1,5$

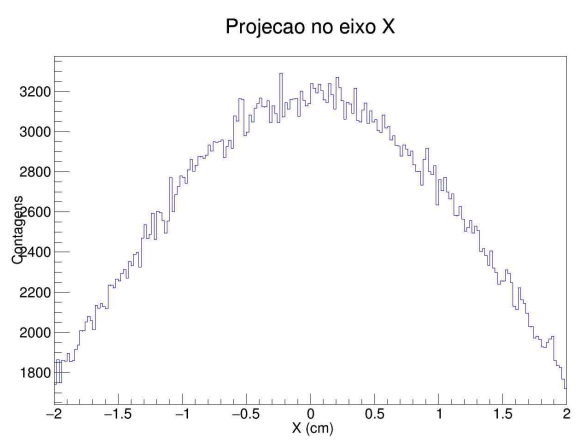

(g) $1,5-1,5(\mathrm{X})$

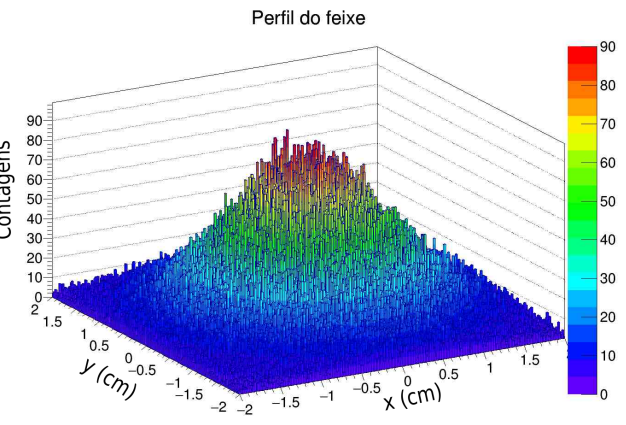

(b) $0,0-0,5$

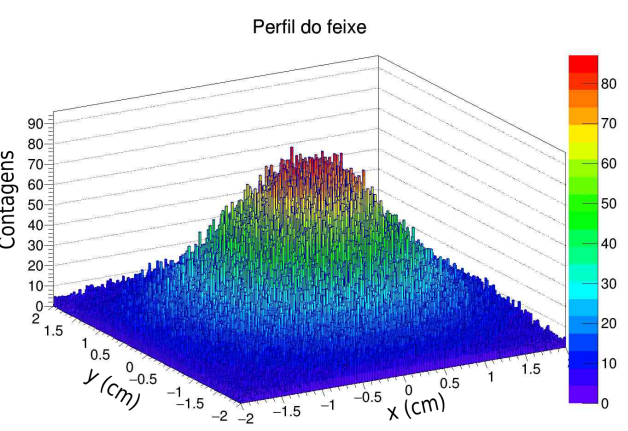

(d) $0,5-0,5$

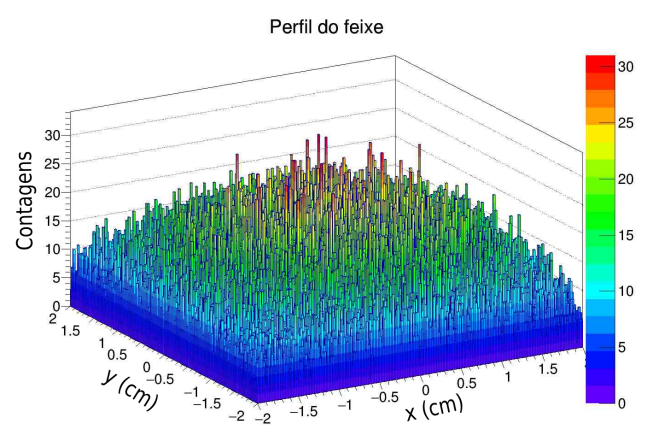

(f) $1,5-1,5$

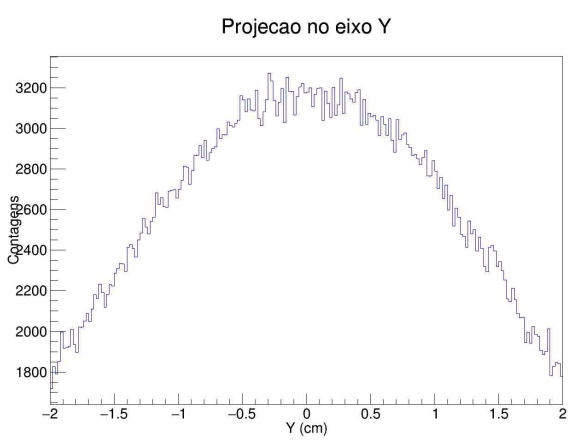

(h) $1,5-1,5(\mathrm{Y})$

Figura 5.12: (a)Perfil do feixe de ${ }^{12} C 50 \mathrm{MeV}$ na posição de irradiação, sem folhas espalhadoras e colimadores. (b)Apenas a segunda folha, espessura de $0,5 \mathrm{mg} / \mathrm{cm}^{2}$. (c) Apenas a primeira folha, espessura de $0,5 \mathrm{mg} / \mathrm{cm}^{2}$. (d)Folhas 1 e 2 com espessura de $0,5 \mathrm{mg} / \mathrm{cm}^{2}$.(e)Folha $1 \mathrm{de} 0,5 \mathrm{mg} / \mathrm{cm}^{2}$ e folha 2 com espessura de $1,5 \mathrm{mg} / \mathrm{cm}^{2}$.(f)Folhas 1 e 2 com espessura de $1,5 \mathrm{mg} / \mathrm{cm}^{2}$. (g)Projeção na direção horizontal da condição da Figura 5.12f. (h)Projeção na direção vertical da condição da Figura 5.12f. 


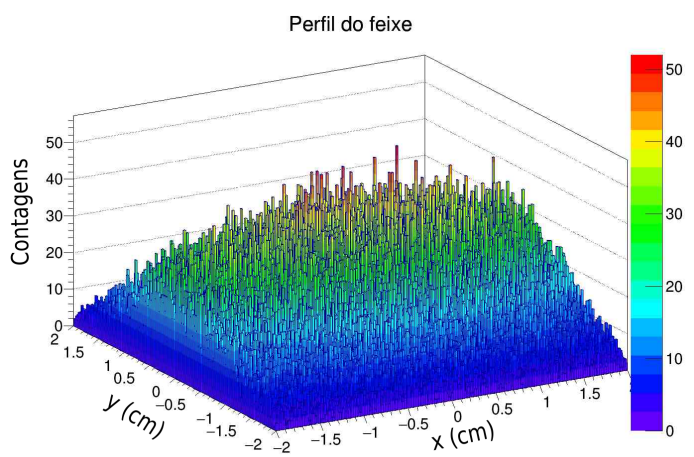

(a) $0,0-0,0$

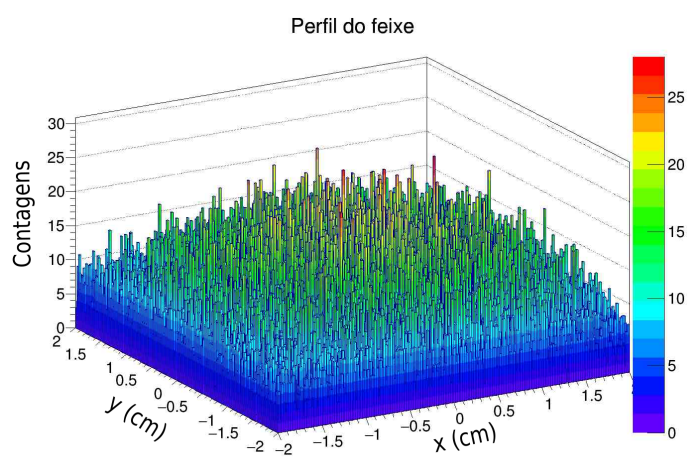

(c) $0,5-0,0$

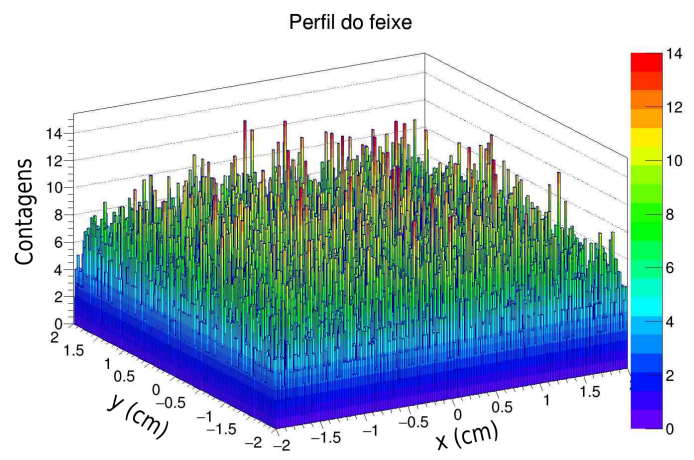

(e) $0,5-1,5$

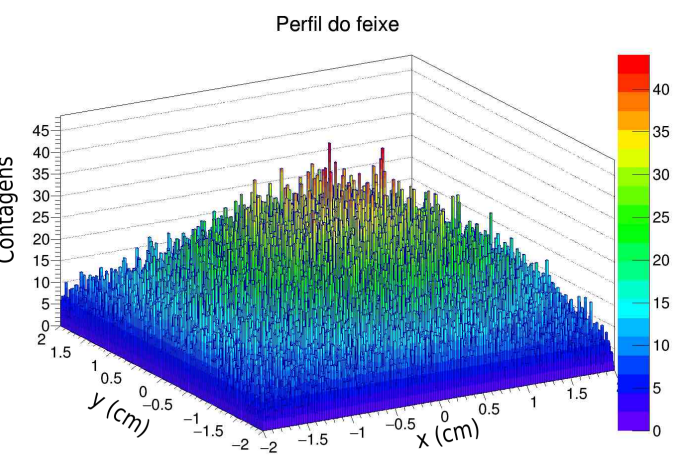

(b) $0,0-0,5$

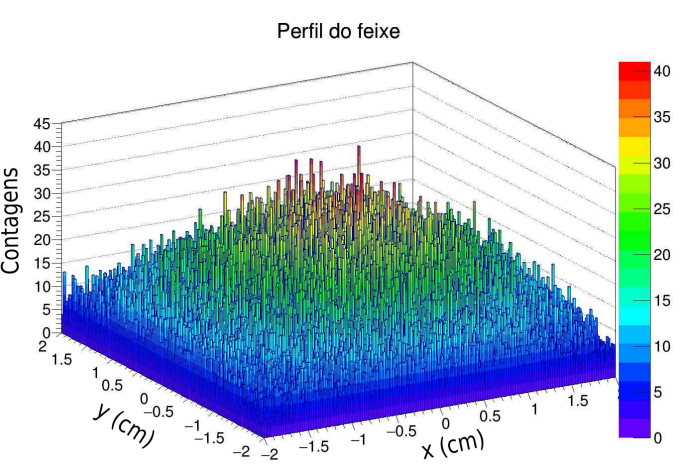

(d) $0,5-0,5$

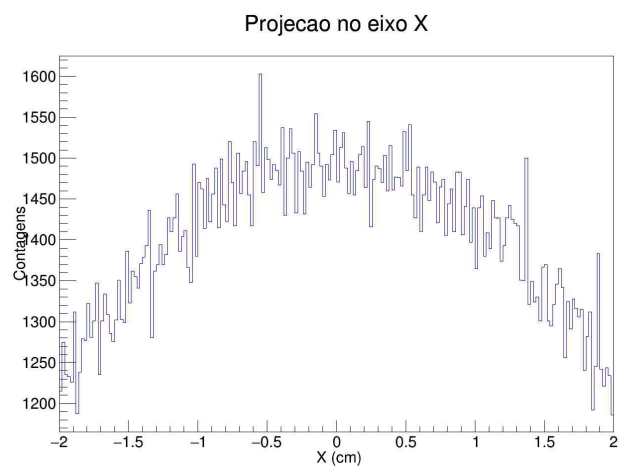

(f) $0,5-1,5(\mathrm{X})$

Figura 5.13: (a)Perfil do feixe de ${ }^{28}$ Si $70 \mathrm{MeV}$ na posição de irradiação, sem folhas espalhadoras e colimadores. (b)Apenas a segunda folha, espessura de $0,5 \mathrm{mg} / \mathrm{cm}^{2}$. (c) Apenas a primeira folha, espessura de $0,5 \mathrm{mg} / \mathrm{cm}^{2}$. (d)Folhas 1 e 2 com espessuras de 0,5 $\mathrm{mg} / \mathrm{cm}^{2}$.(e)Folha $1 \mathrm{de} 0,5 \mathrm{mg} / \mathrm{cm}^{2}$ e folha $2 \mathrm{com}$ espessura de $1,5 \mathrm{mg} / \mathrm{cm}^{2}$.(f)Projeção na direção horizontal da condição da Figura 5.13e. 
o grau de achatamento da distribuição, isto é, importância relativa dos termos que se distanciam do centro em relação ao valor médio. Este parâmetro é adimensional e é interpretado em termos de que valores negativos indicam uma distribuição mais achatada e, portanto, mais uniforme na porção central, sendo que quanto menor o valor, mais achatada (ou platicúrtica) ${ }^{4}$. O mesmo procedimento de obter o valor médio foi realizado para a medida de curtose, e as incertezas neste parâmetro foram, em média, de $0,7 \%$. Por último, a uniformidade, segundo a definição de Montenegro (Equação 2.22), utilizando como probabilidade máxima o valor no pico da distribuição e mínima o valor da distribuição num raio de $7,5 \mathrm{~mm}$ a partir do centro. Novamente, o cálculo foi feito para as duas direções perpendiculares e o valor médio foi considerado como representativo da condição. As Figuras 5.14 a 5.17 ilustram os parâmetros de análise para o feixe de carbono. Os gráficos foram gerados no programa ROOT e contam com interpolação entre os valores simulados para melhor visualização.

\footnotetext{
${ }^{4}$ Em curvas bem-comportadas, o parâmetro curtose pode ser analisado desta maneira, embora existam distribuições com picos pronunciados e curtose baixa. Para comparação dos resultados obtidos, pode-se comparar com a distribuição gaussiana (curtose 0) ou com a distribuição uniforme (curtose $0,2)$.
} 


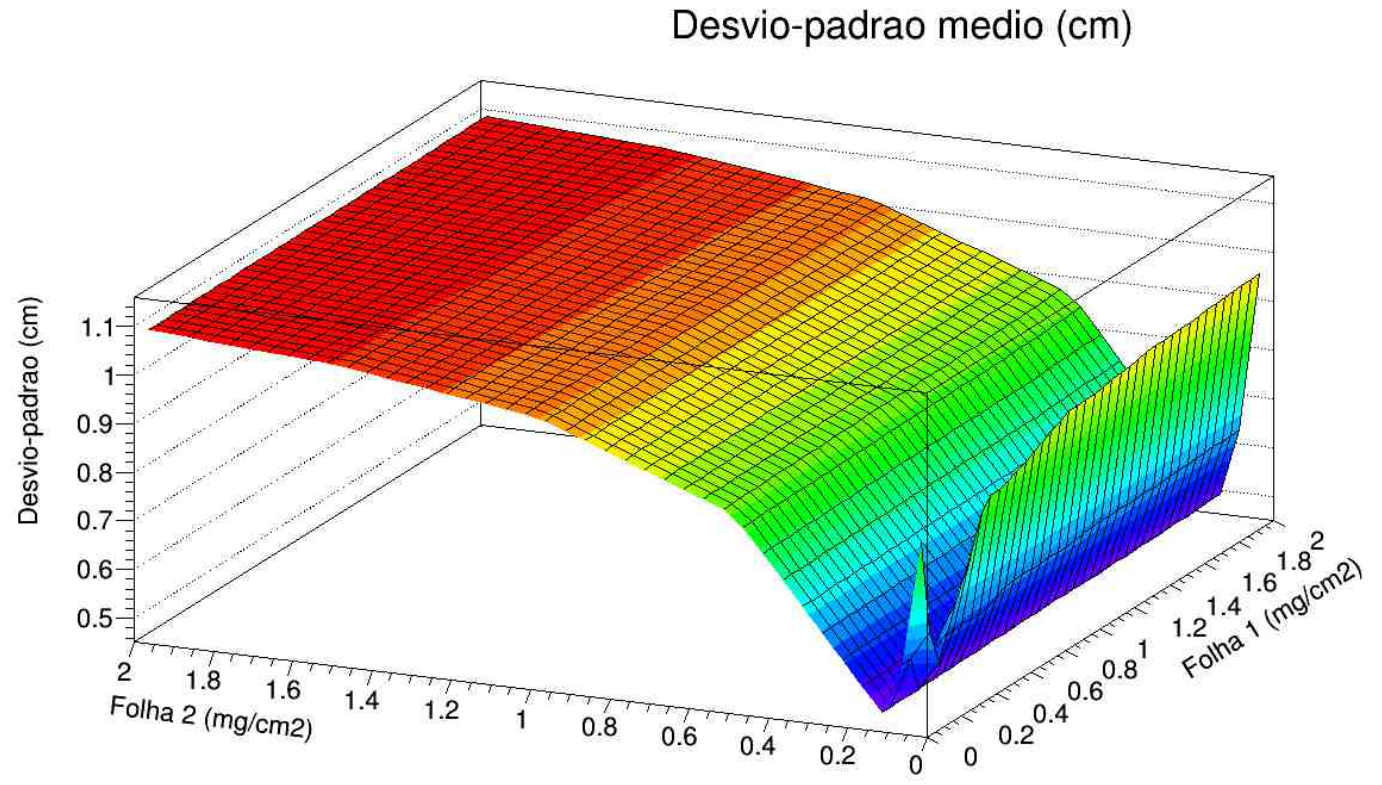

Figura 5.14: Comportamento do desvio-padrão do feixe de ${ }^{12} C 50 \mathrm{MeV}$ para diferentes distribuições.

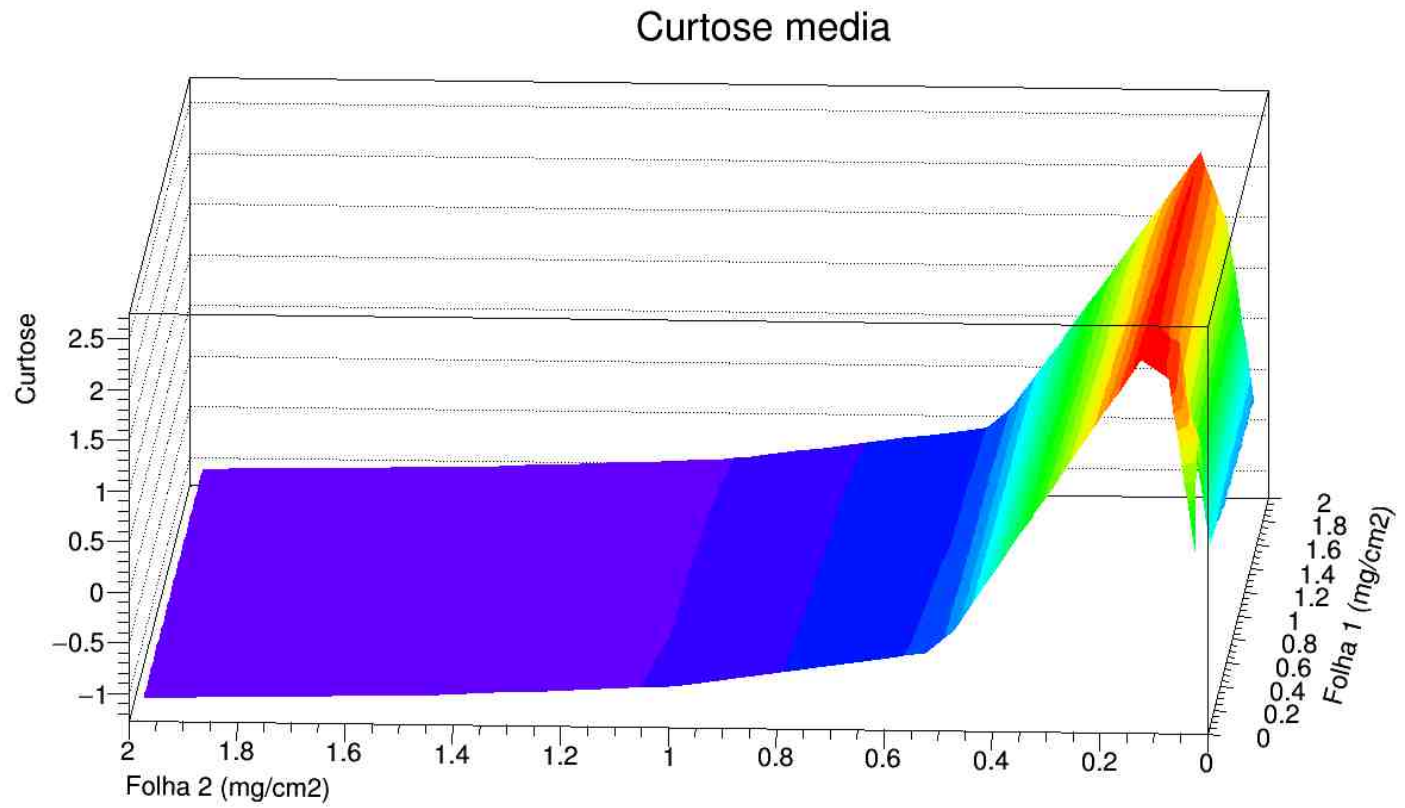

Figura 5.15: Comportamento da curtose do feixe de ${ }^{12} C 50 \mathrm{MeV}$ para diferentes distribuições. 


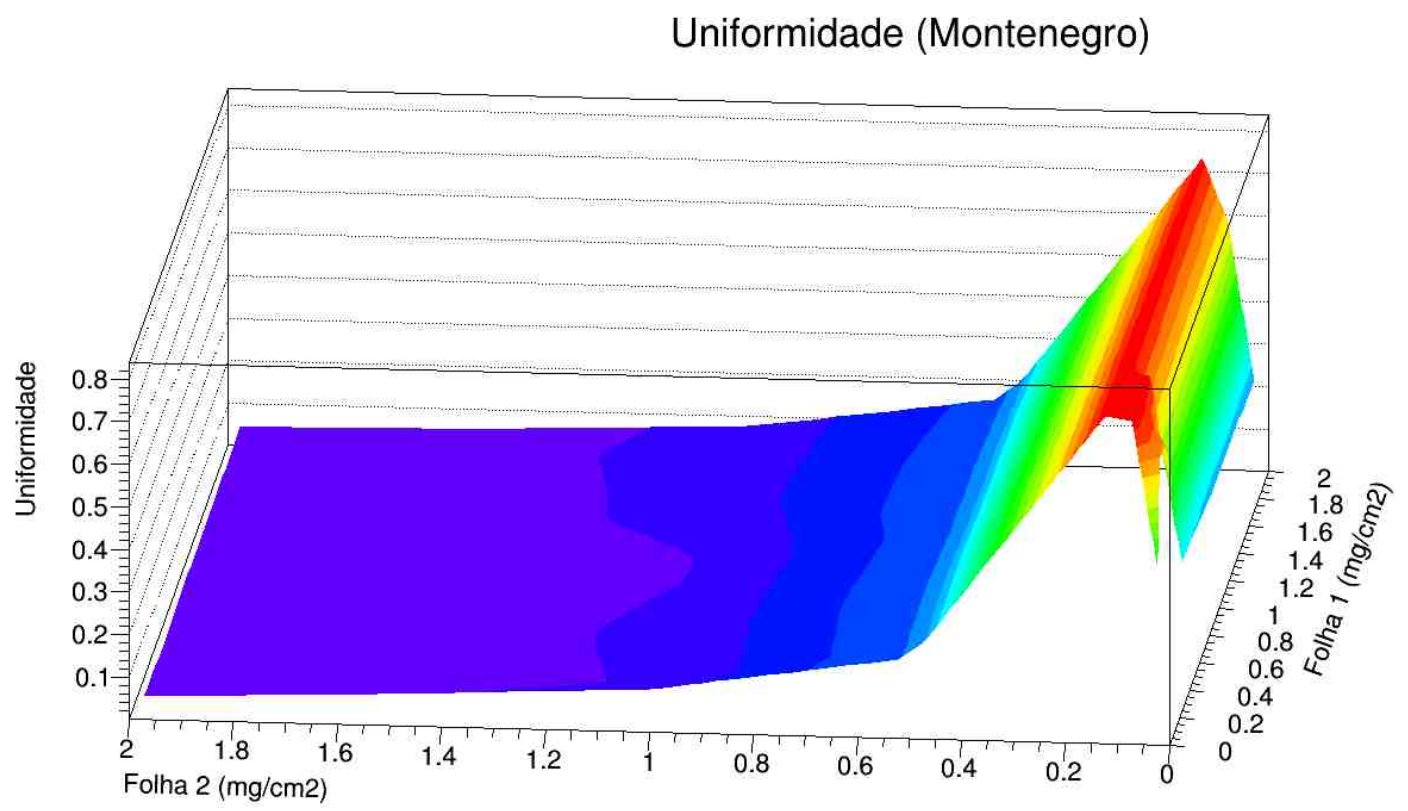

Figura 5.16: Comportamento da uniformidade do feixe de ${ }^{12} C 50 \mathrm{MeV}$ para diferentes distribuições.

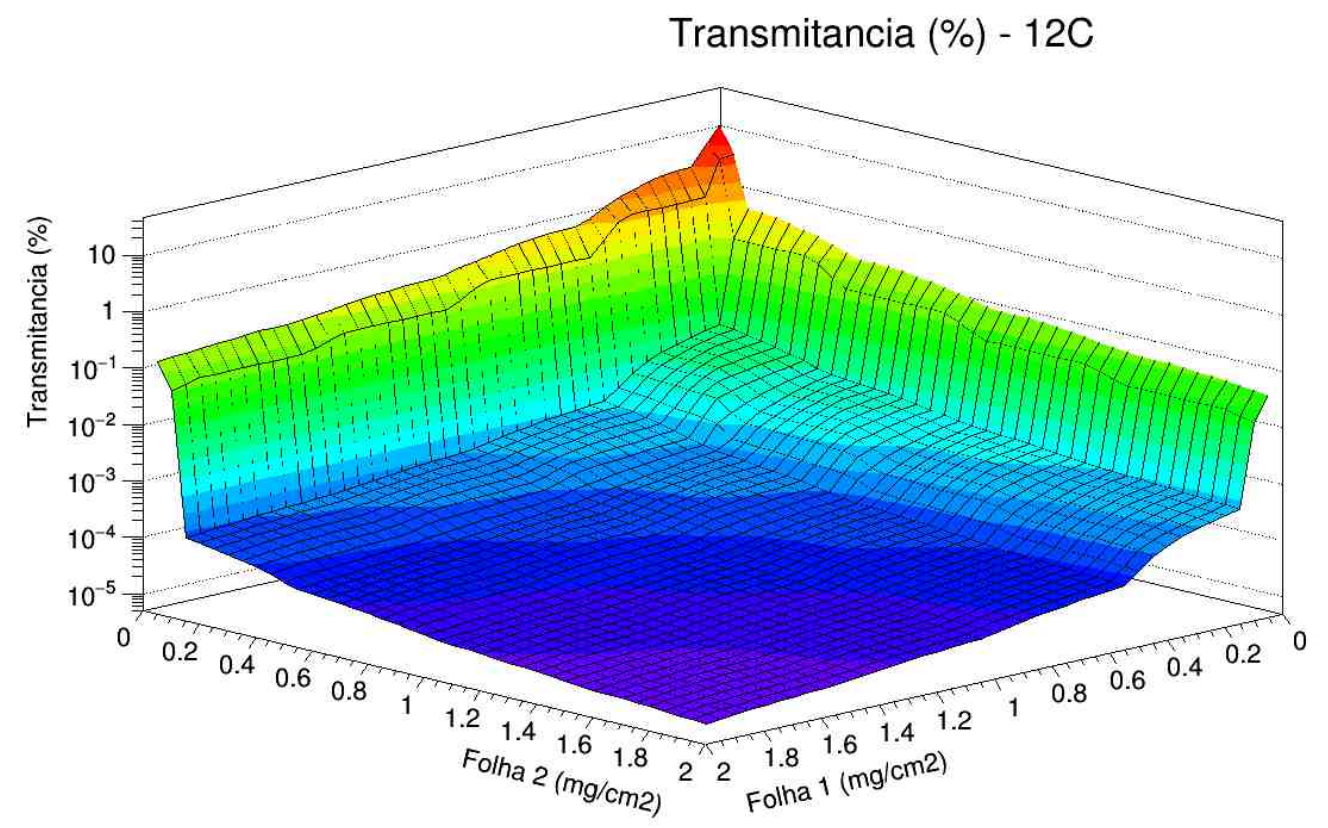

Figura 5.17: Comportamento da transmitância do feixe de ${ }^{12} C 50 \mathrm{MeV}$ para diferentes distribuições. 
Conforme pode ser observado, o desvio padrão nas combinações de duas folhas é dependente principalmente da espessura da folha 2 , sendo que a folha 1 só influencia de forma apreciável os valores de desvio padrão quando esta é a única folha presente. O mesmo comportamento é observado para os parâmetros curtose e uniformidade que, por possuírem exatamente o mesmo comportamento, podem ser tratados como equivalentes na descrição do perfil do feixe. Observa-se que, no caso do feixe de carbono, os valores de uniformidade inferiores a 0,1 ocorrem para valores de folha 2 da ordem de $1,0 \mathrm{mg} / \mathrm{cm}^{2}$, concordando com os valores obtidos pelo método Meyer-Montenegro, e que correspondem por sua vez a valores de curtose inferiores a 0,5. A transmitância do feixe, por sua vez, apresenta maior variação com a espessura de ambas as folhas, seja na configuração de folha única em qualquer posição, seja na combinação de ambas, quando a atenuação é mais pronunciada, chegando a fatores de $10^{-7}$ para duas folhas de $2,0 \mathrm{mg} / \mathrm{cm}^{2}$. Conclui-se então que a influência da primeira folha na condição de espalhamento por duas folhas dá-se principalmente na intensidade do feixe, sendo pouco importante na uniformidade e que boas condições de uniformidade correspondem à valores de desvio-padrão superior a 1,0 cm e curtose inferior a -0,5. Tal situação ocorre pela presença do colimador antes da segunda folha que, ao eliminar as partículas espalhadas pela primeira folha, também delimita a emitância de entrada na segunda folha para a emitância de um feixe com diâmetro e divergência muito pequenos. As Figuras 5.18 a 5.20 mostram os resultados obtidos para o feixe de silício, onde o mesmo comportamento é observado, apenas obtendo-se valores adequados de uniformidade utilizando espessuras ligeiramente menores de espalhadores do que previsto pelo método Meyer-Montenegro. 


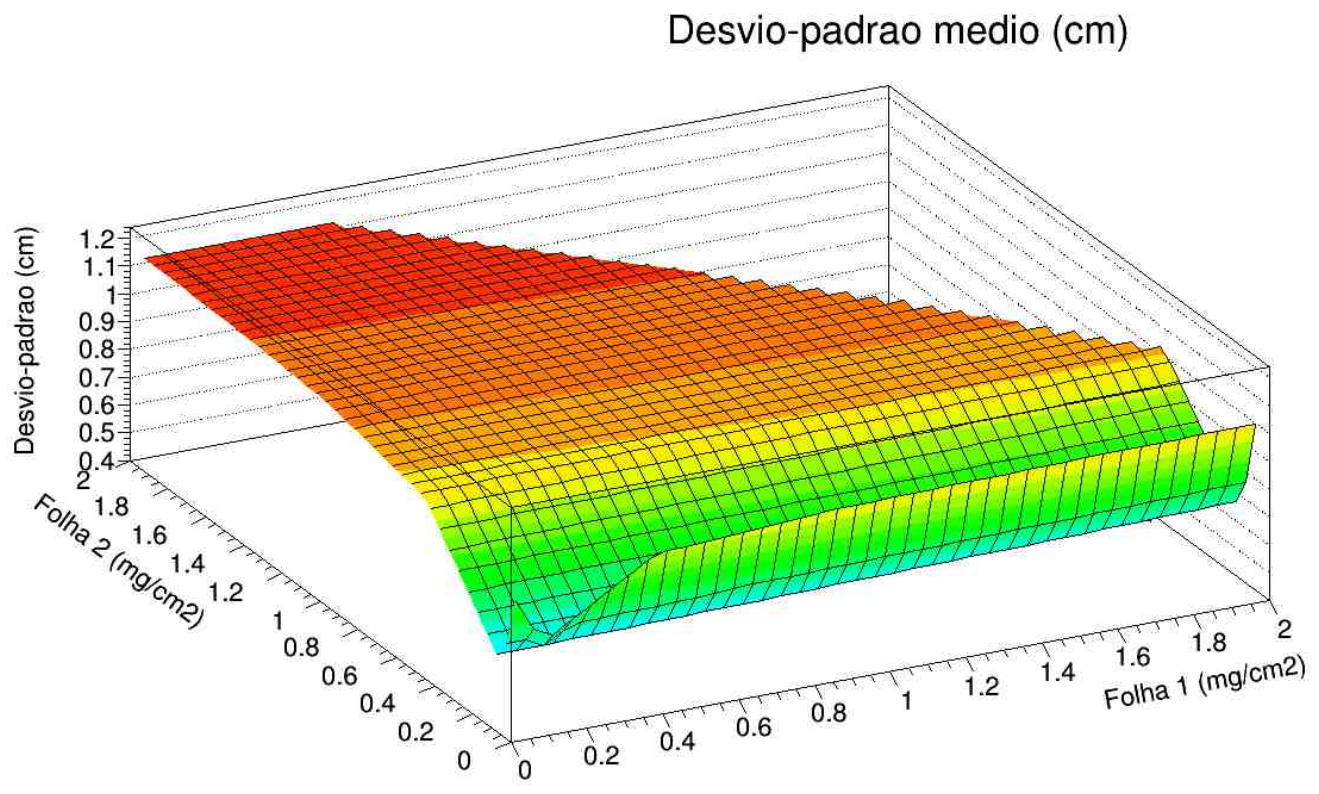

Figura 5.18: Comportamento do desvio-padrão do feixe de ${ }^{28} \mathrm{Si} 70 \mathrm{MeV}$ para diferentes distribuições.

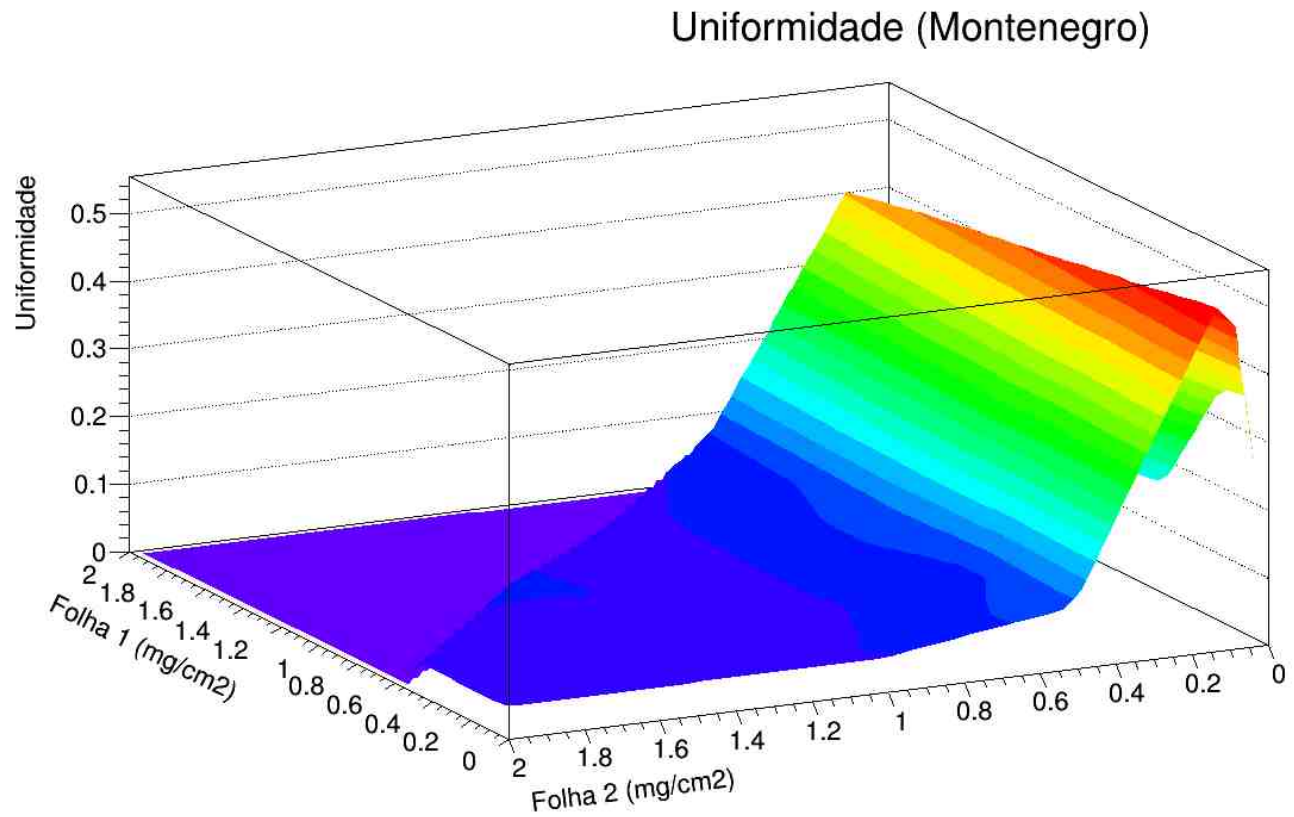

Figura 5.19: Comportamento da uniformidade do feixe de ${ }^{28}$ Si $70 \mathrm{MeV}$ para diferentes distribuições. 


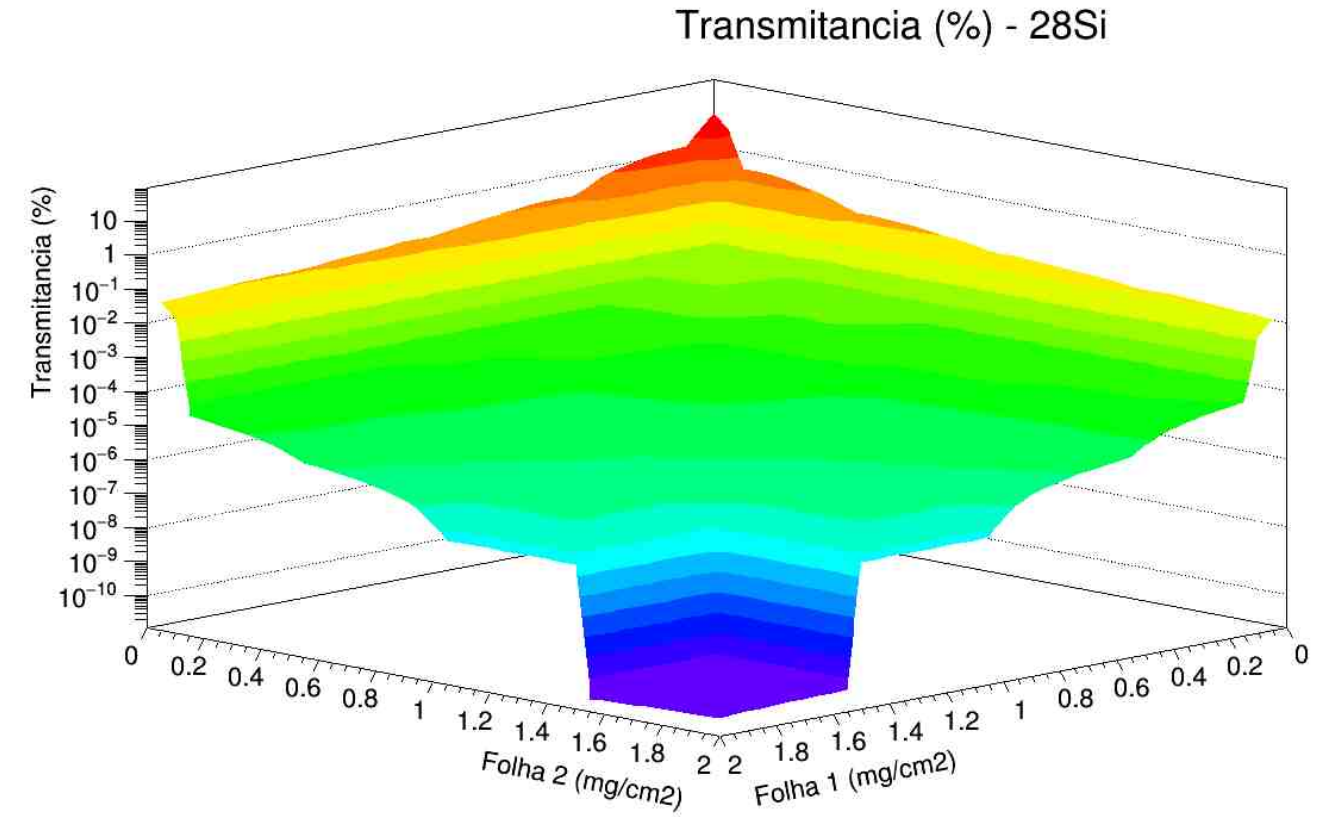

Figura 5.20: Comportamento da transmitância do feixe de ${ }^{28}$ Si $70 \mathrm{MeV}$ para diferentes distribuições.

Os valores obtidos para a transmitância dos feixes na condição de espalhamento múltiplo em duas folhas com focalização adequada permitem reduzir a intensidade do feixe inicial do acelerador, da ordem de $10^{10}$ a $10^{12}$ partículas/s aos valores exigidos pelas normas, de modo que optou-se então por construir a nova canalização na condição mais versátil possível, constituída por uma configuração que permita a desfocalização do feixe e espalhamento em até duas folhas de ouro, e que será apresentada no próximo Capítulo. 


\section{Capítulo 6}

\section{Sistema de Feixes Iônicos para}

\section{Irradiações e Aplicações (SAFIIRA)}

Com base nos cálculos realizados, foi possível projetar e construir uma nova canalização de feixe dedicada aos estudos em Física Nuclear e Atômica Aplicada, com ênfase em efeitos de radiação em dispositivos eletrônicos. Diversas considerações foram feitas de modo a construir o sistema mais versátil possível, o que incluiu algumas modificações no projeto óptico ótimo, porém sem prejudicar as características necessárias ao estudo de efeitos de radiação em dispositivos eletrônicos. A característica multiuso do sistema rendeu-lhe o nome de Sistema de Feixes Iônicos para IRadiações e Aplicações, cujo acrônimo é SAFIIRA. Neste capítulo serão detalhados todos os sistemas desenvolvidos, compromissos feitos entre as diversas configurações, aplicabilidade, facilidade de execução e custos.

\subsection{Estrutura Física}

A nova canalização foi montada na posição zero grau da sala experimental do Laboratório Aberto de Física Nuclear, onde havia anteriormente uma outra canalização 
para o estudo de material biológico com feixes iônicos [55]. O número de adaptações necessárias para instalar a câmara de irradiação, os sistemas de monitoramento de feixe e a recuperação e melhoria do sistema de vácuo levaram à decisão de desmontar a canalização antiga e refazer o projeto.

De acordo com o novo projeto (Capítulo 5), a montagem da canalização deveria incluir uma câmara de irradiação e duas posições para a colocação de folhas espalhadoras de feixe. Optou-se por manter a posição do quadrupolo (elemento 2 na Figura 6.1), que foi tomada como base no projeto, e a estrutura de suporte da linha até a válvula limitante do setor de ultra-alto-vácuo (elemento 8 da Figura 6.1). A estrutura de suporte deste ponto em diante é separada permitindo a isolação de potenciais de terra entre o acelerador e a estação de análise de dados, sendo que a canalização também é isolada neste ponto através de um tubo cerâmico.

A estrutura da canalização foi construída com perfis em U de aço carbono, fixados no piso e entre si. Os elementos da canalização são presos nas estruturas através de suportes e bases com ajustes de centralização, todos confeccionados em aço, exceto a base da câmara de irradiação, em alumínio.

A nova estrutura divide-se em três setores (Figura 6.1), a saber: setor I, correspondente ao ultra-alto-vácuo, contém os elementos ópticos e primeiro monitoramento de feixe; setor II contém as posições de folhas espalhadoras e monitoramento do feixe após o espalhamento e setor III, onde está a câmara de irradiaçao. Os setores são separados entre si por meio de válvulas gaveta, sendo que os setores II e III operam no regime de alto-vácuo.

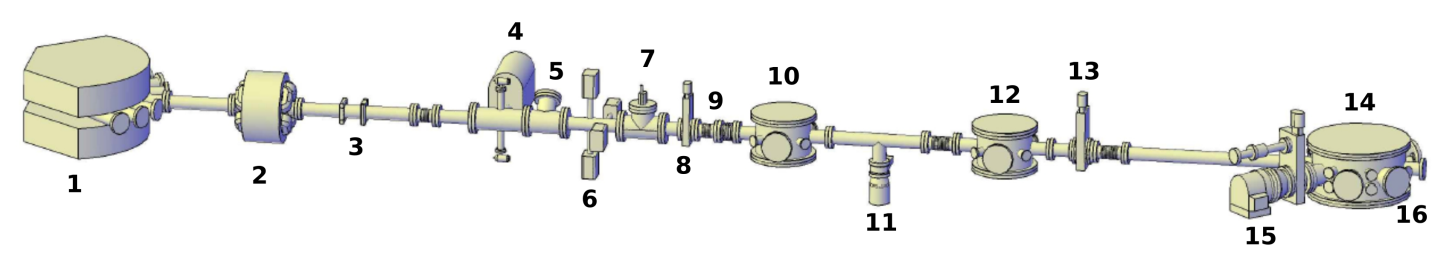

Figura 6.1: Esquema ilustrativo da canalização (cortesia de J.C. Terassi) 
O setor I compreende o Switching Magnet (elemento 1 na Figura 6.1), o dubleto de quadrupolos (2), os trimmers (3) utilizados para deflexão transversal do feixe, a bomba órbitron (4), o beam scanner (5), as fendas colimadoras motorizadas (6), o copo de Faraday (7) e a válvula gaveta (8).

O setor II possui a cerâmica de isolação (9), as câmaras de espalhamento (10 e 12), a bomba turbo-molecular (11) e a segunda válvula gaveta (13). O setor III possui a câmara de irradiação (14), a bomba turbo-molecular (15) e a saída para feixe externo (16). Maiores detalhes serão apresentados nas próximas seções.

\subsection{Manipulação e monitoramento de feixe}

O primeiro elemento que permite a manipulação do feixe é o próprio Switching Magnet, que em teoria não deveria ser utilizado, mas que é necessário para compensar o campo magnético residual caso tenha havido utilização anterior para direcionar o feixe para outra canalização. Tem-se então dois pares de trimmers, um antes e outro depois do dubleto de quadrupolos. Os trimmers são pares de bobinas que produzem campo magnético transversal à propagação do feixe e, portanto, realizam a deflexão do feixe neste plano. O dubleto de quadrupolos foi posicionado de forma a produzir foco com elevada divergência no copo de Faraday e foco com baixa divergência na câmara de irradiação. Para outras condições de focalização, pode-se ainda utilizar o quadrupolo localizado antes do Switching Magnet.

O beam scanner [64] consiste de um fio em formato de foice preso a um eixo inclinado a $45^{\circ}$ em relação à canalização. Este eixo fica preso num motor de corrente contínua e faz com que o fio, ao girar, intercepte o feixe nas duas direções transversais [61], sendo que os elétrons secundários emitidos pelo fio são coletados num cilindro metálico isolado eletricamente da canalização. A visualização do sinal de coleta de carga num osciloscópio fornece a informação sobre a distribuição espacial do feixe nas duas direções 
transversais.

As fendas colimadoras [64] são dois pares de bloqueadores de tântalo utilizados para definir a região de passagem do feixe. Cada bloqueador pode ser movimentado de forma independente através de motores de corrente contínua controlados por meio de um sistema NI-PXI [71] utilizando uma placa de aquisicão e controle DAQ Multifuncional [72]. As fendas possibilitam também a medida de intensidade de corrente para melhor centralização do feixe na canalização.

O copo de Faraday [64] consiste de um copo de tântalo isolado e com supressão geométrica para permitir a medida correta de corrente de feixe, contando ainda com uma fonte projetada e construída para fornecer -320 V de tensão para supressão elétrica. O copo de Faraday possui acionamento pneumático conjunto com o beam scanner de modo a permitir, em conjunto com as fendas e o beam scanner, a obtenção do feixe com as melhores características possíveis na canalização.

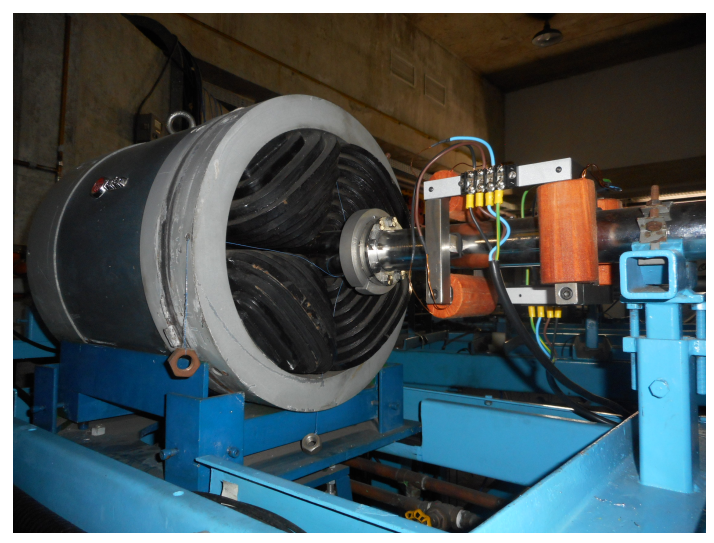

(a)

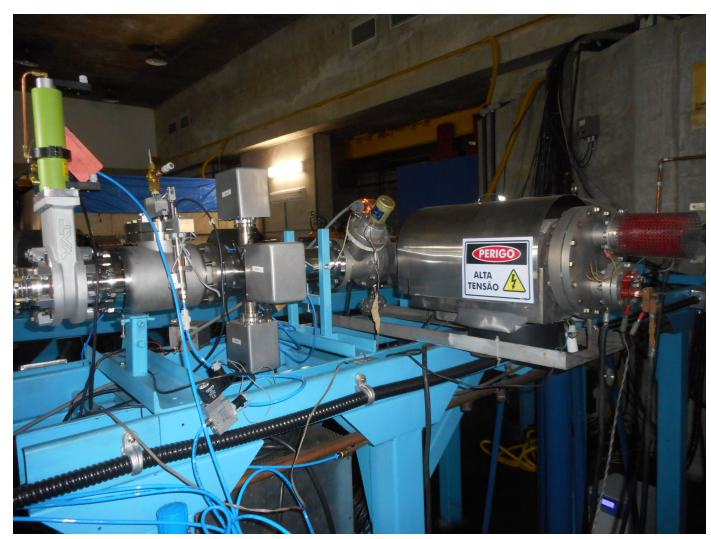

(b)

Figura 6.2: (a)Quadrupolo e trimmers. (b)Beam Scanner, fendas e copo de Faraday.

Após o setor I não existem mais elementos ópticos que permitam atuar sobre o feixe de maneira controlada, apenas colimadores e as folhas espalhadoras. A Figura 6.2 mostra fotos de alguns dos elementos descritos acima. 


\subsection{Câmaras de espalhamento}

Considerando o caráter multiuso dessa nova canalização, decidiu-se que as folhas espalhadoras deveriam ser posicionadas em colunas de alvos em pequenas câmaras, permitindo assim a utilização de diversos alvos num mesmo experimento sem quebra de vácuo, monitoramento do feixe com detectores de barreira de superfície e até mesmo utilização dessas câmaras para outros experimentos de física nuclear. Foram construídas nas oficinas do IFUSP duas câmaras gêmeas com $20 \mathrm{~cm}$ de altura e $40 \mathrm{~cm}$ de diâmetro (elementos 10 e 12 na Figura 6.1), com flanges padrão de gasket de alumínio,

posicionadas na direção do feixe, na medida de $4 \frac{1}{4}$ ", duas flanges de 6 "ortogonais ao feixe com o-ring e 4 flanges KF-40 intermediárias para colocação de instrumentação e passadores. Numa das flanges de 6"foi colocado um visor de vidro temperado e a outra flange sustenta a coluna de alvos com posicionamento manual através de um micrômetro. Ambas as câmaras possuem colimadores de tântalo de 1,5 mm de diâmetro na entrada, isolado da câmara, para diminuir a intensidade do feixe a ser espalhado. Os colimadores podem ser conectados a um picoamperímetro para fornecer leitura de corrente de feixe.

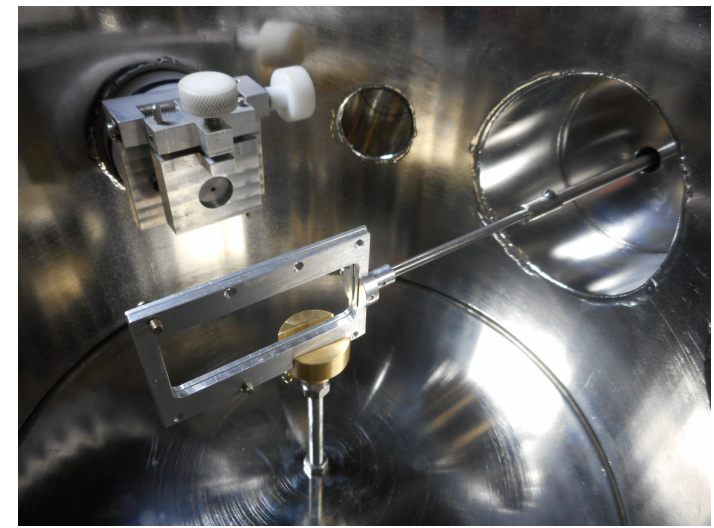

(a) Câmara 1

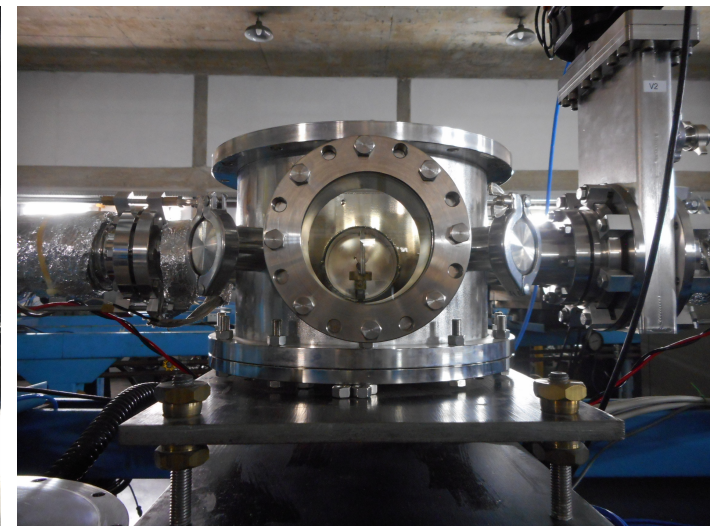

(b) Câmara 2

Figura 6.3: (a)Visão interna da câmara 1, com o colimador e a coluna de alvos. (b)Visão externa da câmara 2 , com o visor de vidro temperado. 
A câmara de irradiação possui $18 \mathrm{~cm}$ de altura e $50 \mathrm{~cm}$ de diâmetro, possuindo 6 flanges de 6"de diâmetro, das quais 4 possuem vedação por o-ring e 2 possuem vedação com gasket de cobre tipo Conflat. Uma das flanges com o-ring está conectada a uma válvula gaveta, que isola a bomba turbo-molecular, e duas flanges Conflat são dedicadas à instalação de passadores elétricos para vácuo (Figura 6.4). A câmara possui, na montagem permanente, um passador multipino do tipo DB-50 dedicado à comunicação de dispositivos sob teste com o ambiente externo, quatro passadores BNC e um passador multipino de 32 pinos do tipo circular, dedicados à instrumentação nuclear e ao monitoramento de feixe com fotodiodos. Na base da câmara situa-se o porta-amostras conectado ao manipulador motorizado (seção 6.6), permitindo a colocação de amostras com até 15 cm de altura. A câmara possui ainda flanges KF-40 (2), KF-25 (6) e KF-16 (1), utilizadas para a instalação de medidores de pressão, instrumentação geral e arejamento. Encontra-se em projeto a instalação de um prato motorizado para esta câmara além de uma nova coluna de alvos situada na frente do porta-amostra dedicada ao monitoramento do feixe com fotodiodos e colimação. Uma das flanges de 6 "foi utilizada para a instalação de um visor de vidro temperado, em frente do qual há uma câmara USB que permite visualizar da sala de controle a movimentação do porta-amostras e LEDs de diagnóstico do sistema sob teste. A flange frontal de $4 \frac{1}{4}$ ” possui também um visor de vidro temperado utilizado para visualização e alinhamento dos alvos e dispositivo sob teste; futuramente será instalado o sistema composto por um copo de Faraday e a janela para extração do feixe em ar, também em fase de projeto. Nesta câmara também está instalado, numa das flanges a $45^{\circ}$, um detector a gás utilizado em medidas de ERDA [73]. 


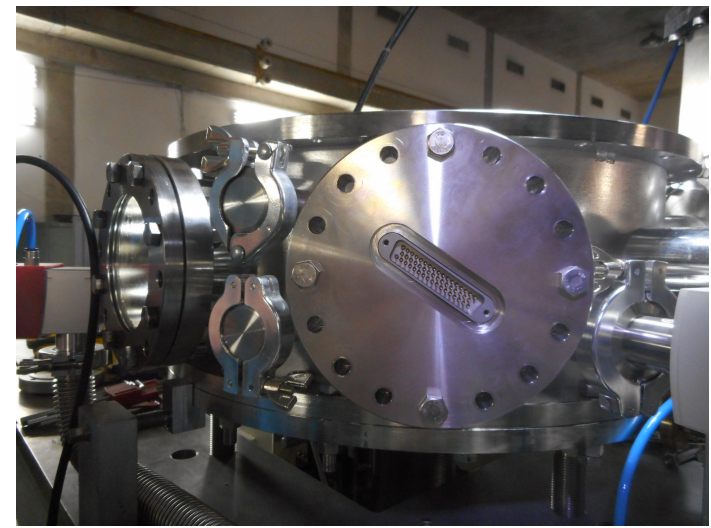

(a) Câmara 1

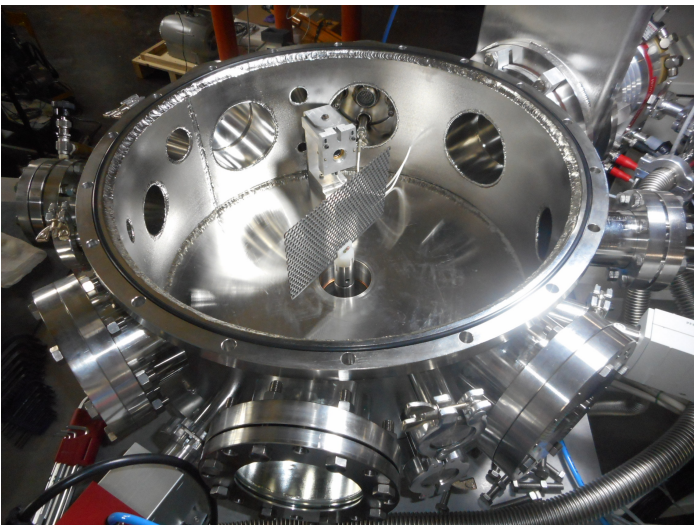

(b) Câmara 2

Figura 6.4: (a)Detalhe do passador multipino DB-50 e do visor. (b)Visão interna da câmara de irradiação, evidenciando o porta-amostra e um detector barreira de superfície.

\subsection{Calibração e monitoramento de fluxo}

A calibração e monitoramento são feitos por meio de um detector do tipo barreira de superfície [32] localizado em ângulo dianteiro superior a $45^{\circ}$ em relação ao feixe após a primeira folha espalhadora, permitindo conhecer a intensidade do feixe por meio do espalhamento simples (Rutherford). A calibração do feixe é realizada com um detector barreira de superfície na posição de irradiação com um colimador de $0,5 \mathrm{~mm}$. Registrando o número de eventos neste detector e no detector localizado na câmara 1 (normalizador), obtém-se o fluxo de partículas e um fator de calibração que representa a proporcionalidade entre o número de partículas por centímetro quadrado na posição de irradiação e o número de partículas incidentes no detector de normalização. Durante as medidas, o número de contagens no normalizador é então multiplicado pelo fator de calibração para obter a fluência do feixe durante o ensaio. 


\subsection{Sistema de vácuo}

O sistema de vácuo da canalização é composto por uma bomba órbitron no setor I responsável pelo ultra-alto-vácuo, duas bombas turbo-moleculares para o alto-vácuo nos setores II e III e suas respectivas bombas de backing, utilizadas também para pré-vácuo através de um sistema de bypass [74].

A bomba órbitron funciona ionizando as moléculas do ar residual e facilitando a sua combinação com o vapor de titânio sublimado que deposita-se nas paredes da bomba. É possível obter pressões até a faixa de $10^{-9}$ Torr com esta bomba, uma vez que neste setor são utilizadas apenas vedações metálicas. Um sensor do tipo Bayard-Alpert é utilizado neste setor [74].

No setor II são utilizadas vedações metálicas (gaskets de alumínio) ao longo da canalização e o-rings de neoprene para a vedação das demais flanges. No tubo que liga as duas câmaras gêmeas estão acoplados o medidor combinado, que consiste de um sensor tipo Pirani para a faixa de pré-vácuo e um sensor tipo Bayard-Alpert para a faixa de alto-vácuo, além da bomba turbo molecular de $67 \mathrm{l} / \mathrm{s}$, através de uma válvula gaveta [74]. A escolha desta bomba turbo molecular deu-se pela facilidade de operação e porque a condutância da boca da bomba é compatível com a condutância do tubo que liga as câmaras, de modo que bombas com maior velocidade de bombeamento sofreriam perda de eficiência. Duas válvulas pneumáticas $90^{\circ}$ permitem alternar o modo de operação da bomba mecânica entre bomba de pré-vácuo e bomba backing. Na saída da bomba turbomolecular está acoplado um sensor Pirani permitindo o acompanhamento da pressão de saída da bomba. A bomba mecânica utilizada é do tipo sem óleo com rotores roots de $28 \mathrm{l} / \mathrm{s}$ de velocidade de bombeamento [74].

No setor III também são utilizadas vedações metálicas (gaskets de alumínio) ao longo da canalização e o-rings de neoprene nas flanges da câmara 3, exceto pelas flanges de passadores que utilizam gaskets de cobre padrão Conflat. O bombeamento na câmara 
3 segue o mesmo sistema das câmaras gêmeas, com a diferença de que a bomba turbo molecular de 260 l/s está acoplada diretamente à câmara e a bomba mecânica possui velocidade de $40 \mathrm{l} / \mathrm{s}$. O diâmetro da boca da bomba turbo molecular é o mesmo da abertura das flanges de $6 "$ ", possuindo portanto a máxima condutância possível na câmara. Os medidores de pressão utilizados são do mesmo tipo do setor II.

Os setores são isolados uns dos outros, bem como as bombas turbo moleculares do sistema, por válvulas gaveta no padrão ISO e que possuem vedações com o-rings de Viton. Todos os setores possuem ao menos um bellows (tubo flexível) para permitir o alinhamento fino do sistema. Devido à alta taxa de degaseificação dos bellows em razão de sua elevada superfície, estes foram envolvidos em fita térmica numa montagem permanente, permitindo atingir pressões baixas mais rapidamente. Pressões mais baixas são atingidas quando o arejamento é feito com nitrogênio seco através de válvulas agulha, localizadas no tubo entre as câmaras gêmeas e na câmara 3.

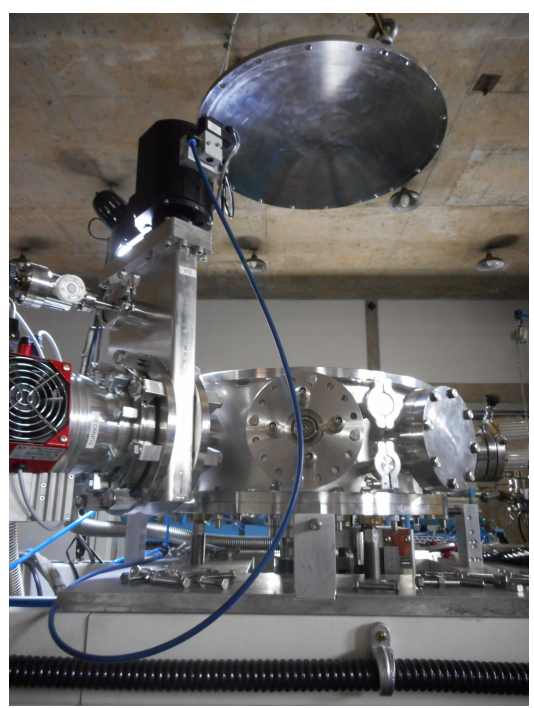

(a)

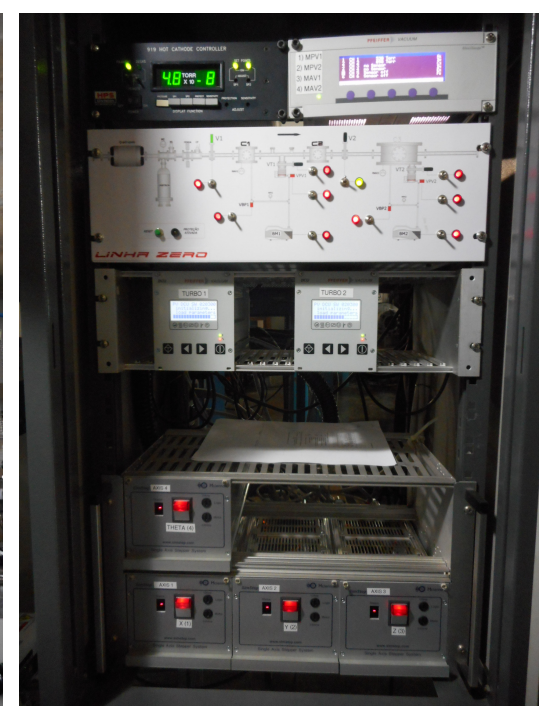

(b)

Figura 6.5: (a)Câmara de irradiação com os passadores multipino de 32 pinos e BNCs, bomba turbo molecular de $260 \mathrm{l} / \mathrm{s}$ acoplada à válvula gaveta pneumática. (b)Rack de controle dos sistemas de vácuo. A leitura de pressão no setor I é de $4,8 \times 10^{-8}$ Torr. 
Um rack dedicado aos sistemas de vácuo e controle do manipulador de amostras foi montado, incluindo um painel projetado pela equipe técnica do Laboratório Aberto de Física Nuclear para o controle de todas as válvulas pneumáticas e das bombas mecânicas. Com esta configuração, o setor I usualmente trabalha em pressões de $5 \times 10^{-8}$ Torr, o setor II em $\sim 4 \times 10^{-6}$ Torr e o setor III em $\sim 2 \times 10^{-6}$ Torr em cerca de uma hora de bombeamento partindo de pressão atmosférica. A Figura 6.5 mostra a bomba turbo molecular instalada na câmara de irradiação e o rack com o painel de controle do sistema de vácuo, os medidores de pressão, as unidades controladoras das bombas turbo-moleculares e as unidades controladoras do manipulador de amostras.

\subsection{Amostras e alvos}

A colocação de amostras na câmara de irradiação pode ser feita por meio de um porta-alvos ou de placas perfuradas que permitem a fixação de amostras como placas de circuito impresso utilizando parafusos. Tanto o porta-alvos como as placas perfuradas (três tamanhos estão disponíveis) são acoplados no manipulador de amostras através de um suporte universal que permite a fácil troca de amostras. A movimentação da amostra é feita através de um estágio motorizado de quatro eixos, permitindo a movimentação nas três direções cartesianas e rotação em torno do eixo vertical. A precisão na movimentação no plano da câmara é de $2,5 \mu$ m dentro de um círculo de raio 50 $\mathrm{mm}$ e no eixo de vertical de $1 \mu \mathrm{m}$ com amplitude de $50 \mathrm{~mm}$. Os motores de passo são posicionados fora do ambiente de vácuo e a movimentação do eixo onde a amos-

tra é presa é feita através de um bellows, permitindo assim operação em ambiente de ultra-alto-vácuo.

Os motores de passo são controlados através de drivers de comunicação serial RS232, sendo que estes módulos podem ser configurados quanto à: posição atual (em passos), velocidade, aceleração, entre outras variáveis. Além disso, estes módulos pos- 
suem a capacidade de gravar a quantidade de passos efetivamente dada pelo motor, sendo possível detectar colisões do alvo com obstáculos ou perda de passos. A Figura 6.6a mostra o suporte para amostras e a Figura 6.6b mostra o corpo do estágio motorizado. Para o controle do manipulador de amostras foi desenvolvido um programa de controle da movimentação na plataforma LabView, cujo funcionamento é descrito a seguir.

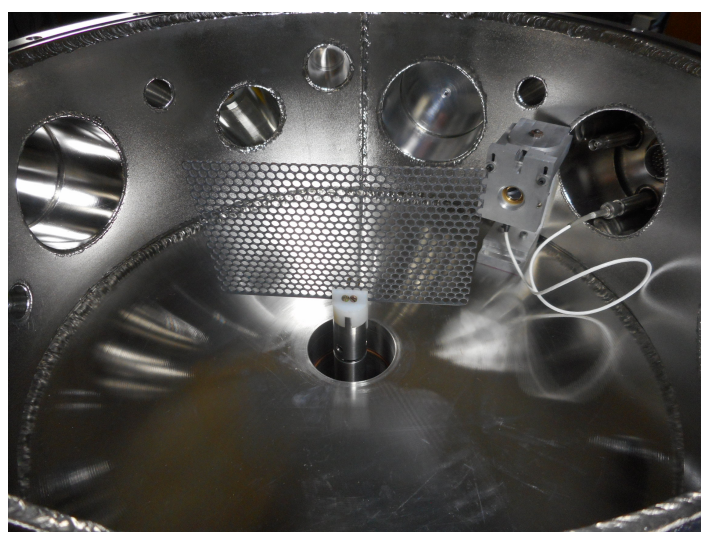

(a)

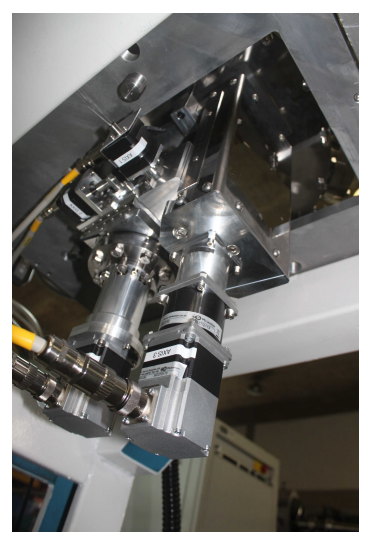

(b)

Figura 6.6: (a)Grade de fixação de amostras e placas de circuito impresso acoplada ao suporte universal. (b)Estágio motorizado de 4 eixos com precisão micrométrica.

Define-se primeiro os arquivos de log do sistema, sendo que um arquivo irá gravar todos os movimentos realizados com a hora de realização e outro arquivo será sempre reescrito ao fim do programa com a última posição. Ao iniciar o programa, a última posição é lida do arquivo e enviada para os módulos controladores. O operador deve então fornecer a configuração do porta-amostra utilizado, sendo que as configurações já estão pré-estabelecidas numa lista. Esta configuração permite que o sistema encontre os limites de movimentação com base no tamanho da amostra e também fazer os gráficos de posição da amostra em relação ao feixe de partículas. A interface do programa é mostrada na Figura 6.7.

Uma vez terminada a etapa de configuração, o programa aguarda os valores de 
posição desejada e o comando de movimentação (botão "VAI"), ou então os comandos de retorno à posição anterior ou à posição de referência $\left(" \operatorname{HOME}^{\prime}=(0,0,0,0)\right)$. Ao receber o comando de movimentação, para cada variável $(x, y, z, \theta)$ o programa compara a posição atual e a posição futura, e, caso sejam diferentes, faz o movimento relativo para a nova posição ordenando ao controlador a quantidade de passos a ser dada numa determinada direção. Após o fim da operação, é solicitado ao controlador o número de passos dado e, no caso de diferença com o valor enviado, é dada a quantidade de passos de forma a corrigir a posição. O movimento de cada eixo é independente e o programa apenas realiza o movimento em um eixo após completar o movimento anterior.

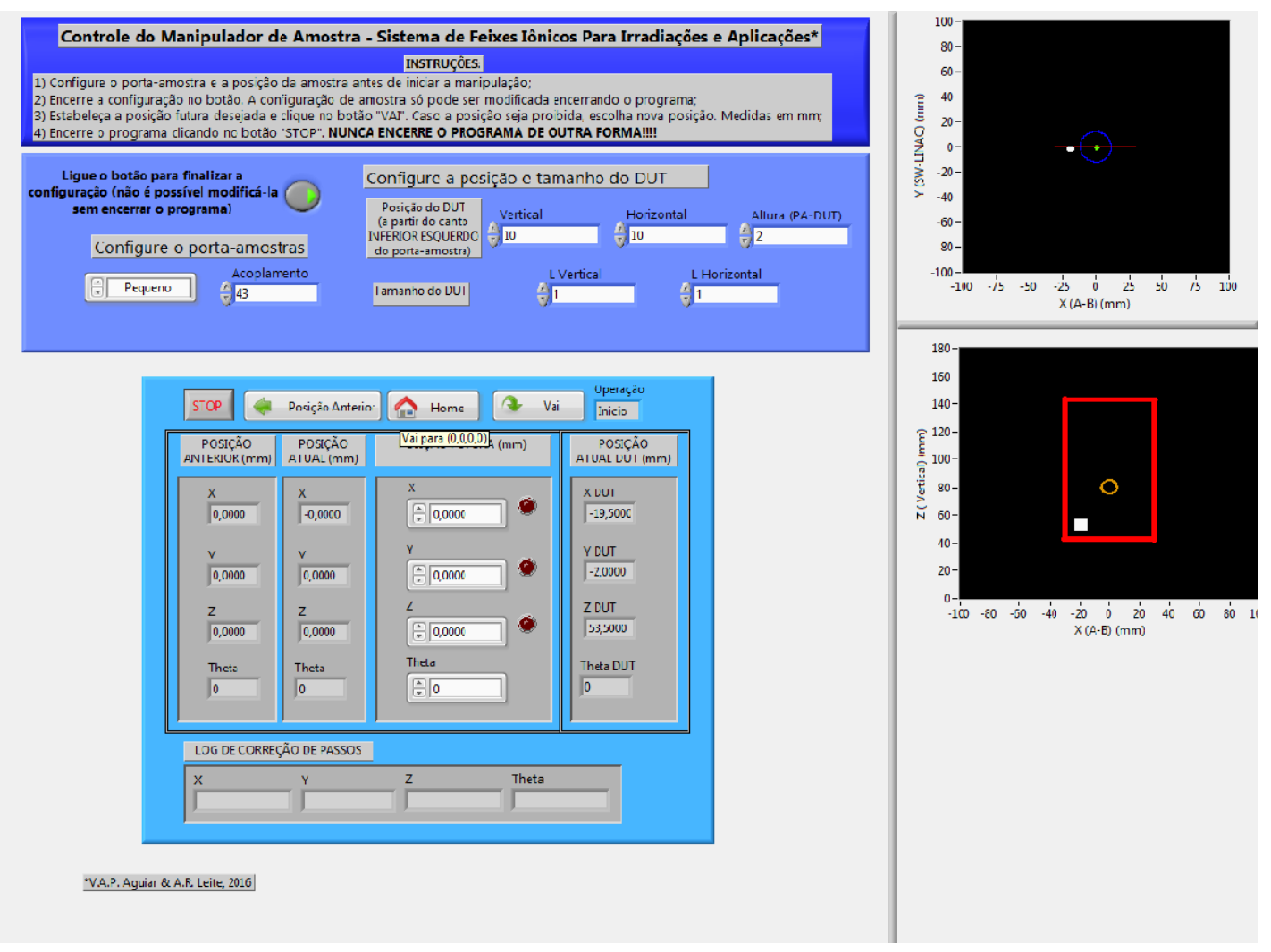

Figura 6.7: Painel do programa, escrito em LabView, para movimentação de amostras utilizando o estágio motorizado.

Após a movimentação, o programa calcula as novas posições dos limites do porta- 
amostra incluindo as projeções nos eixos no caso de rotação do eixo, calcula a nova posição da amostra, registra o movimento no arquivo de log e constrói os gráficos indicativos de posição para visualização na tela. Nos paineis à direita da Figura 6.7 se observam as posições do porta-amostras e da amostra nos planos XY (horizontal) e XZ (vertical).

\subsection{Eletrônica e aquisição de dados}

A preocupação com ruído oriundo da rede elétrica e de loops de terra levou a um projeto completo de instalação elétrica na nova canalização, no qual de um lado da canalização é encontrada a fiação da rede não-estabilizada (suja), destinada aos equipamentos de potência, e do outro lado a fiação da rede estabilizada (limpa), destinada à aquisição de dados. Do painel de disjuntores da linha de potência da sala experimental "A"do LAFN são trazidos os cabos de terra, neutro e fases, chegando a uma caixa de disjuntores da canalização seguida por uma chave magnética para evitar acidentes com picos de tensão/corrente. A linha então segue até o final da canalização, alimentando três painéis de tomadas com disjuntores. Do painel de disjuntores de instrumentação vêm os cabos de terra, neutro e fase $(127 \mathrm{~V})$ da linha limpa, que passa por um estabilizador de tensão antes de seguir para as duas caixas de disjuntores com tomadas para alimentação dos módulos. Dedicou-se um lado dos perfis em U, que formam a base da canalização, apenas para cabos de potência e sensores de vácuo e o outro lado aos cabos de instrumentação de modo a diminuir as interferências eletromagnéticas [75, 76].

A eletrônica para aquisição de dados, controle de dispositivos sob teste e controle do sistema posicionador possui: uma estação NI-PXI, duas fontes de tensão reguláveis de 30V , um osciloscópio de $1 \mathrm{GHz}$ com 4 canais, um computador para aquisição de dados, um rack com BINs para instrumentação padrão NIM $[32,77]$, um sistema CAMAC de uso comum do Laboratório [78] e um rack para instrumentação em geral. A aquisição 
de dados de detectores pode ser feita por meio da utilização do CAMAC e da eletrônica NIM para até 8 detectores, porém este sistema não permite integração com o sistema manipulador de amostra, de modo que desenvolveu-se um sistema híbrido NIM-PXI para aquisição de sinais de detectores do tipo barreira de superfície. O sistema é descrito brevemente a seguir.

A eletrônica usual para aquisição em singles com o sistema CAMAC consiste em um pré-amplificador conectado ao detector e um amplificador para amplificação e conformação do sinal. Do amplificador, o sinal unipolar é enviado a uma entrada do ADC (Analog-to-Digital Converter) do sistema CAMAC [32, 77], enquanto o sinal bipolar é enviado a um analisador monocanal (TSCA), cuja função é gerar um pulso lógico no padrão NIM $[32,77]$ toda vez que o sinal de entrada passe pelo crivo de seleção, dado por uma janela de tensão. Tal pulso lógico é enviado a um Gate and Delay Generator (GDG), que gera um sinal lógico de gate, isto é, um sinal negativo quadrado com largura e atraso ajustáveis. Este sinal de gate tem como objetivo determinar uma janela temporal para os eventos de interesse, sendo que o sinal unipolar deve chegar ao CAMAC durante a duração temporal deste pulso negativo, enviado à porta strobe do ADC do sistema CAMAC.

A estação NI-PXI conta com um módulo DAQ que possui 16 entradas de ADC para valores de tensão até $10 \mathrm{~V}$, permitindo inclusive a aquisição de sinais controlada por um sinal de trigger. Todavia, este ADC possui frequência baixa $(1 \mathrm{MHz})$, sendo necessário tornar o pico do pulso do amplificador largo o suficiente para adequada medida do valor de tensão de pico. Para tanto, utilizou-se um sistema do tipo peak holder, responsável por aumentar a largura temporal do pico do sinal introduzido. O módulo utilizado foi um Linear Gate and Stretcher (LGS) da ORTEC [77] conectado ao sinal do amplificador antes deste ser introduzido no ADC da placa DAQ do NI-PXI. Outro detalhe é que, ao contrário do sistema CAMAC, o NI-PXI adquire os dados na mudança de estado (subida) de um sinal TTL, utilizando portanto o gate positivo e 
com mudança de estado (subida) durante o máximo do sinal a ser adquirido. Com a utilização dos atrasos adequados nos sinais, ambos os sistemas podem ser utilizados em paralelo, com resultados bastante satisfatórios. A Figura 6.8 ilustra o esquema da eletrônica utilizada para aquisição dos sinais dos detectores de partículas.

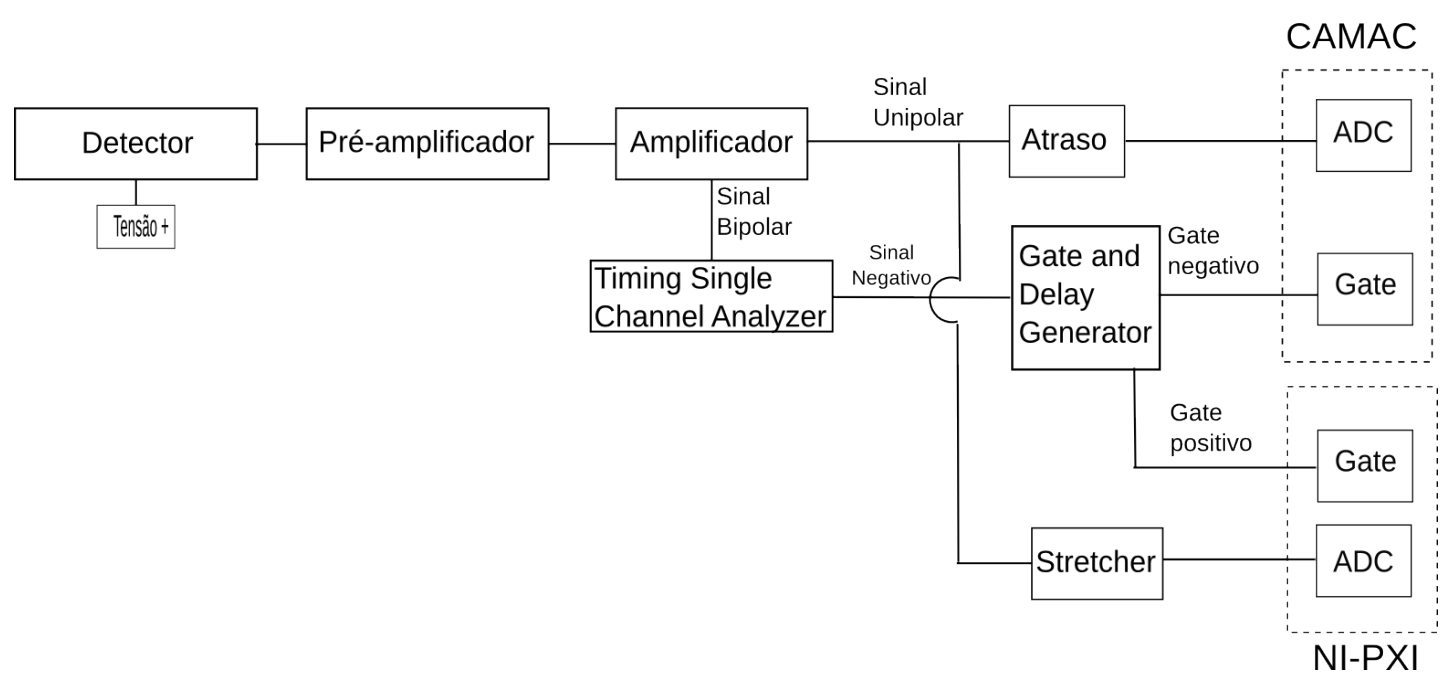

Figura 6.8: Esquema da eletrônica utilizada para aquisição dos sinais dos detectores de barreira de superfície

O programa de aquisição desenvolvido para uso com o sistema NI-PXI aguarda o comando para iniciar a aquisição, quando envia ao hardware a instrução para adquirir os sinais, na porta do ADC configurada, a cada sinal de trigger recebido. O buffer selecionado é de 10 contagens, quando então a placa DAQ descarrega os valores medidos em um vetor de dados na memória do computador. Quando o usuário solicita a atualização do histograma (através de um botão ou de um número pré-determinado de contagens no vetor), os dados deste vetor são carregados num histograma permitindo obter um espectro do sinal e uma tabela ASCII com os dados. Este sistema mostrou-se capaz de diferenciar eventos com intervalo de $2 \mu$ s entre eles após a passagem pelo Linear Gate and Stretcher. A Figura 6.9 mostra o programa de aquisição e a Figura 6.10 apresenta a eletrônica completa de aquisição de dados e controle. 


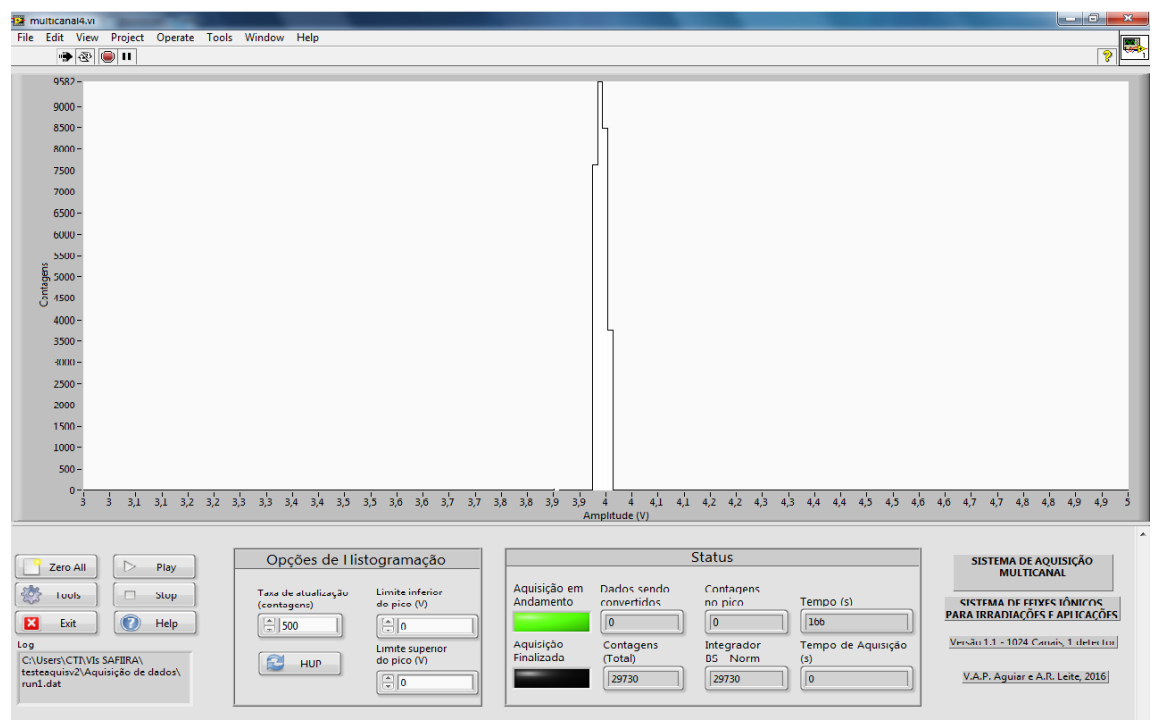

Figura 6.9: Painel do programa LabView de aquisição de dados com o sistema NI-PXI, escrito na linguagem LabView.

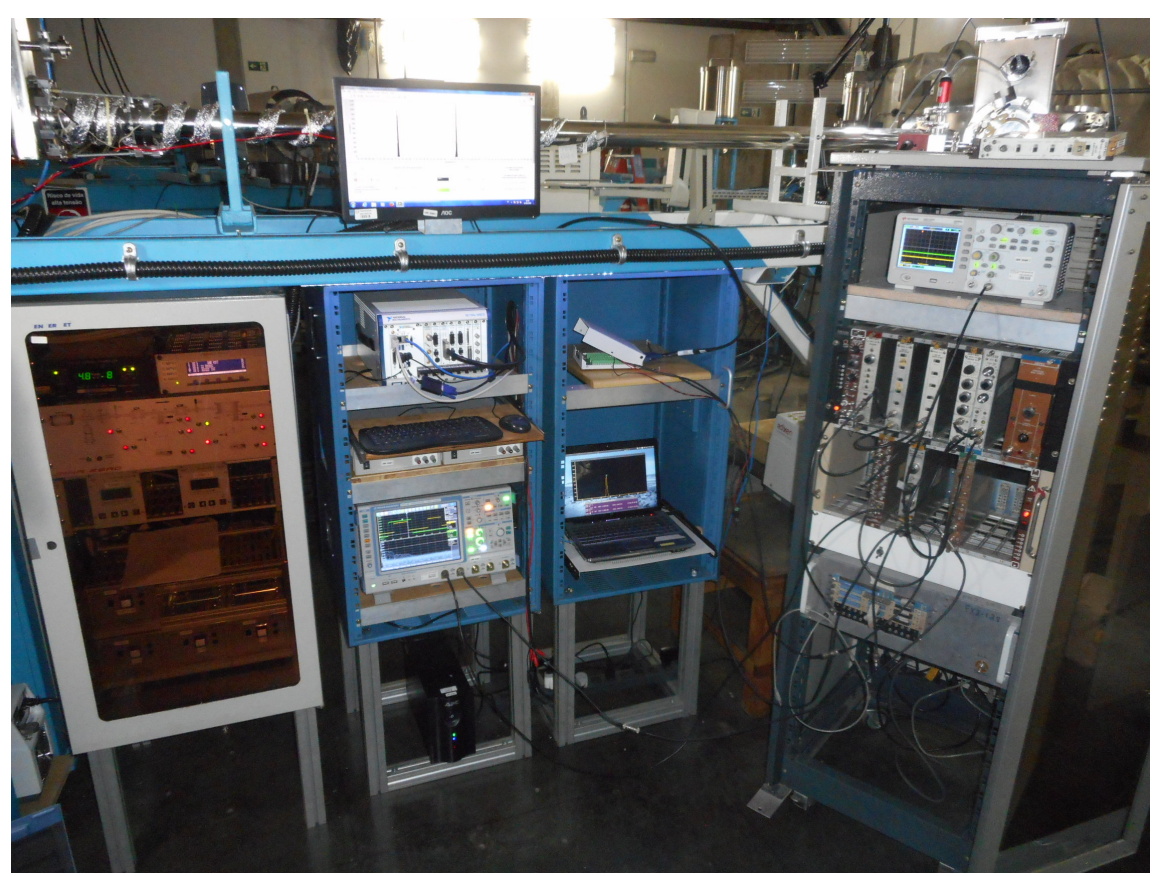

Figura 6.10: Fotografia da eletrônica de aquisição e controle.

Utilizando um módulo gerador de funções acoplado ao NI-PXI foi ainda desenvolvido um pulsador digital capaz de gerar pulsos padrão NIM [32], pulsos típicos de detectores 
com tempo de subida e descida ajustáveis, pulsos gaussianos uni e bipolares, além de ondas senoidais, triangulares e quadradas, permitindo teste de eletrônica, simulação de eventos e injeção de sinais em sistemas eletrônicos.

Desde 2016 a nova canalização encontra-se pronta para os experimentos de irradiação de dispositivos eletrônicos e aplicações diversas, como teste de detectores, por exemplo. Vários experimentos têm sido realizados com a participação de diversos pesquisadores de várias instituições e, em paralelo, têm sido projetadas melhorias para a canalização.

Na Figura 6.11 é apresentada uma fotografia geral da nova canalização a zero grau do LAFN desenvolvida para o estudo dos efeitos de íons pesados em dispositivos eletrônicos e em experimentos de física nuclear básica e aplicada em geral.

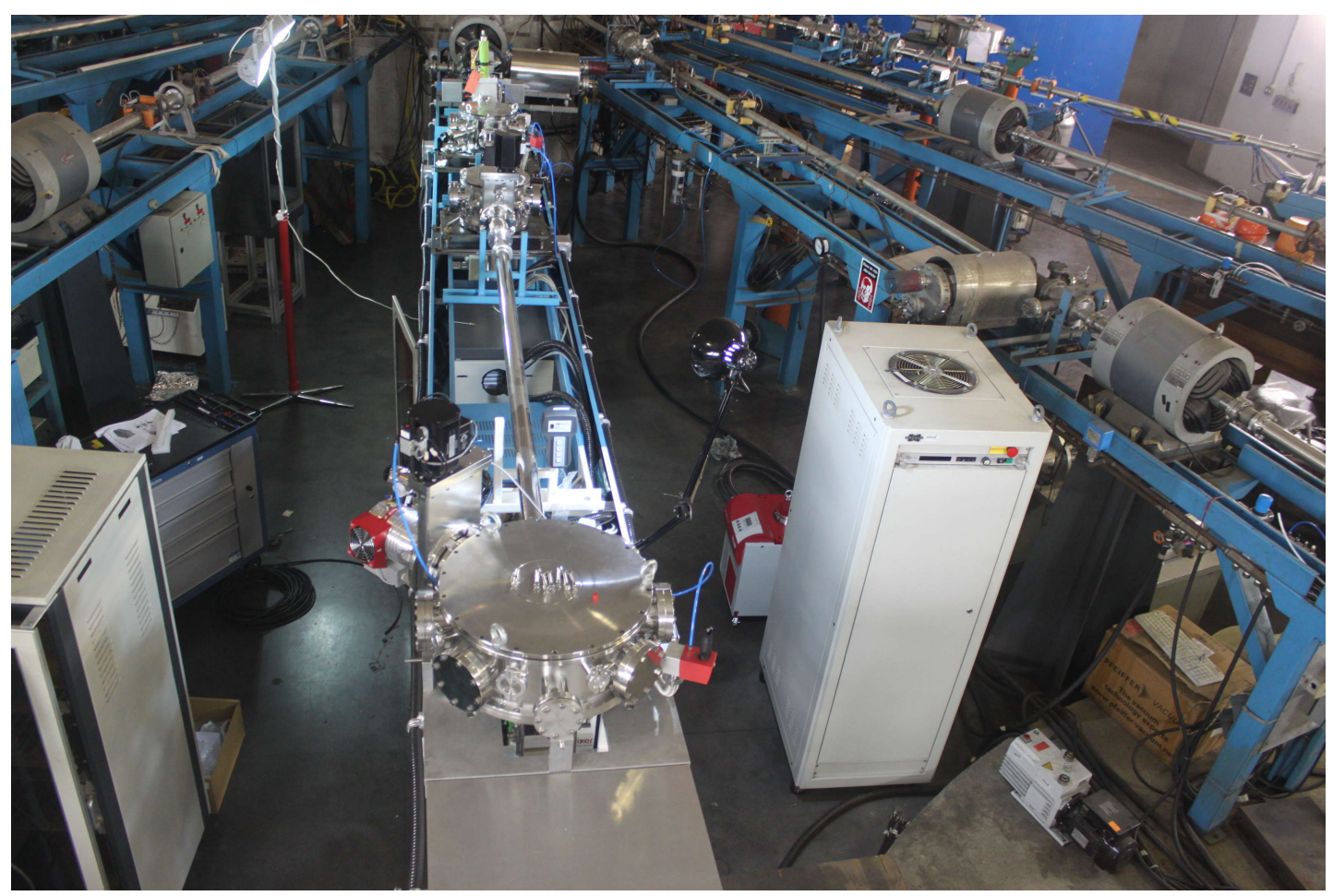

Figura 6.11: Sistema de Feixes Iônicos para Irradiações e Aplicações. 
Capítulo 6. Sistema de Feixes Iônicos para Irradiações e Aplicações (SAFIIRA) 104 


\section{Capítulo 7}

\section{Caracterização do SAFIIRA}

Neste capítulo serão apresentados os resultados obtidos para a uniformidade do feixe e as observações acerca da utilização do novo sistema.

\subsection{Uniformidade do Feixe}

A caracterização do feixe pode ser feita através de dois métodos principais: a observação do sinal no beam scanner e a medida de uniformidade na câmara final. Utilizando um feixe de ${ }^{16} \mathrm{O} 42 \mathrm{MeV}$, para testes do sistema de movimentação das fendas e as condições de focalização do feixe direto nas câmara de irradiação, obteve-se o perfil do feixe no beam scanner, utilizando abertura de $5 \mathrm{~mm}$ nas fendas da canalização. O sistema do beam scanner (seção 6.2) mede a distribuição espacial do feixe através de sua interação com um fio metálico em movimento, de modo que sua distribuição espacial é convertida numa distribuição temporal do sinal de carga coletada. Na Figura 7.1, observa-se que o perfil do feixe é constituído por duas distribuições temporais de carga (cada uma referente a um dos eixos transversais à propagação) muito semelhantes entre si, evidenciando que os sistemas ópticos associados do acelerador Pelletron e da nova canalização são capazes de prover um feixe com baixo astigmatismo. As dimensões do 
feixe nesta região evidentemente dependem da posição de focalização, conforme será discutido na seção 7.2 .

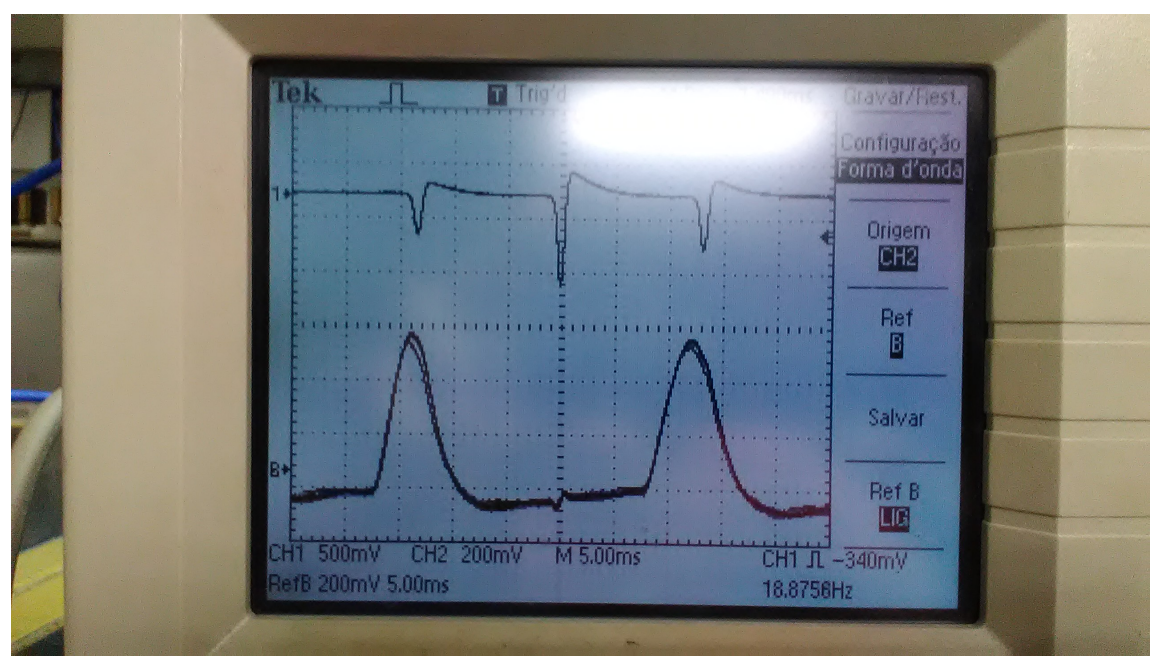

Figura 7.1: Sinal de coleta de carga no beam scanner (abaixo), indicando dispersão transversal do feixe de entrada na canalização, utilizando feixe de ${ }^{16} O 42 \mathrm{MeV}$. O sinal no canal 1 (acima) é o sinal de pick-up, que serve como referência de tempo.

Materiais cintiladores emitem luz visível característica sob a incidência de radiação ionizante. A utilização de folhas cintiladoras permitiu observar o feixe diretamente na câmara de irradiação. A Figura 7.2a mostra a luz emitida por um cintilador de fósforo com o feixe focalizado na câmara de irradiação. Apesar do diâmetro do feixe ser da ordem de alguns milímetros, sob feixe direto o elevado número de elétrons delta emitidos nas interações provoca a cintilação do material num diâmetro maior do que o feixe. A Figura $7.2 \mathrm{~b}$ mostra o feixe desfocado incidindo numa folha cintiladora de sulfeto de zinco de $4 \mathrm{~cm}$ de diâmetro. Neste caso, a corrente de feixe é menor e portanto o efeito de elétrons delta longe da região de interação diminui consideravelmente. As manchas escuras são causadas pela fita utilizada para fixar a folha. A utilização de cintiladores foi escolhido como um dos métodos de diagnóstico (qualitativo) de feixe nas operações de rotina. 


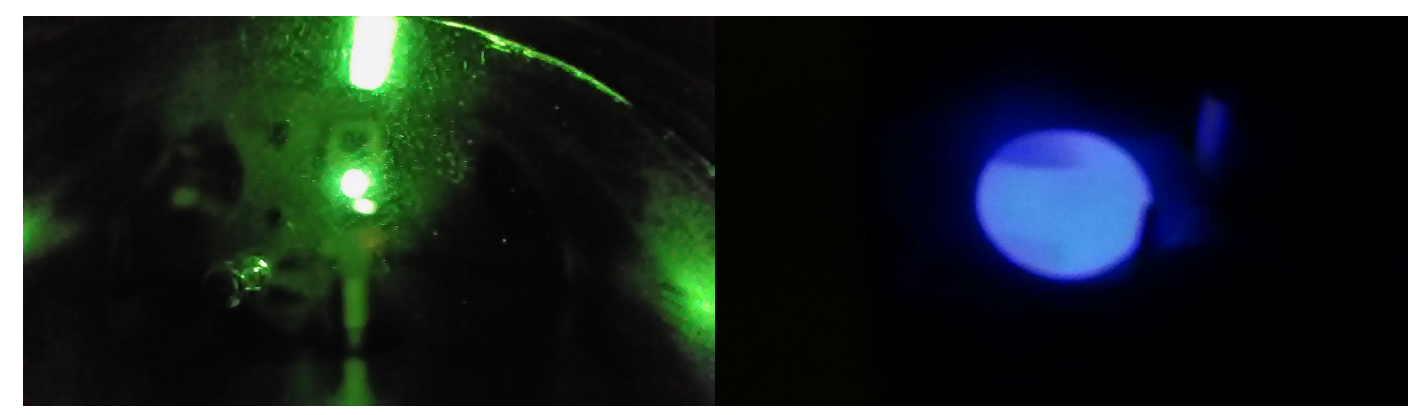

(a)

(b)

Figura 7.2: (a)Feixe direto incidente em cintilador de $\mathrm{P}$, na câmara de irradiação.(b)Feixe desfocalizado incidente em cintilador de ZnS, na câmara de irradiação.

As medidas de uniformidade do feixe foram realizadas por meio de um detector de barreira de superfície posicionado no manipulador de amostra, sendo que a posição do porta-amostra e os números de contagens no detector de normalização e do plano de irradiação eram monitorados e controlados pelo programa de varredura, conforme especificado no Capítulo 6, permitindo obter as distribuições de partículas no plano de irradiação.

Diferentes combinações alvos espalhadores-feixe-energia foram utilizadas nas medidas de uniformidade. Com certas combinações de folhas espalhadoras e feixes utilizados, o número de contagens no detector de normalização era bastante reduzido, prejudicando a análise. A Figura 7.3 mostra o resultado obtido para o feixe de ${ }^{12} \mathrm{C}$ a $35 \mathrm{MeV}$ utilizando a segunda folha espalhadora de $649 \mu \mathrm{g} / \mathrm{cm}^{2}$, bem como as projeções nos eixos horizontal (x) e vertical (y). A Figura 7.4 mostra alguns resultados para diferentes condições utilizando feixe de ${ }^{16} \mathrm{O}$.

Conforme pode ser observado na Figura 7.3, o procedimento de normalização, embora seja fundamental para corrigir eventuais quedas na intensidade do feixe, torna-se muito impreciso quando o número de contagens no normalizador é reduzido, produzindo variações maiores do que as reais. Apesar disso, pode-se observar que foram obtidas boas uniformidades de feixe nestas condições. Na Figura 7.4, observa-se que diversas 


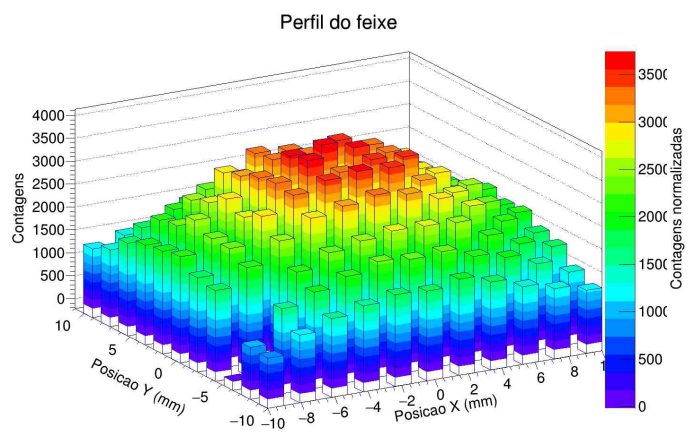

(a)

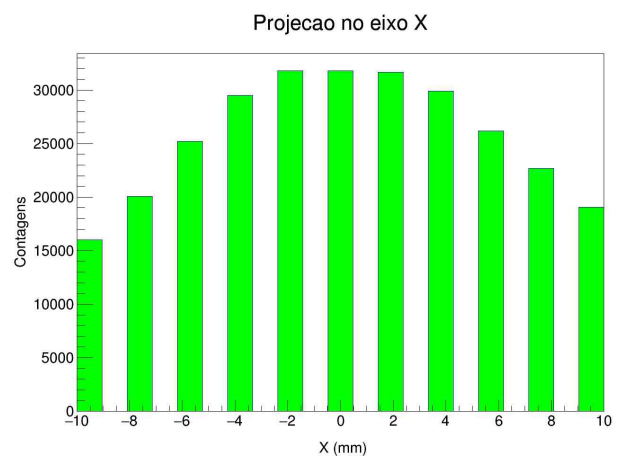

(c)

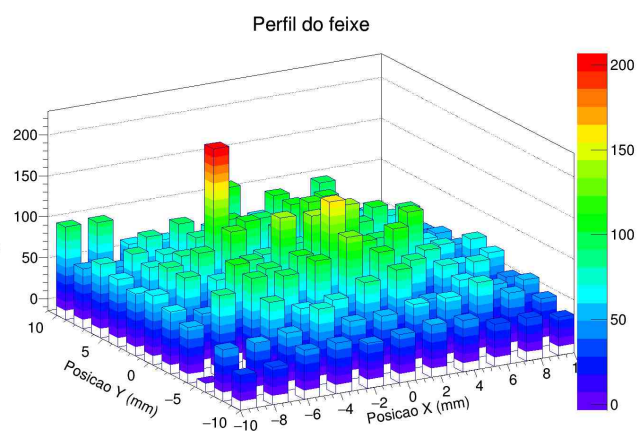

(b)

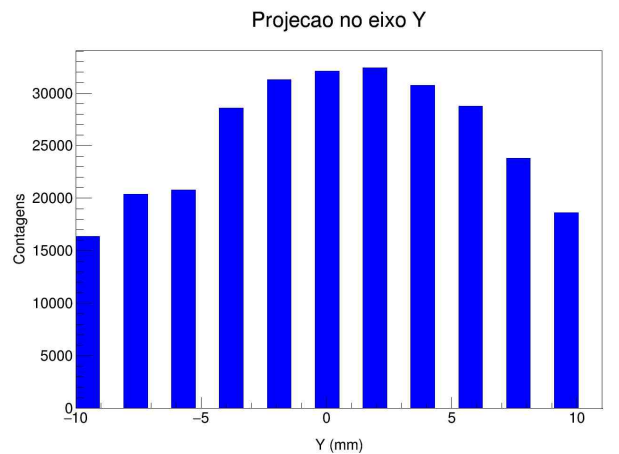

(d)

Figura 7.3: Distribuições de partículas na posição de irradiação para diversas condições de espalhamento do feixe de ${ }^{12} C 35 \mathrm{MeV}$ e segunda folha espalhadora de $649 \mu \mathrm{g} / \mathrm{cm}^{2}$. (a)Perfil de contagens totais. (b)Perfil de contagens normalizadas. (c)Projeção horizontal do perfil em (a). (d)Projeção vertical do perfil em (a). 


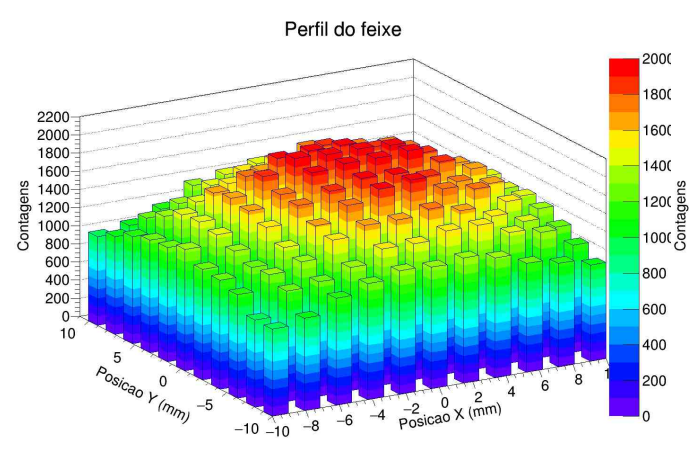

(a)

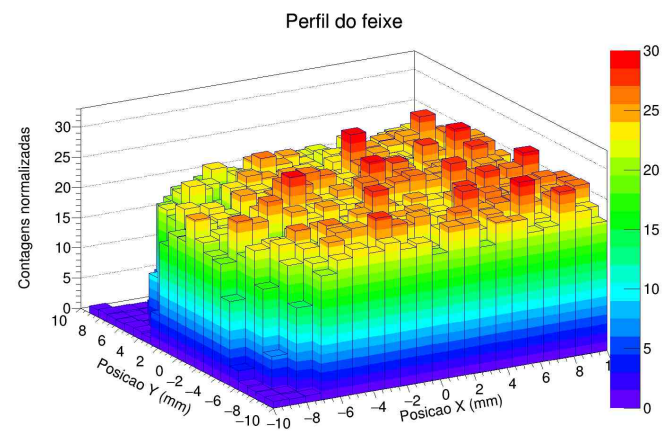

(c)

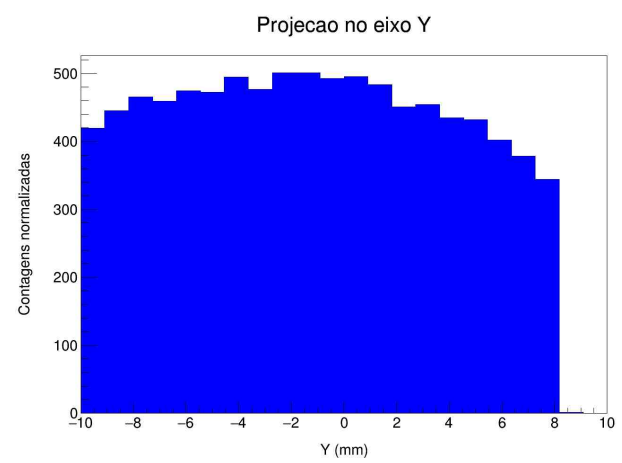

(e)

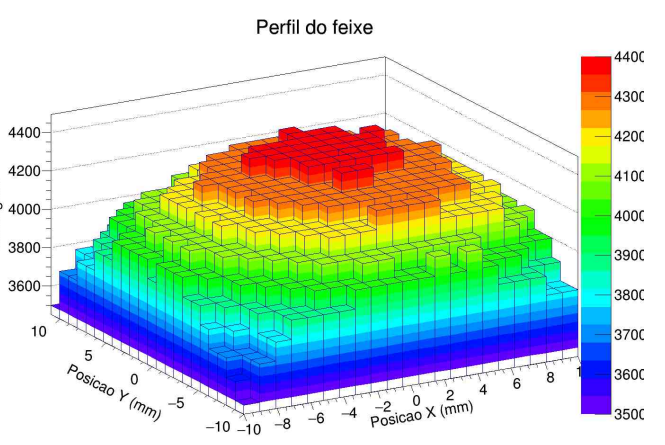

(b)

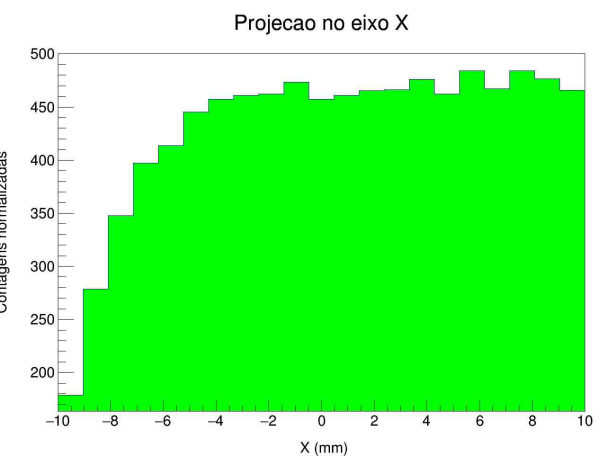

(d)

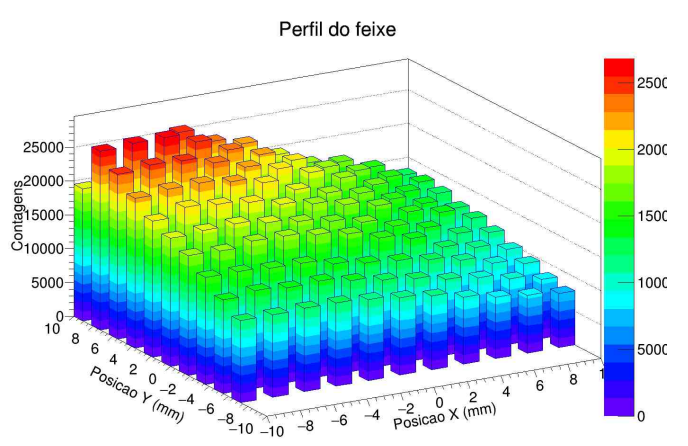

(f)

Figura 7.4: Distribuições de partículas na posição de irradiação para diversas condições de espalhamento do feixe de ${ }^{16} O$. (a)Perfil do feixe de ${ }^{16} O 35 \mathrm{MeV}$ na posição de irradiação, utilizando a segunda folha espalhadora de $649 \mu \mathrm{g} / \mathrm{cm}^{2}$. (b)Perfil do feixe de ${ }^{16} \mathrm{O} 42 \mathrm{MeV}$ na posição de irradiação, utilizando a segunda folha espalhadora de $649 \mu \mathrm{g} / \mathrm{cm}^{2}$. (c)Perfil do feixe de ${ }^{16} O 35 \mathrm{MeV}$ na posição de irradiação, utilizando a segunda folha espalhadora de $1300 \mu \mathrm{g} / \mathrm{cm}^{2}$. (d)Projeção horizontal do perfil em (c). (e)Projeção vertical do perfil em (c). (f)Perfil do feixe de ${ }^{16} O 63 \mathrm{MeV}$ na posição de irradiação, utilizando a apenas a primeira folha espalhadora de $657 \mu \mathrm{g} / \mathrm{cm}^{2}$. 


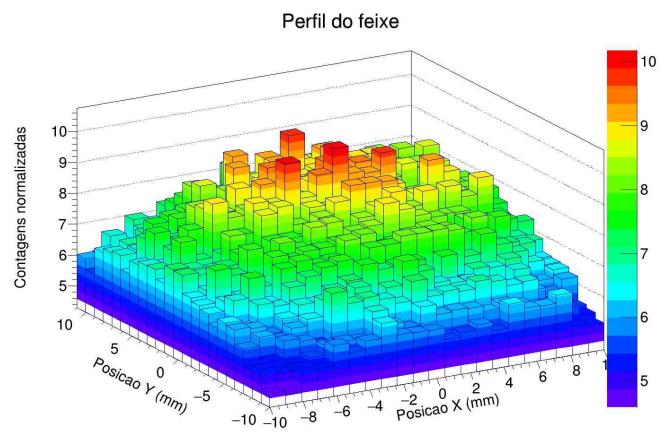

(a)

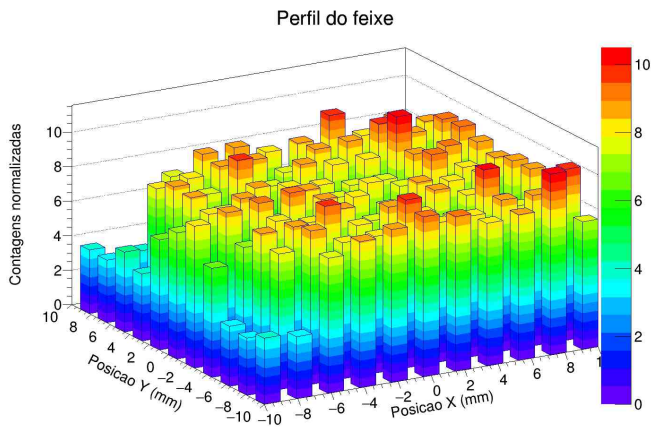

(b)

Figura 7.5: Distribuições de partículas na posição de irradiação para diversas condições de espalhamento do feixe de ${ }^{28} \mathrm{Si} 47 \mathrm{MeV}$. (a)Perfil do feixe (normalizado) de ${ }^{28} \mathrm{Si} 47$ $\mathrm{MeV}$ na posição de irradiação, utilizando a segunda folha espalhadora de $649 \mu \mathrm{g} / \mathrm{cm}^{2}$, obtendo uniformidade de 0,10(4). (b)Perfil do feixe (normalizado) de ${ }^{28} \mathrm{Si} 47 \mathrm{MeV}$ na posição de irradiação, utilizando a segunda folha espalhadora de $1300 \mu \mathrm{g} / \mathrm{cm}^{2}$, obtendo uniformidade de $0,03(3)$.

combinações de energias e folhas resultam num feixe com as características desejadas, com a restrição de que o alinhamento dos colimadores deve ser muito preciso, conforme evidenciado nas Figuras 7.4c, 7.4d e 7.4e. A Figura 7.4f mostra o caso de apenas uma folha espalhadora na primeira câmara do sistema, procedimento que minimiza as perdas de energia do feixe nos processos de espalhamento, porém não reduzindo suficientemente a intensidade do feixe e tornando o sistema mais sensível a desalinhamentos. A Figura 7.5 mostra alguns dos resultados obtidos para feixes de silício, onde observa-se que mesmo para folhas mais finas pode-se obter boa uniformidade.

As tabelas 7.1 a 7.3 sumarizam alguns dos resultados obtidos para a uniformidade do feixe. Os cálculos foram feitos tomando a uniformidade média das projeções horizontal e vertical, utilizando o procedimento descrito por [54] (Equação 2.22), em que a uniformidade $\epsilon$ depende do mínimo valor de intensidade na área considerada (no caso, um diâmetro de $1,5 \mathrm{~cm}$ ), do máximo valor de intensidade e do valor médio entre eles, sendo então dada por: 


$$
\epsilon=\frac{I_{\max }-I_{\min }}{2<I>}
$$

Valores menores indicam feixe mais uniforme, e, idealmente, devem ser menores do que 0,1 para corresponder a uniformidade superior a $90 \%$. Devido ao baixo número de contagens (normalizadas pelo número de contagens no detector posicionado na câmara 1) especialmente nos casos de feixes mais uniformes, as incertezas nestes casos podem chegar em até $100 \%$

Tabela 7.1: Uniformidades calculadas para feixes de ${ }^{16} O$ a várias energias e segunda folha espalhadora de $649 \mu \mathrm{g} / \mathrm{cm}^{2}$.

\begin{tabular}{cc}
\hline Energia $(\mathrm{MeV})$ & Uniformidade \\
\hline 35 & $0,139(22)$ \\
42 & $0,146(9)$ \\
62 & $0,243(18)$ \\
\hline
\end{tabular}

Tabela 7.2: Uniformidades calculadas para feixes de ${ }^{16} \mathrm{O} 42 \mathrm{MeV}$ e segunda folha espalhadora de diversas espessuras.

\begin{tabular}{cc}
\hline Espessura da folha espalhadora $\left(\mu \mathrm{g} / \mathrm{cm}^{2}\right)$ & Uniformidade \\
\hline $649(65)$ & $0,146(9)$ \\
$1300(130)$ & $0,0787(20)$ \\
$657(66)^{1}$ & $0,096(15)$ \\
\hline
\end{tabular}

\footnotetext{
${ }^{1}$ Apenas a primeira folha espalhadora
} 
Tabela 7.3: Uniformidades calculadas para diversos feixes a várias energias e segunda folha espalhadora de $649 \mu \mathrm{g} / \mathrm{cm}^{2}$.

\begin{tabular}{ccc}
\hline Feixe & Energia $(\mathrm{MeV})$ & Uniformidade \\
\hline${ }^{12} \mathrm{C}$ & 35 & $0,163(16)$ \\
${ }^{16} \mathrm{O}$ & 35 & $0,139(22)$ \\
${ }^{28} \mathrm{Si}$ & 47 & $0,096(41)$ \\
${ }^{35} \mathrm{Cl}$ & 42 & $0,09(5)$ \\
${ }^{63} \mathrm{Cu}$ & 78 & $0,05(6)$ \\
\hline
\end{tabular}

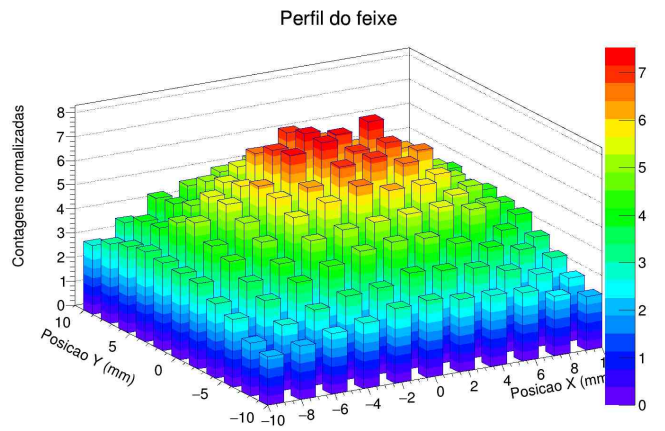

(a)

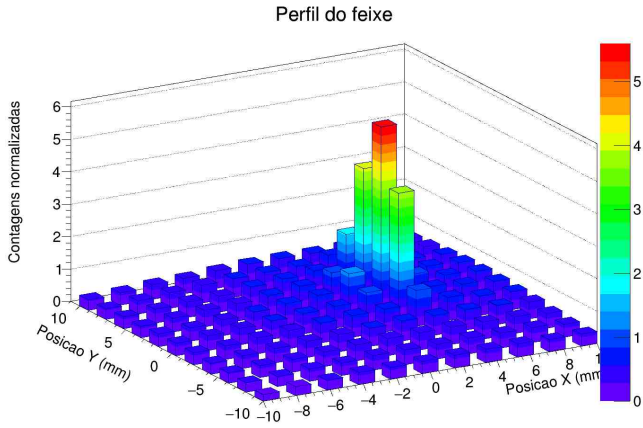

(b)

Figura 7.6: Distribuições de partículas na posição de irradiação para diversas condições de espalhamento do feixe de ${ }^{19} F 49 \mathrm{MeV}$. (a)Perfil do feixe (normalizado) de ${ }^{19} F 47$ $\mathrm{MeV}$ na posição de irradiação, utilizando a segunda folha espalhadora de $552 \mu \mathrm{g} / \mathrm{cm}^{2}$. (b)Perfil do feixe (normalizado) de ${ }^{19} F 49 \mathrm{MeV}$ na posição de irradiação, utilizando a segunda folha espalhadora de $828 \mu \mathrm{g} / \mathrm{cm}^{2}$, com um pequeno furo.

Observou-se que a uniformidade do feixe na posição de irradiação é dependente da qualidade dos alvos espalhadores, de modo que estes devem ser uniformes em espessura e, na medida do possível, isentos de deformações. As imperfeições no alvo espalhador de $649 \mu \mathrm{g} / \mathrm{cm}^{2}$ podem explicar porque a uniformidade medida para o feixe de ${ }^{12} C$ não apresentou o resultado esperado. A Figura 7.6 mostra os resultados de perfil do feixe (normalizado) de ${ }^{19} \mathrm{~F} 49 \mathrm{MeV}$ para duas folhas espalhadoras diferentes, uma delas apresentando um pequeno furo (um erro experimental, uma vez que não foi observado durante a montagem), num caso extremo de imperfeição da folha espalhadora. 
Por último, na Figura 7.7 podemos comparar os perfis obtidos para dois feixes com números atômicos bastante diferentes, a saber: prótons e ${ }^{63} \mathrm{Cu}$. Embora as duas medidas tenham sido feitas com espessuras diferentes de espalhador, a diferença de 25\% na espessura do espalhador não compromete a comparação neste caso.

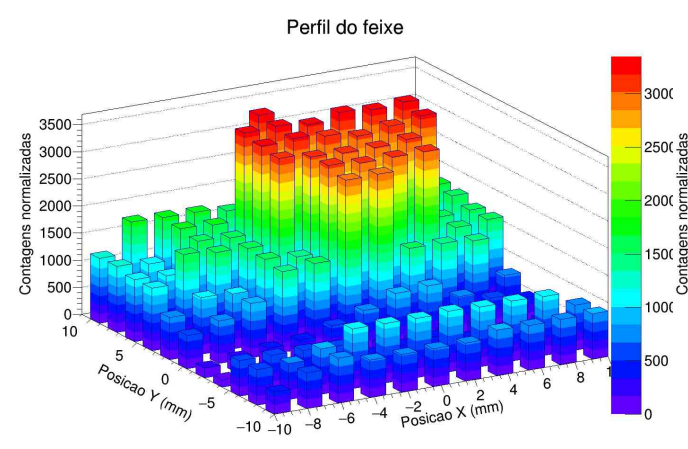

(a)

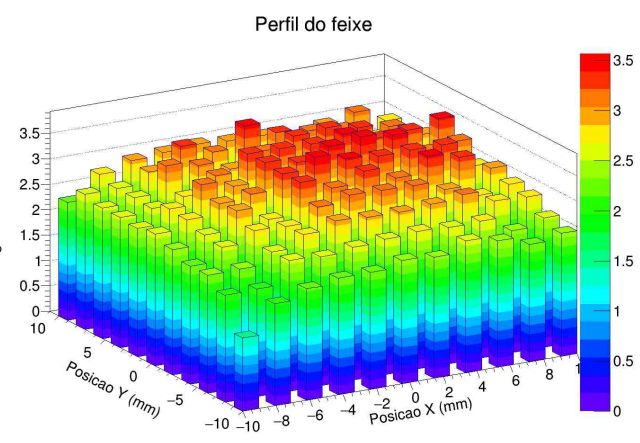

(b)

Figura 7.7: Distribuições de partículas na posição de irradiação para feixes de ${ }^{1} H 15$ $\mathrm{MeV}$ e ${ }^{63} \mathrm{Cu} 78 \mathrm{MeV}$. (a)Perfil do feixe (normalizado) de ${ }^{1} \mathrm{H} 15 \mathrm{MeV}$ na posição de irradiação, utilizando a segunda folha espalhadora de $806 \mu \mathrm{g} / \mathrm{cm}^{2}$. (b)Perfil do feixe (normalizado) de ${ }^{63} \mathrm{Cu} 78 \mathrm{MeV}$ na posição de irradiação, utilizando a segunda folha espalhadora de $649 \mu \mathrm{g} / \mathrm{cm}^{2}$, com um pequeno furo.

Como pode ser observado, a uniformidade para o feixe de prótons $15 \mathrm{MeV}$, calculada como sendo 0,200(3) com folha espalhadora de $806 \mu \mathrm{g} / \mathrm{cm}^{2}$ não atende as características desejadas, estando, porém, de acordo com o previsto (Equação 2.26 e Figura 5.7). No caso do feixe de ${ }^{63} \mathrm{Cu} 78 \mathrm{MeV}$ e folha espalhadora de $649 \mu \mathrm{g} / \mathrm{cm}^{2}$ a uniformidade calculada foi 0,05(6), adequada aos experimentos de irradiação de dispositivos eletrônicos.

\subsection{Otimização da operação}

Durante a fase de testes e caracterização e os diversos experimentos realizados, foi possível determinar as melhores condições de operação do sistema, incluindo algumas mudanças que serão discutidas a seguir. 
A observação mais importante quanto à utilização do sistema diz respeito à condição de focalização do feixe. A primeira consideração é que a focalização do feixe nas fendas da canalização, embora suficiente para promover a emitância desejada, possui o inconveniente de, dada a pequena distância entre o quadrupolo e as fendas, não garantir que a direção do feixe seja centrada na canalização. Desta forma, optou-se por focalizar o feixe na câmara de irradiação no início da operação para garantir o direcionamento. Durante esta etapa, busca-se manter as correntes lidas nas 4 fendas aproximadamente iguais, o que resulta num feixe com astigmatismo, dado que as fendas verticais e horizontais não estão localizadas no mesmo plano. O astigmatismo é evidenciado pela mancha causada pelo feixe no primeiro colimador. Apesar do astigmatismo, optou-se por este método pois sua influência tende a se anular após a colimação e o espalhamento múltiplo, de modo que vantagem obtida com o diagnóstico simples de observar se as correntes lidas nas fendas são semelhantes compensa qualquer efeito negativo desta metodologia.

No projeto original, foi considerado que apenas o quadrupolo da canalização seria o suficiente para obter um feixe com as características adequadas. De fato, o quadrupolo 4 (Figura 4.2) é normalmente usado com corrente baixa apenas para correção de foco para o switching magnet em todas as canalizações do acelerador Pelletron, porém observou-se que a melhor condição de focalização na câmara de irradiação ocorre com a utilização conjunta dos quadrupolos 4 (antes do switching magnet) e 5 (canalização). Convém mencionar que também é possível obter condição de trabalho utilizando apenas um dos quadrupolos, embora essa operação seja mais demorada e não otimizada.

Após a focalização do feixe na câmara de irradiação, os alvos de ouro são posicionados nas câmaras gêmeas, utilizando espessuras escolhidas de maneira a garantir a uniformidade, fluxo e energia de feixe desejados. O fluxo é calibrado medindo-se a razão entre as contagens no detector posicionado no centro da câmara de irradiação e o monitor, posicionado na câmara 1. Conforme o monitor está posicionado num ângulo 
de $\sim 45^{\circ} \mathrm{em}$ relação ao alvo, o número de contagens no detector varia de acordo com a seção de choque de Rutherford, de modo que, para feixes leves, a taxa de contagens no monitor é mais baixa, devendo-se realizar calibrações mais longas de modo a ter incerteza final dentro da faixa aceitável para o experimento.

As medidas de calibração são feitas ajustando-se a focalização de modo a atingir o fluxo desejado. Observou-se que o fator de normalização, isto é, a razão entre contagens no detector posicionado na câmara de irradiação e o monitor varia quando o ajuste do fluxo é feito através do quadrupolo da canalização. Todavia, o fator se mantém (dentro de 10\% de tolerância) ao variar a corrente no quadrupolo 4. Tal fenômeno se dá em razão de que, ao variar a corrente no quadrupolo 4, as partículas nas trajetórias centrais são pouco afetadas, ao passo que as partículas periféricas são movidas para fora da região de aceitação do quadrupolo 5: desta forma, obtém-se a diminuição do fluxo de partículas sem mudança apreciável no fator de normalização.

\subsection{Exemplos de utilização ${ }^{2}$}

Diversos experimentos foram realizados no SAFIIRA, permitindo, com o uso, identificar as possibilidades de melhorias. Uma breve descrição é apresentada a seguir.

Numa colaboração com o Centro de Tecnologia de Informação Renato Archer (CTI) e o INPE, diversos experimentos foram feitos envolvendo o chip SpaceWire ${ }^{3}$. Primeiramente, o sistema foi configurado em um FPGA e diversas metodologias de mitigação dos efeitos provocados por radiação foram testadas, permitindo a escolha da mais adequada. Após o desenvolvimento do ASIC, este foi testado no SAFIIRA com feixes de ${ }^{12} \mathrm{C},{ }^{16} \mathrm{O},{ }^{28} \mathrm{Si},{ }^{35} \mathrm{Cl},{ }^{63} \mathrm{Cu}$ e ${ }^{107} \mathrm{Ag}$, observando-se, nos testes de engenharia, baixo

\footnotetext{
${ }^{2} \mathrm{O}$ autor agradece aos grupos de pesquisa colaboradores que propuseram e trouxeram os experimentos aqui citados para serem realizados no SAFIIRA.

${ }^{3}$ Circuito digital de interface de comunicação de rede seguindo protocolo SpaceWire da ESA, permitindo que subsistemas do satélite o utilizem como meio de comunicação entre si, com redução de volume, massa e maior velocidade.
} 
número de ocorrências nos registradores de eventos corrigidos. Posteriormente, foram realizados testes de usuário no mesmo chip e não foram observados erros na saída de dados, demonstrando a eficácia dos processos de mitigação utilizados.

Também foram feitos testes utilizando o feixe colimado em $0,5 \mathrm{~mm}$ para determinar a posição de maior ocorrência de falhas no SAMPA chip ${ }^{4}$, desenvolvido pelo grupo do Centro de Instrumentação de Física de Altas Energias do IFUSP (HEPIC) . Para tanto, neste primeiro teste de varredura realizado, um detector do tipo barreira de superfície anular foi posicionado de modo que o chip ficasse exposto através do furo no detector, e uma varredura prévia foi feita para mapear o detector e, portanto, determinar as posições relativas das estruturas do chip. A varredura foi feita com passos de $0,5 \mathrm{~mm}$, e o perfil observado para o detector é apresentado na Figura 7.8, onde fica clara a estrutura do detector. A imagem do detector não aparece completa pois o objetivo era de apenas determinar sua borda interna.

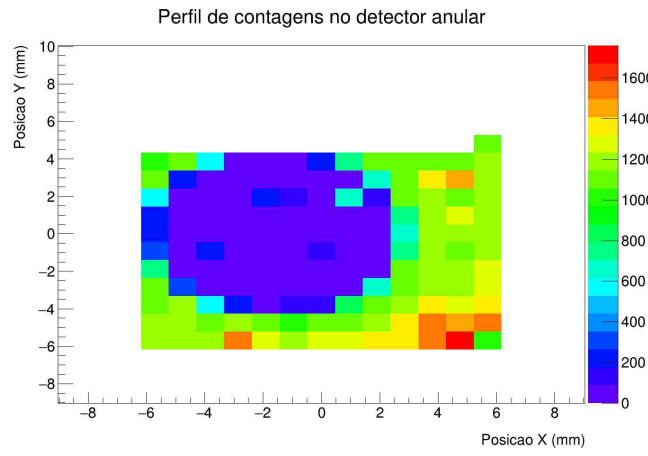

(a)

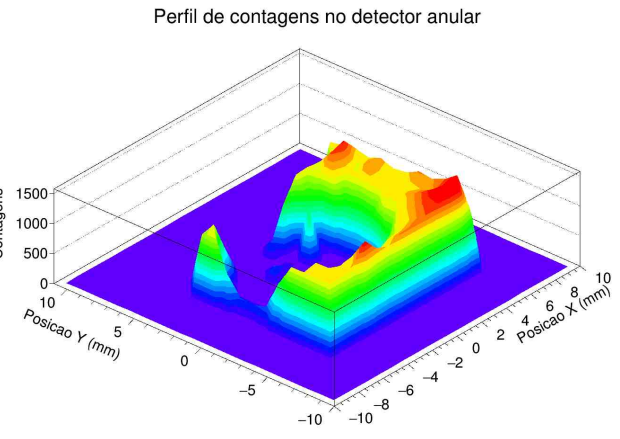

(b)

Figura 7.8: Perfil de contagens no detector anular (a)Gráfico de cores, evidenciando o passo utilizado. (b) Gráfico tridimensional, ilustrando o furo central do detector.

Em colaboração com pesquisadores da UFRGS e PUC-RS, foram feitas medidas de seção de choque de upsets em FPGAs aplicando-se diferentes técnicas de mitigação de falhas. Tais experimentos, em geral, envolviam feixes de ${ }^{16} \mathrm{O}$ em energias entre $40 \mathrm{e}$

\footnotetext{
${ }^{4}$ Circuito integrado analógico-digital para aquisição de dados no experimento ALICE, do CERN
} 
$50 \mathrm{MeV}$, porém com fluxos baixos, da ordem de $\sim 200$ particulas $/ \mathrm{s} / \mathrm{cm}^{2}$. Mantendo-se constantes os parâmetros do feixe, é possível determinar, entre as diversas técnicas de mitigação existentes, as mais adequadas para cada situação. Testes prévios de varredura utilizando feixes micro-colimados também foram realizados, com resultados promissores.

Ainda foram feitos experimentos em parceria com o Centro Universitário da FEI em dispositivos ARM, em dispositivos para (possível) uso no experimento ATLAS e em transistores de potência visando observar efeitos de single-event burnout.

\subsection{SAFIIRA como estação multi-uso: possibilidades e pers- pectivas}

\subsubsection{Irradiações diversas}

Além do estudo de efeitos de radiação em dispositivos eletrônicos, feixes de íons pesados acelerados com características semelhantes podem ser utilizados para irradiação de diversos materiais, visando a microfabricação [79], estudo de efeitos de radiação em polímeros e outros materiais de uso aeroespacial [80, 81] e também em bens culturais analisados por técnicas de feixes iônicos [82], onde a deposição de energia pela utilização dos feixes pode causar a degradação de tintas e compostos orgânicos de forma ainda não completamente compreendida.

As aplicações em sistemas biológicos incluem o estudo de alterações em sistemas biológicos em função da radiação, causando aberrações cromossômicas, alterações no crescimento, entre outros efeitos [83, 84, 85, 86], imageamento de massas (em conjunto com técnicas de Ion Beam Analysis) [87, 88, 89, 90] e testes de fármacos com potencial efeito radioprotetor [91]. 


\subsubsection{Análise de materiais}

Conforme será detalhado na Parte III, o conhecimento preciso das camadas de metalização e isolamento de cada dispositivo é essencial para determinação correta de LET efetivo e dose na camada sensível [28]. A utilização de técnicas de Ion Beam Analysis como, por exemplo, Rutherford Back-scattering (RBS) [92, 73] e Particle-Induced X-ray Emission (PIXE) [73] permitem que o estudo de efeitos de dispositivos eletrônicos seja feito de maneira completa. Para tanto, é possível utilizar o SAFIIRA como uma estação de alta energia para estas análises, uma vez que o acelerador Pelletron opera em tensões muito superiores às do acelerador do Laboratório de Análise de Materiais com Feixes Iônicos, necessitando apenas da instalação de detectores de partículas carregadas e raios X em posições determinadas na câmara de irradiação. No momento já foi instalado um detector a gás para medidas utilizando a técnica Elastic Recoil Detection Analysis (ERDA). A utilização de microfeixes colimados permite maior resolução espacial nas análises.

\subsubsection{Produção de nêutrons}

Dentre os diversos estudos de efeitos de radiação em dispositivos eletrônicos, os estudos envolvendo feixes de nêutrons merecem destaque, principalmente no caso de componentes eletrônicos de uso aeroespacial, uma vez que dispositivos de controle embarcados utilizados em aviônica encontram-se expostos a um espectro de nêutrons oriundos da interação de raios cósmicos com a atmosfera, espectro este bastante intenso em torno de $10 \mathrm{MeV}$ na região da Anomalia Magnética do Atlântico Sul [7]. Neste caso, as irradiações em laboratório permitem estudar a ocorrência de efeitos de eventos isolados (SEE) causados por nêutrons, como, por exemplo, bit-flips em dispositivos digitais, ou mesmo efeitos de danos por deslocamento de átomos da rede cristalina, que alteram as características elétricas de dispositivos [93]. Estudos controlados em cada faixa de energias de nêutrons permitirão melhor previsão de falhas e otimização de projetos de 
sistemas embarcados.

A produção de feixes de nêutrons pode ser feita de diversas maneiras, como por exemplo utilizando-se fontes de fissão $\left({ }^{252} \mathrm{C} f\right)$ ou do tipo ${ }^{241} \mathrm{Am}-\mathrm{Be}$, geradores por reações fotonucleares e reatores nucleares [94]. Estas fontes, em geral, apresentam um espectro contínuo de energia, sendo que fontes como ${ }^{252} \mathrm{Cf}$ e Am-Be possuem energia média na faixa de poucos $\mathrm{MeV}$, enquanto que o espectro de um reator é concentrado na faixa de nêutrons térmicos e epitérmicos. Para muitas aplicações, como por exemplo para irradiações de materiais ou utilização em pesquisa nuclear básica, feixes monoenergéticos ou quase-monoenergéticos de nêutrons são desejáveis. Geradores de nêutrons com base nas reações ${ }^{2} H\left({ }^{2} H, n\right)^{3} H e$ e ${ }^{3} H\left({ }^{2} H, n\right){ }^{4} H e$ produzem feixes monoenergéticos com energia de $2,5 \mathrm{MeV}$ e $14 \mathrm{MeV}$, respectivamente, porém possuem a desvantagem de que a energia só pode ser diminuída com uso de técnicas de termalização. Diante dessas dificuldades, a utilização de reações nucleares com íons pesados mostra-se um caminho promissor para obter feixes de nêutrons rápidos com espectro concentrado em uma faixa relativamente estreita (poucos $\mathrm{MeV}$ ) de energias.

Diversas reações com íons pesados têm sido utilizadas para a produção de feixes de nêutrons, porém muitas possuem espectro monoenergético apenas a baixas energias, quando os canais de break-up não são importantes. À medida que canais inelásticos e de break-up se tornam possíveis, os espectros tornam-se mais amplos. Na literatura encontram-se diversos estudos de produção de feixes de nêutrons [95, 96, 97, 98, 99, 100, 101]. Dentre as reações que podem ser realizadas no acelerador Pelletron, a reação inversa ${ }^{1} H\left({ }^{7} \mathrm{Li}, n\right)^{7} \mathrm{Be}$ [102] possui particular interesse uma vez que, por tratar-se de uma reação com cinemática inversa, promove a focalização cinemática do feixe de nêutrons, produzindo nêutrons entre 1 e $4 \mathrm{MeV}$ de energia e pode ser feita por meio de uma combinação alvo-projétil disponível no laboratório.

Para a produção de feixes de nêutrons, os alvos são instalados na câmara 1, sendo que no caso de alvos grossos, como ${ }^{9} B e(\sim 0.25 \mathrm{~mm})$, o fluxo de partículas pode ser 
obtido pela corrente no alvo integrada, enquanto que, com alvos finos o suficiente para a passagem do feixe de íons, a corrente pode ser obtida num copo de Faraday, localizado na câmara 2. A deteç̧ão dos nêutrons pode ser realizada por meio de um detector do tipo barreira de superfície com um conjunto de dois colimadores e uma folha de polietileno, realizando-se portanto a espectroscopia dos prótons de recuo num ângulo conhecido $\left(0^{\circ}\right)$ definido pelos dois colimadores. A eficiência de conversão em função da energia dos nêutrons é obtida em [103, 104]. Os estudos de viabilidade já foram realizados e o suporte do detector de medida de intensidade do feixe na câmara de irradiação já foi projetado tendo em vista essa aplicação. 
Parte III

\section{Efeitos de Radiação em}

Dispositivos Eletrônicos: Influência das Camadas de Passivação e Metalização nos Efeitos Observados 


\section{Capítulo 8}

\section{Efeitos de Radiação Ionizante em}

\section{Dispositivos Eletrônicos}

Neste Capítulo será apresentada uma breve descrição das propriedades dos dispositivos semicondutores, seguida dos efeitos de radiação nos mesmos. Por fim, os processos de coleta de carga e determinação da energia efetiva depositada são considerados.

\subsection{Dispositivos Semicondutores}

Atualmente, quase a totalidade dos sistemas eletrônicos são compostos por dispositivos semicondutores, que aparecem no dia-a-dia na forma de células fotovoltaicas, processadores e memórias de computadores e smartphones, microcontroladores, sistemas embarcados, entre outros. As propriedades dos semicondutores (das junções, em especial) permitem tal gama de aplicações ao tornar possível que a corrente elétrica flua em apenas um sentido ou então com uma intensidade controlada externamente, como numa válvula tríodo, e, mais importante, um elevado grau de miniaturização. Dentre os materiais semicondutores, podemos destacar o silício como sendo o mais importante, embora também existam outros como o germânio e materiais compostos como 
por exemplo o arseneto de gálio [105].
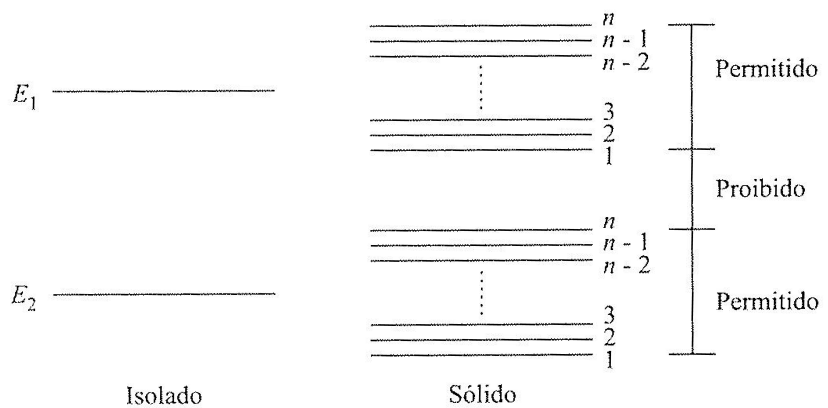

(a)
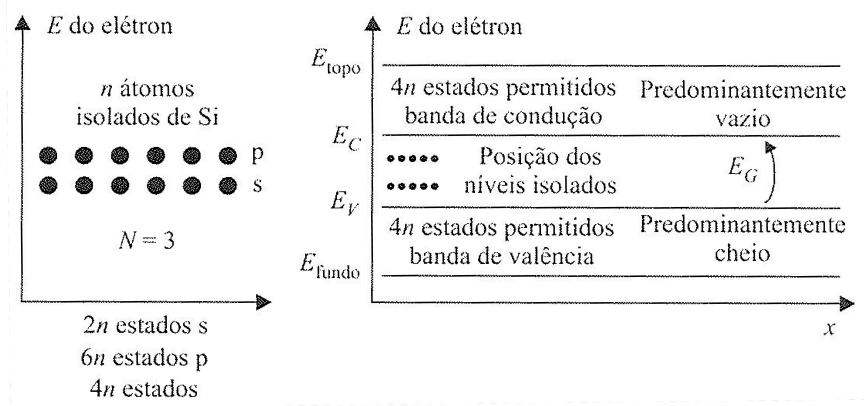

(b)

Figura 8.1: (a)Formação de estrutura de bandas em rede. (b)Estrutura de banda e ocupação do silício (Figuras reproduzidas de [105]).

O silício é um elemento da família IV-A e possui quatro elétrons de valência. Um conjunto grande de átomos de silício pode se arranjar de maneira amorfa ou na forma cristalina, caso em que os átomos ocupam posições determinadas na rede, de modo que o potencial interatômico apresenta periodicidade. De modo geral, quando dois átomos de eletronegatividades semelhantes estão próximos, os orbitais eletrônicos de um são hibridizados aos do outro (acoplamento entre estados), de maneira que os pares de elétrons ocupam um orbital compartilhado por ambos os átomos, caracterizando uma ligação covalente. Numa rede cristalina com n átomos, os níveis de energia, já próximos, sofrem acoplamentos e criam amplas faixas de energia (bandas) de estados permitidos, 
como ilustrado na Figura 8.1, havendo também valores de energia intermediários e portanto não permitidos (bandas proibidas) [44, 105].

A energia de separação entre uma banda totalmente preenchida e uma semi-preenchida (largura da banda proibida) depende do material, podendo ser alta (> $3 \mathrm{eV}$ - isolante), baixa ( $\sim 3 \mathrm{eV}$ - semicondutor) muito baixa ou até negativa (condutores). O acoplamento preserva o número de estados passíveis de ocupação, ou seja, no caso do silício, em que o orbital 3s é totalmente ocupado e o estado 3p possui 2 elétrons, havendo então estados disponíveis para 4 elétrons, numa rede de n átomos, cada banda irá comportar 4 n elétrons, respeitando-se o princípio da exclusão de Pauli e a ocupação preferencial dos níveis de energia mais baixa. Pode-se determinar as energias das bandas pelo modelo de Kronig e Penney [105], que calcula os níveis de energia de um elétron (na primeira aproximação de Born [35]) submetido a um potencial periódico (rede cristalina) dos núcleos. A solução da equação de Schrödinger é dada em função da barreira de potencial entre os átomos e da distância entre eles.

Ocorre condução elétrica na presença de um campo elétrico apenas nas bandas não totalmente ocupadas, por um motivo simples: as bandas totalmente ocupadas não possuem estados livres para serem ocupados pelo elétron, que ganha energia cinética ao ser acelerado pelo campo [105]. De modo geral, chamamos aos estados ocupados de banda de valência e os estados livres acessíveis de banda de condução. A promoção de elétrons de uma banda à outra ocorre por efeitos térmicos (mesmo à temperatura ambiente) ou por excitação externa (por radiação, por exemplo), desde que, em qualquer dos casos, ocorra uma transferência de energia superior à largura da banda proibida, além da transferência de momento, dependendo do material semicondutor. Defeitos cristalinos quebram a periodicidade do potencial e levam à formação de estados localizados, com poucos níveis de energia, permitidos dentro da banda proibida. Podemos chamar estes estados de "estados-armadilha", pois armadilham elétrons na banda proibida.

Ao ocorrer a promoção de um elétron da banda de valência à banda de condução, 
existe um estado vazio na banda de valência, permitindo que esta também possa conduzir elétrons. Esta "lacuna"comporta-se na presença de um campo elétrico como uma carga positiva de mesmo módulo que a carga do elétron, podendo ser considerada, assim como o elétron, um portador de carga.

O silício e o germânio são chamados de semicondutores intrínsecos: o número de portadores de carga a uma dada temperatura é muito baixo, sendo a distribuição de ocupação dos estados dada pela função de distribuição de Fermi-Dirac (Equação 8.1). O aumento da concentração de portadores é feito por meio da adição (por crescimento epitaxial, difusão térmica ou implantação iônica) de elementos dopantes, que são solubilizados de forma substitucional na rede cristalina do silício. Caso seja adicionado um elemento da família IIIA (boro, alumínio, índio, etc), que possui um elétron a menos que o silício na camada de valência, haverá uma ligação covalente incompleta na rede, e, portanto, uma lacuna extra. Tal geração de um portador positivo faz com que este semicondutor seja chamado de material tipo p. A inserção de um elemento da família VA (fósforo, astato, antimônio, etc), também de forma substitucional, adiciona um elétron extra à rede, que, por não ocupar nenhum estado possível na banda de valência, é promovido à banda de condução. A concentração elevada de portadores negativos faz com que este semicondutor seja chamado de material tipo $\mathbf{n}$. A adição de dopantes altera a posição do nível de Fermi do semicondutor, aumentando a presença de portadores de carga a uma dada temperatura [105],

$$
f(E)=\frac{1}{1+e^{\left(E-E_{F}\right) / k T}}
$$

onde $f(E)$ é a fração de portadores, $E_{F}$ representa a energia do nível de Fermi, $k$ é a constante de Boltzmann e $T$ é a temperatura (em kelvin).

Os portadores de carga movem-se através do material semicondutor por meio das ações de difusão e de deriva. Na difusão, os portadores se movem da região no cristal 
com maior concentração para a de menor concentração, ação que ocorre exclusivamente devido a efeitos térmicos. A ação de deriva ocorre na presença de um campo elétrico, quando os elétrons e lacunas movem-se em direções contrárias. As velocidades de deriva dos elétrons e lacunas dependem de suas mobilidades e do campo elétrico, variando com o campo até um valor máximo [105]. A densidade de corrente $\vec{J}$ no dispositivo é dada pela soma das contribuições de deriva e difusão para elétrons e lacunas, da seguinte forma (Equação 8.2) [106]:

$$
\begin{gathered}
\overrightarrow{J_{n}}=e \mu_{n} n \vec{\varepsilon}+e D_{n} \nabla n \\
\overrightarrow{J_{p}}=e \mu_{p} p \vec{\varepsilon}-e D_{p} \nabla p \\
\vec{J}=\overrightarrow{J_{n}}+\overrightarrow{J_{p}}
\end{gathered}
$$

onde $\mu_{n, p}$ representa a mobilidade dos portadores negativos e positivos, $n, p$ as concentrações dos portadores, $D_{n, p}$ os coeficientes de difusão dos portadores no material, $\nabla(n, p)$ os gradientes de concentração dos portadores e $\vec{\varepsilon}$ o campo elétrico. A mobilidade dos elétrons em silício com baixa dopagem e a $300 \mathrm{~K}$ é de $1500 \mathrm{~cm}^{2} / \mathrm{Vs}$ e das lacunas nas mesmas condições é de $450 \mathrm{~cm}^{2} / \mathrm{Vs}$.

A existência de elétrons na banda de condução e lacunas na banda de valência não é um processo estático: a geração de portadores pode ocorrer por meio de processos que transfiram aos elétrons da banda de valência energia e momento suficientes para sua promoção à banda de condução, tais como: processos térmicos, efeito fotoelétrico (princípio dos detectores semicondutores do tipo $\mathrm{Si}(\mathrm{Li})$ e GeHP), deposição de energia por partículas carregadas (princípio dos detectores semicondutores do tipo barreira de superfície) [32, 44], entre outros. Na presença de um campo elétrico, pode ocorrer a multiplicação de portadores, se a energia adquirida por estes for suficiente para a criação de novos pares. A recombinação de portadores pode ocorrer por meio da transição direta entre as bandas no caso de semicondutores como o GaAs, ou por meio de transição indireta através dos estados-armadilha na banda proibida para semicondutores como 
o silício, pela necessidade da transferência de momento adicionalmente à de energia. Quanto maior a taxa de recombinação de portadores, menor o tempo de vida médio de um portador minoritário, e o tempo de vida necessário depende das aplicações e deve ser especificado no projeto de um dispositivo semicondutor, através da especificação de impurezas geradoras de armadilhas [44, 105].

\subsubsection{Estruturas de Dispositivos Semicondutores}

De modo geral, dispositivos semicondutores são construídos através de combinações entre materiais tipo p, tipo n, metais e isolantes. Os processos de fabricação envolvem etapas químicas e de fotolitografia [105]. A junção mais simples é a junção p-n (diodo), em que um material tipo p e um tipo n são justapostos, como ilustrado na Figura 8.2. Tal configuração cria uma região de depleção na junção, com a aniquilação de portadores e criação de um campo elétrico que compensa a ação da difusão (situação estática). Na presença de um campo elétrico na configuração de polarização direta, uma corrente passa através do dispositivo, corrente esta dependente da dopagem dos materiais p e n, e portanto, da concentração de portadores. Sob polarização inversa, a região de depleção é aumentada e nenhuma corrente se observará, porém caso ocorra a criação de portadores (por exemplo, por incidência de radiação), os portadores serão separados pelo campo elétrico e criarão um pico de voltagem até sua aniquilação pela fonte externa de campo [44]. Este tipo de junção forma os detectores do tipo barreira de superfície utilizados em física nuclear para detecção de partículas carregadas. As junções p-n também formam os transistores de junção bipolar, quando duas junções (npn ou pnp) são feitas em série e controla-se a corrente entre as pontas (fonte e dreno) aplicando-se tensão no material central (base).

A junção metal-semicondutor, além de fazer o contato elétrico do semicondutor com o meio externo, possui algumas propriedades semelhantes à junção p-n, com características retificadoras. Na junção metal-semicondutor, o nível de Fermi dos materiais 
se iguala na região da junção e aparece uma barreira de potencial que impede que os elétrons de um material migrem para o outro.

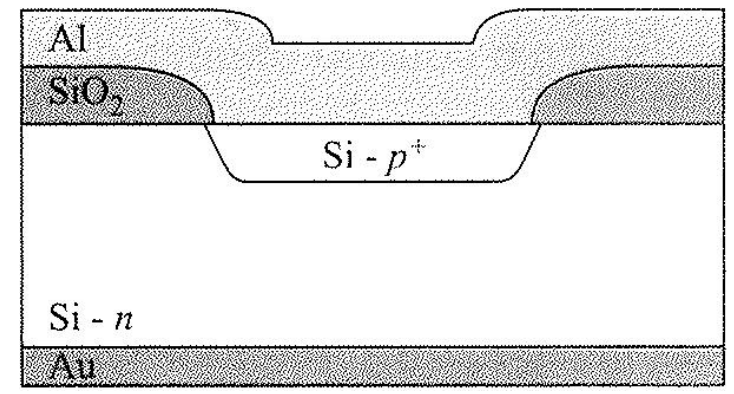

Figura 8.2: Representação esquemática de um diodo de junção p-n (reproduzido de [105])

A junção MOS (Metal-Oxide-Semiconductor) é provavelmente a mais importantes nos dispositivos modernos. A junção MOS caracteriza-se por um metal (Al, Au ou outro material condutor) sobre uma camada de óxido de silício (isolante), depositado sobre o silício. Esta junção é base do dispositivo MOSFET (Metal-Oxide-Semiconductor Field Effect Transistor) e das estruturas CMOS (Complementary MOS).

\section{MOSFET}

O transistor consiste num dispositivo em que uma tensão externa permite a modulação da corrente que passa através dele, como as antigas válvulas tríodo. Atualmente, o tipo de transistor mais comum são os do tipo MOSFET, os transistores de efeito de campo com junção metal-óxido-semicondutor.

Neste tipo de dispositivo, a junção MOS forma o terminal de porta (gate), localizado entre a fonte e o dreno do transistor. Ao aplicar uma tensão ao contato metálico da porta, o campo elétrico induzido no semicondutor propicia o acúmulo de portadores na região próximo à porta e entre a fonte e o dreno. O isolante (óxido de sílício, em geral) impede que haja transferência de cargas entre o semicondutor e o metal de porta. A partir de um certo valor de tensão, a concentração de portadores no silício torna-se alta 
o suficiente para que um campo elétrico estabelecido entre a fonte e o dreno possa fazer corrente fluir através do semicondutor [105]. A Figura 8.3 ilustra o esquema de um MOSFET, e a Figura 8.4 mostra uma fotografia de um transistor n-MOS. Na prática, a geometria das estruturas pode ser mais complicada de maneira a maximizar a eficiência do dispositivo.

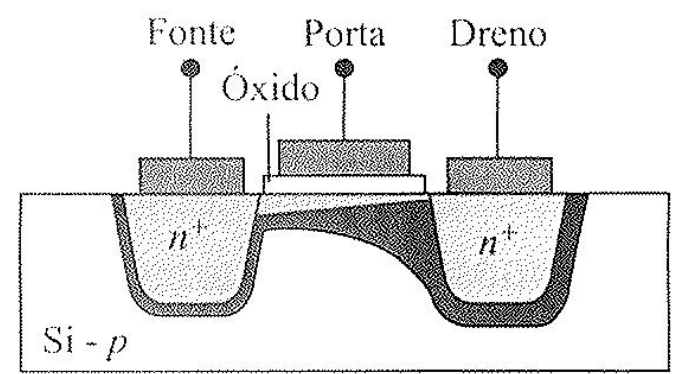

Figura 8.3: Representação esquemática de um MOSFET (reproduzido de [105])

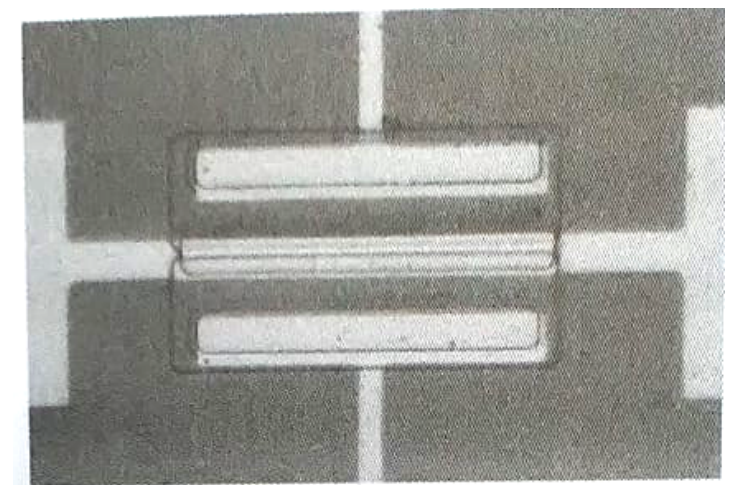

Figura 8.4: Fotografia de um n-MOSFET (reproduzido de [105])

O valor da corrente entre a fonte e o dreno dependerá tanto da tensão $V_{D}$ entre os pólos quanto da tensão $V_{P}$ de porta. Para uma dada tensão de porta, existe um valor de tensão fonte-dreno abaixo do qual a relação $I_{D} \times V_{D}$ é linear; a partir deste valor, a corrente é constante independente da tensão $V_{D}$, sendo chamada de corrente de saturação [106]. A Figura 8.5 ilustra curvas I-V para um n-MOSFET genérico. Quando o dispositivo opera na faixa linear, a injeção de portadores de carga através de radiação, 
por exemplo, é capaz de criar um pulso de corrente observável.

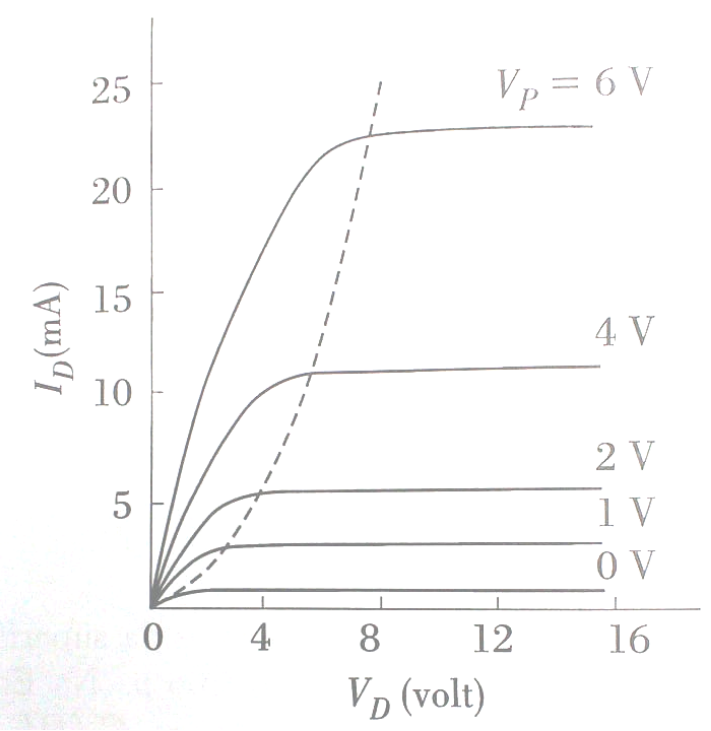

Figura 8.5: Curvas características de um n-MOSFET genérico (reproduzido de [106])

\section{CMOS e dispositivos digitais}

Dispositivos semicondutores individuais podem ser agrupados numa mesma pastilha de silício, formando estruturas com funções mais complexas. Entre tais estruturas, existem as estruturas CMOS (Complementary Metal-Oxide-Semicondutor), em que um transistor p-MOS é associado a um dispositivo n-MOS. A associação de diversos componentes permite a construção de portas lógicas, formando a base para dispositivos digitais, conforme ilustra a Figura 8.6. 


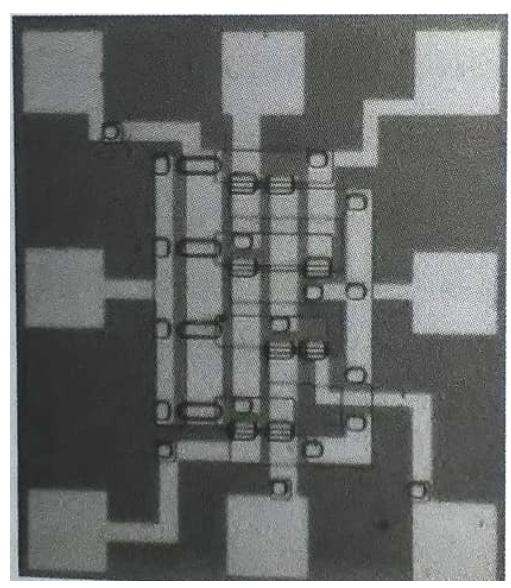

Figura 8.6: Fotografia de um circuito flip-flop (reproduzido de [105])

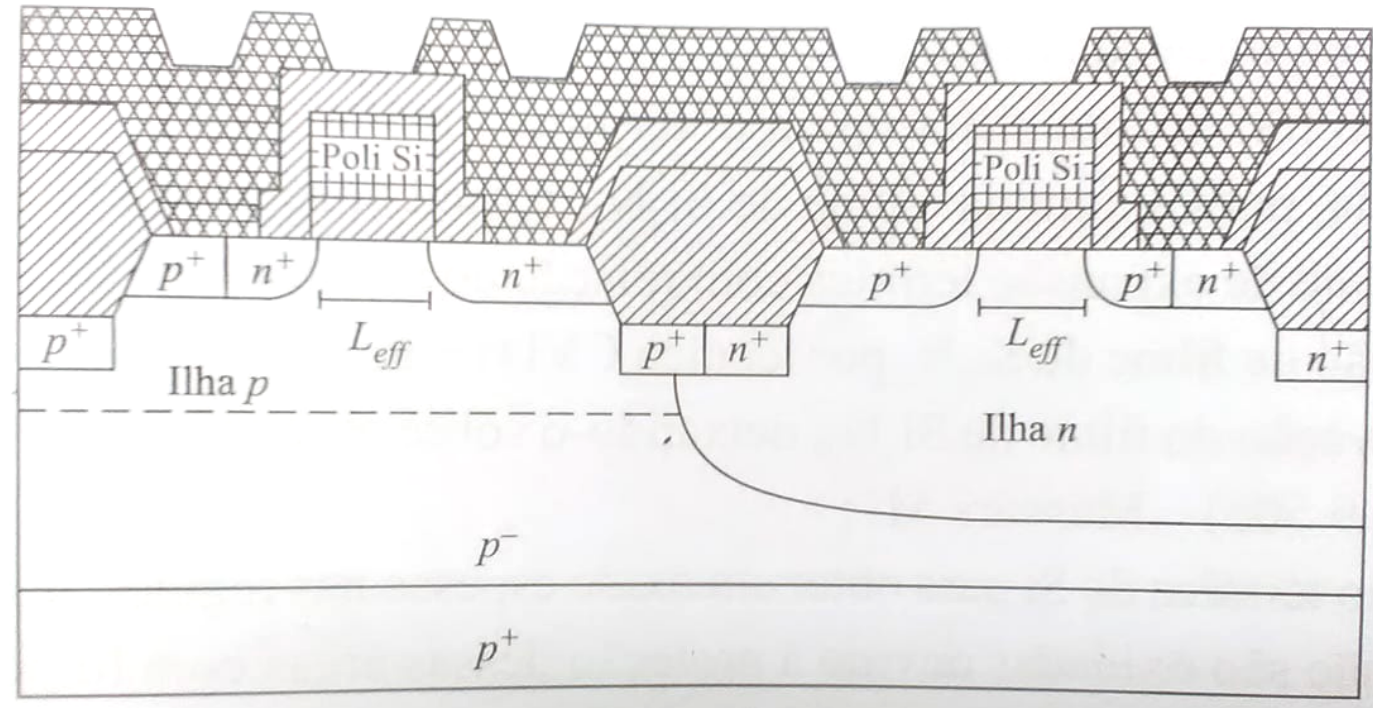

Figura 8.7: Desenho esquemático de uma estrutura CMOS (reproduzido de [105])

A combinação de diversos transistores num dispositivo exige do processo de fabricação o crescimento de diversas camadas de metalização e isolação de maneira a promover as ligações elétricas nos pólos dos componentes e isolação entre estes. As Figuras 8.7 a 8.11 ilustram as diversas camadas de material que podem existir entre a superfície exposta e a região entre a fonte e o dreno de cada transistor individual. A estas camadas dá-se o nome de Backend-of-Line - BEOL. 


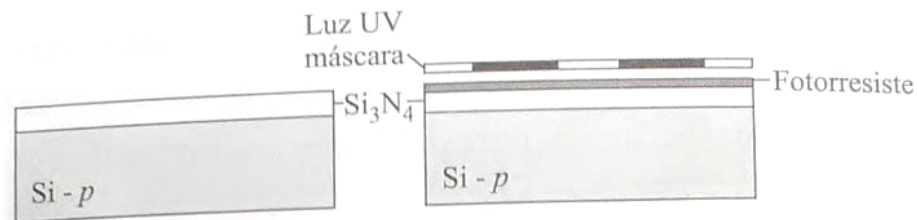

(a)

(b)

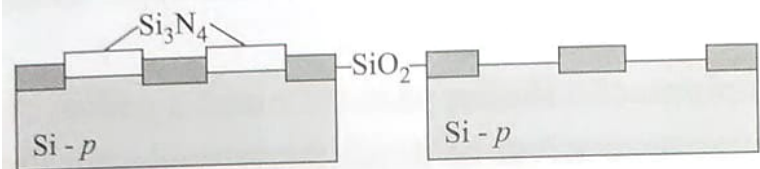

(c)

(d)

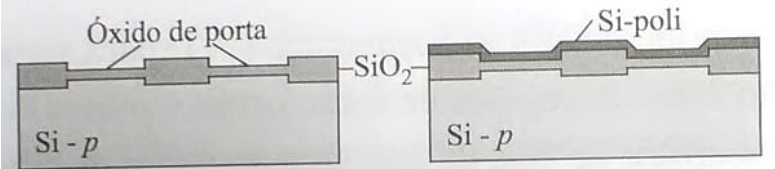

(e)

(f)

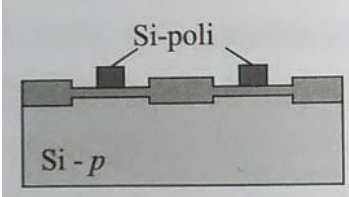

(g)

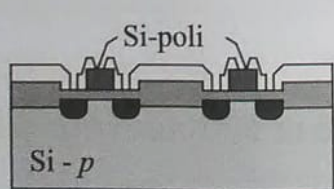

(i)

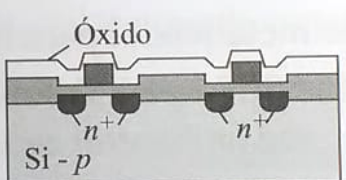

(h)

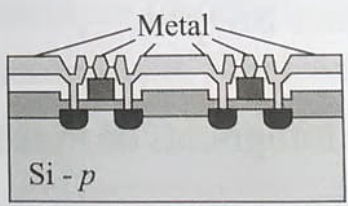

(j)

Figura 8.8: Ilustração da sequência de fabricação de uma estrutura nMOS (reproduzido de [105])

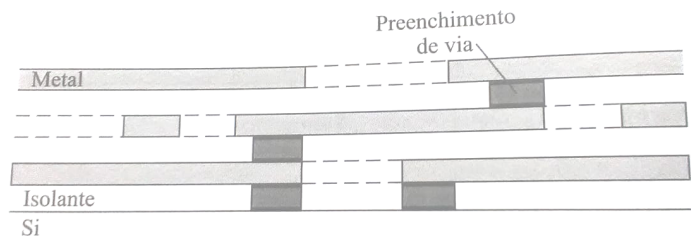

Figura 8.9: Ilustração esquemática de uma estrutura de três níveis de metalização (reproduzido de [105]) 


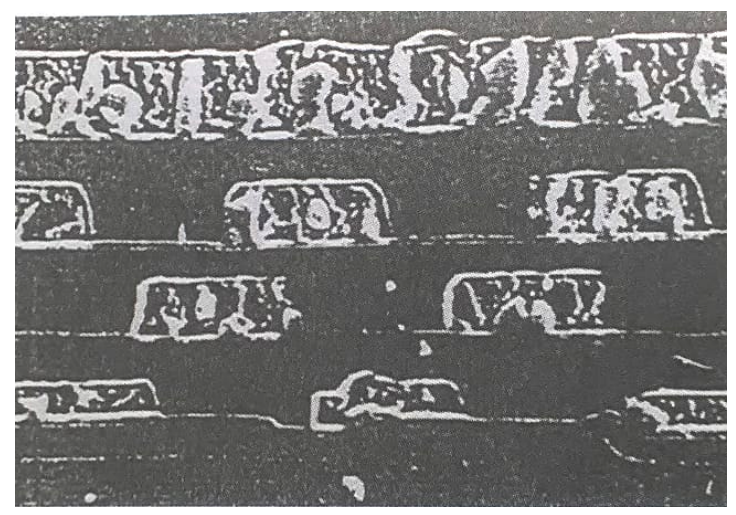

Figura 8.10: Eletromicrografia de uma seção transversal de uma estrutura com quatro níveis de metalização (reproduzido de [105])

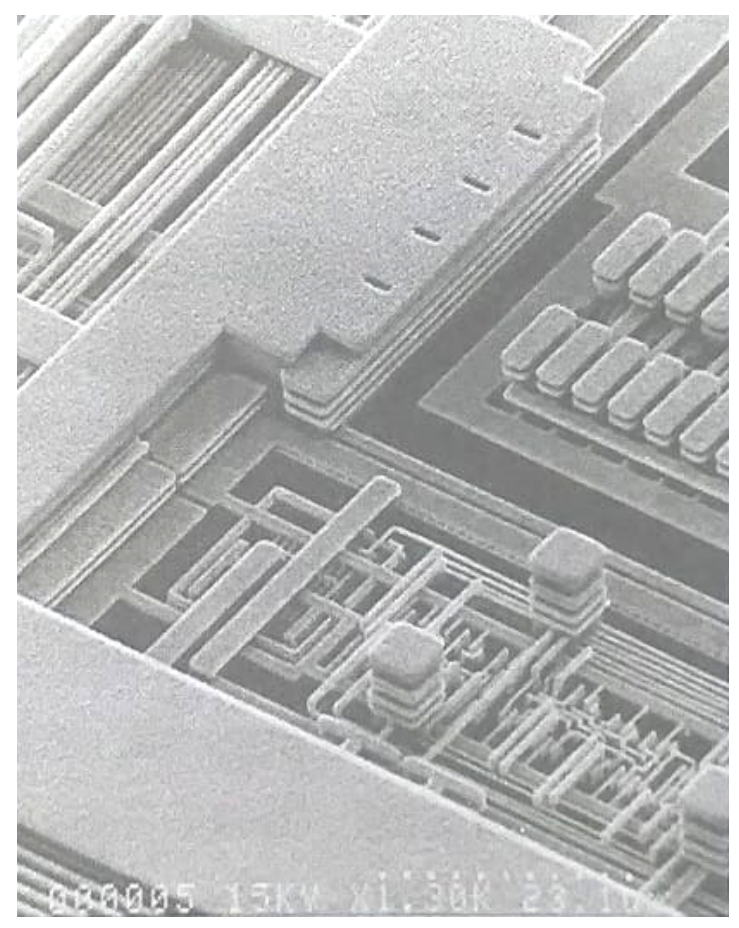

Figura 8.11: Eletromicrografia de uma estrutura com seis níveis de metalização, após corrosão seletiva do material isolante (reproduzido de [105])

Dentre as estruturas que podem ser construídas com a associação de transistores estão as memórias do tipo SRAM (Static Random Access Memory), um tipo de memória volátil, isto é, perde a informação armazenada ao ser desligada. Um bit de memória 
SRAM é composto geralmente por 6 transistores ${ }^{1}$, sendo que a informação binária ( 0 ou 1) encontra-se armazenada na associação de 4 deles e os outros dois bits são utilizados para leitura e escrita da memória. Alterações no estado um transistor na memória SRAM podem levar à alteração do valor armazenado naquele bit.

As memórias SRAM são largamente utilizadas na eletrônica atual pelo seu baixo consumo de energia e confiabilidade, seja como cache de memória em processadores ou em sistemas embarcados. Entre as aplicações das memórias SRAM estão os circuitos de FPGAs.

Field Programmable Gate Arrays (FPGAs) são hardwares lógicos configuráveis, isto é, um conjunto de transistores que podem ser associados de diferentes formas de modo a obter as combinações desejadas de portas lógicas. Essa característica de poder modificar a configuração do hardware permite que o desenvolvedor de sistemas faça testes e protótipos de aplicações, técnicas de correção de erros e confiabilidade, processamento, entre outras [107].

Entre as várias tecnologias de programação de FPGAs, a mais utilizada é aquela baseada em SRAM. Neste caso, associado a cada porta lógica há um bit de memória SRAM, cujo valor (0 ou 1) define se a ligação está ou não ativa. Desta maneira, podese configurar o FPGA carregando na memória SRAM de configuração (cRAM) uma sequência de bits (bitstream) que associe os valores desejados a cada porta lógica. Esta operação deve ser realizada sempre que o dispositivo for reiniciado. No caso de alguma alteração no valor de algum bit da cRAM, a funcionalidade do FPGA pode ser alterada [107].

\footnotetext{
${ }^{1}$ Também existem SRAMs com 4, 8 ou até 10 transistores por bit.
} 


\subsection{Efeitos de Radiação Ionizante em Dispositivos Eletrô- nicos}

Conforme descrito no Capítulo 1, a interação da radiação num meio material pode depositar uma certa quantidade de energia, que, dependendo do tipo de material, pode gerar ionizações no meio. No caso de um semicondutor, a energia depositada leva à criação de pares de portadores de carga, que, na presença de um campo elétrico, podem manifestar-se na forma de um pulso de corrente num terminal de medida. De fato, desde a década de 1950, percebeu-se que a radiação ionizante era uma importante causa de falhas em dispositivos semicondutores, e este fato despertou o interesse de empresas do ramo de tecnologia, como a IBM, a Intel e a Texas Instruments [1].

Na década de 1960 já se havia observado que a eletrônica embarcada em satélites não era imune a falhas, e diversos estudos foram feitos para determinar a influência da radiação cósmica sobre os dispositivos eletrônicos. Observou-se que tanto partículas provenientes do Sol quanto extra-galáticas (incluindo-se prótons, nêutrons, partículas alfa, partículas sub-nucleares e íons pesados, estes representando menos de 1\%) poderiam causar falhas nos dispositivos, fosse por via direta, fosse por meio de reações nucleares. Com o tempo, observou-se também que falhas ocorriam em dispositivos terrestres e embarcados em aviação comercial: tais efeitos eram devidos à contaminação por isótopos alfa-emissores no encapsulamento dos dispositivos [1, 3] e pela interação de raios cósmicos com a atmosfera terrestre, criando chuveiros de partículas que incluem prótons, nêutrons e até mesmo píons e múons [5, 108, 10, 2], todos eles capazes de gerar efeitos de radiação sobre dispositivos eletrônicos.

O constante desenvolvimento de novos materiais e tecnologias de fabricação de dispositivos, tornando os componentes básicos cada vez menores e em maior quantidade, faz com que o estudo dos efeitos de radiação em dispositivos eletrônicos não seja saturado, uma vez que determinadas tecnologias podem ser mais resistentes a alguns efeitos 
e mais suscetíveis a outros $[3,9]$. No caso de sistemas de baixo custo e/ou fácil manutenção, comumente se faz a troca do dispositivo que apresente erros induzidos por radiação; todavia, no caso de eletrônica embarcada em satélites, por exemplo, deve-se garantir um tempo de operação bastante longo sem falhas que venham a comprometer o sistema. Sistemas que exigem alta confiabilidade também devem ser projetados de maneira a minimizar a ocorrência de tais falhas.

Além do projeto de dispositivos com características específicas para utilização em ambientes de radiação, há um crescente interesse pela utilização de dispositivos comerciais padrão, os chamados COTS (Commercial-of-the-shelf), devido ao baixo custo e alta disponibilidade. No entanto, tais dispositivos necessitam de caracterização prévia sob radiação para determinar seu comportamento, e informações estruturais detalhadas sobre sua estrutura em geral não são disponibilizadas pelos fabricantes.

Os efeitos de radiação em dispositivos eletrônicos são separados em três classes principais: efeito de Dose Ionizante Total (TID), Dano por Deslocamento (DD) e Efeitos de Eventos Isolados (SEE).

\subsubsection{Dose Ionizante Total (Total Ionizing Dose - TID)}

Os efeitos oriundos de dose ionizante total no dispositivo podem ser causados por todas as formas de radiação ionizante, uma vez que todas são capazes de depositar energia no dispositivo. Por ser um efeito cumulativo, só é observável após uma determinada quantidade de radiação incidir sobre o dispositivo, sendo que, dependendo do tipo de radiação, este efeito pode aparecer combinado a outros. Para estudos isolados de TID, em geral são usados fótons de raios $\mathrm{X}$ e gama, elétrons ${ }^{2}$ e prótons, embora estes também sejam capazes de gerar as outras classes de efeitos.

Cargas geradas na região de depleção sofrem recombinação ou então são coletadas pelos terminais do dispositivo, porém nos casos em que a radiação interage numa re-

\footnotetext{
${ }^{2}$ Recentemente têm sido observados outros efeitos de radiação causados por elétrons, de modo que hoje não são mais considerados como apenas causadores de TID [109].
} 
gião isolante, como, por exemplo, o óxido de porta de dispositivos do tipo MOS, a reduzida mobilidade dos portadores nesse meio associado ao campo elétrico pode gerar um acúmulo de cargas.

O dióxido de silício utilizado em semicondutores é, em geral, amorfo, de modo que, na interface entre o óxido e o silício cristalino dopado da região ativa, o potencial interatômico periódico da rede é perturbado, levando à criação de armadilhas de potencial. Estas armadilhas podem tornar-se centro de acumulação de lacunas, uma vez que, sob a ação de um campo elétrico, as lacunas não conseguem se mover o suficiente para fora do óxido, pois sua mobilidade no dióxido de silício é ordens de grandeza menor que a dos elétrons [44]. Embora haja uma certa recombinação entre elétrons e lacunas, existe um acúmulo residual de cargas positivas armadilhadas no óxido de silício, em especial na região de interface. Este acúmulo pode ser parcialmente corrigido por um tratamento térmico (annealing), podendo este ser induzido ou não. A irradiação em um dispositivo em operação, ou seja, com um campo elétrico interno ao dióxido de silício potencializa o efeito.

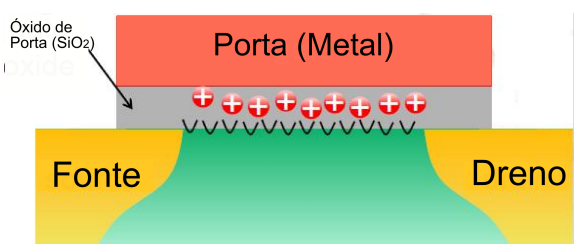

Figura 8.12: Armadilhamento de cargas positivas no óxido de porta (adaptada de [110].)

Os efeitos destas cargas armadilhadas são diversos, porém podemos sumarizá-los na degradação dos parâmetros elétricos dos dispositivos: diminuição da transcondutância, aumento das correntes de fuga por meio da criação de canais parasitas (ocasionando aumento da potência consumida), redução da tensão de breakdown, aumento do ruído rosa $^{3}$, mudanças na curva característica do dispositivo e mudança no valor de tensão

\footnotetext{
${ }^{3}$ ruído com intensidade que varia inversamente com a frequência, portanto dominante a baixas frequências, que é ocasionado pelas flutuações estatísticas das propriedades dos materiais
} 
de limiar (threshold) de transistores [93].

\subsubsection{Dano por Deslocamento (Displacement Damage - DD)}

Os danos por deslocamento são gerados pela componente não-ionizante da perda de energia (NIEL) por partículas como nêutrons, núcleos de recuo, íons pesados, prótons e elétrons de alta energia [15]. Colisões atômicas não-ionizantes levam ao deslocamento de átomos da rede, podendo criar diversos defeitos cristalinos, tais como vacâncias, pares de Frenkel, deslocamento para posições intersticiais, entre outros. A Figura 8.13 ilustra os defeitos cristalinos que caracterizam os danos por deslocamento [93]. Tais defeitos agem como regiões de acúmulo de carga devido ao efeito armadilha. Submeter o dispositivo a um aumento controlado de temperatura pode provocar o annealing (recozimento) do cristal, minizando os efeitos indesejáveis ${ }^{4}$.

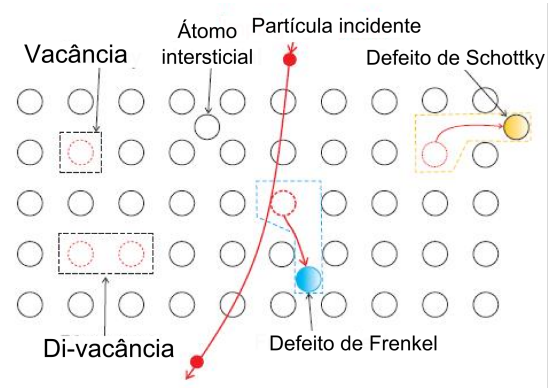

Figura 8.13: Ilustrações dos defeitos cristalinos causados pela incidência de radiação (adaptada de [93])

Os danos por deslocamento afetam principalmente transistores de junção bipolar e dispositivos como CCDs e detectores de germânio hiperpuro utilizados em física nuclear. Dispositivos do tipo MOS são pouco afetados por danos por deslocamento.

Os estudos de efeitos de danos por deslocamento podem ser realizados com feixes de íons pesados e, mais comumente, utilizando fontes de nêutrons como geradores D-T,

\footnotetext{
${ }^{4}$ Embora possa ocorrer recuperação a temperatura ambiente, esta é desprezível.
} 
reatores de fissão e instalações de spallation $^{5}$.

\subsubsection{Efeitos por Eventos Isolados (Single Event Effects - SEE)}

São chamados de Efeitos por Eventos Isolados (Single Event Effects) os efeitos em dispositivos eletrônicos causados pela incidência de uma única partícula ionizante, desde que esta partícula seja capaz de gerar uma quantidade de pares elétron-lacuna suficientemente grande para causar perturbações no circuito em operação. Durante muito tempo, foram consideradas partículas causadoras de SEE os íons pesados, desde partículas alfa $[3,5]$ até os elementos transurânicos, assim como os múons e píons $[5,10]$ e os produtos de reações e processos de espalhamento, que podem envolver nêutrons, prótons e partículas sub-nucleares $[4,5,10,11]$. À medida que a quantidade de carga necessária para desencadear um SEE foi diminuindo devido à diminuição dos componentes básicos de um dispositivo, observou-se que prótons e elétrons também podem gerar efeitos de eventos isolados por meio de ionização direta [12, 13, 41, 109].

Os ensaios para verificação de SEE podem ser conduzidos com nêutrons [11] (que provocam SEE por via indireta), lasers [12], aceleradores de prótons, elétrons e íons pesados $[1,10,12]$ e fontes radioativas alfa-emissoras ou fissionáveis, que ionizam o material pelos processos apresentados no Capítulo 1. Os experimentos com laser baseiam-se na formação de uma quantidade de pares elétron-lacuna no semicondutor semelhante à gerada na passagem de um íon pesado pela camada ativa do dispositivo. Para tanto, necessita-se de um laser de pulso ultracurto, com luminosidade da ordem de $10^{15} \mathrm{~W} / \mathrm{cm}^{2}$ e comprimento de onda adequado. Os experimentos com laser emulam os resultados de íons pesados de uma forma mais simples e barata, além de permitir a varredura de área em busca de regiões sensíveis de forma mais econômica que um microfeixe iônico. Todavia, o tamanho do spot é muito maior do que o traço de ionização de um íon pesado,

\footnotetext{
${ }^{5}$ spallation é a produção de nêutrons de alta energia por meio do espalhamento inelástico de prótons de alta energia em alvos pesados.
} 
não correspondendo, portanto, exatamente ao mesmo fenômeno [12]. Neste trabalho, daremos destaque às interações de íons pesados.

Podemos dividir os Efeitos de Eventos Isolados (SEE) em duas classes: não-destrutivos, que geram interferências ou falhas momentâneas que podem ser corrigidas com a reinicialização do sistema ou do ciclo, e destrutivos, que tornam o dispositivo inoperante de forma definitiva [93].

\section{SEE Não-Destrutivos}

- Single Event Upset - SEU: a geração de carga produz picos de corrente/tensão que afetam a lógica (on/off) do dispositivo. Em geral, esses efeitos podem ser resumidos como a transformação de um bit de 0 para 1 ou vice-versa. Tais efeitos afetam principalmente dispositivos digitais. No caso de dispositivos digitais afetados em vários bits, este efeito é chamado de Multiple Bit Upset - MBU;

- Single Event Transient - SET: um efeito transiente (pulsos de voltagem/corrente) que se propaga através de todo o circuito, podendo ocasionar diversos SEU. Sua correção é complexa, uma vez que o efeito transiente gerado no dispositivo pode ser detectado apenas em outro ponto do circuito. Novas tecnologias são mais suscetíveis a SET, pois a carga crítica é menor.

- Single Event Functional Interrupt - SEFI: sub-classe de SEU relacionada à dispositivos digitais de alta densidade como FPGAs, pois a radiação pode afetar o sistema lógico do componente.

\section{SEE Destrutivos}

- Single Event Latch-Up - SEL: um tiristor ${ }^{6}$ parasita é ativado em circuitos CMOS por uma partícula de alto LET, causando uma espécie de "curto-circuito", gerando alto fluxo de corrente e sobreaquecimento que podem destruir o dispositivo. Como

\footnotetext{
${ }^{6}$ tiristores são dispositivos semicondutores multicamadas que operam em regime de chaveamento e são compostos por, no mínimo, três junções semicondutoras.
} 
o tiristor parasita é ativado nas camadas profundas (abaixo dos canais fonte e dreno), é importante que a partícula seja capaz de depositar energia nesta região.

- Single Event Burn-out - SEB: dispositivos de potência em estado desligado podem ser ativados por uma partícula capaz de gerar carga suficiente para queimar o dispositivo.

- Single Event Gate Rupture - SEGR: afeta principalmente dispositivos de potência do tipo MOS. A coleção de cargas na interface $\mathrm{Si} / \mathrm{Si}_{2}$ quebra sua rigidez dielétrica, aumentando o campo na porta e levando a uma condição de alta corrente capaz de queimar o dispositivo.

Com a diminuição e adensamento dos dispositivos numa mesma pastilha, a tolerância a SEE vem diminuindo, uma vez que as capacitâncias envolvidas e a quantidade de carga necessária para mudanças de estado são menores, acarretando que partículas incapazes de gerar efeitos em dispositivos de 30 anos atrás, hoje sejam motivo de preocupação [10, 109].

\section{Coleção de carga}

Ao penetrar num dispositivo semicondutor, um íon pesado irá depositar energia pelos processos já descritos no Capítulo 1, sendo comum estudar os SEE a partir da quantidade de energia depositada pela partículas por unidade de comprimento ao longo da trajetória, isto é, o LET da partícula. Em silício, uma partícula com LET de 1 $\mathrm{MeV} / \mu \mathrm{m}$ irá criar $2,8 \times 10^{5}$ pares elétron-lacuna por $\mu \mathrm{m}$, o que corresponde a uma densidade de carga de $\pm 44,5 \mathrm{fC} / \mu \mathrm{m}$. Evidentemente, partículas com LET maior irão gerar maior quantidade de pares ${ }^{7}$. Além da ionização primária, causada pelo íon incidente, existe ainda uma cascata de ionizações secundárias causadas pelos elétrons da ionização primária com energia suficiente para provocar outras ionizações. Esta estrutura é cha-

\footnotetext{
${ }^{7} \mathrm{LET}$ no valor de $97 \mathrm{MeV} / \mathrm{mg} / \mathrm{cm}^{2}$ corresponde a uma densidade de carga de $1 \mathrm{pC} / \mu \mathrm{m}$
} 
mada de traço de ionização da partícula e, em materiais semicondutores como o silício, possui duração da ordem de picossegundos [111, 112]. Nesta região, a alta concentração de pares elétron-lacuna, muito acima da dopagem típica em semicondutores, apresenta um comportamento coletivo que modifica o campo elétrico externo, e que chamamos de plasma elétron-lacuna (electron-hole plasma - EHP). A estrutura desta região do traço, que expande-se radialmente no tempo através da difusão ambipolar e cuja densidade longitudinal de portadores depende do LET local da partícula incidente [111, 112, 113], modifica o campo elétrico e influencia a coleta de carga pelo dispositivo.

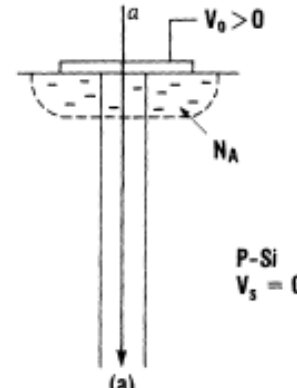

(a)

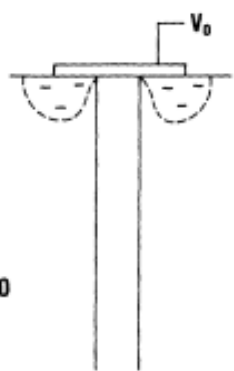

(b)

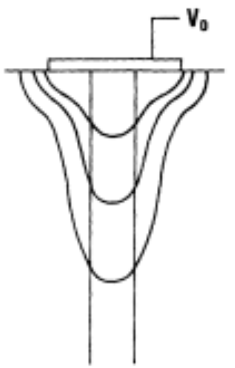

(c)

Figura 8.14: Processo de formação do funil de coleta de carga. (a) Passagem de uma partícula alfa através de uma junção np. A região hachurada representa a região de depleção, com concentração de aceitadores $N_{A}$. (b) Camada de depleção sendo neutralizada pela coluna de plasma. (c) Linhas equipotenciais estendem-se da região de depleção original para o traço de ionização (reproduzido de [111]).

Na ausência de campo elétrico, apenas os fenômenos de difusão e recombinação ocorrem entre os elétrons e lacunas, de modo que qualquer sinal de pulso de corrente num sistema de diagnóstico seria devido à difusão de portadores. Num dispositivo operacional, isto é, no qual existe um campo elétrico na região de depleção, ocorre a separação dos elétrons e lacunas nesta região e coleção das cargas de acordo com as relações 8.2. No caso em que a partícula incidente possui um alcance dentro do material maior que a espessura da camada de depleção, o EHP altera a distribuição de portadores minoritários na camada de depleção, causando sua neutralização (colapso). 
O campo elétrico aplicado, por sua vez, estende-se pelo centro da coluna de ionização, que ainda preserva uma quase neutralidade de carga. O campo elétrico que penetra ao longo do traço de ionização é então responsável pela separação entre elétrons e lacunas ao longo deste, transportando as cargas da região inicialmente neutra para a região de depleção $[12,111,114]$. A Figura 8.14 ilustra os processos envolvidos neste efeito, ao qual se dá o nome de "funil", a Figura 8.15 ilustra o comportamento elétrico do meio e a Figura 8.16 ilustra os três processos de coleta de carga.
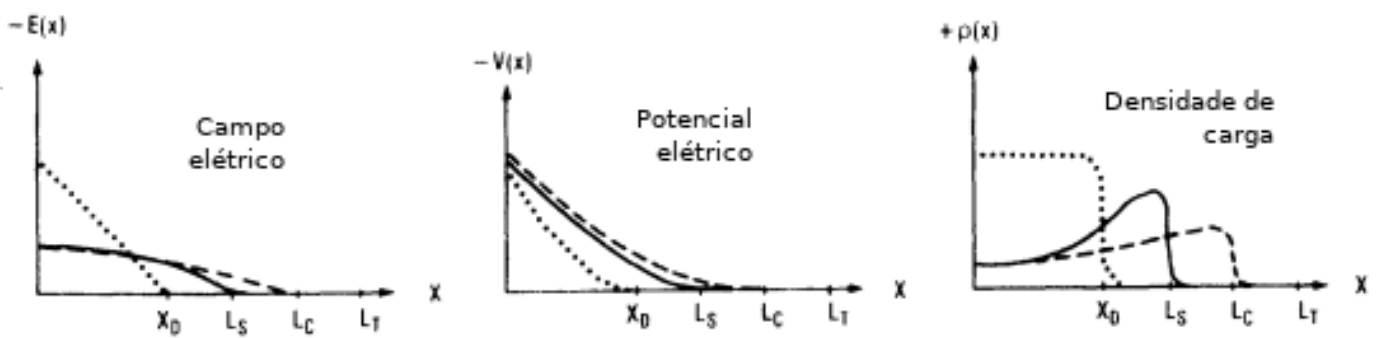

Figura 8.15: Comportamento dos parâmetros elétricos na presença do funil, sendo que a linha pontilhada representa a variação dos parâmetros antes da interação da partícula carregada, a linha tracejada a ocorrência de funil desconsiderando o efeito de blindagem do plasma (que impede o funil de estender-se até o fim do traço de ionização) e a linha cheia representa o funil considerando a blindagem. $X_{D}, L_{S}, L_{C}$ e $L_{T}$ são, respectivamente, o comprimento de depleção, o comprimento de coleção de carga (com blindagem), o comprimento de coleção de carga (sem blindagem) e o comprimento do traço de ionização. (adaptada de [115]).

Na situação da ocorrência do funil, não necessariamente toda a carga do traço de ionização é coletada, pois o campo elétrico irá atuar apenas durante a existência do EHP, que deixa de existir quando a concentração de portadores na região de depleção é tal que esta se reestabelece nas condições antes da interação [111]. Quando o funil não mais existe, os pares restantes irão se difundir pelo semicondutor [108, 10, 12]. O pulso de corrente no semicondutor é então formado pela soma das contribuições direta, através do funnelling e por meio da difusão. A Figura 8.17 ilustra a forma do pulso, que é afetada pelo dispositivo considerado e pela quantidade de áreas sensíveis 
independentes existentes no dispositivo [116].

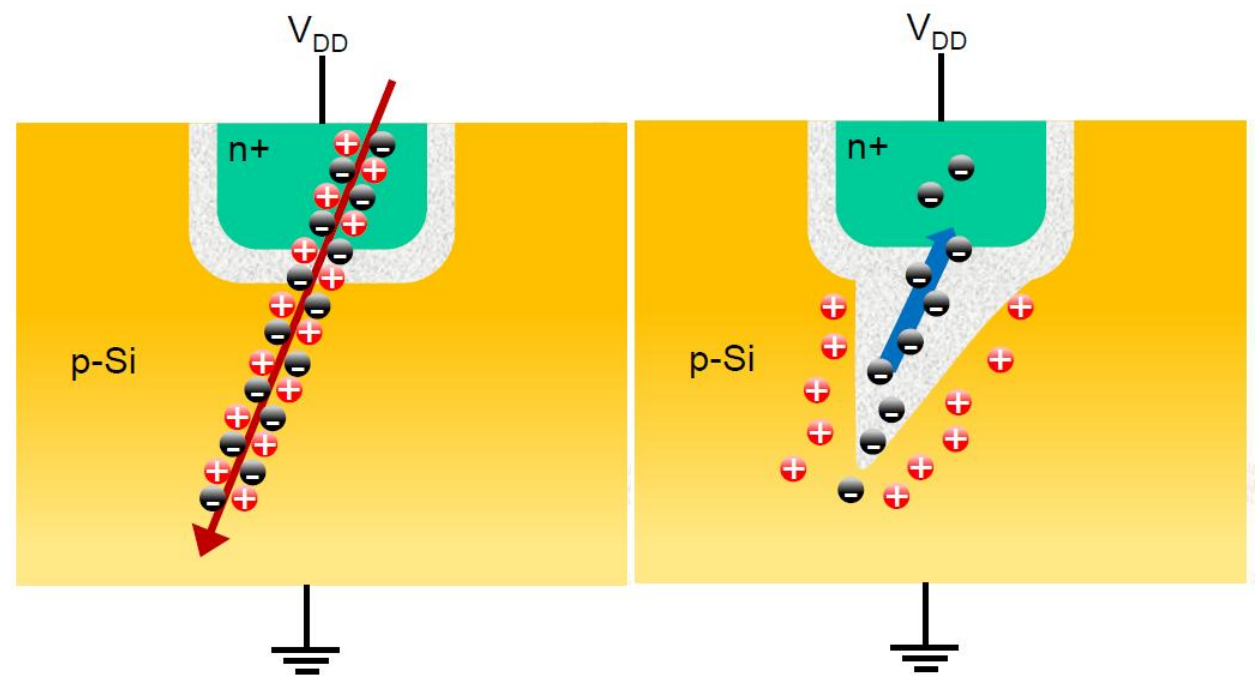

(a) Deriva

(b) Funil

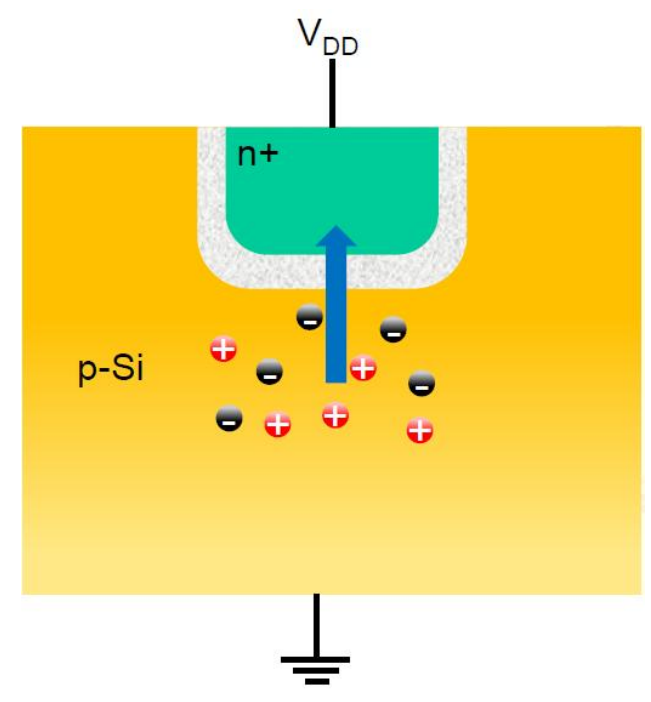

(c) Difusão

Figura 8.16: Ilustrações dos efeitos provocados pela passagem de um íon em um transistor. (a)Ionizações na passagem do íon. (b)Efeito-funil que permite maior coleção de carga. (c) Difusão do excesso de portadores restante. (Figuras adaptadas de [110]) 


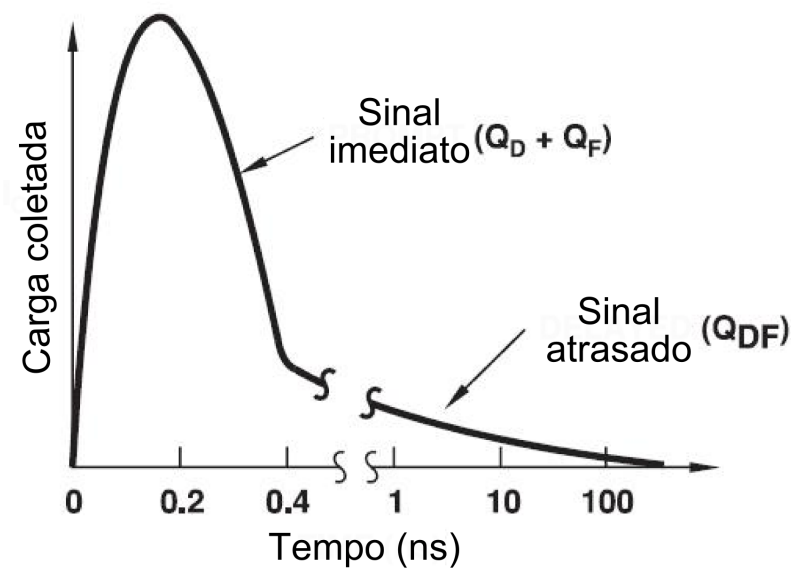

Figura 8.17: Forma do pulso gerado por um Efeito de Evento Isolado (SEE) (Figura adaptada de [108]).

A descrição completa de todos os fenômenos envolvidos é bastante complexa e depende do perfil de dopagem e estrutura do dispositivo, LET da partícula incidente em função da energia em cada ponto da trajetória, ângulo e posição de incidência e da resolução das equações de Poisson e de continuidade resultantes em função do tempo. Este cálculo é bastante complexo e além do escopo deste trabalho, sendo necessária a utilização de softwares especializados. Todavia, definições sobre a coleta de carga e algumas descrições semi-empíricas serão úteis nos capítulos subsequentes. Para os objetivos deste trabalho, a descrição dos processos de deriva e funil são suficientes, de modo que o processo de coleta de carga por difusão não será detalhado, porém o leitor irá encontrar estas informações nos artigos referenciados.

Definimos a carga coletada pelos processos de deriva e funil como:

$$
Q_{c}=\frac{q}{w} \int_{x=0}^{L_{e f f}} \frac{d E(x)}{d x} d x=q \int_{x=0}^{L_{e f f}} \overline{N_{0}}(x) d x
$$

nas quais tem-se que $q$ é a carga elementar, $w$ é a energia necessária para a criação de um par elétron-lacuna, $L_{e f f}$ é o comprimento efetivo da região de coleta de cargas, ou seja, o comprimento do funil e da região de depleção ao longo da trajetória 
da partícula ${ }^{8}, \frac{d E(x)}{d x}$ é o poder de freamento da partícula no meio e $\overline{N_{0}}$ é a densidade de pares elétron-lacuna no $\operatorname{traço}^{9}[111,113,118]$. Dessa maneira, a carga coletada depende do comprimento do funil, para o qual não há expressão analítica [118], porém existem modelos semi-empíricos úteis, apesar de nem sempre equivalentes. Segundo $\mathrm{Hu}$ e colaboradores [118], pode-se expressar o comprimento do funil apenas em função de parâmetros do dispositivo, portanto independente da partícula incidente:

$$
L_{f}=\left(1+\frac{\mu_{n}}{\mu_{p}}\right) \frac{W_{D}}{\cos \theta}
$$

em que $\mu_{n}, \mu_{p}$ são, respectivamente, as mobilidades dos elétrons e lacunas, $W_{D}$ é o comprimento da região de depleção e $\theta$ é o ângulo de incidência da partícula. No modelo mais elaborado de Oldham et al. [111, 112, 118] (Equação 8.5), que leva em conta o tempo de duração do plasma de elétrons-lacunas $\tau_{C}$ (Equação 8.6), o comprimento do funil depende ainda da tensão de depleção $V_{0}$ aplicada, da densidade de portadores no início do traço de ionização $N_{0}$, da concentração de dopantes $N_{A}$, da velocidade média das lacunas $v_{P}$, da constante de difusão ambipolar $D^{10}$ e de um fator $K$ (ajustado a dados experimentais) que representa a blindagem do campo elétrico causada pelos pares elétron-lacuna, e possui especial importância ao analisar dados obtidos com íons de penetração no dispositivo inferior a 14 mathrm $\mu m$ [112]. Segundo [112], os valores de $D, K$ e $v_{P}$ para silício são, respectivamente $25 \mathrm{~cm}^{2} / \mathrm{s}, 1,3 \times 10^{-10} \mathrm{~cm} /$ par e $\frac{\mu_{n} V_{0}}{W_{D}}$. De acordo com este modelo, o comprimento efetivo de coleta de carga depende do alcance do íon incidente e também da natureza deste.

\footnotetext{
${ }^{8}$ Devido ao processo de formação do funil, considera-se o comprimento deste como o comprimento da região de coleção de carga, uma vez que a região de depleção sofre o colapso. Alguns autores [117] consideram como funil apenas a porção abaixo da depleção original

${ }^{9}$ Estas definições assumem que o LET é numericamente igual ao poder de freamento, o que não é necessariamente verdade, conforme o Capítulo 1.

${ }^{10}$ Difusão ambipolar refere-se à difusão simultânea dos portadores positivos e negativos.
} 


$$
\begin{gathered}
L_{f}=\sqrt{\mu_{n} V_{0} \exp \left(-K N_{0}\right)} \tau_{C}^{2 / 3}=\sqrt{\mu_{n} V_{0} \exp \left(-K N_{0}\right)}\left(\frac{3 N_{0}}{8 \pi N_{A} v_{P} \sqrt{D}}\right)^{1 / 3} \\
L_{f}=\left(\frac{3 N_{0}}{8 \pi N_{A} v_{P} \sqrt{D}}\right)^{3 / 2}
\end{gathered}
$$

Nenhum destes modelos apresentados leva em consideração a variação radial de densidade de portadores no traço de ionização, que deve ser incluída em modelos mais completos. Liu e colaboradores [113] modelaram a interação utilizando o código GEANT4 e demonstram quais as variações de LET no traço de ionização devem ser consideradas:

- Íons de alta energia (> 8.0 MeV/u) em dispositivos grandes ${ }^{11}$ : pode-se considerar o LET constante e igual ao superficial;

- Íons de alta energia (> 8.0 MeV/u) em dispositivos pequenos: deve-se considerar a variação radial do LET;

- Íons de baixa energia $(<0.3 \mathrm{MeV} / u)$ em dispositivos grandes: deve-se considerar a variação longitudinal do LET;

- Íons de baixa energia $(<0.3 \mathrm{MeV} / \mathrm{u})$ em dispositivos pequenos: deve-se considerar tanto a variação longitudinal quanto radial do LET;

Por último, define-se ainda a eficiência de coleta de carga $E C C$, que representa a fração da carga medida em relação à carga depositada. Como a eficiência de coleta de carga está intimamente ligada tanto ao comprimento real do funil e depleção quanto do alcance da partícula no meio, neste trabalho iremos assumir que toda a carga gerada no comprimento efetivo de coleta de carga é mensurável, ou seja, $E C C=1[119,120]$.

\footnotetext{
${ }^{11}$ Por "grande"e "pequeno"entende-se a dimensão típica (nó tecnológico) comparada ao raio do traço de ionização
} 


\section{Seções de Choque de SEE}

Dado que uma partícula deposite energia e leve à coleta de carga por um nó sensível do dispositivo, resta determinar se esta coleta de carga leva ou não a um evento observável e, caso positivo, com qual probabilidade.

A seção de choque de eventos representa a área efetiva de interação e pode ser compreendida como uma medida indireta da probabilidade de ocorrência de eventos. A seção de choque é calculada por:

$$
\sigma=\frac{\text { eventos }}{\Phi}
$$

onde $\Phi$ é a fluência do feixe acumulada durante o ensaio, em [partículas $\left./ \mathrm{cm}^{2}\right]$, o que faz com que a unidade de seção de choque seja uma unidade de área. No caso em que toda a área sensível apresente efeitos, tem-se a seção de choque de saturação, isto é, seu valor não aumenta, mesmo que aumente-se o LET incidente e, portanto, a carga depositada $[10,15]$.

Experimentos de caracterização de SEE em dispositivos normalmente são realizados para medir a seção de choque de eventos observados em função de parâmetros como LET incidente, tensão aplicada, ângulo de incidência, técnicas de mitigação empregadas, entre outros. A descrição do comportamento da seção de choque em função do parâmetro de ensaio permite comparar dispositivos diferentes a partir do mínimo de informações possível. Nos experimentos em que a seção de choque é medida em função do LET incidente, é usual obter como resultado uma distribuição de dados como mostrada na Figura 8.18, em que os dados seguem uma distribuição cumulativa de Weibull (Equação 8.8), onde $\sigma_{\text {sat }}$ é a seção de choque de saturação, $L E T_{t h}$ é o LET de limiar e W e s são parâmetros de ajuste $^{12}$.

\footnotetext{
${ }^{12}$ width e shape, descrevem a curvatura entre o limiar e a saturação.
} 


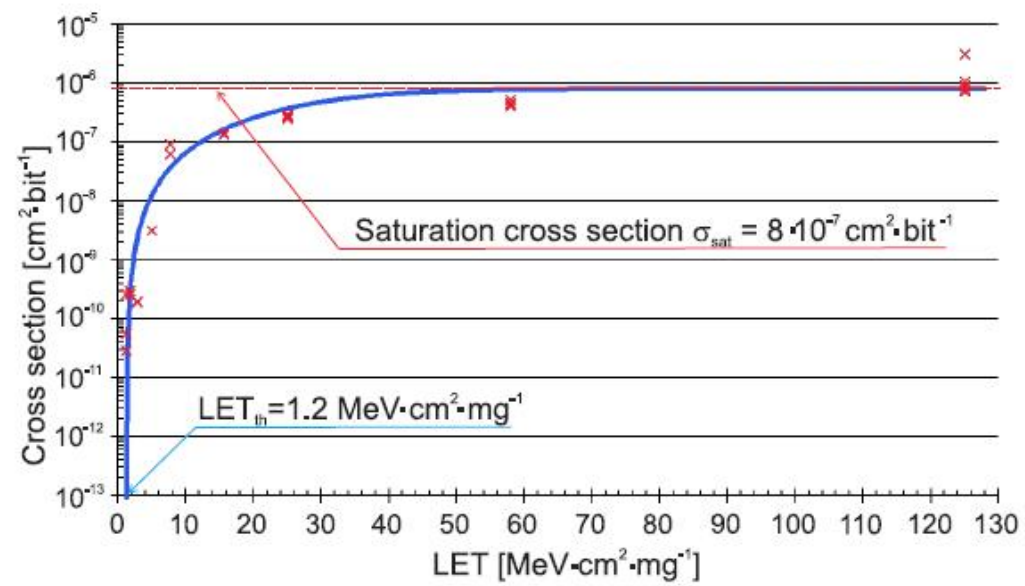

Figura 8.18: Exemplo de dados de seção de choque de SEE em função do LET incidente em um FPGA Xilinx Virtex VQVR300 e ajuste teórico (extraído de [93]).

$$
\sigma=\sigma_{s a t}\left[1-e^{-\left(\frac{L E T-L E T_{t h}}{W}\right)^{s}}\right]
$$

Alguns autores [121] criticam a modelagem em termos da distribuição cumulativa de Weibull, pois a seção de choque de saturação obtida a partir do ajuste pode não ser condizente com a realidade se não houver certeza de que os dados estendem-se até esta região. Além disso, a representação usual na comunidade é de que os dados de seção de choque sejam expostos em escala logarítmica e os valores de LET em escala linear, o que pode mascarar erros sistemáticos muito superiores aos erros estatísticos [121]. Valores incorretos de seção de choque de saturação influenciam o cálculo de taxa de falha em operação, sendo uma preocupação para a engenharia de projeto. Uma proposta alternativa à utilização da curva de Weibull é a distribuição acumulada lognormal, com escala linear no eixo da seção de choque e escala logarítmica no eixo do LET [121], mas que ainda não possui ampla utilização na comunidade.

Conforme apresentado, a deposição de energia é capaz de gerar um efeito observável apenas quando ocorre numa região em que a carga pode ser coletada; esta região é 
chamada de região sensível do dispositivo, cujo formato influencia em cálculos de taxa de erros para aplicações em que as partículas podem incidir em todas as direções [121, 117]. Dentre os modelos para a representação da região (ou volume) sensível, o modelo mais simples de larga utilização é o modelo RPP (Rectangular Paralellepiped), no qual a região sensível é considerada um paralelepípedo com área superficial igual à seção de choque de saturação e profundidade igual a região de depleção. Nesta aproximação, podemos considerar a camada sensível do dispositivo como um capacitor de placas paralelas, cuja capacitância C é dada em termos de suas dimensões e da permissividade do meio [10, 15, 108]:

$$
C=\frac{Q}{\Delta V}=\epsilon_{m} \cdot \frac{S}{d}=\epsilon_{m} \cdot \frac{x y}{d}
$$

na qual $Q$ é a carga coletada, $\Delta V$ é a diferença de potencial aplicada, $\epsilon_{m}$ é a permissividade elétrica do meio, $d$ a distância entre as placas (onde é aplicada a tensão) e $S$ a área das placas, que pode ser dada em termos dos lados $x$ e $y$, assumindo um capacitor de placas retangulares. A carga gerada pelo íon na região sensível do dispositivo é calculada pela conversão da energia depositada em pares elétron-lacuna, na relação de 0,01 pC gerado para cada $\mathrm{MeV}$ de energia depositada.

Por último, o LET de limiar ${ }^{13}$ (threshold $L E T$ - $L E T_{t h}$ ) representa o mínimo valor de LET capaz de gerar um evento observável ${ }^{14}$. Se o dispositivo fosse constituído completamente por células idênticas, todas apresentando a mesma sensibilidade e todos parâmetros de operação (campo elétrico, camada de depleção, etc) fossem idênticos e constantes para todas as células, a curva de seção de choque de SEE em função do LET seria dada por uma função degrau, saindo de zero e atingindo o valor de saturação com $L=L_{t h}$, em vez das distribuições observadas. Existem duas interpretações para este comportamento [117], ambas utilizadas em modelos complexos:

\footnotetext{
${ }^{13}$ Muitas vezes representado como carga de limiar.

${ }^{14}$ segundo a NASA, para um fluência de $10^{7}$ partículas $/ \mathrm{cm}^{2}$ [10].
} 
- Variações célula-a-célula (CC): o processo de fabricação é responsável por variações estatísticas nos parâmetros de cada célula de um componente, de maneira que, aumentando o LET, aumenta o número de células cujo limiar encontra-se abaixo do valor em questão;

- Produção, transporte e coleta de carga (PTC): todas as células podem ser consideradas iguais e o caráter estocástico da produção, transporte e coleta de carga é responsável pela variação na sensibilidade. Nesta interpretação, os valores de seção de choque observados podem ser entendidos como o produto da seção de choque de saturação pela probabilidade de uma partícula com dado LET gerar em evento observável.

Modelos mais adequados e considerando dispositivos mais complexos envolvem simulações de Monte Carlo e uma descrição detalhada da geração e tranporte de cargas e do volume sensível $[4,117,122,123,124,125]$. Dentre estes modelos, podemos citar o devido a Murat e colaboradores [126], em que detalhes da estrutura e evolução temporal do traço de ionização são levados em conta através de simulações de Monte Carlo, demonstrando inclusive a importância do straggling em energia e da camada de passivação/metalização nos efeitos observados.

Existem ainda modelos simplificados que consideram que toda a coleta de carga ocorre por difusão, ignorando os efeitos não-lineares como a combinação deriva-funil. Estas abordagens $[127,128]$ possuem a vantagem de incluir no modelo de seção de choque a carga depositada fora da região sensível real do dispositivo, que modelos que ignoram a difusão só contemplam por meio da suposição de um volume sensível irreal. Por não permitir calcular de maneira correta o pulso de corrente gerado num evento, estes modelos foram propostos para aplicação em dispositivos CMOS. Dentre estes modelos, um dos mais recentes e interessantes é o apresentado por Sogoyan e colaboradores [128], em que a curva de seção de choque é descrita por: 


$$
\sqrt{\sigma}=\frac{L}{\sqrt{\pi}} \frac{L E T}{L E T_{0}}
$$

em que $L$ e $L E T_{0}$ são os parâmetros ajustáveis do modelo e $L$ representa a distância efetiva entre duas células CMOS. Este modelo é limitado ao caso de tecnologias de poços profundos (espessura de dopagem).

Por depender do LET na região de coleta de cargas (volume sensível), fica claro que, em aceleradores de partículas em que a energia não é suficientemente alta, estes ensaios devem ser realizados levando em conta não apenas a variação do LET ao longo do volume sensível, mas também após o feixe incidente atravessar as diversas camadas de isolamento e de metalização presentes no dispositivo (BEOL). Os próximos capítulos serão dedicados ao estudo de dois casos de efeitos de eventos isolados em dispositivos eletrônicos, um analógico e um digital, utilizando o arranjo experimental descrito na Parte II e com base nos conceitos apresentados neste Capítulo e no Capítulo 1. 


\section{Capítulo 9}

\section{Um caso analógico}

Neste capítulo serão mostrados os procedimentos experimentais e de análise de dados para a obtenção de informação estrutural sobre um dispositivo analógico, no caso o transistor MOSFET tipo-p 3N163.

\subsection{MOSFET 3N163}

O dispositivo 3N163 é um transistor MOSFET tipo p de fabricação da Linear Integrated Systems [129], utilizado em aplicações de amplificação e chaveamento. Quando polarizado de maneira a operar na região linear, a resposta de corrente medida é proporcional à criação de portadores de carga na região sensível do dispositivo devido à interação de uma partícula carregada no meio. Esta característica permite a análise dos dados de maneira similar à conduzida com um detector do tipo barreira de superfície. É um dispositivo antigo, de grandes dimensões (comparado aos dispositivos eletrônicos modernos), de modo que podemos ignorar os efeitos do tamanho do traço de ionização e interações periféricas, consistindo num bom caso para o desenvolvimento de metodologia. 


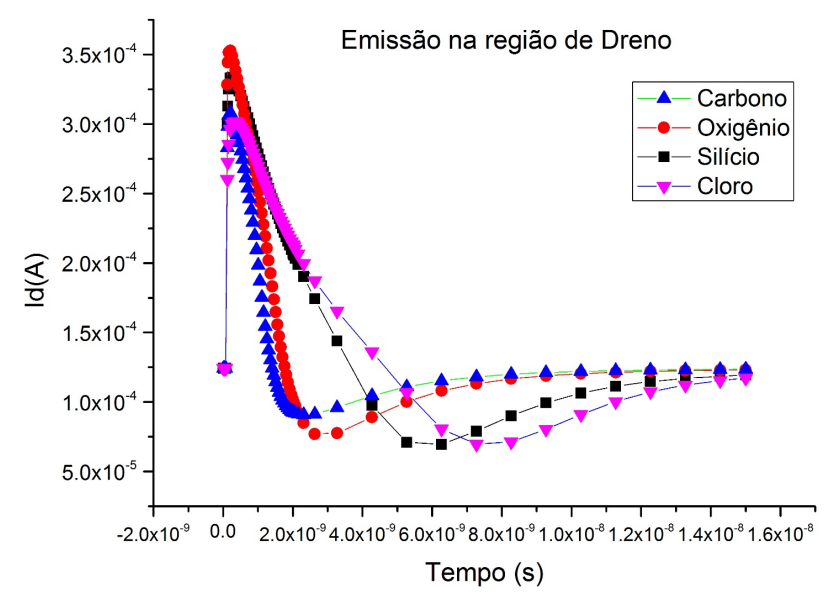

(a)

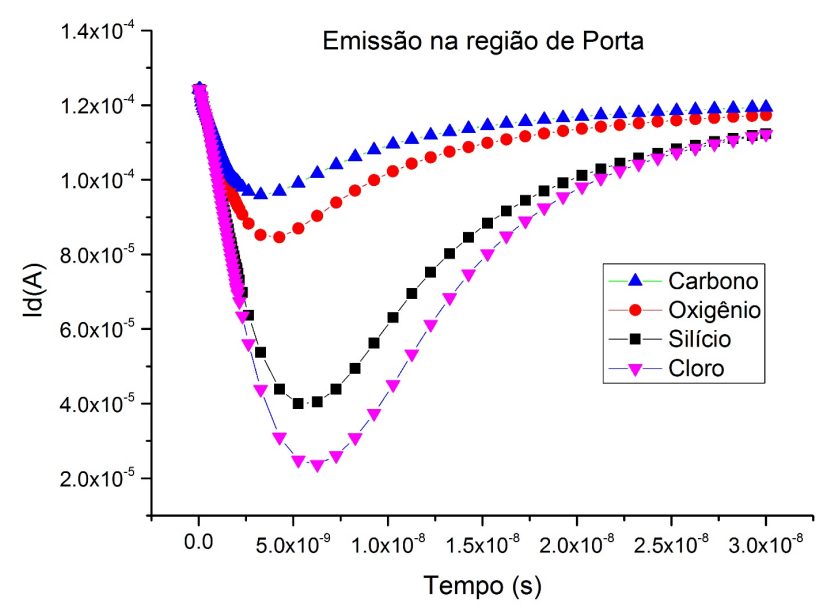

(b)

Figura 9.1: (a) Resumo das correntes $I_{D}$ 's ao longo do tempo para um conjunto de íons na região de dreno do dispositivo $3 \mathrm{~N} 163$.(b) Resumo das correntes $I_{D}$ 's ao longo do tempo para a um conjunto de íons na região de porta do dispositivo 3N163. (Reproduzido de [130])

Simulações realizadas pelo grupo de pesquisa em efeitos de radiação em dispositivos eletrônicos do Centro Universitário da FEI (UniFEI) em softwares especializados para análise de dispositivos semicondutores indicam a forma aproximada do pulso de corrente 
obtido a partir da interação de íons pesados com LET entre 2,6 e 17,1 MeV/mg/ $\mathrm{cm}^{2}$ nas regiões de porta e dreno do dispositivo (Figura 9.1), porém sem considerar a função resposta do sistema real de aquisição de dados utilizado nas medições[130].

Para a aquisição de dados, foi desenvolvida pelo grupo da UniFEI um circuito eletrônico usado em conjunto com o transistor 3N163, responsável por polarizar o DUT (Device Under Test) na região de operação linear. As cargas geradas por ionização são coletadas no terminal do transistor 3N163. Se esta carga for maior que a carga crítica (a qual provoca um pico de corrente/tensão), torna-se observável o evento induzido por radiação.

Neste circuito estão presentes bornes para alimentação de tensão (V+, V- e GND) utilizada na polarização do circuito; um conector BNC para acoplar o osciloscópio, o qual fará a leitura da corrente de dreno do dispositivo. Também estão disponíveis trimpots responsáveis por ajustar as tensões $V_{D}$ e $V_{P}$ do dispositivo. A Figura 9.2 mostra o esquema elétrico do circuito eletrônico e a Figura 9.3 mostra a placa com este circuito utilizada nos experimentos[130].

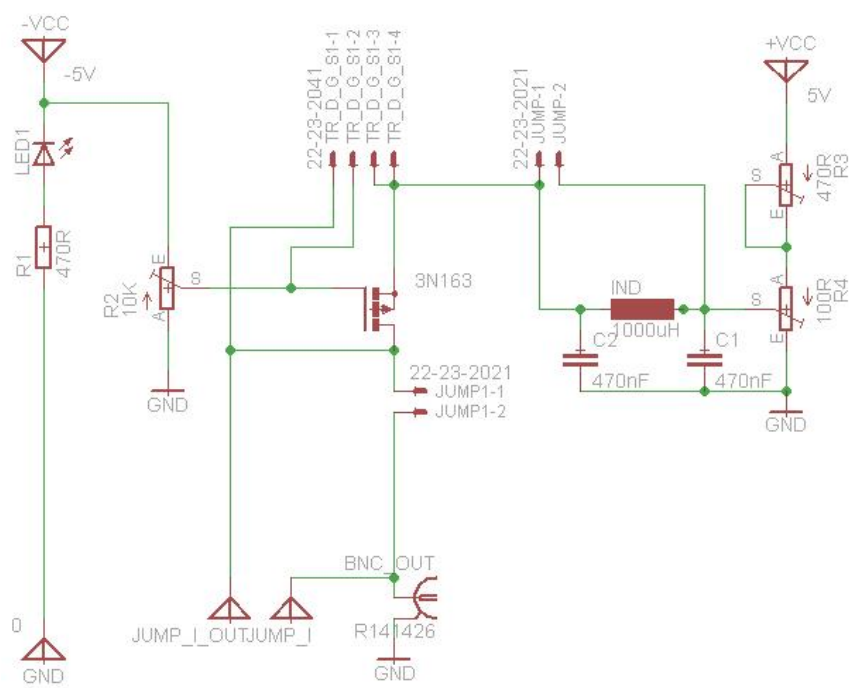

Figura 9.2: Esquema elétrico da placa Sensora de Eventos em transistor PMOS 3N163. (Reproduzido de [130]). 


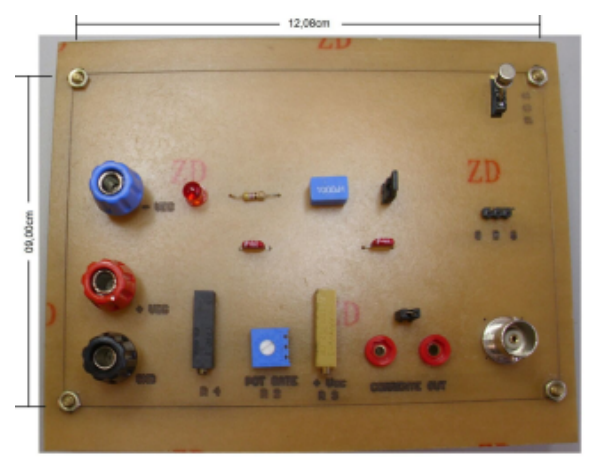

Figura 9.3: Vista da placa Sensora de Eventos para o transistor PMOS 3N163. (Reproduzido de [130])

\subsection{Ensaios com feixes de íons pesados no SAFIIRA}

A placa com o dispositivo sob teste foi montada num suporte porta-amostras, posicionado atrás do sistema manipulador de amostras. Neste manipulador foi montado um conjunto composto por um copo de Faraday e um detector barreira de superfície para medida da intensidade do feixe e calibração. O feixe foi espalhado através de duas folhas de ouro, sendo a primeira com espessura $307(31) \mu \mathrm{g} / \mathrm{cm}^{2}$, após a qual localizavase o detector de normalização, e a segunda de espessura $552(55) \mu \mathrm{g} / \mathrm{cm}^{2}$. O ajuste de foco do feixe foi feito de maneira a obter fluxo inferior a $3 \times 10^{5} \mathrm{part} / \mathrm{s} / \mathrm{cm}^{2}$.

Cada medida foi composta por uma rodada de calibração do fluxo de partículas e uma rodada de irradiação, buscando-se manter a incerteza final no número de eventos inferior a 5\%, exceto nos casos de baixíssima seção de choque, em que o tempo necessário seria proibitivo. No caso dos feixes mais pesados, a preocupação com o tempo de irradiação era aumentada devido ao desgaste prematuro das folhas de carbono do acelerador Pelletron [28].

A escolha dos feixes e energias foi feita de maneira a obter valores de LET numa faixa ampla $\left(\sim 2 \mathrm{MeV} / \mathrm{mg} / \mathrm{cm}^{2} \mathrm{a} \sim 45 \mathrm{MeV} / \mathrm{mg} / \mathrm{cm}^{2}\right)$, e ainda obtendo alguns feixes com LET quase uniforme numa penetração de cerca de $10 \mu \mathrm{m}$ em silício, e outros com 
grande variação de LET nesta faixa. Desta maneira, seria possível utilizar a relação LET x carga coletada como ferramenta para investigar a estrutura do dispositivo. A Figura 9.4 ilustra a variação do LET em função da penetração em silício para alguns dos feixes utilizados:
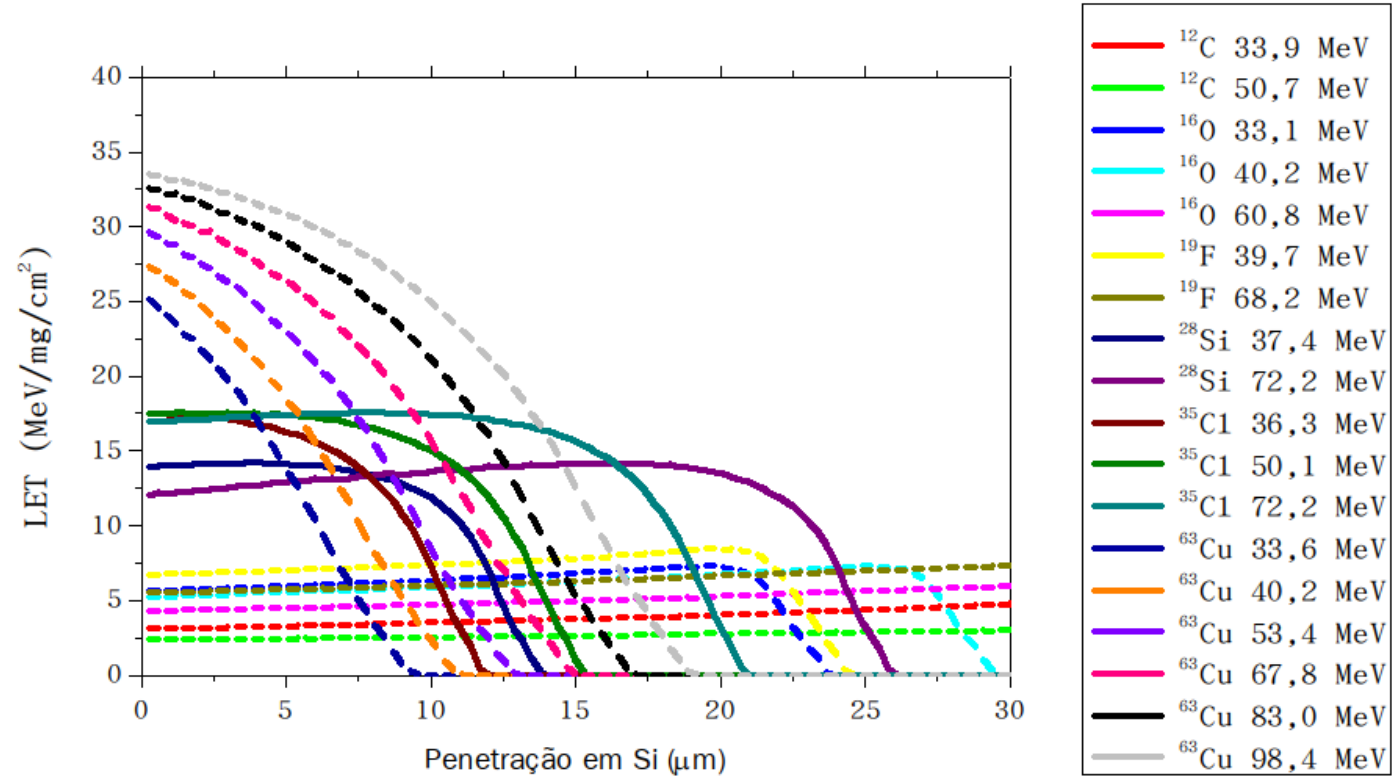

Figura 9.4: Variação do LET com a penetração em silício para alguns dos feixes utilizados.

A Tabela 9.1 apresenta os feixes utilizados nas irradiações do 3N163, a energia inicial e a energia efetiva após o espalhamento pelas duas folhas de ouro, o alcance e LET calculados para incidência em silício.

Os sinais dos pulsos de corrente do dispositivo foram adquiridos utilizando um osciloscópio RTO1012 da Rohde\&Schwarz com taxa de aquisição de 10GS/s e trigger digital. Os sinais foram posteriormente analisados utilizando ROOT. Para eliminar sinais de ruído que pudessem ativar o trigger do osciloscópio, o máximo de tensão dos sinais foi comparado com a média RMS do fundo ${ }^{1}$, devendo ser maior que duas vezes

\footnotetext{
${ }^{1}$ Ruído eletrônico que compõe as variações da linha de base do osciloscópio, fora da região do pulso de corrente.
} 
este valor para ser considerado um evento válido.

Tabela 9.1: Feixes iônicos e energias utilizados nas irradiações do 3N163, energia efetiva na superfície do dispositivo, alcance e valores de LET superficial calculados para silício.

\begin{tabular}{ccccc}
\hline $\begin{array}{c}\text { Feixe } \\
\text { Ionico }\end{array}$ & $\begin{array}{c}\text { Energia } \\
(\mathrm{MeV})\end{array}$ & $\begin{array}{c}\text { Energia Efetiva } \\
(\mathrm{MeV})\end{array}$ & $\begin{array}{c}\text { Alcance } \\
(\mu \mathrm{m})\end{array}$ & $\begin{array}{c}L E T_{\text {superficial }} \\
\left(\mathrm{MeV} / \mathrm{mg} / \mathrm{cm}^{2}\right)\end{array}$ \\
\hline${ }^{12} \mathrm{C}$ & $35 ; 52$ & 33,$9 ; 53,7$ & 38,$2 ; 72,4$ & 2,$9 ; 2,2$ \\
${ }^{16} \mathrm{O}$ & $35 ; 42 ; 62,5$ & 33,$1 ; 40,2 ; 60,8$ & 22,$6 ; 28,5 ; 48,2$ & 5,$4 ; 5,0 ; 4,1$ \\
${ }^{19} \mathrm{~F}$ & $42 ; 70$ & 39,$7 ; 68,2$ & 23,$2 ; 44,5$ & 6,$5 ; 5,4$ \\
${ }^{28} \mathrm{Si}$ & $42 ; 60 ; 78$ & 37,$4 ; 55,5 ; 72,2$ & 13,$0 ; 18,8 ; 19,7$ & 14,$0 ; 12,8 ; 16,6$ \\
${ }^{35} \mathrm{Cl}$ & $42 ; 56 ; 78$ & 36,$3 ; 50,1 ; 72,2$ & 10,$8 ; 14,2 ; 19,7$ & 18,$1 ; 17,6 ; 16,6$ \\
${ }^{48} \mathrm{Ti}$ & $56 ; 78$ & 48,$4 ; 70,0$ & 12,$5 ; 15,5$ & 23,$0 ; 23,8$ \\
${ }^{63} \mathrm{Cu}$ & $42 ; 49 ; 63 ;$ & 33,$6 ; 40,2 ; 53,4 ;$ & 8,$0 ; 9,0 ; 10,9 ;$ & 27,$3 ; 28,6 ; 30,4 ;$ \\
& $78 ; 93 ; 110$ & 67,$8 ; 83,0 ; 98,4$ & 12,$9 ; 15,0 ; 17,0$ & 31,$4 ; 31,9 ; 32,0$ \\
${ }^{107} \mathrm{Ag}$ & $60 ; 110$ & 48,$8 ; 95,6$ & $9 ; 13,8$ & 36,$2 ; 46,0$ \\
\hline
\end{tabular}

Para todas as condições foram adquiridos entre 1000 e 10000 eventos válidos, dependendo do tempo necessário para a aquisição, exceto em quatro casos de baixa seção de choque, a saber: ${ }^{12} \mathrm{C} 56 \mathrm{MeV},{ }^{63} \mathrm{Cu} 42 \mathrm{e} 49 \mathrm{MeV}$ e ${ }^{107} \mathrm{Ag} 60 \mathrm{MeV}$, em que foram registrados 15, 191, 203 e 494 eventos, respectivamente. A Figura 9.5 ilustra os sinais típicos observados para feixes de ${ }^{16} \mathrm{O} 42 \mathrm{MeV}$ e ${ }^{63} \mathrm{Cu} 110 \mathrm{MeV}$, bem como a curva ajustada aos sinais, que será descrita adiante. Observa-se que os sinais observados com feixes leves, como oxigênio, possuem a estrutura aproximada de uma dupla gaussiana, ao passo que, para íons mais pesados $\left({ }^{28} \mathrm{Si}\right.$ em diante), o pico possui a forma aproximada de uma gaussiana simples.

Diante da impossibilidade de analisar a grande quantidade de sinais obtidos $(\sim$ $3 \times 10^{5}$ ), foi necessário desenvolver um programa computacional específico para esta tarefa. Conforme mencionado anteriormente, o primeiro passo foi separar os eventos para analisar cada um separadamente numa janela de aquisição e avaliar o nível de ruído para cada sinal adquirido. Uma vez que o sinal sempre ocorre aproximadamente na mesma posição (trigger), o ruído foi avaliado no primeiro $1 / 3$ da janela e no último 
$1 / 3$ da janela. Utilizou-se então uma biblioteca específica em ROOT para busca de picos em um espectro, limitando a 3 picos por janela. Convém mencionar que a estrutura dos picos observados não era gaussiana, de maneira que a função escolhida foi a somatória de 3 gaussianas com centróides nas posições dos picos encontrados. Este procedimento permitiu descrever de maneira satisfatória os eventos automaticamente. Da função ajustada foram obtidos o valor máximo (amplitude, em $\mathrm{mV}$ ), o desvio padrão (largura do sinal, em ns) e a área acima do fundo (carga coletada, em pC). Os valores destes parâmetros foram organizados em histogramas, revelando que, para feixes pesados, as distribuições de carga e amplitude apresentam comportamento bimodal, conforme Figura 9.6, além de diversos valores com distribuições próximas à distribuição uniforme, que por enquanto chamaremos de outliers. Observou-se ainda que a distância entre os dois picos na distribuição bimodal de cargas é diferente para feixes com diferentes valores de LET, sendo maior quanto maior o LET da partícula incidente, como pode ser observado na Figura 9.7.

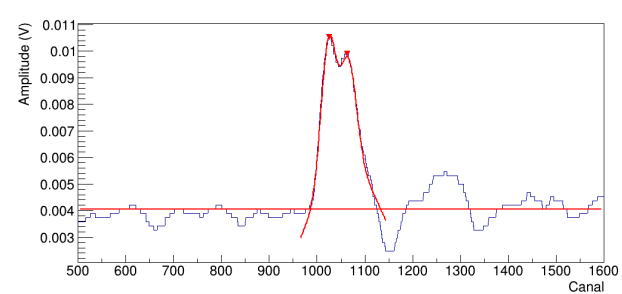

(a)

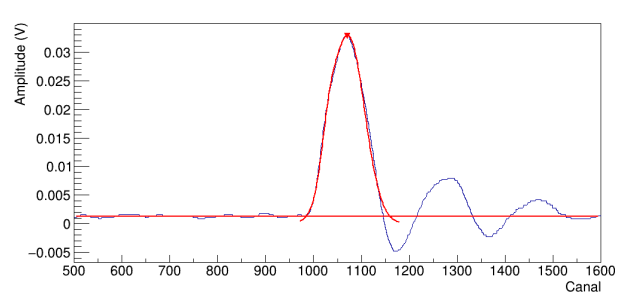

(b)

Figura 9.5: Sinais de carga coletada observados no osciloscópio e curvas de ajuste, para feixes de ${ }^{16} \mathrm{O} 42 \mathrm{MeV}$ e ${ }^{63} \mathrm{Cu} 110 \mathrm{MeV}$. (a) Sinal de coleta de carga do feixe de ${ }^{16} \mathrm{O} 42$ $\mathrm{MeV}$. (b) Sinal de coleta de carga do feixe de ${ }^{63} \mathrm{Cu} 110 \mathrm{MeV}$. Nestes sinais, cada canal no eixo das abcissas corresponde a 50 ps. 


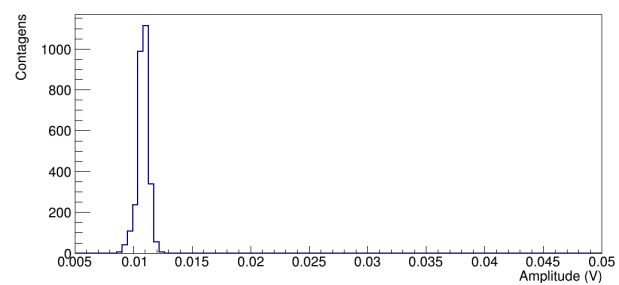

(a)

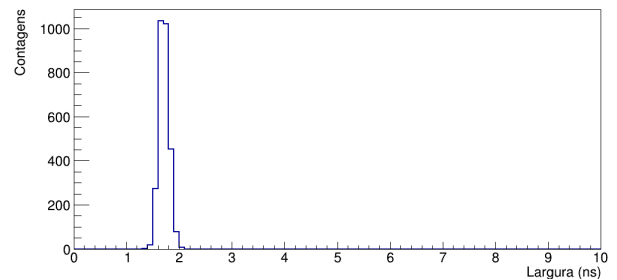

(c)

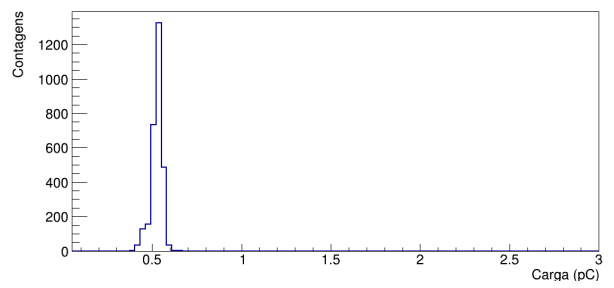

(e)

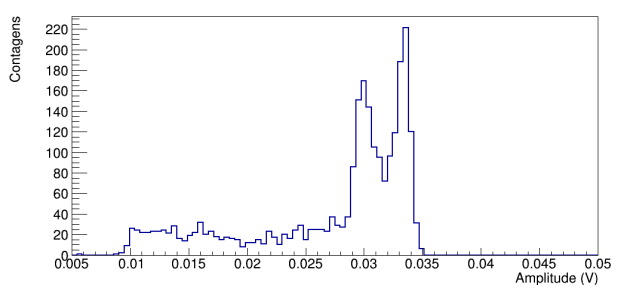

(b)

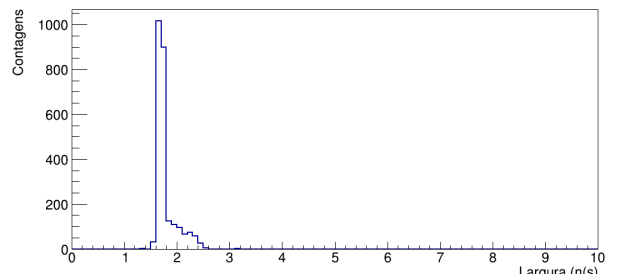

(d)

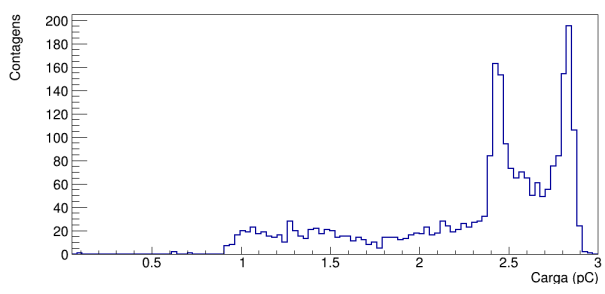

(f)

Figura 9.6: Distribuições de amplitude, largura e carga dos eventos observados para feixes de ${ }^{16} \mathrm{O} 42 \mathrm{MeV}$ e ${ }^{63} \mathrm{Cu} 110 \mathrm{MeV}$. (a)Distribuição de amplitudes para feixe de ${ }^{16} \mathrm{O}$ $42 \mathrm{MeV}$. (b)Distribuição de amplitudes para feixe de ${ }^{63} \mathrm{Cu} 110 \mathrm{MeV}$. (c)Distribuição de larguras para feixe de ${ }^{16} \mathrm{O} 42 \mathrm{MeV}$.(d)Distribuição de larguras para feixe de ${ }^{63} \mathrm{Cu} 110$ $\mathrm{MeV}$.(e)Distribuição de cargas para feixe de ${ }^{16} \mathrm{O} 42 \mathrm{MeV}$.(f)Distribuição de cargas para feixe de ${ }^{63} \mathrm{Cu} 110 \mathrm{MeV}$. 


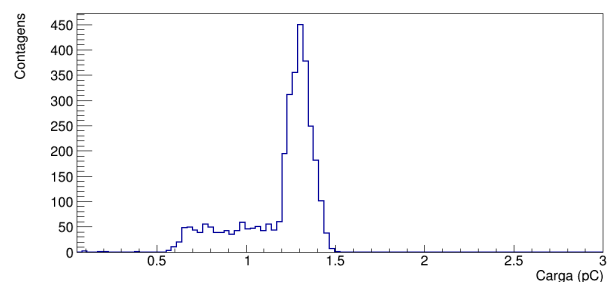

(a)

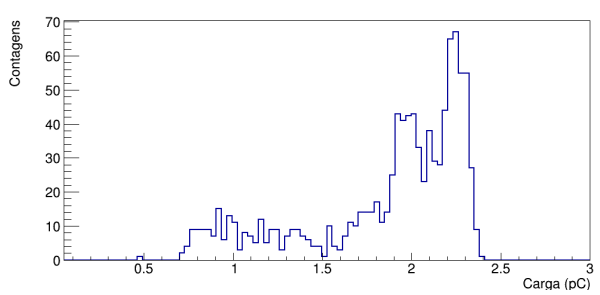

(c)

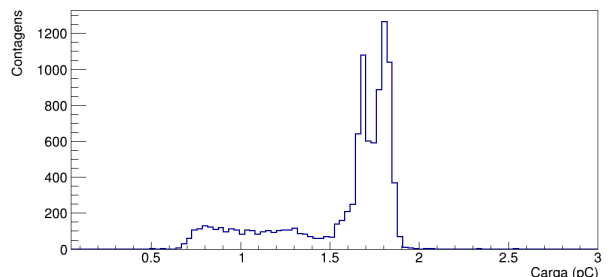

(b)

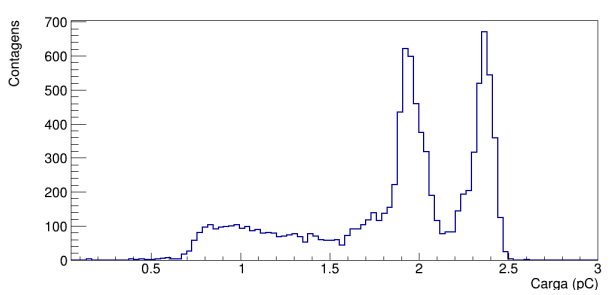

(d)

Figura 9.7: Distribuições de carga coletada para feixes com energia inicial de $78 \mathrm{MeV}$. (a) ${ }^{28} \mathrm{Si}$. (b) ${ }^{35} \mathrm{Cl}$. (c) ${ }^{48} \mathrm{Ti}$. (d) ${ }^{63} \mathrm{Cu}$.

Embora os valores de energia efetiva destes feixes sejam diferentes, é bastante clara a mudança na separação entre os picos da distribuição com a mudança do número atômico e, portanto, do LET. Sabendo que a carga possui uma relação de proporcionalidade com a energia depositada na região de coleta, esta distribuição de carga pode representar uma distribuição de energias coletadas. Além disso, caso toda a energia incidente fosse capaz de gerar a carga coletada, as três distribuições apresentadas na Figura 9.7 deveriam apresentar aproximadamente os mesmos valores, a menos de uma correção pela energia efetiva. Contrariamente a essa hipótese, o feixe de ${ }^{35} \mathrm{Cl}$, que possui maior energia efetiva, apresenta menor valor máximo de carga coletada.

Para observar melhor as tendências dos dados e isolar os dois picos nas distribuições bimodais, foram construídos os gráficos bidimensionais apresentados na Figura 9.8. Nestes gráficos, pode-se destacar que existe linearidade entre a amplitude do pulso e a carga coletada, exceto por alguns dos pontos observados, o que implica numa largura aproximadamente constante. 


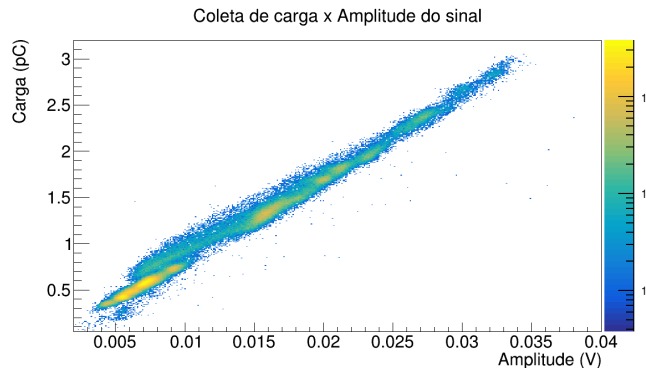

(a)

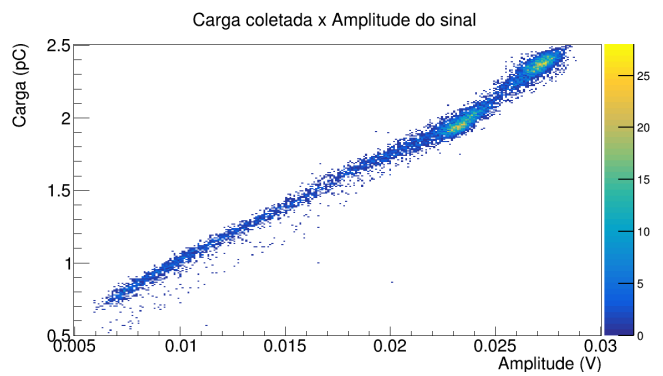

(c)

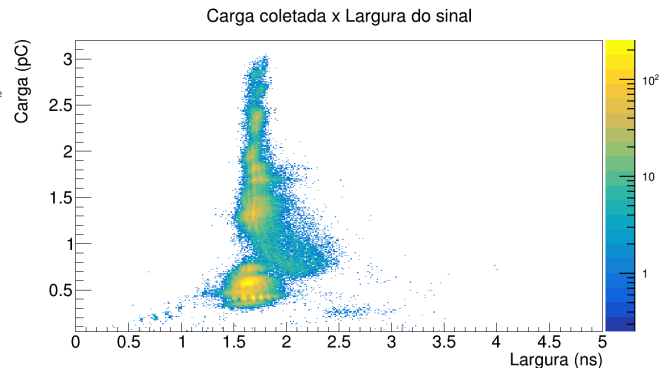

(b)

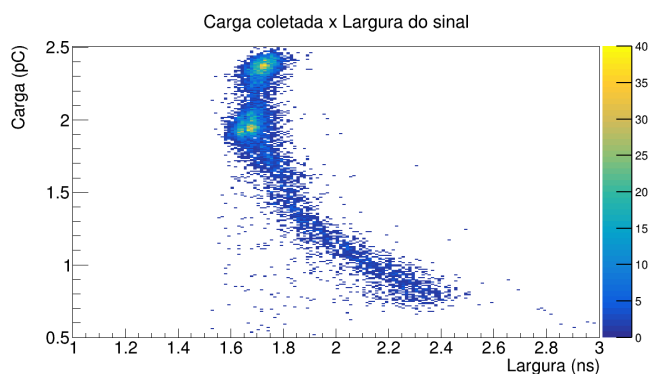

(d)

Figura 9.8: Distribuições bidimensionais carga $\mathrm{x}$ amplitude e carga $\mathrm{x}$ largura dos sinais analisados (a) Amplitude $\mathrm{x}$ carga para todos os sinais analisados em todas as condições íon x energia medidas. (b) Carga $\mathrm{x}$ largura para todos os sinais analisados em todas as condições íon $\mathrm{x}$ energia medidas. (c) Amplitude x carga para os sinais obtidos com feixe de ${ }^{63} \mathrm{Cu} 78 \mathrm{MeV}$.(d) Carga x largura para os sinais obtidos com feixe de ${ }^{63} \mathrm{Cu} 78$ $\mathrm{MeV}$.

De fato, no gráfico de carga $\mathrm{x}$ largura os mesmos pontos desviam-se da tendência de uma largura de pulso aproximadamente constante. Nos gráficos correspondentes ao feixe de ${ }^{63} \mathrm{Cu}$, pode-se perceber mais claramente (em conjunto com a Figura 9.7) que tais pontos com formato ligeiramente diferente correspondem à porção da distribuição aproximadamente uniforme. Uma segunda verificação manual destes sinais não indicou nenhuma razão para que fossem excluídos. A Figura 9.9 mostra a projeção no eixo x da Figura 9.8b, evidenciando o aspecto aproximadamente normal da distribuição de larguras, com pequeno efeito dos dados que possuem forma diferente. 


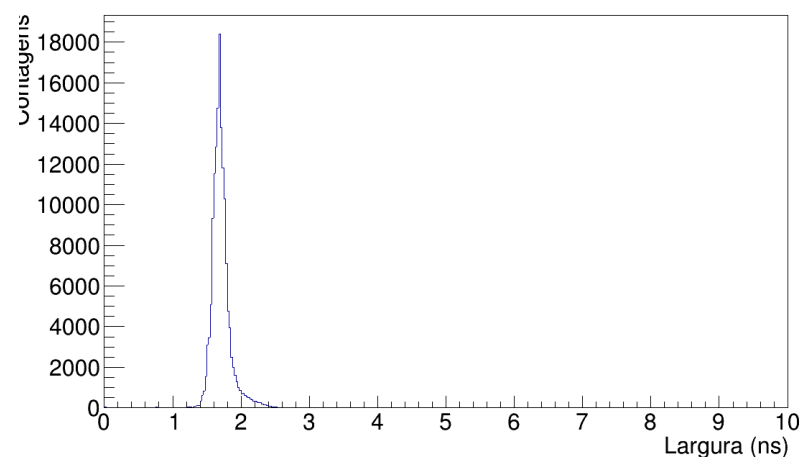

Figura 9.9: Distribuição de larguras de pulso para todos os eventos observados.

Com base nos resultados obtidos e nos modelos apresentados no Capítulo 8, podemos elaborar algumas hipóteses sobre os processos de coleta de carga no MOSFET tipo-p 3N163:

- Os sinais adquiridos possuem polaridade positiva, indicando que não houve coleta de carga depositada por íons incidentes na região de porta, conforme as simulações da Figura 9.1 ${ }^{2}$;

- Existem dois processos de coleta de carga no dispositivo, deriva/funil e difusão, cada um deles com duração diferente, dando origem aos eventos que possuem largura de pulso diferente. Um destes eventos é muito mais provável de ocorrer do que o outro;

- Dado que a carga coletada é uma medida de energia depositada na região sensível, a existência de um comportamento bimodal para o caso de íons pesados sugere a mudança de energia de uma parte das partículas antes da chegada à camada sensível. Para o caso de íons leves, essa mudança não é observável;

- Nem toda a energia do íon que chega à camada sensível é coletada, uma vez que íons diferentes de mesma energia apresentam carga coletada diferente, o que

\footnotetext{
${ }^{2}$ Foram realizados testes com trigger negativo. Não foram observados eventos.
} 
sugere a existência no transistor de uma profundidade sensível máxima.

Neste ponto, informações adicionais sobre a estrutura do dispositivo são necessárias para compreender os fenômenos envolvidos. Inicialmente, será dada ênfase aos dois picos das distribuições de carga.

\subsection{Microscopia eletrônica de varredura}

A utilização das técnicas de microscopia eletrônica de varredura e microanálise por sistema de dispersão em energia de raios X (MEV-EDS) permite identificar e medir áreas pequenas do dispositivo bem como conhecer sua composição química elementar, excetuando-se elementos abaixo do carbono na tabela periódica. Através da interação do feixe de elétrons com a amostra, ocorre a emissão de elétrons, ditos secundários, da superfície desta, fornecendo informação topológica da amostra. As excitações causadas pelo feixe também provocam a emissão de raios X característicos para identificação dos elementos presentes [131].

Antes da análise ao microscópio eletrônico, é importante realizar antes uma préanálise ao microscópio óptico para identificar as regiões de interesse. As fotomicrografias apresentadas na Figura 9.10 foram feitas num microscópio Carl Zeiss Axioplan II e numa lupa estereoscópica Carl Zeiss Stemi SV-11 do Laboratório de Petrografia Sedimentar do Instituto de Geociências da Universidade de São Paulo (IGc-USP).

Na Figura 9.10c observa-se claramente a estrutura entrelaçada entre o canais de fonte, dreno e porta, sendo que o contato de porta está ligado na região superior esquerda, o contato de dreno na região superior direita e o contato da fonte na região inferior direita. Os contatos aparecem num tom amarelo granulado, e entre eles distinguem-se três regiões: um substrato (fundo), uma região larga (verde) e uma região fina (vermelha). Estas designações serão importantes a seguir.

O dispositivo foi então submetido à análise em um microscópico eletrônico de varre- 


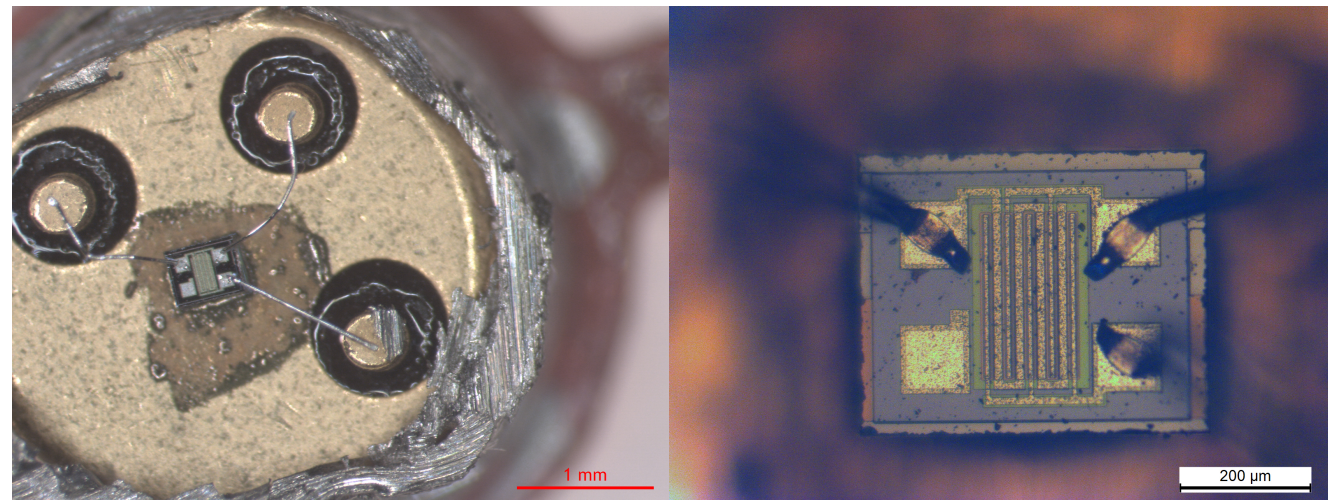

(a)

(b)

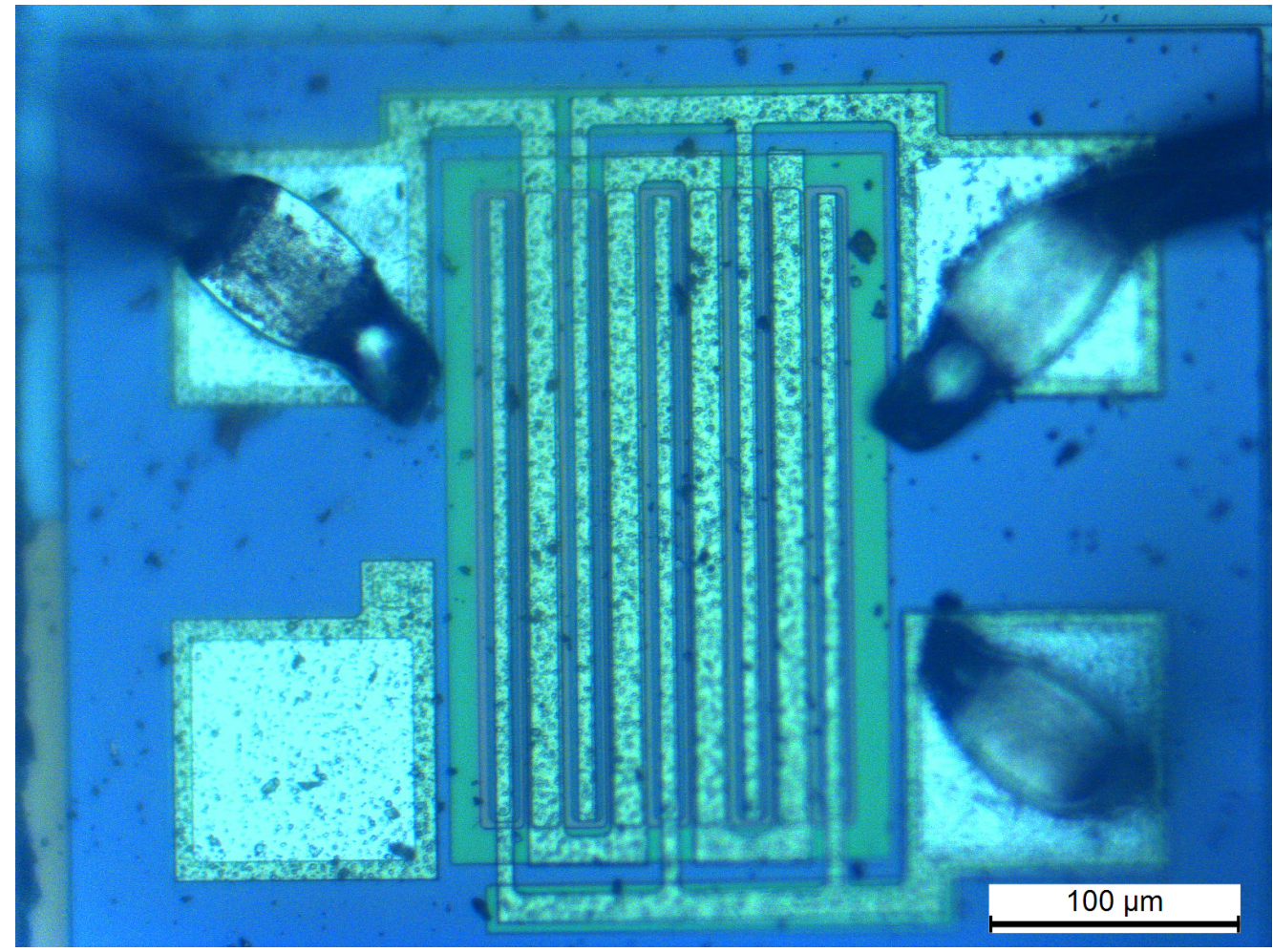

(c)

Figura 9.10: Fotomicrografias do p-MOSFET 3N163 em diferentes níveis de aumento. 
dura FEI do Centro de Pesquisas Geocronológicas do IGc-USP ${ }^{3}$. Devido à impossibilidade de realizar o recobrimento da amostra, operou-se no modo baixo-vácuo do microscópio $^{4}$, ideal para evitar carregamento eletrostático da amostra e geração de artefatos de imagem. Foi realizada primeiramente uma eletromicrografia geral do dispositivo e mapeamento dos elementos presentes em maior quantidade, conforme ilustrado na Figura 9.11.

Foram observados também os elementos oxigênio, carbono, ferro, níquel, estanho, prata e ouro, porém em concentrações muito inferiores e não localizadas. A eletromicrografia e os mapeamentos realizados permitem inferir que o substrato é formado majoritariamente por silício, como esperado, os contatos são feitos de alumínio e existe uma camada contendo nitrogênio uniformemente distribuída. O fato de ser observado silício mesmo nas posições em que também se encontra o alumínio pode significar que os contatos são finos o suficiente para que o feixe interaja com o silício do substrato e/ou que também exista uma camada contendo silício sobre os contatos. Associado à presença uniforme do nitrogênio, podemos concluir que esta camada é de nitreto de silício $\mathrm{Si}_{3} N_{4}$, um composto cerâmico largamente utilizado na indústria microeletrônica para passivação dos dispositivos contra corrosão ${ }^{5}$.

Na sequência, foram feitas microanálises das regiões identificadas nas Figuras 9.10c e 9.12a (fundo, verde, vermelho e contato), variando a energia dos elétrons, e, portanto, a penetração do feixe e profundidade de emissão de raios X característicos. Para cada condição foi analisada a razão percentual atômica entre os elementos silício e nitrogênio, que devem ocorrer na proporção $3 / 4$ no $S i_{3} N_{4}{ }^{6}$. Os outros elementos observados não apresentaram nenhum padrão observável, exceto pelo alumínio cuja presença aumenta

\footnotetext{
${ }^{3} \mathrm{O}$ autor agradece o apoio do Prof. Dr. Paulo C.F. Giannini e do Dr. Isaac Jamil Sayeg na utilização dos equipamentos do IGc-USP.

${ }^{4}$ Em tecnologia do vácuo, utiliza-se o termo pré-vácuo. O modo de operação "baixo-vácuo"do microscópio corresponde aproximadamente à faixa 1-10 Torr.

${ }^{5}$ Rigorosamente, poderia tratar-se de um composto de silício, nitrogênio e hidrogênio, porém a razão entre os elementos observada não corrobora esta hipótese, como ficará claro no texto.

${ }^{6}$ Em materiais eletrônicos, pode ocorrer variação de $5 \%$ nos percentuais desses elementos no composto [37].
} 


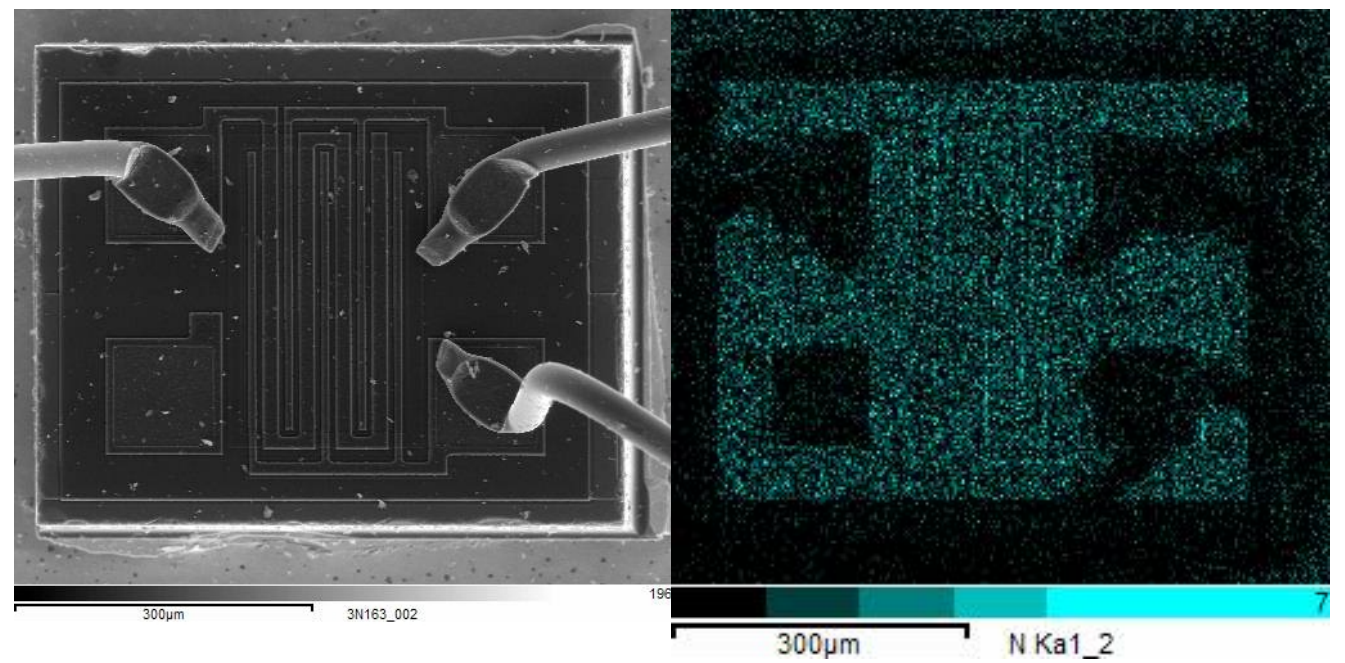

(a)

(b)

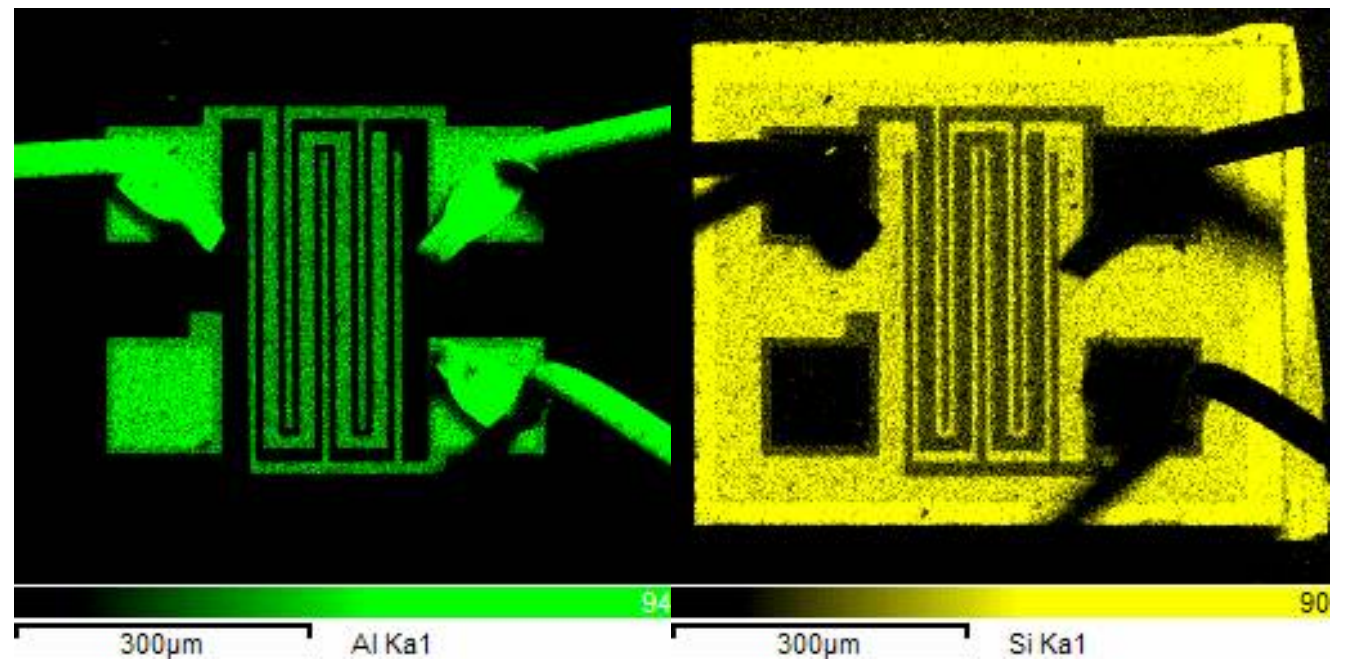

(c)

(d)

Figura 9.11: Eletromicrografia e mapeamento do p-MOSFET 3N163, utilizando tensão de aceleração de $20 \mathrm{kV}$. (a) Eletromicrografia de elétrons secundários do p-MOSFET 3N163. (b) Distribuição espacial do elemento nitrogênio. (c) Distribuição espacial do elemento alumínio.(d) Distribuição espacial do elemento silício. 
significativamente ao analisar o contato metálico. A Figura 9.12b ilustra os dados obtidos.

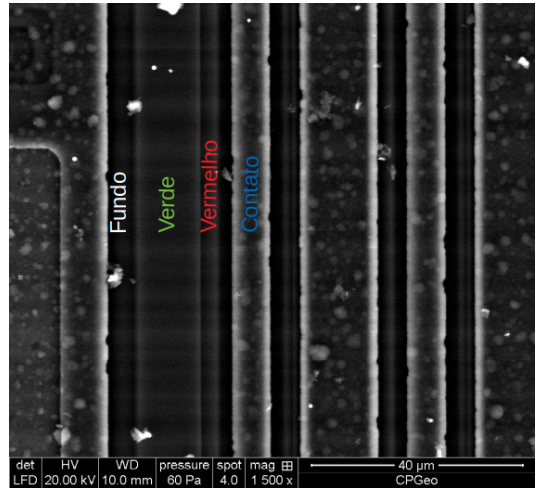

(a)

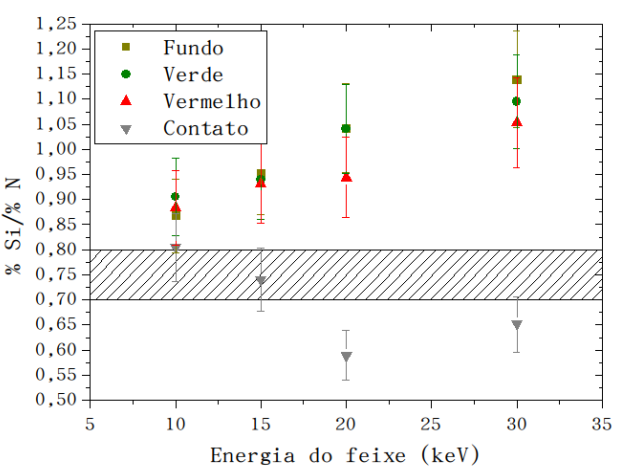

(b)

Figura 9.12: Microanálise química das quatro estruturas identificadas no p-MOSFET 3N163. (a) Detalhe da região analisada, com identificação das quatro regiões de interesse. (b) Razão da concentração atômica de silício e nitrogênio no p-MOSFET 3N163 a diferentes energias do feixe de elétrons e regiões de análise.

Observa-se que a tensões de aceleração superiores a $15 \mathrm{kV}$ os dados são incompatíveis com a composição esperada do nitreto de silício, indicando a contribuição de raios-X provenientes de camadas mais profundas, como o alumínio (no contato) ou o substrato de silício. Não se observou diferença significativa entre as regiões "fundo", "verde"e "vermelho"para a razão $\mathrm{Si} / \mathrm{N}$, apenas alterações da ordem de 1-2\% no teor de oxigênio (entre 3\% e 5\%), indicando que pode haver diferença de composição responsável pela cor observada; entretanto, esta diferença é pequena o suficiente para ter pouca influência na deposição de energia dos íons pesados na situação considerada. Este vasto conjunto de dados experimentais indicou diversas contribuições existentes para compreender a coleção de carga no p-MOSFET 3N163. Esta análise é completada com o uso de simulações computacionais. 


\subsection{Simulações de coleta de carga}

Visando compreender como a estrutura do dispositivo influencia no sinal de coleta de carga observado, foram realizadas diversas simulações computacionais da deposição de energia dos íons pesados nos materiais identificados na seção anterior, buscando não apenas explicar as diferenças nas cargas coletadas, mas também a determinação das espessuras destes materiais no dispositivo e a espessura da região sensível.

Primeiramente, foi realizada uma simples simulação da emissão e absorção de raios $\mathrm{X}$ característicos numa amostra genérica para se determinar a ordem de grandeza da camada superior do dispositivo, assumida como sendo de nitreto de silício. Esta simulação foi feita com o software CASINO, que simula as condições de análise com um microscópio eletrônico de varredura (tensão de aceleração, ângulo de detecção, material sob ensaio, etc.), através do método Monte Carlo e bases de dados de seções de choque de interação elétron-elétron e de ionização. A Figura 9.13 ilustra o volume de interação dos elétrons em camadas de $1000 \mathrm{~nm}$ e $500 \mathrm{~nm}$ de nitreto de silício sobre um substrato de silício, bem como as profundidades máximas de emissão de raios X característicos do silício, sendo que em vermelho é apresentada a intensidade absorvida e em azul a intensidade não-absorvida. Nesta Figura, fica claro que, a $10 \mathrm{keV}$, o feixe não possui energia suficiente para excitar átomos de silício do substrato se o filme de nitreto possuir cerca de $1 \mu \mathrm{m}$, podendo, no entanto, excitar o substrato no caso de um filme de $500 \mathrm{~nm}$; na condição de $15 \mathrm{keV}$, o substrato é excitado o suficiente para alterar a razão medida em qualquer das condições. Como a diferença observada na composição é compatível com a esperada para a energia de $10 \mathrm{keV}$ e apresenta um desvio apreciável, embora ainda compatível, para a energia de $15 \mathrm{keV}$, podemos estabelecer que a espessura da camada de nitreto encontra-se nesta faixa de aproximadamente 0,5 a $1 \mu \mathrm{m}$. Esta informação permite otimizar as simulações de energia depositada.

Assumindo então que a diferença na carga coletada corresponde a diferentes energias 


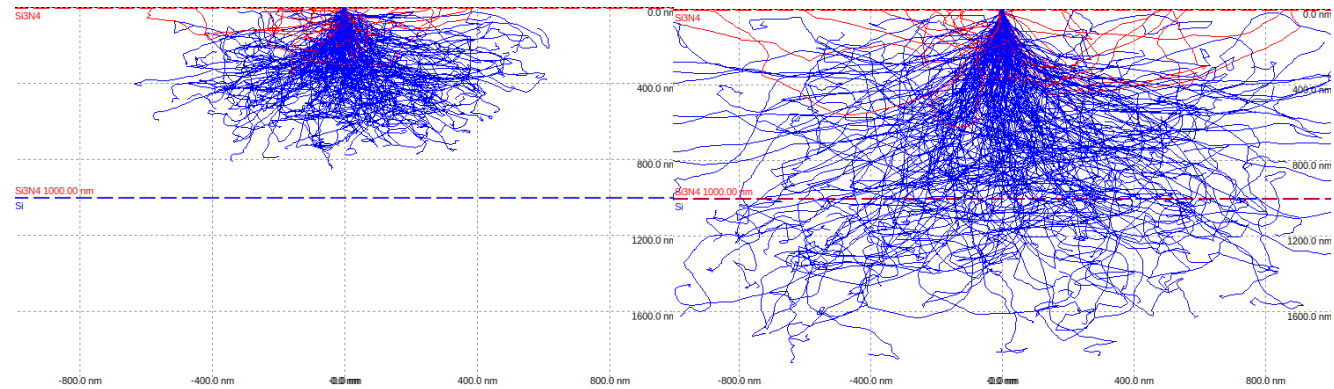

(a)

(b)

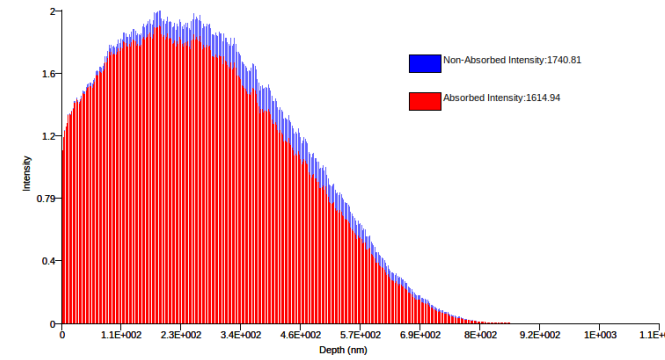

(c)

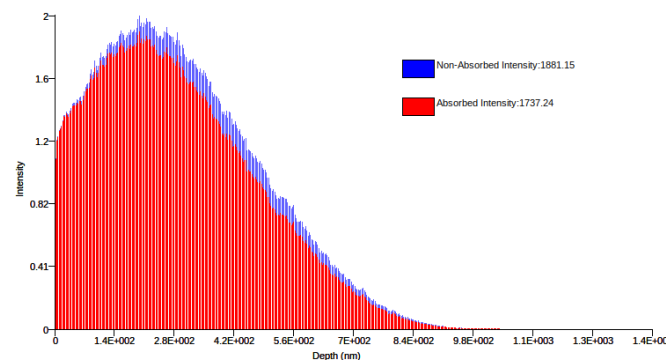

(e)

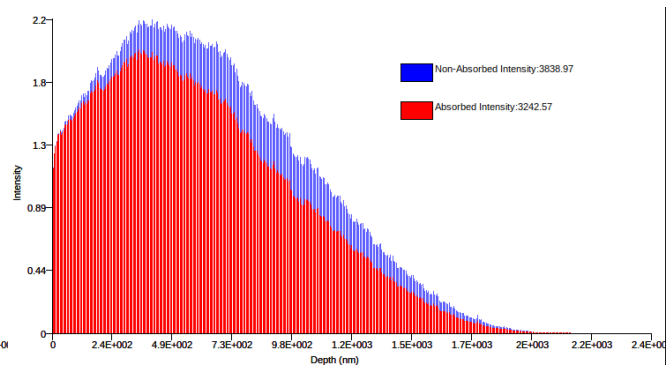

(d)

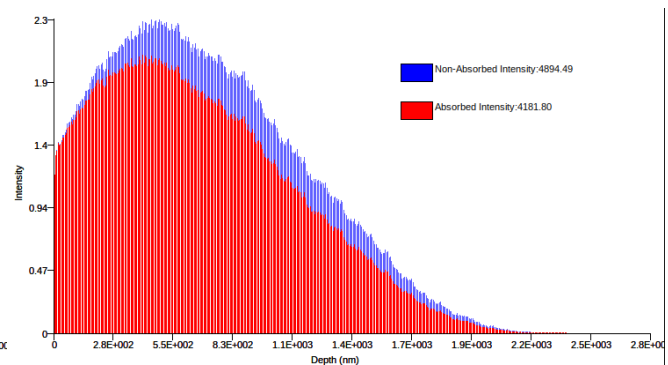

(f)

Figura 9.13: Simulações da interação do feixe de elétrons em camadas de $1000 \mathrm{~nm}$ e $500 \mathrm{~nm}$ sobre silício em energias de $10 \mathrm{keV}$ e $15 \mathrm{keV}$. (a) Volume de interação do feixe de elétrons com energia $10 \mathrm{keV}$, sobre filme $1000 \mathrm{~nm}$ de $S i_{3} N_{4}$ e substrato de silício. (b) Volume de interação do feixe de elétrons com energia $15 \mathrm{keV}$, sobre filme $1000 \mathrm{~nm}$ de $S_{3} N_{4}$ e substrato de silício. (c) Profundidade máxima de emissão de raios X $K \alpha$ do silício para feixe de elétrons com energia $10 \mathrm{keV}$, sobre filme $1000 \mathrm{~nm}$ de $S i_{3} N_{4}$ e substrato de silício. (d) Profundidade máxima de emissão de raios $\mathrm{X} K \alpha$ do silício para feixe de elétrons com energia $15 \mathrm{keV}$, sobre filme $1000 \mathrm{~nm}$ de $S i_{3} N_{4}$ e substrato de silício. (e) Profundidade máxima de emissão de raios X $K \alpha$ do silício para feixe de elétrons com energia $10 \mathrm{keV}$, sobre filme $500 \mathrm{~nm}$ de $S i_{3} N_{4}$ e substrato de silício. (f) Profundidade máxima de emissão de raios $\mathrm{X} K \alpha$ do silício para feixe de elétrons com energia $15 \mathrm{keV}$, sobre filme $500 \mathrm{~nm}$ de $S i_{3} N_{4}$ e substrato de silício. 
do íon incidente na região sensível do dispositivo e com as informações disponíveis, temos:

- Existe uma camada de nitreto de silício com espessura entre 0,5 e 1,0 $\mu \mathrm{m}$ uniformemente distribuída pela superfície do dispositivo;

- O sinal observado não representa incidência na porta, uma vez que a polaridade é positiva;

- Existem contatos de alumínio na região do dreno;

A hipótese levantada é de que, da fração dos íons apresentaram carga coletada através dos fenômenos de deriva e funil, uma parte deles atravessou o contato de alumínio do dreno, perdendo energia, e outra parte incidiu na região entre o dreno e a porta, sem perder energia no alumínio. Como a camada de nitreto está uniformemente distribuída, todos eles atravessaram a camada de nitreto, e a diferença de carga coletada seria apenas reflexo da perda de energia no contato de alumínio, que é maior quanto maior o poder de freamento da partícula no meio, conforme a Figura 9.7.

A diferença de energia foi então calculada com base na diferença entre os dois picos de coleta, considerando o fator de conversão de $22,6 \mathrm{MeV} / \mathrm{pC}$. As incertezas foram calculadas com base no desvio padrão do valor médio dos picos individuais, separados através de cortes no espectro bidimensional ("bananas") de carga por amplitude e combinado quadraticamente às incertezas nos valores ajustados de carga. As incertezas nos valores ajustados se devem aos limites de ajuste escolhidos para os sinais, pois, sendo o ajuste automático, utilizou-se um valor fixo para cada conjunto de sinais. A variação dos limites de ajuste que ainda forneciam resultados coerentes para os sinais produziu uma variação na média de carga coletada correspondente a $200 \mathrm{keV}$ de energia, e este valor foi tomado como incerteza do ajuste.

Para determinar a espessura da camada de alumínio, o software TRIM foi utilizado para simular 400 partículas sendo transmitidas por um alvo de ouro de espessura equi- 
valente às duas folhas utilizadas e um alvo de alumínio. A diferença de energia entre a entrada e a saída do feixe no alvo de alumínio foi comparada à diferença de energia coletada. Este processo foi realizado para todos os íons e energias em que foi possível observar dois picos de coleta de carga, variando a espessura do alvo de alumínio de maneira a obter o melhor ajuste aos dados. A Figura 9.14a mostra os resíduos reduzidos para as condições analisadas (cada condição chamada de "dado"), e a Figura 9.14b mostra os mesmos resultados em função do alcance (em silício) do feixe considerado, para espessura da camada de alumínio igual a 1,035 $\mu \mathrm{m}$. Os resíduos reduzidos e suas incertezas foram calculados de acordo com as Equações 9.1:

$$
\begin{gathered}
r_{i}=\frac{\Delta E_{i}^{e x p}-\Delta E_{i}^{s i m}}{\sigma_{\Delta E_{i}^{e x p}}} \\
\sigma_{r_{i}}=\sqrt{1+\frac{\sigma_{\Delta E_{i}^{s i m}}^{2}}{\sigma_{\Delta E_{i}^{e x p}}^{2}}}
\end{gathered}
$$

em que $\Delta E_{i}^{\text {exp,sim }}$ representam os valores de diferença de energia devido à passagem pelo alumínio experimental e simulada, respectivamente, $\sigma_{\Delta E_{i}^{e x p}}$ são as incertezas dos valores experimental e simulado $i$.

Observam-se tendências claras nestes gráficos de resíduos: na Figura 9.14a, pode-se ver que, para um dado feixe, maiores energias correspondem uma diferença de energia simulada maior, exceto os casos de menor energia e feixes de ${ }^{63} \mathrm{Cu}$. Quando os dados são dispostos em função do alcance em silício (sempre utilizado como referência), observa-se que há um tendência de queda do resíduo reduzido, isto é, aumento do valor simulado, para alcances superiores a $12,7 \mu \mathrm{m}$. O valor de $\chi^{2}$ obtido para esta condição foi 81,6 , muito superior ao valor esperado ${ }^{7}$.

O comportamento dos resíduos para alcance em silício acima de $12,7 \mu$ m pode ter

\footnotetext{
${ }^{7}$ Com 16 graus de liberdade, o valor esperado do $\chi^{2}$ seria de aproximadamente 16 , no caso
} 
origem na dependência da coleção de carga com o alcance da partícula e com o comprimento efetivo de coleta de carga. A Figura 9.15 ilustra o processo: estão representadas como retângulos as 3 camadas que compõe o dispositivo num corte lateral. As setas vermelhas representam uma partícula com alcance maior e as setas verdes representam um partícula de menor alcance. Desprezando, em primeira aproximação, as possíveis variações do tamanho do funil de coleta de carga com o LET e as próprias variações de LET ao passar pelo alumínio, fica claro que no caso de menor alcance tanto a partícula que passa pelo alumínio quanto a que encontra em sua trajetória apenas o nitreto irão depositar a energia residual na camada ativa, que será convertida em carga; para a partícula de alcance maior, aquela que atravessa o alumínio pode não depositar toda sua energia na região ativa, gerando um déficit na energia coletada, da seguinte forma:

$$
\begin{gathered}
\Delta E_{\text {real }}=\left(E_{\text {nit }}+\delta E\right)-E_{A l} \\
\Delta E_{\text {medido }}=E_{\text {nit }}-E_{A l} \\
\delta E=\Delta E_{\text {real }}-\Delta E_{\text {medido }}
\end{gathered}
$$

em que $\Delta E_{\text {real,medido }}$ representam os valores real e medido da diferença de energia, $E_{n i t, A l}$ as energias coletadas pelas partículas que passaram apenas pela camada de nitreto e pelas que passaram pelas camadas de nitreto e alumínio, respectivamente, e $\delta E$ representa a energia depositada fora da região ativa. Valores menores de $\Delta E_{\text {medido }}$, por sua vez, resultam em valores menores de resíduo, explicando qualitativamente os resultados observados na Figura 9.14. Desta forma, restringindo a análise aos feixes com alcance em silício inferior a $12,7 \mu \mathrm{m}$ obtemos os valores de $\chi^{2}$ apresentados na Figura 9.16, cujo valor mínimo igual a 7,5 ocorre para uma camada de alumínio de 1,28(2) $\mu \mathrm{m}$ para 6 graus de liberdade, correspondendo a cerca de $28 \%$ de probabilidade do $\chi^{2}$ ser excedido. A Figura 9.17 apresenta o gráfico de resíduos para a espessura de 1,285 $\mu \mathrm{m}$ de alumínio. 


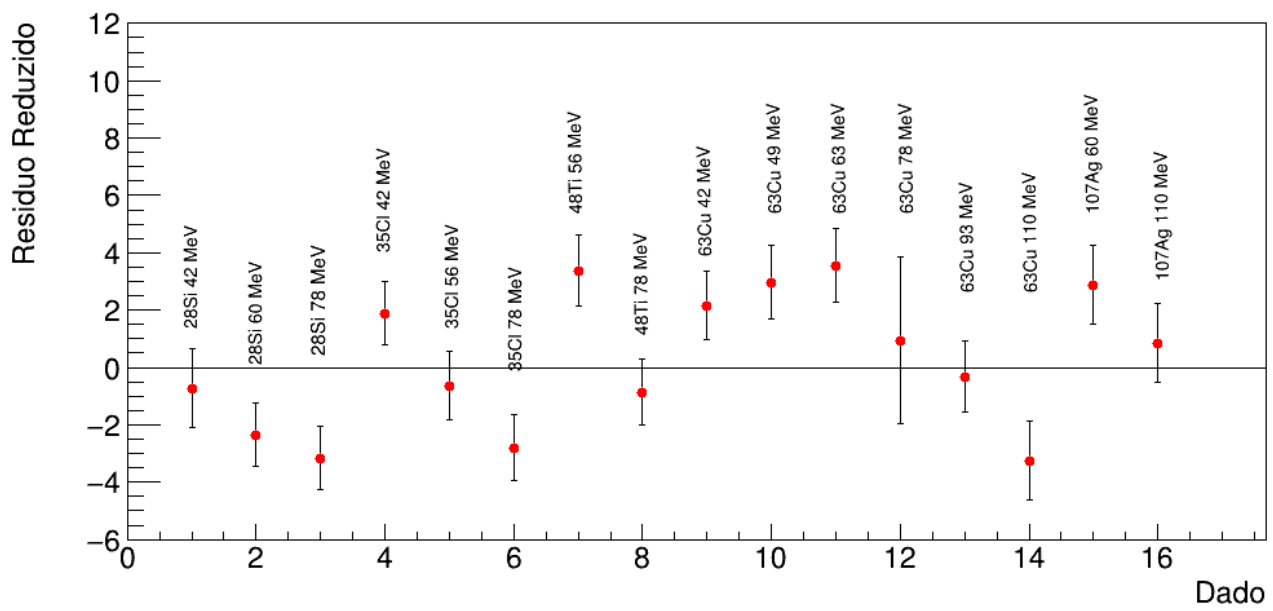

(a)

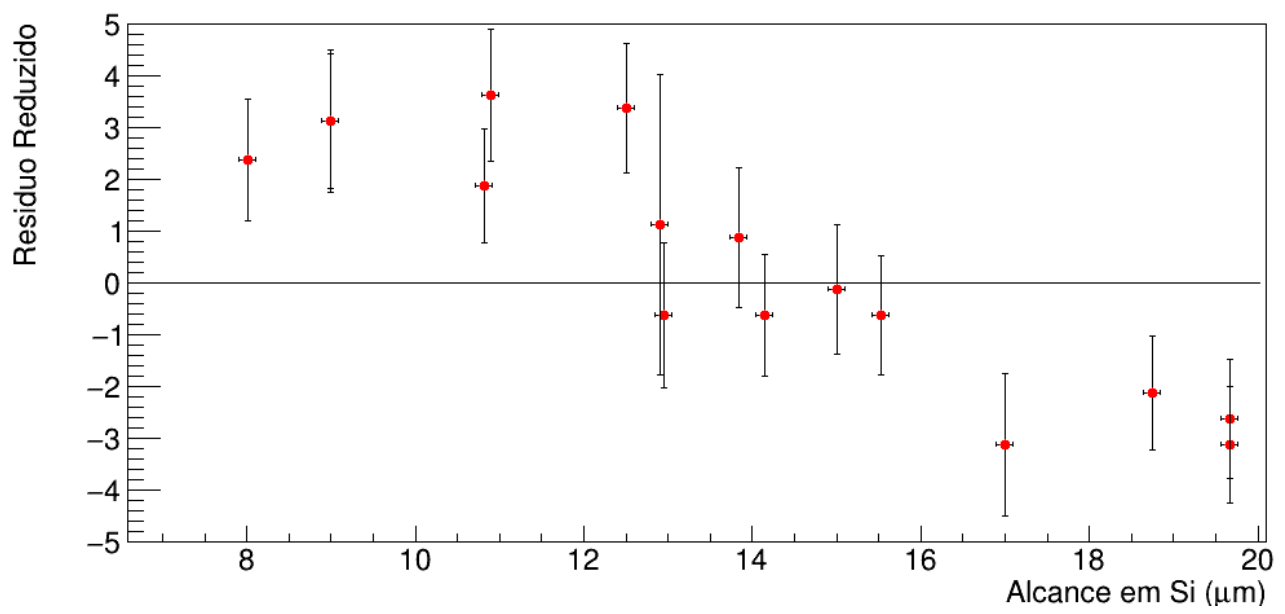

(b)

Figura 9.14: Resíduos reduzidos para a diferença de energia observada nos eventos de íons pesados no p-MOSFET 3N163, simulados utilizando espessura de alumínio de 1,035 $\mu \mathrm{m}$. (a) Resíduo reduzido para cada condição (dado) analisada. (b) Resíduo reduzido em função do alcance em silício. 


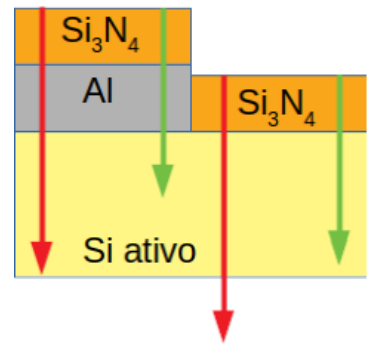

Figura 9.15: Ilustração dos casos de coleta completa e incompleta de carga.

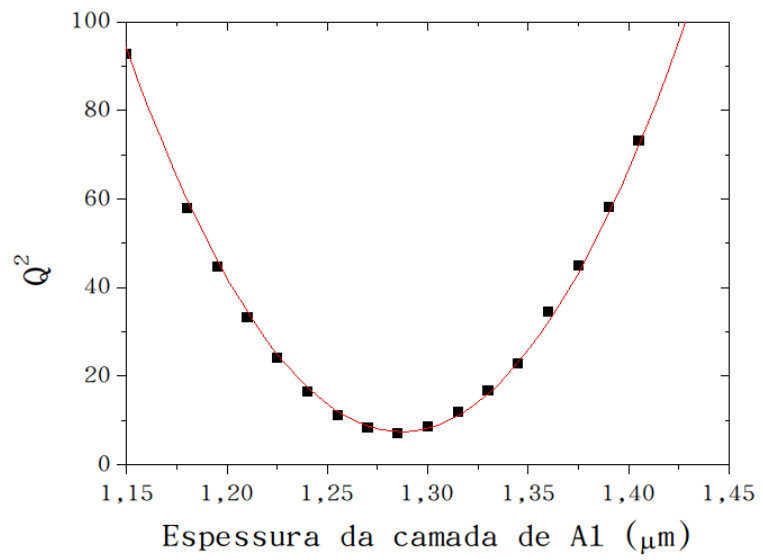

Figura 9.16: Distribuição de $\chi^{2}$ em função da espessura do filme de alumínio simulado.

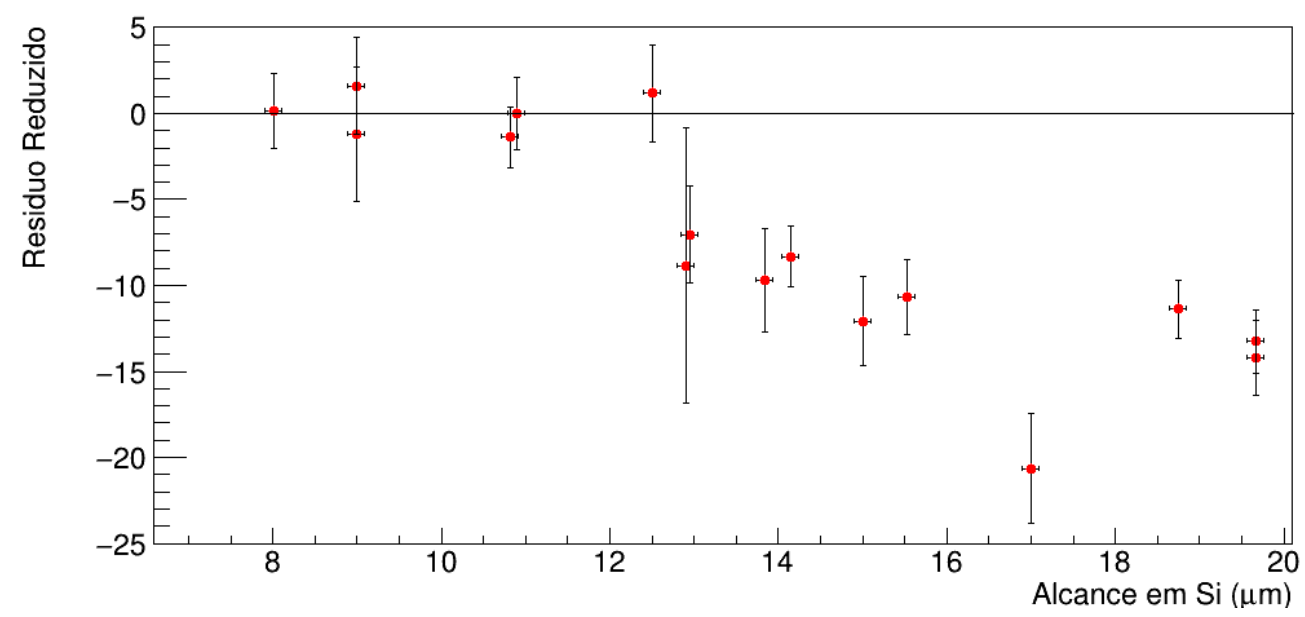

Figura 9.17: Resíduos reduzidos para a diferença de energia observada nos eventos de íons pesados no p-MOSFET 3N163, simulados utilizando espessura de alumínio de $1,285 \mu \mathrm{m}$. 
Determinada a espessura da camada de alumínio, é necessário determinar a região de coleta de carga e a espessura do nitreto de silício. O procedimento adotado é semelhante ao empregado para a determinação da camada de alumínio, com a diferença que os valores experimentais utilizados foram os de carga coletada para cada íon e condição, incluindo a passagem ou não pela camada de alumínio. A comparação foi feita entre a energia de entrada e saída da camada ativa, de maneira a poder avaliar se um erro na estimativa da camada de nitreto estaria sendo compensado por um erro na camada ativa.

A primeira abordagem com relação à camada ativa consistiu em considerar a camada ativa de espessura constante para todos os íons, sendo dependente apenas de parâmetros do dispositivo, conforme a Equação 8.4. A Figura 9.18 mostra os gráficos de resíduos reduzidos para a condição de mínimo do $\chi^{2}$. O valor mínimo de $\chi^{2}$ obtido foi igual a 1170, para a espessura de $0,65 \mu \mathrm{m}$ de nitreto de silício e $9,2 \mu \mathrm{m}$ de camada ativa. Além do valor elevado de $\chi^{2}$, observa-se nos gráficos de resíduos a tendência de superestimação da região de coleta de carga, em especial para os íons de maior número atômico, porém sem correlação com o alcance em silício. Uma vez que todas as fontes de erros aleatórios foram consideradas, observa-se que o modelo de espessura de coleta de carga é inadequado para a descrição dos dados, sendo apenas uma aproximação válida no caso de medidas com incerteza elevada. De maneira a obter os valores representativos deste modelo e suas respectivas incertezas, adotou-se o procedimento de normalizar os valores de $\chi^{2}$ de maneira que $\chi_{\min }^{2}=39$ (número de graus de liberdade). A Figura 9.19 mostra o mapa de $\chi^{2}$ em função da espessura da camada de nitreto de silício e da camada ativa, evidenciando a independência entre as duas variáveis neste modelo. Do mapa, obtém-se que as espessuras representativas da camada de nitreto de silício e da camada ativa são, respectivamente, iguais a $0,73(6) \mu \mathrm{m}$ e $9,4(2) \mu \mathrm{m}^{8}$.

\footnotetext{
${ }^{8}$ Eventuais diferenças entre o valor mínimo simulado e os obtidos a partir do mapeamento devem-se ao processo de suavização por interpolação das curvas do mapa de $\chi^{2}$
} 


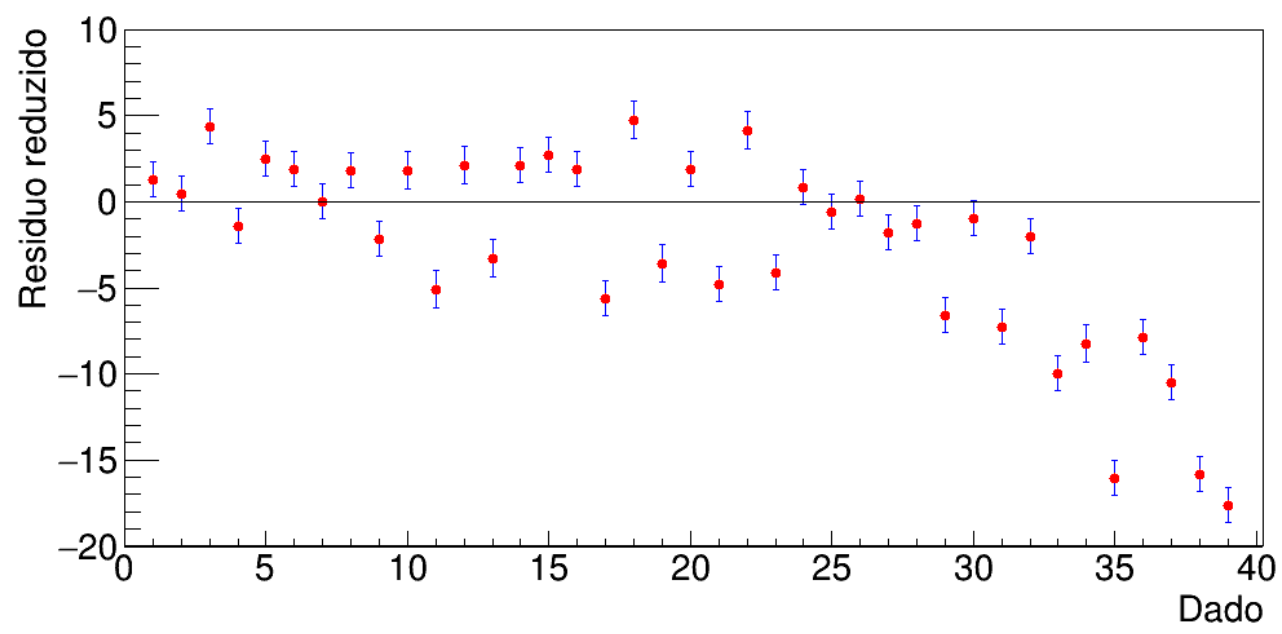

(a)

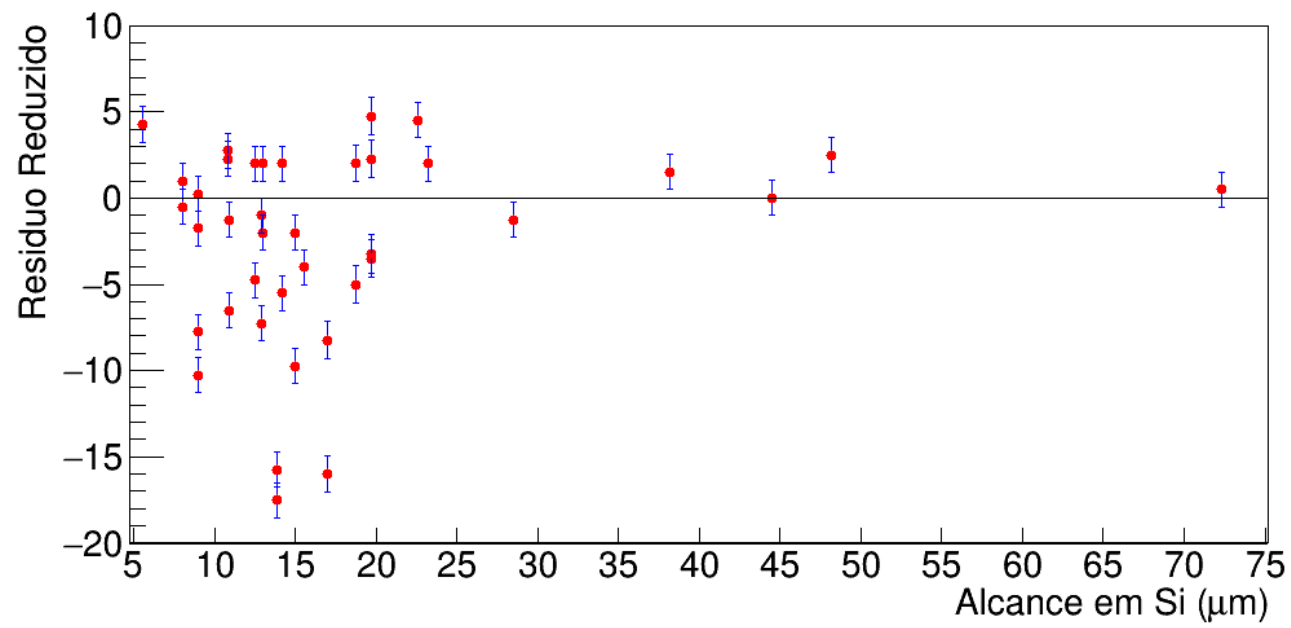

(b)

Figura 9.18: Resíduos reduzidos para a carga coletada na condição de $\chi^{2}$ mínimo. (a) Resíduo reduzido para cada condição (dado) analisada. (b) Resíduo reduzido em função do alcance em silício. 


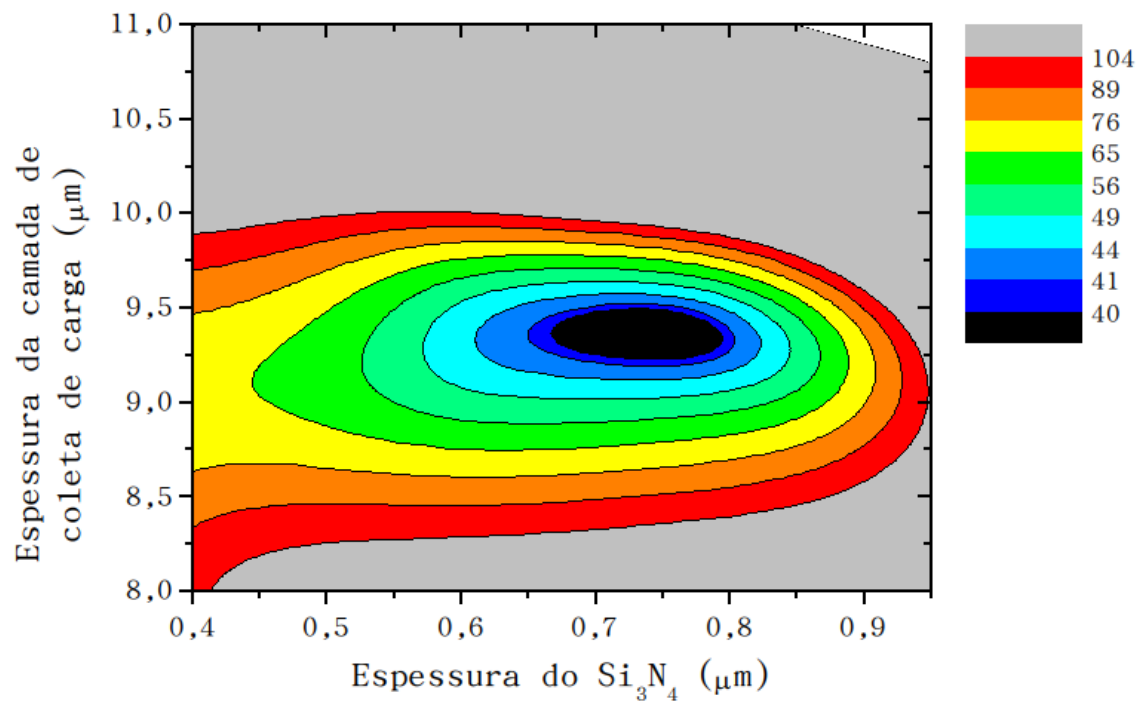

Figura 9.19: Distribuição de $\chi^{2}$ normalizado em função das espessuras do filme de nitreto de silício e da camada ativa. Os dados foram obtidos com passos de 0,05 $\mu \mathrm{m}$ de nitreto de silício e $0,2 \mu \mathrm{m}$ de silício. As curvas apresentadas foram suavizadas por interpolação.

O modelo de funil variável, conforme a Equação 8.5, possui dependência não apenas com o íon incidente, mas também com parâmetros do dispositivo, como dopagem, espessura de depleção, etc. Para contornar esta limitação, podemos combinar e reescrever as Equações 8.3 e 8.5 assumindo que a densidade média de pares produzidos é igual à densidade no ínicio do traço. Esta aproximação é válida apenas para os íons leves, dentro de uma incerteza de aproximadamente 10\%. A Equação 9.3 mostra que é possível escrever a carga coletada como uma relação linear com os parâmetros do dispositivo, representados por $\kappa$

$$
\begin{gathered}
Q=q \overline{N_{0}} L_{f}=q N_{0} \sqrt{\mu_{n} V_{0} \exp \left(-K N_{0}\right)}\left(\frac{3 N_{0}}{8 \pi N_{A} v_{P} \sqrt{D}}\right)^{1 / 3} \\
\Longrightarrow q N_{0}^{4 / 3} \sqrt{e^{-K N_{0}}} \kappa=\xi \kappa
\end{gathered}
$$

onde a variável $\xi$ depende apenas do íon em questão e todos os outros parâmetros já 
foram definidos anteriormente. A Figura 9.20 mostra o resultado do ajuste aos íons leves para obter o valor de $\kappa$ :

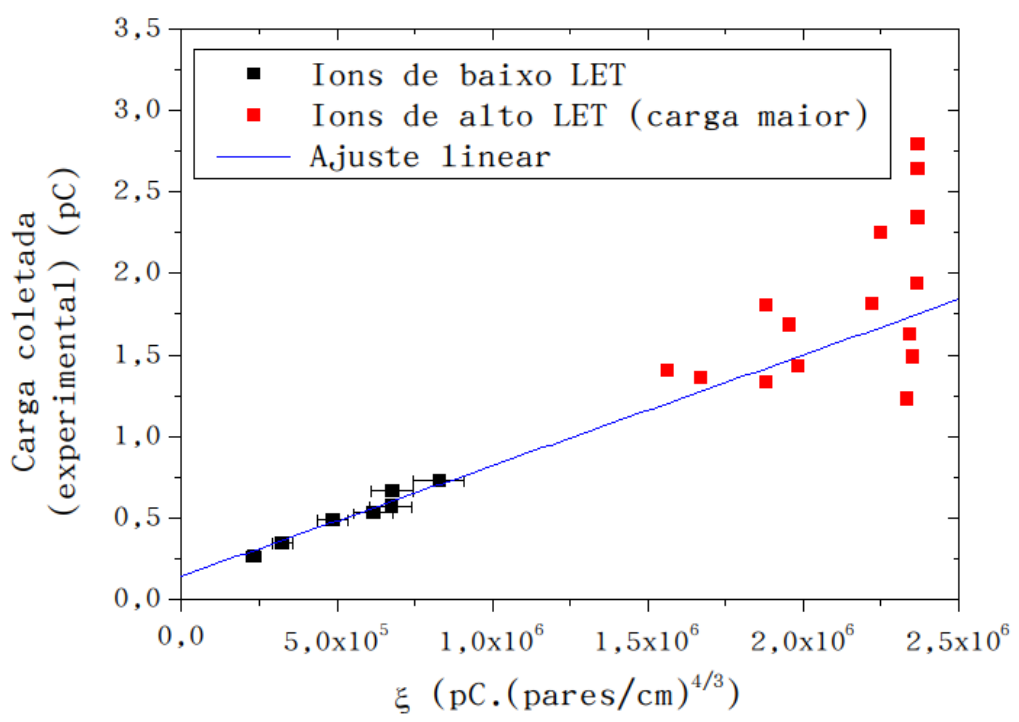

Figura 9.20: Relação de linearidade entre a carga e o parâmetro $\kappa$, dependente das características do dispositivo. O coeficiente de determinação da reta ajustada em relação aos pontos pretos é de 0,96, enquanto que em relação aos pontos vermelhos é de 0,23.

O valor do parâmetro $\kappa$ obtido foi de $6,78(88) \times 10^{-7} \mathrm{~cm}^{4 / 3}$ e o parâmetro linear do ajuste foi de $0,14(5) \mathrm{pC}$, marginalmente compatível com zero ${ }^{9}$. O valor de $\kappa$ que representa o dispositivo pode então ser utilizado para ajustar os dados com o modelo de funil variável. Neste modelo, assumimos o comprimento do funil dado pela Equação 8.5, com uma componente de carga coletada por difusão, em que a carga gerada após a região do funil pode, por difusão, chegar até este e ser coletada durante o tempo de duração do EHP. Segundo [111], o tempo de coleta de carga é dado por:

$$
\tau_{c}=\left(\frac{3 N_{0}}{8 \pi N_{A} v_{P} \sqrt{D}}\right)^{3 / 2}=\frac{\kappa^{2} N_{0}^{2 / 3}}{\mu_{n} V_{0}}
$$

\footnotetext{
${ }^{9}$ Como se verá adiante, o valor de $k$ proposto não é o mais adequado ao ajuste de dados. Com o valor de $k$ obtido neste trabalho, os valores de $\xi$ calculados são deslocados para a direita, aumentando a compatibilidade com zero do coeficiente linear da reta ajustada sem alterar o valor de $\kappa$.
} 
e o comprimento máximo que a carga pode difundir-se até atingir o funil durante este tempo igual a $\sqrt{D \tau_{c}}$ [120], em que todos os parâmetros foram definidos anteriormente. A Figura 9.21 mostra o comportamento da região de coleta de carga em função do LET do íon incidente.

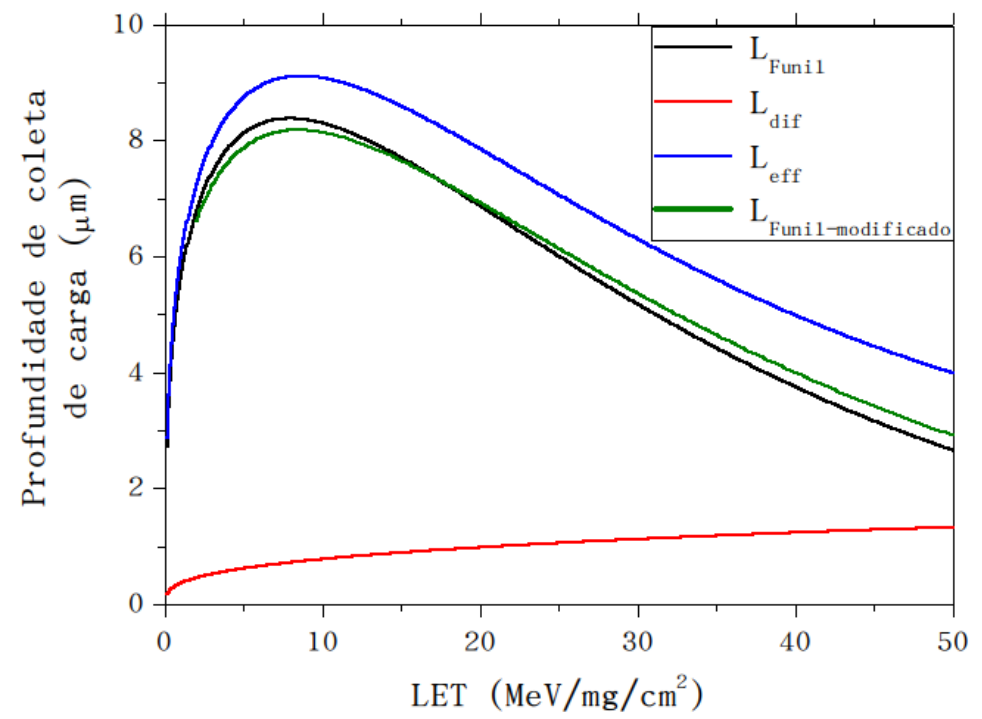

Figura 9.21: Espessura da região de coleta de carga em função do LET do íon no início da camada sensível.

Os primeiros resultados obtidos com esse modelo mostraram que o valor de $K=$ $1,3 \times 10^{-10} \mathrm{~cm} /$ par proposto por [112] não reproduz bem os dados; de fato, este valor havia sido obtido para íons de ${ }^{63} \mathrm{Cu} 70 \mathrm{MeV}$ a diversas tensões de porta $V_{0}$. Foram realizadas diversas simulações de maneira a obter a melhor descrição dos eventos observados, utilizando 3 formas de cálculo e variando o valor de $\mathrm{K}$ :

1. Funil segundo a Equação 8.5, incluindo a contribuição da difusão;

2. Funil segundo a Equação 8.5, incluindo a contribuição da difusão, com estequiometria da camada de nitreto de silício alterada para incluir o oxigênio observado na microanálise química; 
3. Comprimento de funil modificado $L_{\text {funil-modificado }}=\sqrt{e^{-K\left(N_{0}+1 / N_{0}\right)}} N_{0}^{1 / 3} \kappa$ (curva verde na Figura 9.21), incluindo a contribuição da difusão.

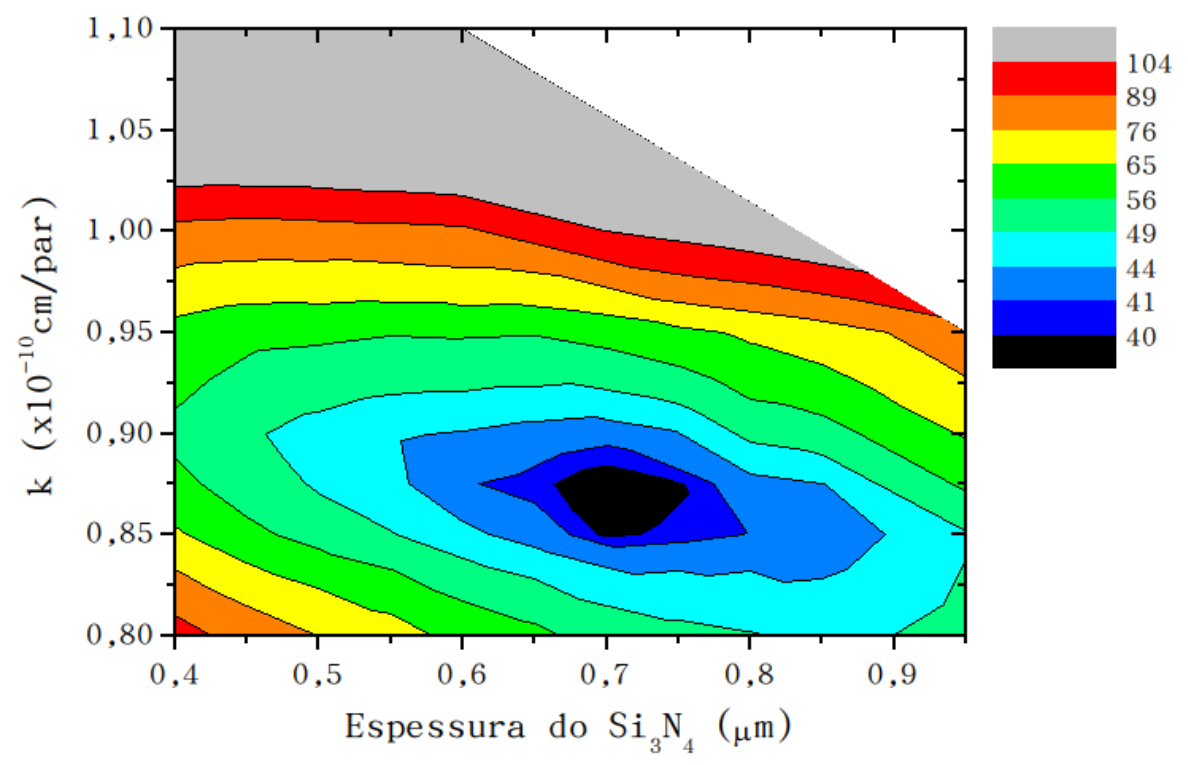

Figura 9.22: Distribuição de $\chi^{2}$ normalizado em função da espessura do filme de nitreto de silício e do valor do parâmetro $k$. Os dados foram obtidos com passos de $0,05 \mu \mathrm{m}$ de nitreto de silício e $0,25 \times 10^{-11} \mathrm{~cm} /$ par de silício. As curvas apresentadas foram suavizadas por interpolação.

As três situações geraram distribuições de resíduos bastante semelhantes, bem como valores mínimos de $\chi^{2}$, a saber: 1141, 1157 e 1158, respectivamente, todas com valor de $K=8,75 \times 10^{-11} \mathrm{~cm} /$ par e espessura de nitreto de silício igual a $0,70 \mu \mathrm{m}$. Novamente, aplicou-se o método de normalizar os valores de $\chi^{2}$ de maneira a obter as incertezas nos parâmetros com nível de confiança de 68\%, para a condição (1). A Figura 9.22 mostra o mapa de $\chi^{2}$ em função da espessura da camada de nitreto de silício e do valor de $k$, evidenciando a dependência entre as duas variáveis neste modelo, pois o comprimento da região de coleta de carga depende da energia com que o íon a atinge e que, por sua vez, depende da espessura da camada de nitreto de silício. Assim, os valores representativos obtidos para a espessura da camada de nitreto de silício e do 
parâmetro $k$ são, respectivamente, iguais a $0,71(5) \mu \mathrm{m}$ e $\left.8,7(2) \times 10^{(}-11\right) \mathrm{cm} / \mathrm{par}^{10}$.

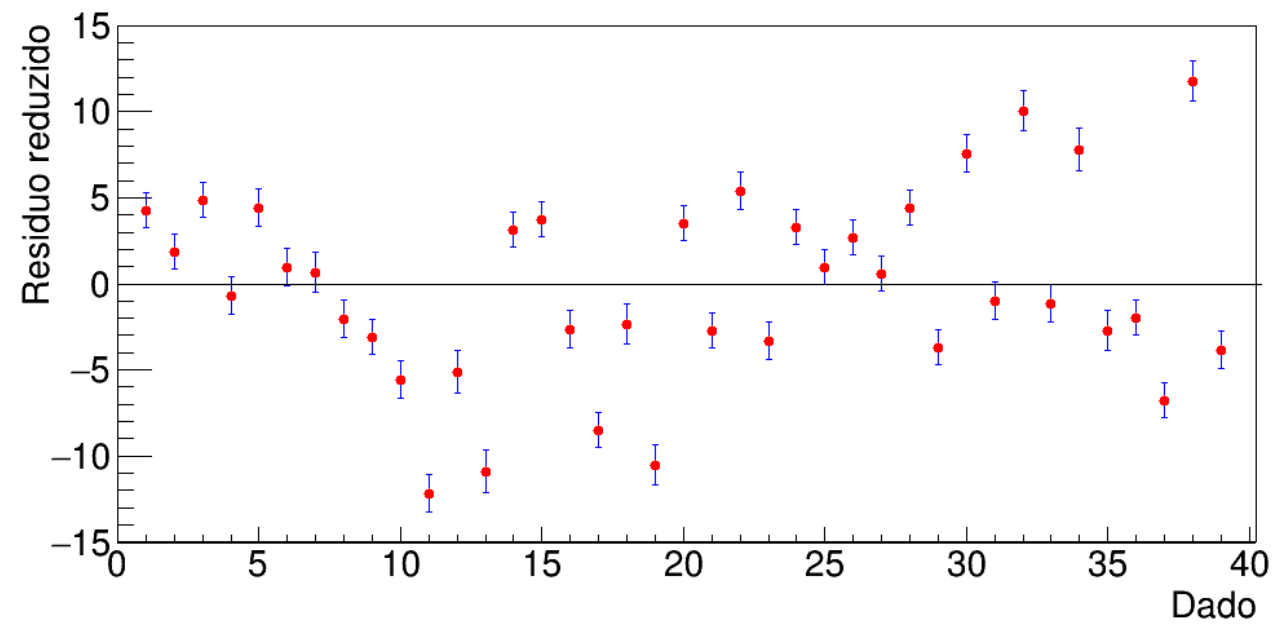

(a)

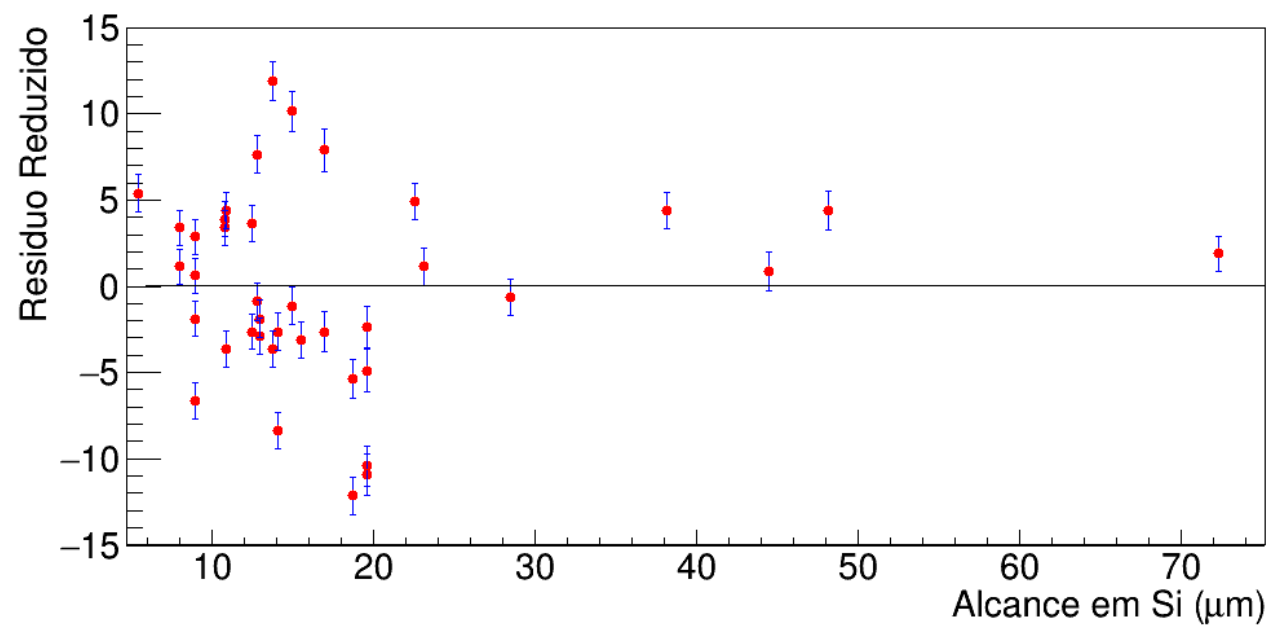

(b)

Figura 9.23: Resíduos reduzidos para a carga coletada na condição de $\chi^{2}$ mínimo e funil variável com fator $K=8,75 \times 10^{-11} \mathrm{~cm} /$ par. (a) Resíduo reduzido para cada condição (dado) analisada. (b) Resíduo reduzido em função do alcance em silício.

Por último, foi feita a variação da espessura de silício que minimizava o resíduo para cada íon separadamente, em passos de $0,05 \mu \mathrm{m}$. A Figura 9.23 mostra a distribuição

\footnotetext{
${ }^{10} \mathrm{O}$ baixo número de valores de $k$ simulados prejudicou a suavização por interpolação das curvas do mapa de $\chi^{2}$
} 
de resíduos para o caso (1) e a Figura 9.24 mostra os resultados das espessuras que minimizam cada resíduo.

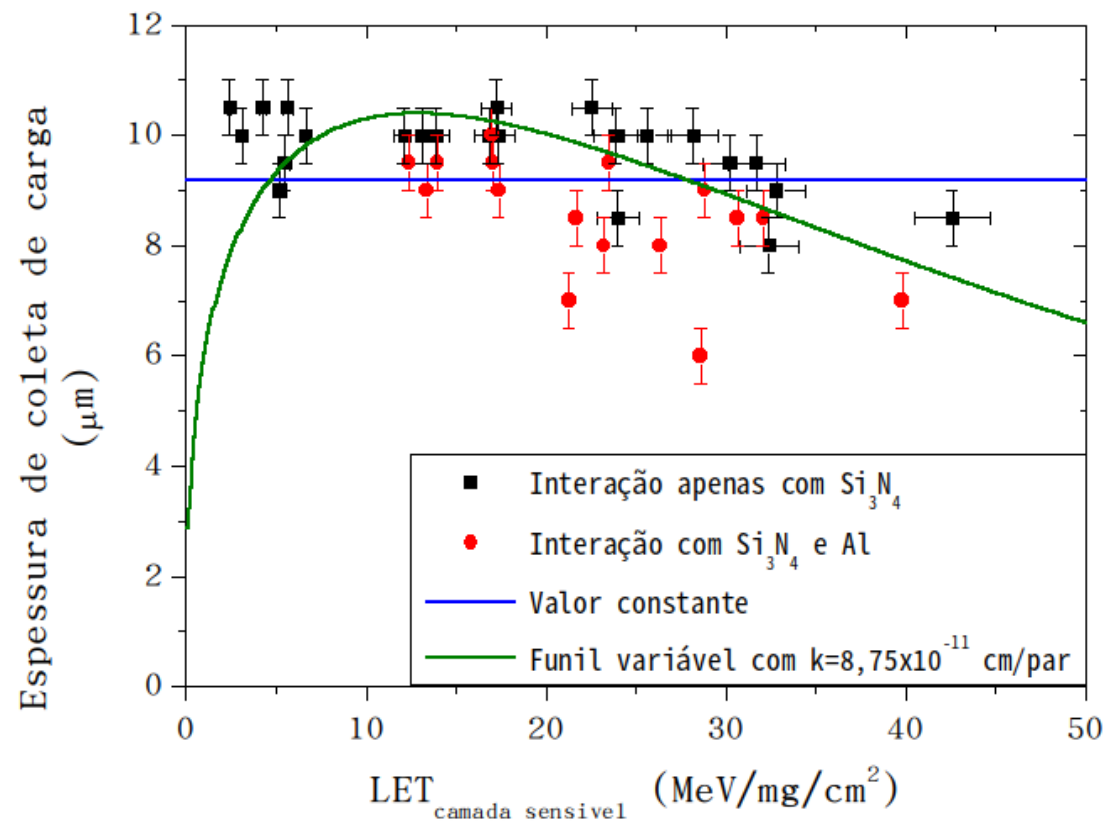

Figura 9.24: Espessura da região de coleta de carga que minimiza o resíduo em função do LET do íon no início da camada sensível.

\subsection{Resultados e considerações sobre a análise do caso ana- lógico}

Os valores de $\chi^{2}$ obtidos em todos os casos simulados para a região de coleta de carga foram extremamente altos $(\sim 1000)$, muito acima do número de graus de liberdade do sistema, indicando que os modelos utilizados são incompletos (ou mesmo inadequados) para a descrição da coleta de carga no p-MOSFET 3N163. Todavia, buscou-se uma maneira de descrever os fenômenos observados com o mínimo possível de informação extra sobre o dispositivo, que no caso correspondeu apenas à análise por microscopia eletrônica de varredura. Mesmo com a limitação de informações, observou-se que a descrição de espessura constante, apesar de prover valor de $\chi^{2}$ próximo aos outros observados, 
falha na descrição dos íons com alto número atômico e energia, de maneira tendenciosa, como na Figura 9.18a. Em contrapartida, a distribuição de resíduos é quase-aleatória para a condição de funil variável com valor de $K=8,7(2) \times 10^{-11} \mathrm{~cm} /$ par, e insensível à presença de oxigênio ou à expressão modificada para o comprimento do funil. Dizemos aqui "quase-aleatória"pois nos gráficos de resíduos é bastante claro que os pontos relativos à interação com nitreto+alumínio estão sistematicamente abaixo dos pontos correspondentes incidentes apenas no nitreto de silício, o que indica que existem fatores não considerados no modelo, como por exemplo a não-uniformidade da espessura do nitreto de silício, que poderia inclusive alterar o valor obtido para a espessura do alumínio. A Figura 9.24 mostra claramente como tanto a suposição de espessura constante quanto de funil variável, segundo a expressão proposta, são incompletas na descrição da coleta de carga, porém mostram-se adequados enquanto modelo semi-empírico de determinação de espessura de coleta de carga e independentes de parâmetros do dispositivo, permitindo a análise de dispositivos COTS sem recorrer a ensaios destrutivos ou outras análises, além da microscopia eletrônica de varredura. Tomando o resultado de funil variável como final (devido à distribuição de resíduos), temos que a caracterizaçao da resposta do dispositivo p-MOSFET 3N163 permitiu obter um valor de $K=8,7(2) \times 10^{-11} \mathrm{~cm} /$ par, espessura da metalização de alumínio igual a $1,28(2) \mu \mathrm{m}$ e espessura do nitreto de silício igual a $0,72(6) \mu \mathrm{m}$.

No tocante à seção de choque de ocorrência de eventos, observa-se o comportamento ilustrado na Figura 9.25. Separando os eventos de acordo com a região de interação e, portanto, a carga coletada (apenas nitreto, nitreto e alumínio e outliers), observa-se a diferente área efetiva de interação correspondente a cada um dos grupos de dados; comparando com a área do dreno (linha vermelha) e a área da borda em volta do dreno (linha azul), observa-se que estes valores são da mesma ordem de grandeza, indicando a concordância entre as várias análises realizadas, já que o dreno possui em sua superfície alumínio e nitreto de silício e a borda apenas nitreto de silício. As áreas em questão 
estão representadas na Figura 9.26, e pode-se explicar eventuais diferenças às regiões não consideradas na Figura, mas que podem coletar carga, embora com menor eficiência. Um valor mais preciso destas áreas demandaria a análise da intensidade do fluxo de corrente em cada região.

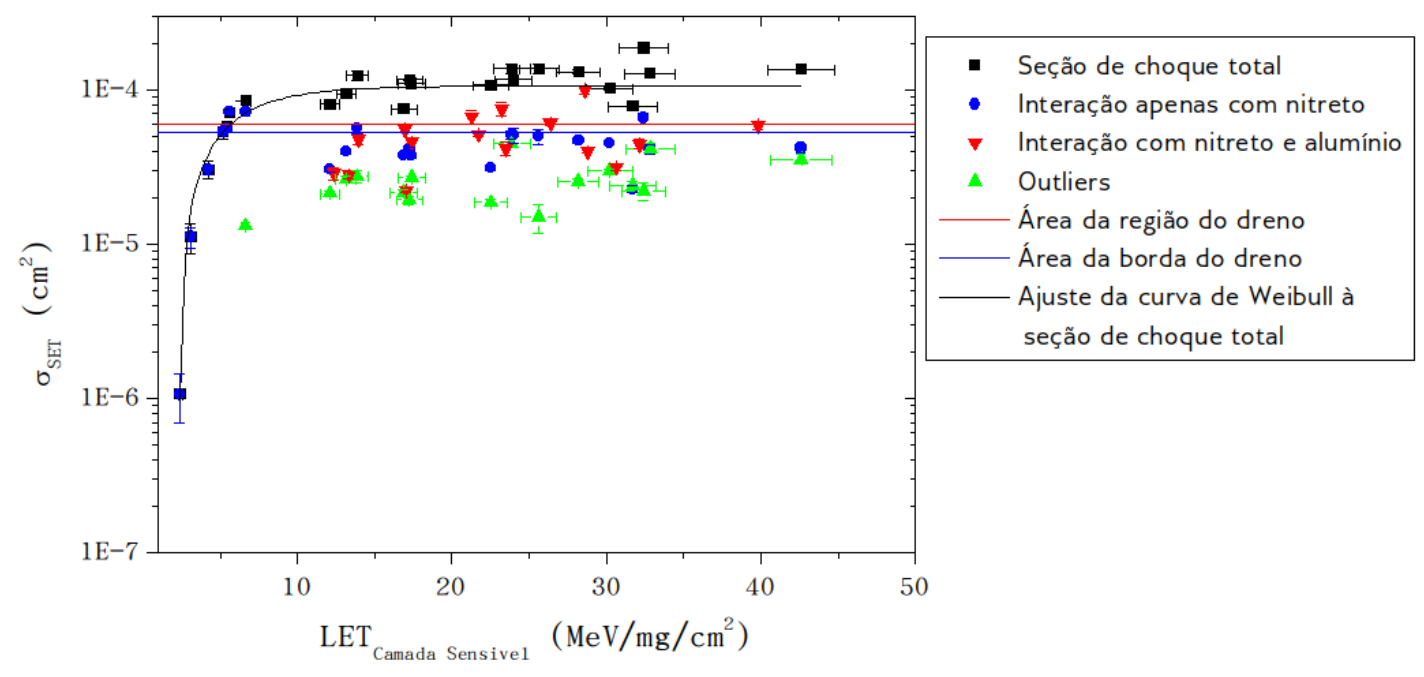

(a)

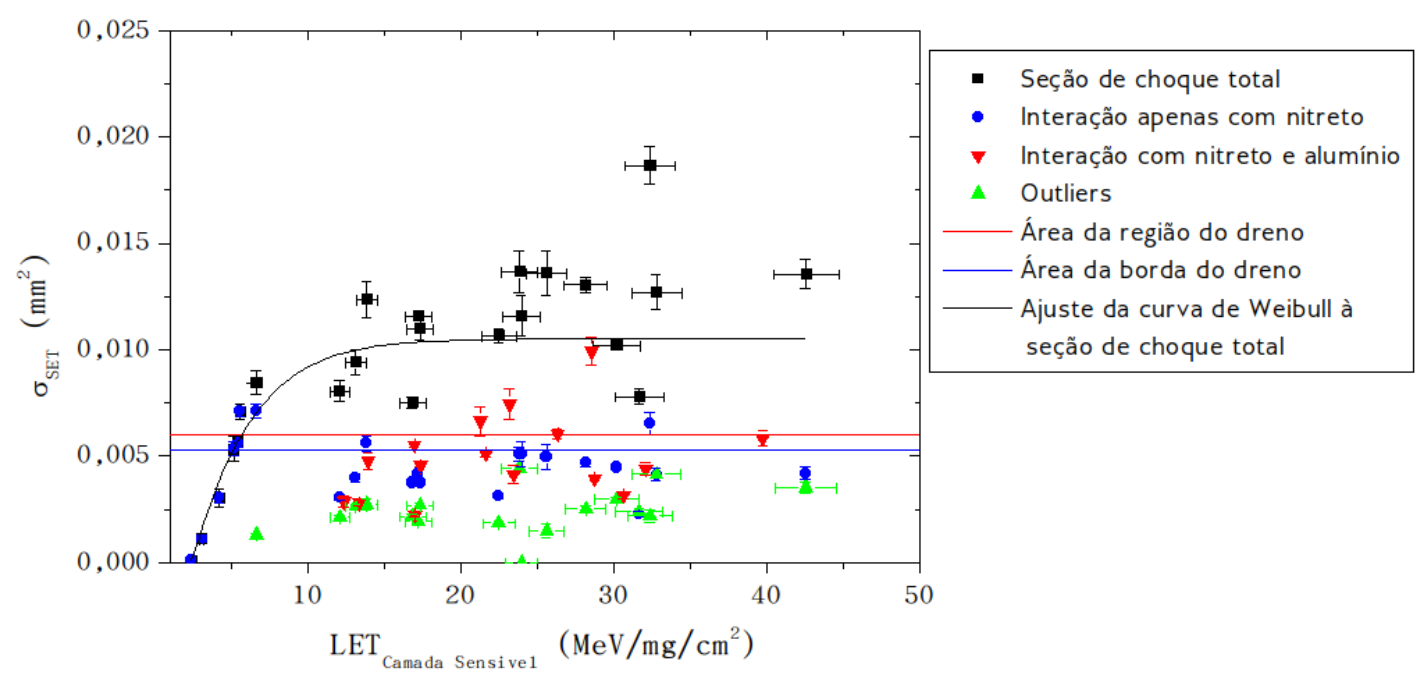

(b)

Figura 9.25: Seção de choque de eventos no p-MOSFET 3N163 em função do LET do íon. (a) Escala logarítmica. (b) Escala linear evidenciando a dispersão dos dados. 


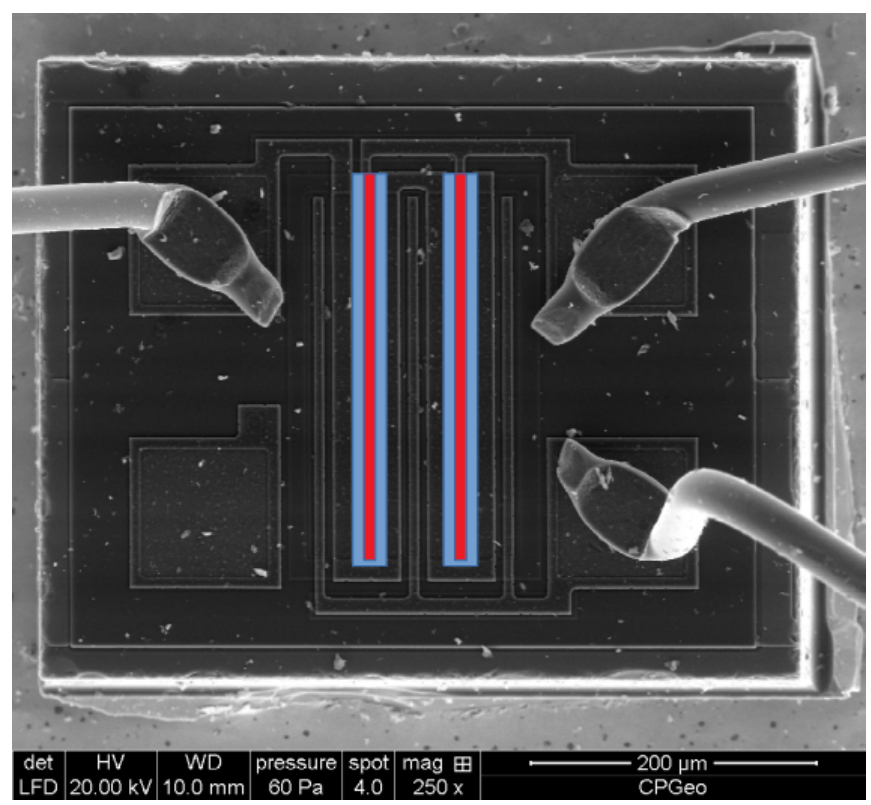

Figura 9.26: Áreas de coleta de carga no dispositivo 3N163. Em vermelho está representada a área do dreno e em azul a área da borda. Outras regiões entre a fonte e o dreno podem coletar carga também, dependendo do campo elétrico.

Os pontos outliers, que correspondem à parte uniforme das distribuições de carga apresentadas na seção 9.2, podem então ser reinterpretados da seguinte maneira: dado que as características do sinal, embora semelhantes, não são iguais às dos íons que interagiram no dreno ou na borda, e possuem, em geral, largura de pulso maiores, eles representam a coleta de carga por difusão numa região onde não há campo elétrico entre a fonte e o dreno, explicando a elevada dispersão dos valores de carga obtidos. Neste caso, existiria uma dependência com o LET do íon incidente que pode não ser descrita pela curva de Weibull. Estas hipóteses necessitam de mais análises para serem corroboradas ou descartadas.

A Figura 9.25b mostra ainda que a dispersão dos dados é maior do que a variação estatística, o que pode indicar a existência de fontes de erro não consideradas ou das diversas simplificações adotadas. Os resultados obtidos com o ajuste da curva de Weibull à seção de choque total são mostrados na Tabela 9.2. 
Tabela 9.2: Parâmetros do ajuste da curva de Weibull à seção de choque total do p-MOSFET 3N163

\begin{tabular}{cc}
\hline Parâmetro & Valor \\
\hline$\sigma_{\text {sat }}\left(\mathrm{cm}^{2}\right)$ & $1,05(6) \cdot 10^{-4}$ \\
$L E T_{\text {th }}\left(\mathrm{MeV} / \mathrm{mg} / \mathrm{cm}^{2}\right)$ & $2,35(13)$ \\
$\mathrm{w}\left(\mathrm{MeV} / \mathrm{mg} / \mathrm{cm}^{2}\right)$ & $3,9(10)$ \\
$\mathrm{s}$ & $1,08(46)$ \\
$\chi_{\text {red }}^{2}$ & 23 \\
\hline
\end{tabular}




\section{Capítulo 10}

\section{Um caso digital}

No capítulo anterior foi apresentado um estudo da resposta de um dispositivo analógico à incidência de íons pesados acelerados, em que a influência e as dimensões das camadas sensíveis e de coleção de carga foram determinadas através de diversas técnicas experimentais e abordagens teóricas e de simulação. Neste capítulo, o caso de um dispositivo digital composto de milhões de transistores será apresentado. A estrutura complexa e a impossibilidade de obter leituras de carga torna este caso mais desafiador sob todos os aspectos.

\section{$10.1 \quad$ FPGA ZYNQ-7020}

O sistema FPGA é um hardware configurável utilizado em diversas aplicações, seja em desenvolvimento ou em sistemas embarcados. Um dos tipos mais comuns de FPGA é o baseado em memórias SRAM, de maneira que a configuração das portas lógicas se dá através da escrita adequada de "0"s e "1"s nesta memória. Esta estrutura permite analisar a ocorrência de bit-flips na memória SRAM de configuração. Determinar a sensibilidade de uma determinada tecnologia usada para a construção de memórias SRAM possui especial interesse aos desenvolvedores de sistemas embarcados. 
Para realizar os ensaios, foi escolhido um FPGA Xilinx Zynq-7000 XC7Z020¹, que possui no mesmo circuito integrado a lógica programável que compõe o FPGA propriamente dito, módulos de I/O e comunicação, um processador $\mathrm{ARM}^{2}$, entre outras funcionalidades $[132,133]$. O dispositivo em questão foi utilizado em uma placa de desenvolvimento educacional PYNQ-Z1 [133], que permite comunicação através de uma entrada USB e configuração em linguagem Python. O dispositivo Zynq-7020 é fabricado em tecnologia $28 \mathrm{~nm}$ e utiliza cerca de $69 \%$ de suas células SRAM (17 megabits) para configuração, e o restante como memória de acesso disponível ao usuário. Nesta tecnologia, a área típica de uma célula de memória SRAM é de cerca ${ }^{3}$ de $0,1 \mu m^{2}$. A Figura 10.1a mostra a placa de desenvolvimento utilizada, a Figura 10.1b mostra o circuito integrado após o processo de desencapsulamento e a Figura 10.1c ilustra as diferentes regiões do circuito integrado.

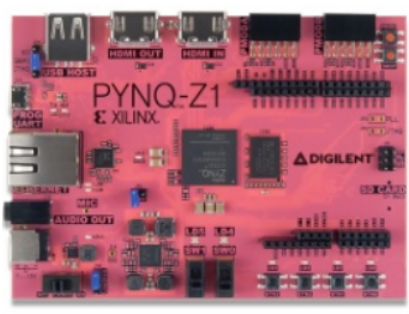

(a)

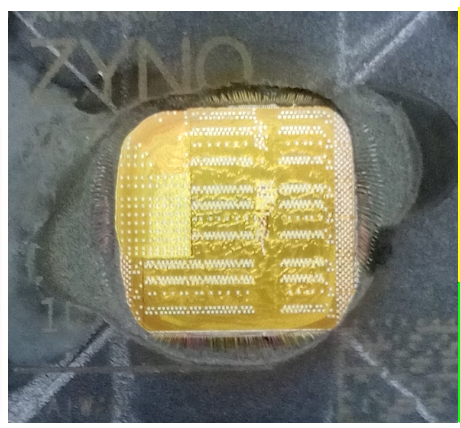

(b)

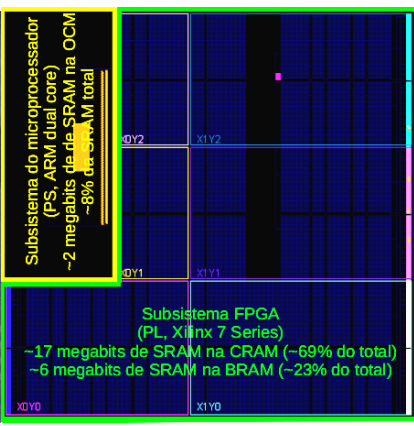

(c)

Figura 10.1: Dispositivo Zynq-7020. (a)Fotografia da placa de ddesenvolvimento PYNQ-Z1. (b) Fotografia do FPGA Zynq-7020 desencapsulado. (c) Desenho esquemático das regiões que compõem o FPGA Zynq-7020 (cortesia de Fábio Benevenuti).

\footnotetext{
${ }^{1} \mathrm{O}$ autor agradece e destaca a colaboração de Fábio Benevenuti da Universidade Federal do Rio Grande do Sul, que cedeu o dispositivo para os experimentos e desenvolveu os designs para observação dos bit-flips no FPGA.

${ }^{2}$ Os microcontroladores ARM (Advanced RISC Machine) possuem uma arquitetura do tipo RISC (Reduced Instruction Set Architecture, que prioriza um conjunto pequeno de instruções simples que podem ser executadas aproximadamente durante o mesmo intervalo de tempo, correspondente a um clock do processador. Este sistema permite melhor utilização dos registradores e diminuição dos acessos à memória, melhorando o desempenho dos sistemas.

${ }^{3}$ Estas informações não são disponibilizadas pelo fabricante.
} 
Para realizar a contagem de bit-flips, a memória de configuração foi preenchida com uma sequência aleatória de "0"s e "1"s, na proporção de $50 \%$ cada. Um script em Python em execução no computador de aquisição de dados enviava à placa a sequência de bits a ser gravada. Uma vez configurada, os sistemas de processamento e comunicação do FPGA foram utilizados para fazer a leitura da memória de configuração e enviar estas informações ao computador de aquisição, que, por comparação com a sequência inicial, era capaz de detectar e contar os bit-flips que ocorreram naquele ciclo de leitura. Após a leitura, a sequência original era reescrita na memória de configuração, e as alterações ocorridas durante este processo eram lidas no próximo ciclo. O programa ainda registrava o endereço dos bits alterados, tornando possível a posterior análise de multiple bit upsets. A probabilidade de alterações não serem registradas durante o processo de gravação foi minimizada utilizando fluxos de partículas abaixo de 2000 particulas $/ \mathrm{s} / \mathrm{cm}^{2}$.

\subsection{Informações estruturais}

Um dispositivo digital como o FPGA Zynq-7020 possui uma estrutura muito mais complexa do que um transistor simples e que ainda depende do corte em que a estrutura é analisada, uma vez que as diversas sub-estruturas não estão distribuídas de maneira uniforme. A Figura 10.2 ilustra a quantidade de materiais diferentes numa estrutura CMOS como o dispositivo de que tratamos aqui.

Dada a enorme quantidade de componentes, o diminuto tamanho e a distribuição não-uniforme, as técnicas analíticas como microscopia eletrônica de varredura, RBS (mesmo com a utilização de microfeixes) ou fluorescência de raios X não permitem, na prática, conhecer todos os detalhes de uma estrutura $\operatorname{assim}^{4}$, de modo que a melhor

\footnotetext{
${ }^{4}$ Tal análise seria inviável tanto em termos de tempo quanto de custo. Mesmo que tal análise fosse realizada, o tratamento de dados e simulações considerando uma estrutura com este nível de complexidade e detalhe seria muito difícil e de pouca utilidade prática.
} 
forma de investigar a influência das camadas de passivação e metalização deve ser em termos de comportamentos médios.

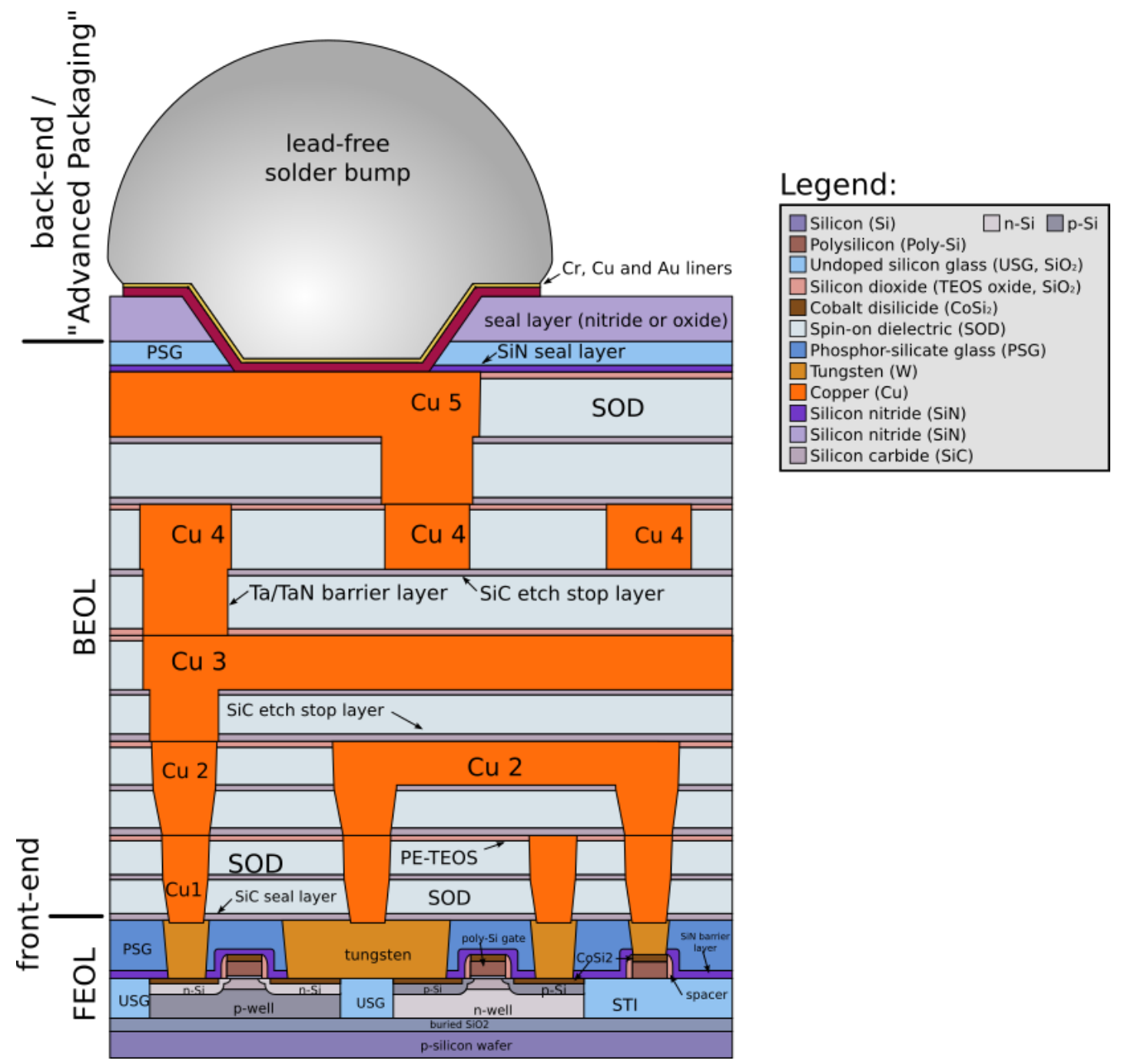

Figura 10.2: Desenho representando os diversos materiais e estruturas em dispositivos como o FPGA Zynq-7020 (reproduzido de [134]).

Segundo informações do fabricante [132], o dispositivo Zynq-7020 possui 11 camadas de metalização, das quais dez são compostas de cobre e uma de alumínio, e o óxido de porta é um óxido metálico de alta constante dielétrica (provavelmente dióxido de háfnio). Em um trabalho anterior utilizando um mesmo modelo de FPGA [135], utilizou-se 
como estimativa para a espessura do BEOL $12,87 \mu \mathrm{m}$, sendo $7,87 \mu \mathrm{m}$ de cobre e $5,0 \mu \mathrm{m}$ de isolante, considerado naquele trabalho como dióxido de silício. A Figura 10.3 mostra uma imagem de microscopia eletrônica de varredura do FPGA Zynq-7020, onde é possível localizar o início da região sensível, onde os contatos e estruturas deixam de existir.

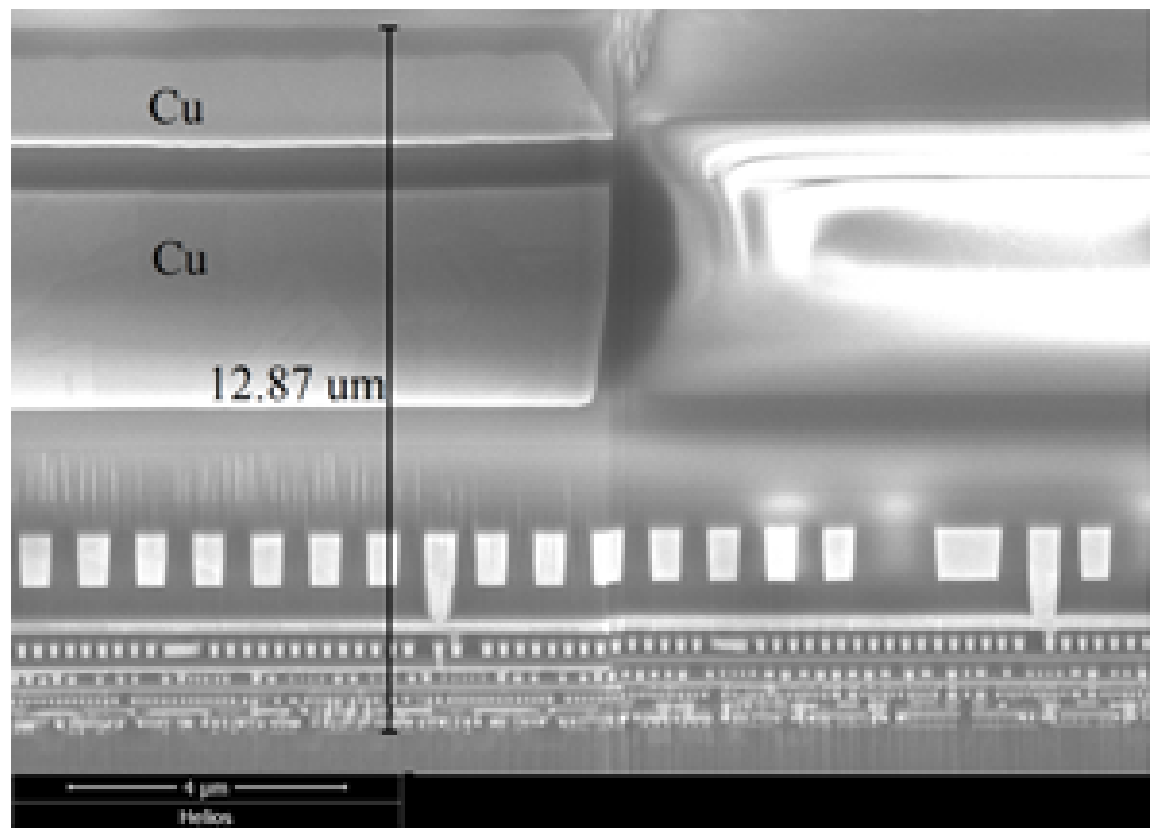

Figura 10.3: Eletromicrografia de uma seção transversal do dispositivo Zynq-7020 (reproduzido de [135]).

Como se verá na próxima seção, estimar que os íons atravessem sempre uma camada de cobre de 12,87 $\mu \mathrm{m}$ e uma camada de 5,0 $\mu \mathrm{m}$ de dióxido de silício é incompatível com os resultados observados neste trabalho, em que os íons mais pesados em energias menores não são capazes de penetrar tal espessura deste material, portanto incapazes de depositar energia na camada sensível, a não ser por processos secundários pouco prováveis [136]. 


\subsection{Ensaios com feixes de íons pesados no SAFIIRA (2)}

Como na montagem anterior, a placa com o dispositivo sob teste foi montada num suporte porta-amostras, posicionado atrás do sistema manipulador de amostra, enquanto neste estava montado um conjunto composto por um copo de Faraday e um detector barreira de superfície para medida da intensidade do feixe e calibração. Em cada uma das câmaras gêmeas foram posicionadas duas folhas de ouro para espalhamento do feixe, e as combinações das folhas resultaram em espessuras totais de 1,57; 2,48 e $2,76 \mathrm{mg} / \mathrm{cm}^{2}$. As diferentes combinações de folhas espalhadoras permitiram pequenas mudanças de energia efetiva do feixe sem mudança nas condições do acelerador, de maneira que apenas a recalibração de fluxo foi necessária. O ajuste de foco do feixe foi feito de maneira a obter fluxo inferior a $2 \times 10^{3} \mathrm{part} / \mathrm{s} / \mathrm{cm}^{2}$.

A cada mudança de energia do feixe, seja na mudança das folhas de ouro ou das condições do acelerador, foi feita uma rodada de calibração do fluxo de partículas e uma rodada de irradiação, sempre otimizando a relação tempo x incerteza de maneira a obter incertezas finais da ordem de $5 \%$, exceto nos casos em que a baixa seção de choque tornaria o tempo proibitivo.

Com o objetivo de determinar a influência da camada sensível no dispositivo digital, os feixes e energias foram escolhidos de maneira a obter uma ampla variação tanto de LET quanto de alcance dos feixes no dispositivo. A Tabela 10.1 apresenta os íons utilizados nas irradiações do FPGA Zynq-7020, a energia inicial e a energia efetiva após o espalhamento pelas duas folhas de ouro e o número de pontos experimentais adquiridos. 
Tabela 10.1: Feixes iônicos e faixas de energias (inicial e efetiva) utilizados nas irradiações do Zynq-7020.

\begin{tabular}{cccc}
\hline $\begin{array}{c}\text { Feixe } \\
\text { Iônico }\end{array}$ & $\begin{array}{c}\text { Energia } \\
(\mathrm{MeV})\end{array}$ & $\begin{array}{c}\text { Energia Efetiva } \\
(\mathrm{MeV})\end{array}$ & $\begin{array}{c}\text { Número de Pontos } \\
\text { Experimentais }\end{array}$ \\
\hline${ }^{1} \mathrm{H}$ & 12 & 12 & 1 \\
${ }^{7} \mathrm{Li}$ & $20-28$ & $19,2-27,7$ & 5 \\
${ }^{10} \mathrm{~B}$ & $16-45$ & $13,1-43,1$ & 21 \\
${ }^{12} \mathrm{C}$ & $20-54$ & $16,5-51,3$ & 37 \\
${ }^{14} \mathrm{~N}$ & $27-42$ & $22,2-37,9$ & 3 \\
${ }^{16} \mathrm{O}$ & $32-70$ & $26,7-65,5$ & 31 \\
${ }^{19} \mathrm{~F}$ & $35-63$ & $27,7-56,8$ & 20 \\
${ }^{28} \mathrm{Si}$ & $56-86$ & $42,4-76,7$ & 25 \\
${ }^{35} \mathrm{Cl}$ & $54-85$ & $36,2-75,2$ & 6 \\
${ }^{48} \mathrm{Ti}$ & $75-90$ & $61,4-76,3$ & 3 \\
${ }^{56} \mathrm{Fe}$ & $75-97$ & $59,1-80,5$ & 2 \\
${ }^{63} \mathrm{Cu}$ & $90-106$ & $72-87,5$ & 3 \\
\hline
\end{tabular}

Foram registrados os bit-flips e a fluência de partículas em cada condição, permitindo o cálculo da seção de choque de eventos. Para evitar erros sistemáticos de contagens, o script de leitura era iniciado e, apenas após um ciclo completo indicar que não houve nenhuma alteração, o feixe era liberado em direção ao dispositivo. Ao final da medida, o feixe era retirado e o número de erros contabilizado apenas após a ocorrência de um ciclo sem erros.

Para todas as condições foram adquiridos entre 50 e 10000 eventos, dependendo do tempo necessário para a aquisição, exceto em quatro casos de baixa seção de choque. No total, foram realizadas 157 irradiações com feixes/energias diferentes.

A Figura 10.4 mostra a variação da seção de choque medida em função da energia efetiva para os feixes entre boro e silício, e a Figura 10.5 mostra a variação da seção de choque em função do alcance calculado tomando a estrutura do BEOL como sendo composta por uma camada de cobre de $7,87 \mu \mathrm{m}$ e uma camada de 5,0 $\mu \mathrm{m}$ de dióxido de silício. 


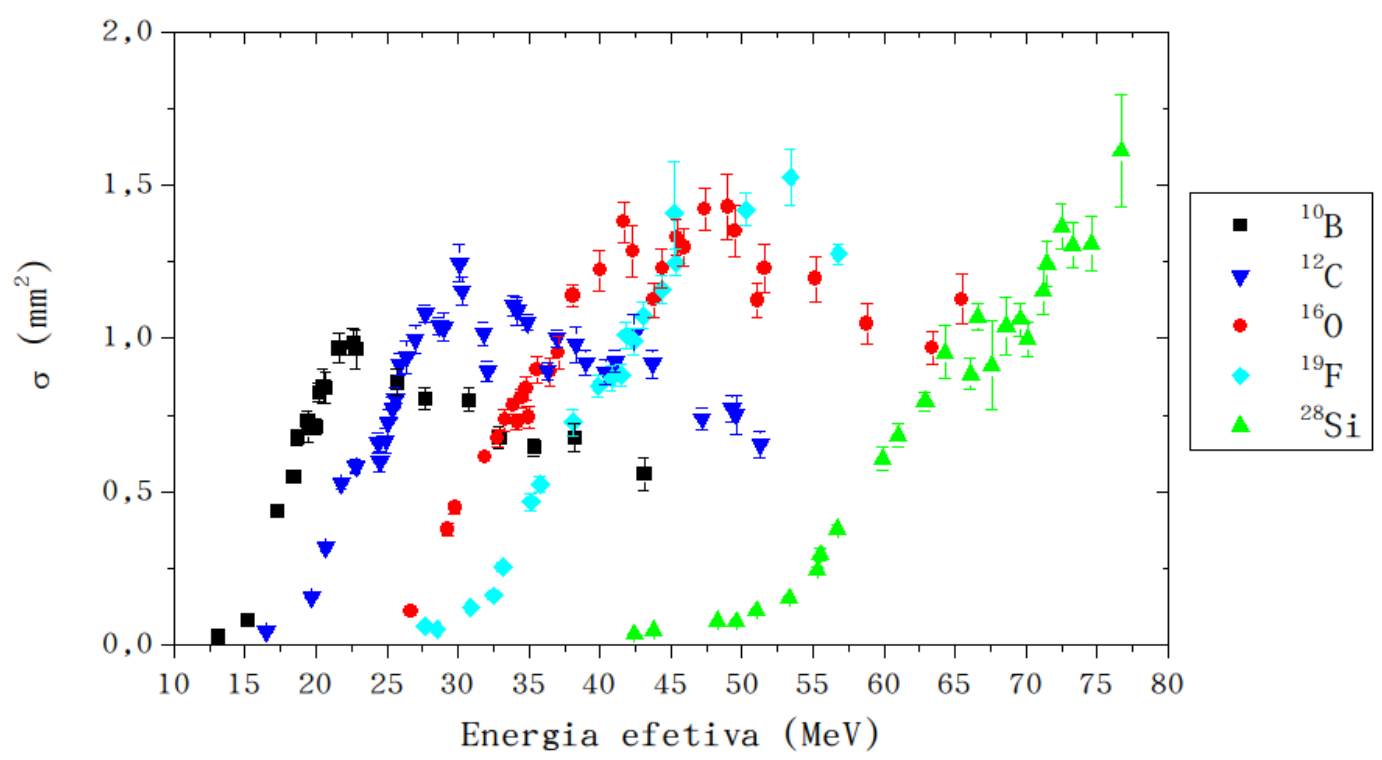

Figura 10.4: Seção de choque de SEU em função da energia efetiva no dispositivo no FPGA Zynq-7020.
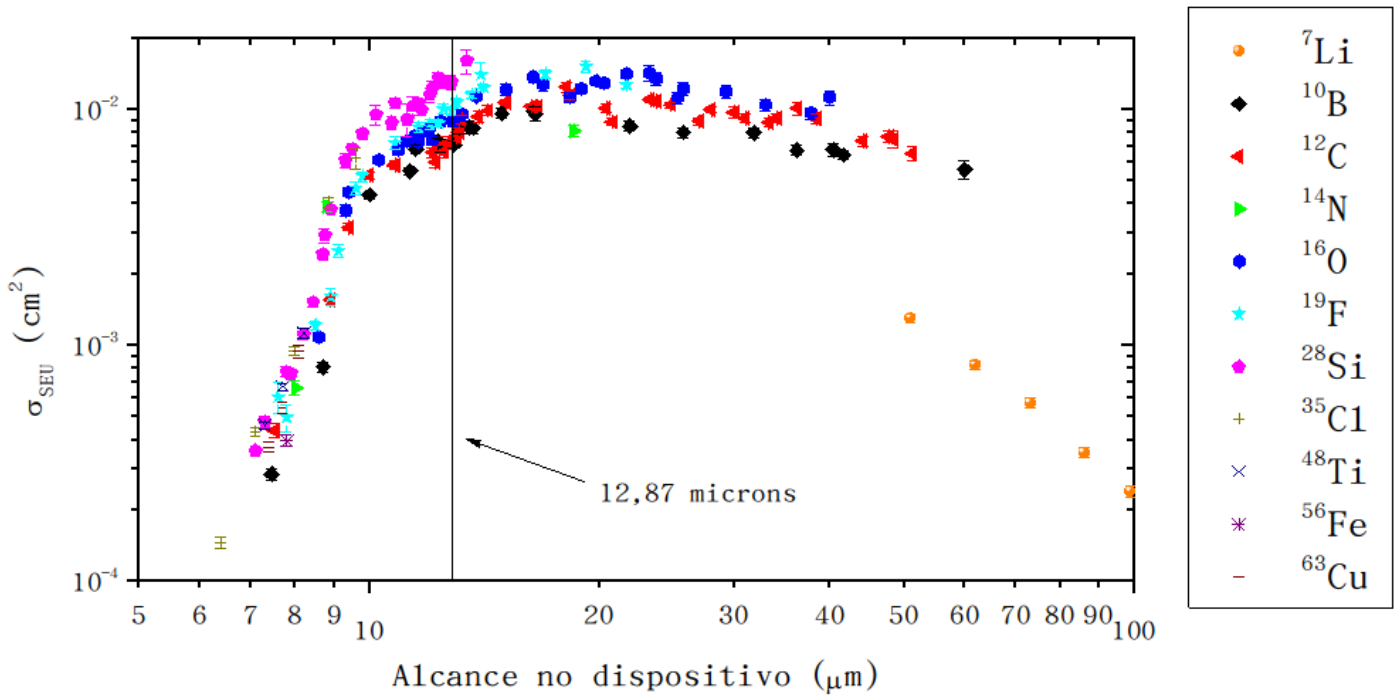

Figura 10.5: Seção de choque de SEU em função do alcance das partículas no FPGA Zynq-7020.

Observa-se uma forte dependência da seção de choque de eventos com a energia e, portanto, a penetração do íon no dispositivo. Considerando a estrutura do BEOL da 
maneira descrita, feixes com penetração muito inferior aos $12,87 \mu$ m são capazes de gerar eventos observáveis. Para explicar este fenômeno, existem três opções:

1. As células de memória não estão localizadas todas no mesmo plano. Esta alternativa não condiz com a tecnologia do dispositivo em questão, e pode ser descartada;

2. Coleção de carga acima da região ativa. Esta hipótese também pode ser descartada devido à ausência da camada de depleção dos transistores, onde a carga coletada é capaz de gerar mudança de estado;

3. Nem todas as partículas, a uma dada energia, são capazes de penetrar até o volume sensível. Entretanto, em algumas regiões a espessura total de cobre é menor, permitindo que tais partículas atinjam a região sensível nestes casos.

A título de exemplo, para os feixes e energias considerados, a penetração em dióxido de silício supera $12 \mu \mathrm{m}$ em todos os casos, justificando maior investigação do caso 3.

\subsection{Simulações de LET efetivo}

Dada a complexidade do dispositivo, o procedimento utilizado no estudo do caso analógico é impraticável, bem como todas as tentativas de simular as diferentes camadas e composições mostrou-se inconclusiva e extremamente exigente em termos computacionais. Para contornar esta dificuldade, adotou-se o procedimento de considerar o BEOL como composto por um único material, em relação ao qual pode-se estudar o comportamento da seção de choque em função da energia do íon incidente. Uma das principais suposições deste modelo é que, para os íons que apresentam um crescimento de seção de choque seguido de uma queda suave, o máximo de seção de choque ocorre na posição do pico de Bragg do íon. Assim, o cálculo da posição do pico de Bragg nesse meio equivalente permite conhecer a profundidade sensível do material. A Figura 10.6 ilustra o procedimento adotado. 
Para obter uma descrição média do meio, considerou-se este composto por dióxido de silício e cobre uniformemente distribuídos, na razão estequiométrica Si:O:Cu=10:20:6 e densidade igual a $2,5 \mathrm{~g} / \mathrm{cm}^{3}$. Sendo a escolha do material completamente arbitrária, estes valores foram adotados tomando como base que as camadas de cobre possuem, em média $0,8 \mu \mathrm{m}$ de espessura (dada a espessura total de $7,87 \mu \mathrm{m}$ ), e tal material possuiria composição equivalente à de dióxido de silício e uma camada de cobre. A este meio chamaremos de "dispositivo equivalente", $D_{e q}$.

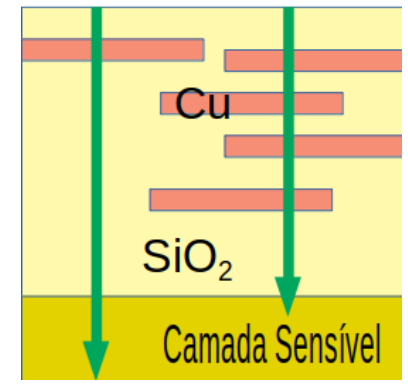

(a)

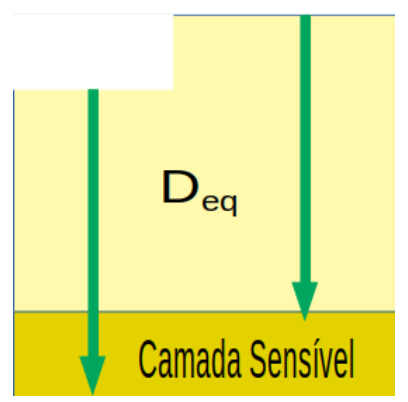

(b)

Figura 10.6: Ilustração do meio equivalente. (a) Estrutura real. (b) Estrutura equivalente.

Com estas suposições, foram construídos gráficos de seção de choque de SEU (normalizada pelo valor máximo) em função do alcance da partícula em $D_{e q}$ e do LET médio depositado na região de coleta de carga. Uma vez que a região de coleta de carga é extensa neste meio fictício, considere-se a região de 8,0 a 10,0 $\mu \mathrm{m}$, correspondente ao alcance das partículas menos penetrantes capazes de gerar upsets. Os cálculos foram realizados por meio da integração da curva de ionização gerada pelo programa SRIM para cada um dos íons analisados. A Figura 10.7 ilustra os valores de seção de choque normalizadas $^{5}$ (mapa de cores) em função do LET entre 8,0 a 10,0 $\mu \mathrm{m}$ e do alcance no meio equivalente. Observa-se que os valores máximos de seção de choque ocorrem para íons com alcance no meio entre 14 e $20 \mu \mathrm{m}$.

\footnotetext{
${ }^{5}$ Valores normalizados pela máxima seção de choque observada, a saber: $0,016(2) \mathrm{cm}^{2}$.
} 


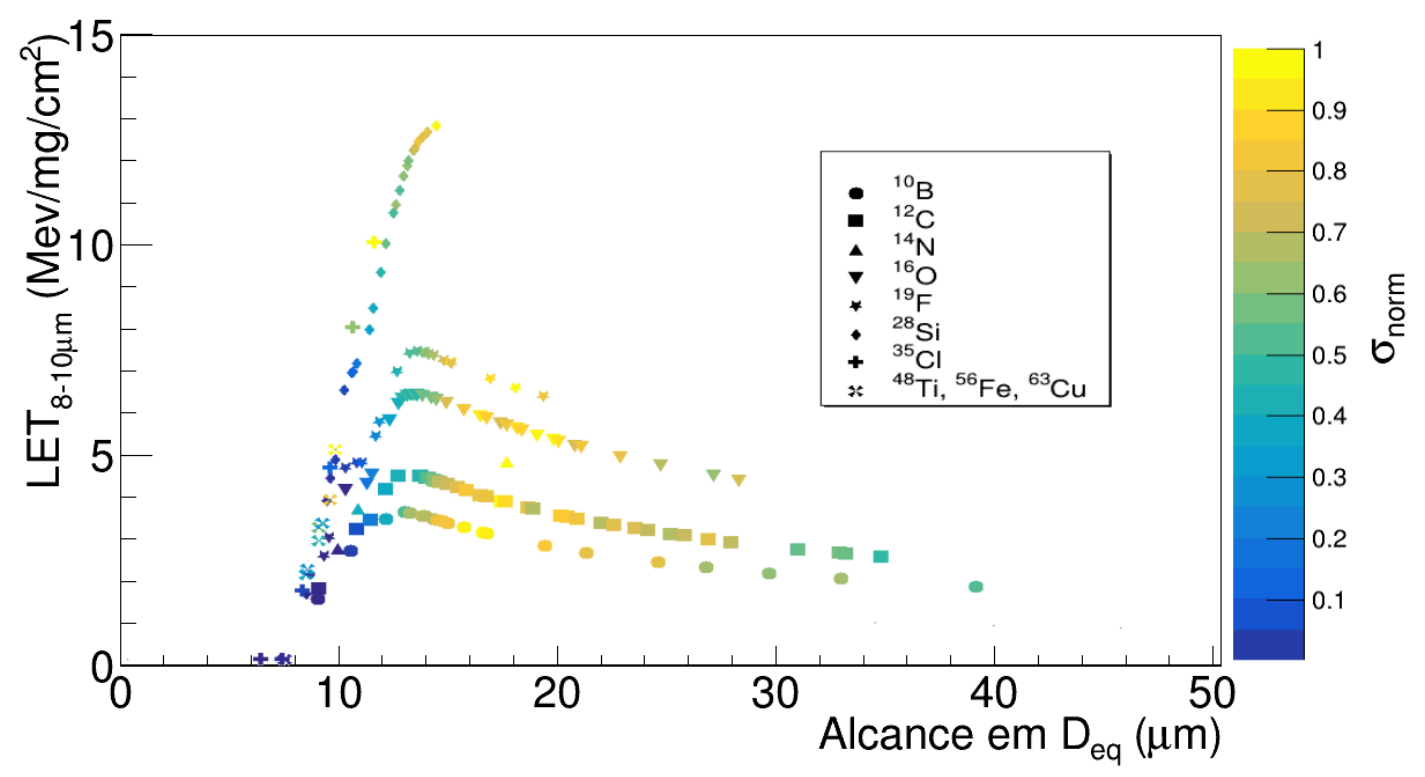

Figura 10.7: Seção de choque (mapa de cor) em função do LET e alcance no meio equivalente.

Partindo do pressuposto de que o pico de Bragg corresponde à máxima seção de choque, a Figura 10.8 ilustra os valores da seção de choque em função do LET entre 14 e $15 \mu \mathrm{m}$, correspondentes ao início da maior área sensível, e em função da posição do pico de Bragg de cada íon no material. Neste caso, observa-se que os máximos valores de LET ocorrem para posições do pico de Bragg entre 14 e $18 \mu \mathrm{m}$ para os íons de ${ }^{10} \mathrm{~B},{ }^{12} \mathrm{C},{ }^{16} \mathrm{O},{ }^{19} \mathrm{~F}$ e ${ }^{28} \mathrm{Si}$ e são correspondentes aos valores máximos de seção de choque.

Estes resultados mostram que, no meio equivalente $D_{e q}$, apenas íons com alcance superior a $20 \mu \mathrm{m}$ são capazes de excitar todas as possíveis áreas sensíveis do dispositivo. Os íons com alcance inferior a $20 \mu \mathrm{m}$ são capazes de excitar apenas uma parte das áreas sensíveis, aquelas que, no dispositivo real, possuem menor número de conexões de cobre entre elas e a superfície, e que, em $D_{e q}$, estariam localizadas em menor profundidade.

A Figura 10.9 mostra a seção de choque de SEU em função do LET para diversas faixas de valores de alcance dos íons. Os valores de LET foram calculados no início 
destas faixas, ou seja, para a faixa de alcance entre 14 e $16 \mu \mathrm{m}$, o LET foi calculado entre 14 e $15 \mu \mathrm{m}$.

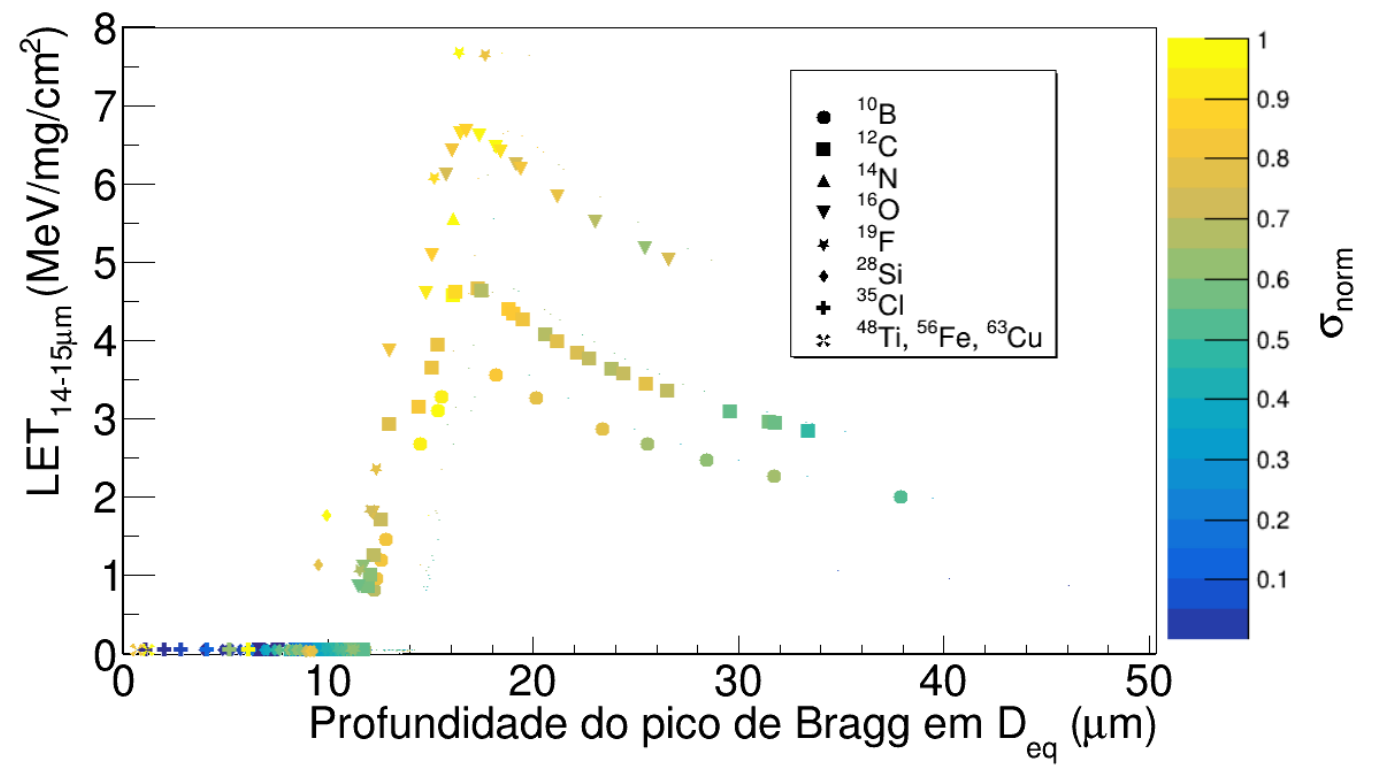

Figura 10.8: Seção de choque (mapa de cor) em função do LET e posição do pico de Bragg no meio equivalente.

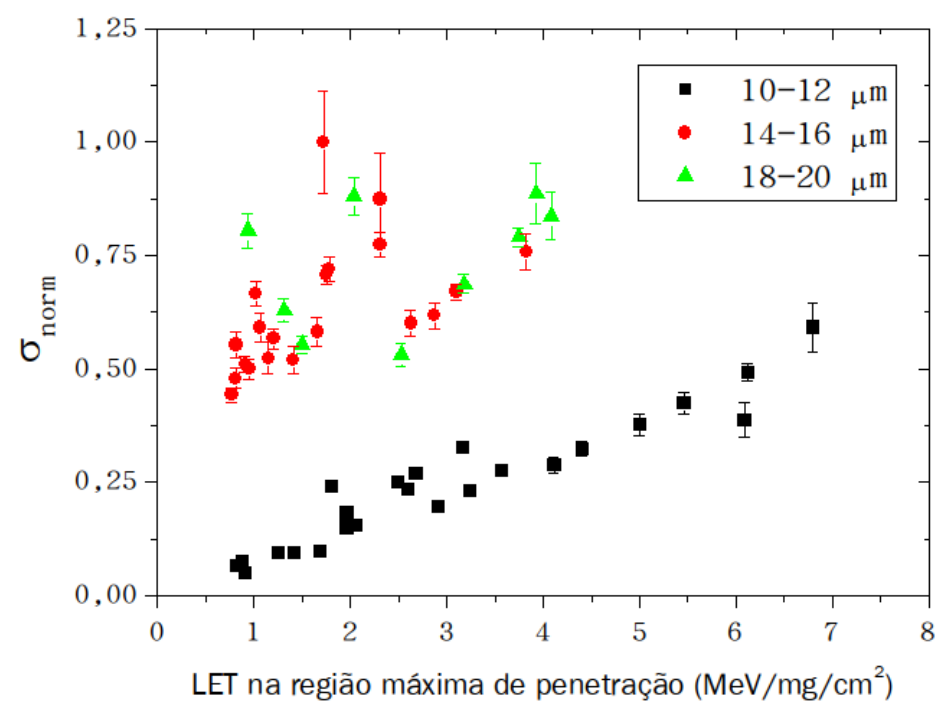

Figura 10.9: Seção de choque em função do LET para diversos valores de alcance no meio equivalente. 


\subsection{Resultados e considerações}

A descrição através de um meio equivalente permite estimar as áreas de coleta de carga em função da penetração do íon, de modo a avaliar as melhores condições de ensaio. Para tanto, é necessária a obtenção de uma ou mais curvas de seção de choque em função da energia do feixe para os feixes de ${ }^{10} \mathrm{~B},{ }^{12} \mathrm{C},{ }^{16} \mathrm{O},{ }^{19} \mathrm{~F}$ e ${ }^{28} \mathrm{Si}$, que possuem elevada penetração nos dispositivos eletrônicos atuais. No caso do FPGA Zynq-7020, obteve-se que a espessura equivalente de máxima excitação corresponde à faixa de 14 a $20 \mu \mathrm{m}$, e cerca de $50 \%$ desta área pode ser excitada por íons com alcance entre 10 e $12 \mu \mathrm{m}$, dependendo do LET. Evidentemente, estes resultados, por hora, representam apenas a ordem de grandeza dos valores observados, uma vez que a dependência LET x alcance num dispositivo complexo como este está longe de ser trivial. Os valores de seção de choque obtidos, por sua vez, concordam com os valores obtidos em FPGAs da mesma família $^{6}$ [137]. Melhorias nas simulações e cálculos e análises adicionais ${ }^{7}$, utilizando as técnicas de microscopia eletrônica de varredura e Rutherford Backscattering estão em andamento, bem como a análise de multiple bit upsets nas várias condições aqui apresentadas.

\footnotetext{
${ }^{6}$ Família refere-se aos FPGAs de tecnologia $28 \mathrm{~nm}$ da Xilinx.

${ }^{7}$ Conforme explicado anteriormente, estas análises devem ser realizadas de maneira complementar e não exaustiva.
} 
Capítulo 10. Um caso digital 


\section{Conclusões}

O desenvolvimento deste projeto permitiu a montagem de uma nova linha de feixe no Laboratório Aberto de Física Nuclear dedicada aos estudos de Física Aplicada, com foco principal no estudo de efeitos de radiação em dispositivos eletrônicos. O projeto do novo sistema aliou cálculos de óptica iônica e de espalhamento múltiplo pela metodologia clássica proposta por Montenegro e colaboradores e utilizando métodos de Monte Carlo. O sistema foi projetado para prover feixes com intensidades entre $10^{2}$ e $10^{5}$ partículas $/ \mathrm{s} / \mathrm{cm}^{2}$ com uniformidade maior que $90 \%$ numa área circular de diâmetro de 1,5 cm, operando em regime de alto-vácuo. Um manipulador de amostras permite a movimentação do dispositivo sob teste com precisão de $2,5 \mu \mathrm{m}$ e um sistema de aquisição de dados dedicado foi desenvolvido, permitindo a automação de medidas. O sistema foi caracterizado com feixes de ${ }^{1} \mathrm{H},{ }^{12} \mathrm{C},{ }^{16} \mathrm{O},{ }^{19} \mathrm{~F},{ }^{28} \mathrm{Si},{ }^{35} \mathrm{Cl}$ e ${ }^{63} \mathrm{Cu}$ a várias energias, apresentando fluxo e uniformidade adequados aos experimentos em diversas configurações de focalização e folhas espalhadoras. As características deste sistema o tornam uma estação multi-uso única na América Latina e que vem sendo utilizada e aprimorada ao longo dos últimos dois anos.

O estudo do transistor 3N163 sob fluxo de íons pesados revelou que os eventos geram um sinal de corrente (convertido em tensão pelo sistema de aquisição) proporcional ao LET da partícula incidente, podendo a partir desta correlação determinar que existe significativa perda de energia dos íons mais pesados nas camadas de passivação e isolamento do dispositivo, de modo que o LET efetivo destes íons na região sensí- 
vel é diminuído. Observou-se também que, como esperado, não existe dependência da amplitude do sinal com a energia da partícula incidente, desde que a partícula possua alcance suficiente dentro do dispositivo. Simulações computacionais de deposição de energia dos íons nos diversas camadas permitiram determinar a espessura da metalização de alumínio em 1,28(2) $\mu m$ e a dependência da camada de coleta de carga com o LET e alcance do íon, porém restrita à região entre 6,0 e 11,0 $\mu \mathrm{m}$.

O estudo do FPGA Zynq-7020 mostrou a dependência da seção de choque observada com o alcance dos íons no dispositivo. O estabelecimento de um meio efetivo para a realização dos cálculos permitiu determinar que a máxima seção de choque é obtida para íons com alcance entre 14 e $20 \mu m$, e que aproximadamente metade da área sensível pode ser sensibilizada por partículas com alcance entre 10 e $12 \mu \mathrm{m}$.

Os desenvolvimentos instrumentais, experimentais, computacionais e teóricos deste trabalho representam um avanço significativo na capacidade, experiência e eficiência do grupo de estudos em efeitos de radiação em dispositivos eletrônicos. A eficiência do SAFIIRA e dos métodos analíticos desenvolvidos permite estudar em detalhe os fenômenos de coleta de carga, que, devido às dificuldades envolvidas, são tema de muitas simulações e poucos experimentos mundo afora.

Por último, este trabalho demonstrou a necessidade de se aliar diversas técnicas para um estudo adequado da coleção de carga por dispositivos eletrônicos. A instalação de um detector de raios X no SAFIIRA irá fornecer mais informações durante as irradiações e expandir as possíveis aplicações do sistema. 


\section{Referências Bibliográficas}

[1] J.F. Ziegler et al. IBM experiments in soft fails in computer electronics (19781994). IBM Journal of Research and Development, 40(1):3-18, janeiro 1996.

[2] J. F.Ziegler. Terrestrial cosmic rays. IBM Journal of Research and Development, 40(1):19-39, janeiro 1996.

[3] D.F. Heidel, K.P. Rodbell, E.H. Cannon, Jr. C. Cabral, M.S. Gordon, P. Oldiges, e H. H. K. Tang. Alpha-particle-induced upsets in advanced CMOS circuits and technology. IBM Journal of Research and Development, 52(3):225-232, may 2008.

[4] H. H. K. Tang. Nuclear physics of cosmic ray interaction with semiconductor materials: Particle-induced soft errors from a physicist's perspective. IBM Journal of Research and Development, 40(1):91-108, january 1996.

[5] Robert C. Baumann. Soft errors in advanced semiconductor devices - part I: The three radiation sources. IEEE Transactions on Device and Materials Reliability, 1(1):17-22, 2001.

[6] ECSS. Space engineering: methods for calculation of the radiation received and its effects, and a policy for design margins. Technical report, European Space Agency, 2008. 
[7] C.A. Federico, O.L. Gonçalez, E.S. Fonseca, I.M. Martin, and L.V.E. Caldas. Neutron spectra measurements in the south atlantic anomaly region. Radiation measurements, 45:1526-1528, 2010.

[8] https://www.esa.int/spaceinimages/Images/2005/01/Spacecraft_faults_ more_common_over_the_South_Atlantic.

[9] M.S. Gordon, K.P. Rodbell, D.F. Heidel, Jr. C. Cabral, E.H. Cannon, e D.D. Reinhardt. Single-event-upset and alpha-particle emission rate measurement techniques. IBM Journal of Research and Development, 52(3):225-232, may 2008.

[10] Claude Leroy e Pier-Giorgio Rancoita. Principles of Radiation Interaction in Matter and Detection. World Scientific, 2 edition, 2009.

[11] Brian D. Sierawski, Kevin M. Warren, Robert A. Reed, Robert A. Weller, Marcus M. Mendenhall, Ronald D. Schrimpf, Robert C. Baumann, e Vivian Zhu. Contribution of low energy $(<10 \mathrm{MeV})$ neutrons to upset rate in a $65 \mathrm{~nm}$ SRAM. In IEEE International, editor, Reliability Physics Symposium, pages 4B.2.1-4B.2.5, 2010.

[12] Francisco Rogelio Palomo Pinto. Eventos singulares em CMOS digital. apostila da Escuela Superior de Ingenieros - Universidad de Sevilla, 2012.

[13] K.P. Rodbell, D.F. Heidel, H.H.K. Tang, M.S. Gordon, P. Oldiges, e C.E. Murray. Low-energy proton-induced single-event-upsets in $65 \mathrm{~nm}$ node, silicon-oninsulator, latches and memory cells. IEEE Transactions on Nuclear Science, 54(6):2474-2479, 2007.

[14] J.M. Trippe, R.A. Reed, R.A. Austin, B.D. Sierawski, R.A. Weller, E.D. Funkhouser, M.P. King, B. Narasimham, B. Bartz, R. Baumann, J. Labello, J. Nichols, R.D. Schrimpf, e S.L. Weeden-Wright. Electron-induced single event upsets in 28 $\mathrm{nm}$ and $45 \mathrm{~nm}$ bulk sram. IEEE Transactions on Nuclear Science, 2015. 
[15] Sophie Duzellier. Radiation effects on electronic devices in space. Aerospace Science and Technology, 9:93-99, 2005.

[16] K. Cirne, M.A.G. Silveira, R.B.B. Santos, S.P. Gimenez, M.D.L. Barbosa, M.H. Tabacnicks, N. Added, N.H. Medina, W.R. De Melo, L.E. Seixas Jr e J.A. De Lima. Comparative study of the proton beam effects between the conventional and Circular-Gate MOSFETs. Nuclear Instruments and Methods in Physics Research $B, 273: 80-82,2011$.

[17] J.A. de Lima, M.A.G. Silveira, K.H. Cirne, R.B.B. Santos e N.H. Medina. X-ray radiation effects in overlapping circular-gate MOSFET's. In Radiation and its effects on components and systems RADECS, pages 88-91, 2011.

[18] S.M. Barbero, S. K. Höffgen, G. Berger e H. Guerrero. Compendium of international irradiation test facilities. Proceedings of RADECS 2011, 2011.

[19] Santiago Sondon, Alfredo Falcon, Pablo Mandolesi, Pedro Julián, Nahuel Vega, Francisco Nesprías, Jorge Davidson, Félix Palumbo e Mario Debray. Diagnose of radiation induced single event effects in a PLL using heavy ion microbeam. In 14th Latin American Test Workshop (LATW), 2013.

[20] V.A.P. Aguiar, N. Added, N.H. Medina, E.L.A.Macchione, M.H. Tabacniks, F.R. Aguirre, M.A.G. Silveira, R.B.B. Santos e L.E. Seixas Jr. Experimental setup for Single Event Effects at the são paulo 8UD Pelletron Accelerator. Nuclear Instruments and Methods in Physics Research B, 332:397-400, 2014.

[21] Fernando Rodrigues Aguirre. Estudo sobre distribuição de cargas em semicondutores sujeitos a radiação ionizante. Dissertação de Mestrado, Universidade de São Paulo, 2017.

[22] N.H. Medina, N. Added, V.A.P. Aguiar, F. Aguirre, R. Giacomini, E.L.A. Macchione, M.A.A. de Melo, J.A. Oliveira, R.B.B. Santos, L.E. Seixas e M.H. Ta- 
bacnicks. Brazilian facilities to study radiation effects in electronic devices. In 2013 14th European Conference on Radiation and Its Effects on Components and Systems (RADECS), 2013.

[23] Laboratório Aberto de Física Nuclear. Acelerador pelletron. http://web. if. usp.br/fnc/node/308.

[24] ESA. Single event effects test method and guidelines. ESA/SCC Basic Specification 1, European Space Agency, October 1995. ESA/SCC Basic Specification 25100.

[25] ESA. Total dose steady-state irradiation test method. ESA/SCC Basic Specification 1, European Space Agency, October 1995. ESA/SCC Basic Specification 22900.

[26] ASTM. Standard guide for the measurement of single event phenomena (SEP) induced by heavy ion irradiation of semiconductor devices. ASTM standard, American Society for Testing and Materials, 2006. F 1192-00.

[27] EIA/JEDEC. Test procedures for the measurement of single-event effects in semiconductor devices from heavy ion irradiation. EIA/JEDEC standard, Electronic Industries Association, 1996. EIA/JESD57.

[28] Vitor Ângelo Paulino de Aguiar. Efeitos de radiação em dispositivos eletrônicos com feixes de Íons pesados. Dissertação de Mestrado, Universidade de São Paulo, 2014.

[29] http://www.usp.br/agen/?p=166874, 2014. [último acesso: 23/09/2014].

[30] Emico Okuno and Elisabeth Mateus Yoshimura. Física das Radiações. Oficina de Textos, 1 edition, 2010.

[31] F. Attix and W. Roesch. Radiation Dosimetry. Academic Press, 2a edição, 1968. 
[32] Glenn F. Knoll. Radiation Detection and Measurement. New York Wiley, 2000.

[33] Roberto Linares. Estudo do freamento de Íons de Cu natural em Au em baixas velocidades. Dissertação de Mestrado, Universidade de São Paulo, 2005.

[34] U. Fano. Penetration of protons, alpha particles and mesons. Annual Reviews of Nuclei Science, 13:1-66, 1963.

[35] D. Griffiths. Introduction to Quantum Mechanics. Pearson Education, 2013.

[36] Roberto V. Ribas. Freamento de Íons Pesados em Sólidos. Tese de doutorado, Universidade de São Paulo, 1982.

[37] J.P. Biersack e M.D. Ziegler J.F. Ziegler. SRIM: The Stopping and Range of Ions in Matter. SRIM Co., 2008.

[38] Roberto Linares. Estudo Sistemático do Freamento de Íons Pesados em Sólidos no Regime de Baixas Velocidades. Tese de doutorado, Universidade de São Paulo, 2008 .

[39] F. Brandolini, N.H. Medina, M. De Poli, P. Pavan, M. Wilhelm, A. Dewald e G. Pascovici. Stopping power of $\mathrm{Nd}$ ions in $\mathrm{Pb}$ determined from gamma-ray lineshape analysis in Coulomb excitation. Nuclear Instruments and Methods in Physics Research B, 132:11-17, 1997.

[40] J.P. Biersack. Basic physical aspects of high energy implantation. Nuclear Instruments and Methods in Physics Research B, 35:205-214, 1988.

[41] A.Akkerman, M. Murat e J. Barak. Delta-electron spectra, inelastic cross-sections and stopping powers of ions in silicon: Comparison between different models. Nuclear Instruments and Methods in Physics Research B, 2014. 
[42] A.Akkerman, M. Murat e J. Barak. Ion track structure calculations in silicon - spatial and temporal aspects. Nuclear Instruments and Methods in Physics Research B, 269:1630-1633, 2011.

[43] T. Colladant, A. L'Hoir, J.E. Sauvestre e O. Flament. Monte-carlo simulations of ion track in silicon and influence of its spatial distribution on single event effects. Nuclear Instruments and Methods in Physics Research B, 245:464-474, 2006.

[44] G. Lutz. Semiconductor Radiation Detectors. Springer, 1999.

[45] Richard Greco, Alex Luce, Yongqiang Wang e Lin Shao. A technique to measure stopping power difference between channeled and non-channeled ions in crystalline solids. Nuclear Instruments and Methods in Physics Research B, 261:538-540, 2007.

[46] Jerry B. Marion e Stephen T. Thornton. Classical dynamics of particles and systems. Thomson Brooks/Cole, 5 edition, 2004.

[47] Rubens Lichtenthäler Filho. Reações nucleares. Notas de aula,IFUSP, 2012.

[48] Kasuo Ueta. Descrição clássica do espalhamento entre duas partículas. Apostila do Departamento de Física Nuclear do IFUSP, 2005.

[49] Djalma Rosa Mendes Jr. Estudo da Reação 8Li(p,a)5He com Feixe Radioativo de 8Li. Tese de doutorado, Universidade de São Paulo, 2009.

[50] W.T. Scott. The theory of small-angle multiple scattering of fast charged particles. Reviews of Modern Physics, 35(2):231-313, 1963.

[51] L. Meyer. Plural and multiple scattering of low-energy heavy particles in solids. Phys. stat. sol., 44:253-268, 1971.

[52] J.B. Marion e B.A. Zimmerman. Multiple scattering of charged particles. Nuclear Instruments and Methods, 51:93-101, 1967. 
[53] B.W. Hooton, J.M. Freeman e P.P Kane. Small angle multiple scattering of 12$40 \mathrm{MeV}$ heavy ions from thin foils. Nuclear Instruments and Methods, 124:29-39, 1975 .

[54] E.C. Montenegro, G.B. Baptista, C.V. Barros Leite, A.G. de Pinho e A.S. Paschoa. Study of a proton beam diffusing system for PIXE analysis. Nuclear Instruments and Methods, 164:231-234, 1979.

[55] N.Carlin, J.C. de Souza, E.M. Szanto, J.C. Acquadro, E. Okuno, J.Takahashi, N.K. Umisedo, F.J. de Oliveira Filho e J.A.C. Vasconcelos. Irradiation facility for radiobiological and molecular biophysics studies at the University of São Paulo Pelletron accelerator laboratory. Nuclear Instruments and Methods in Physics Research A, 540:215-221, 2005.

[56] M. Belli, R. Cherubini, G. Galeazzi, S. Mazzucato, G.Moschini, O. Sapora, G. Simone, and M.A. Tabocchini. Proton irradiation facility for radiobiological studies at a 7 MV Van de Graaf accelerator. Nuclear Instruments and Methods in Physics Research A, 256:576-580, 1987.

[57] Marcos Frizzarini. Projeto e construção de um sistema óptico para microfeixes. Dissertação de mestrado, Universidade de São Paulo, 1995.

[58] Particle Accelerator Physics I. Springer, 1998.

[59] Tiago Fiorini da Silva. Início de operação e caracterização do sistema injetor do mícrotron do ifusp. Dissertação de mestrado, Universidade de São Paulo, 2006.

[60] Stanley Humphries Jr. Principles of Charged Particle Acceleration. John Wiley and Sons, 1999.

[61] R. Hellborg, editor. Electrostatic Accelerators: Fundamentals and Applications. Springer, 2005. 
[62] Laboratório Aberto de Física Nuclear. Fonte de Íons. http://web.if.usp.br/ fnc/node/307.

[63] O. Sala e G. Spalek. The nuclear structure facility at the University of Sao Paulo. Nuclear Instruments and Methods in Physics Research, 122:213-225, 1974.

[64] National Electrostatics Corporation. http://www.pelletron.com.

[65] Victor Rotberg, Dirceu Pereira, M.N. Rao, Nobuko Ueta e Oscar Sala. Calibration of the tandem pelletron accelerator. Revista Brasileira de Física, 6(3), 1976.

[66] Dirceu Pereira. Limiares das reações 27Al(p,n)27Si e 12C(a,n)15O. Dissertação de mestrado, Universidade de São Paulo, 1975.

[67] J. Wyss, D. Bisello e D. Pantano. SIRAD: an irradiation facility at the LNL tandem accelerator for radiation damage studies on semiconductor detectors and electronic devices and systems. Nuclear Instruments and Methods in Physics Research A, 462:426-434, 2001.

[68] M. Pavlovic and I. Strasik. Supporting routines for the SRIM code. Nuclear Instruments and Methods in Physics Research B, 257:601-604, 2007.

[69] PBO Lab 2.0 User Manual.

[70] CERN. ROOT. root.cern.ch.

[71] NI-PXIe-8135 datasheet.

[72] NI-PXIe-6259 datasheet.

[73] Manfredo H. Tabacniks. Os elementos na matéria. Tese de livre-docência, Universidade de São Paulo, 2005.

[74] A. Roth. Vacuum Technology. Elsevier, 3 edition, 2012. 
[75] Thomas Kugelstadt. Removing ground noise in data transmission systems. Technical report, Texas Instruments, 2007.

[76] Measurement Computing. Noise reduction and isolation. Technical report, Measurement computing, 2007.

[77] Roberto V. Ribas. Instrumentação nuclear. Notas de Aula, IFUSP, 2011.

[78] Roberto V. Ribas. A CAMAC data acquisition system based on PC-Linux. Nuclear Instruments and Methods in Physics Research, Section A, Accelerators, Spectrometers, Detectors and Associated Equipment (Print), 483:830-832, 2002.

[79] C. Kim, S. Ahn e D. Jang. Review: Developments in micro/nanoscale fabrication by focused ion beams. Vacuum, 86:1014-1035, 2012.

[80] Adriana de Oliveira Delgado. Processos de modificação molecular em polímeros irradiados com feixe de ions. Tese de doutorado, Universidade de São Paulo, 2012.

[81] ISO/TC 20/SC 14. Space systems: Space environment: Simulation guidelines for radiation exposure of non-metallic materials. Technical report, ISO, 2010.

[82] A. Zucchiatti e F. Agulló-Lopez. Potential consequences of ion beam analysis on objects from our cultural heritage: an appraisal. Nuclear Instruments and Methods in Physics Research B, 278:106-114, 2012.

[83] K. Murai, A. Nishiura, Y. Kazama e T. Abe. A large-scale mutant panel in wheat developed using heavy-ion beam mutagenesis and its application to genetic research. Nuclear Instruments and Methods in Physics Research B, 314:59-62, 2013.

[84] J. Kappke, E.R. Silva, H.R. Schelin, S.A. Paschuk, A. Paschuk, A. Oliveira, N.C. Filho, E.M. Szanto, J. Takahashi e J.C. Souza. Evaluation of Escherichia coli cells 
damages induced by ultraviolet and proton beam irradiation. Brazilian Journal of Physics, 35(3B):805-807, 2005.

[85] X. Xu, B. Liu, L. Zhang e Y. Wu. Mutagenic effects of heavy ion irradiation on rice seeds. Nuclear Instruments and Methods in Physics Research B, 290:19-25, 2012.

[86] Sylvia Ritter e Marco Durante. Heavy-ion induced chromosomal aberrations: a review. Mutation Research, 701:38-46, 2010.

[87] W. Maenhaut. Applications of ion beam analysis in biology and medicine, a review. Nuclear Instruments and Methods in Physics Research B, 35:388-403, 1988.

[88] J. Lee, R. Siegele, Z. Pastuovic, M.J. Hackett, N.H. Hunt, G.E. Grau, D.D. Cohen e P.A. Lay. Light and heavy ion beams analysis of thin biological sections. Nuclear Instruments and Methods in Physics Research B, 306:129-133, 2013.

[89] T. Seki, Y. Wakamatsu, S. Nakagawa, T. Aoki, A. Ishihara e J. Matsuo. Biomaterial imaging with $\mathrm{MeV}$-energy heavy ion beams. Nuclear Instruments and Methods in Physics Research B, 332:326-329, 2014.

[90] H. Yamada, K. Ichiki, Y. Nakata, S. Ninomiya, T. Seki, T. Aoki e J. Matsuo. MeV-energy probe SIMS imaging of major components in animal cells etched using large gas cluster ions. Nuclear Instruments and Methods in Physics Research $B, 268: 1736-1740,2010$.

[91] Alexis H. Haskins, Dylan J. Buglewicz, Hirokazu Hirakawa, Akira Fujimori, Yasushi Aizawa e Takamitsu A. Kato. Palmitoyl ascorbic acid 2-glucoside has the potential to protect mammalian cells from high-let carbon-ion radiation. Nature Scientific Reports, 8:1-7, 2018. 
[92] F.R. Aguirre, T.F. Silva, C.L. Rodrigues, N. Added, V.A.P. Aguiar, N.H. Medina, M.H. Tabacniks, J.A. Martino e P.G.D. Agopian. Measurement of a semiconductor's passivation layer thickness. Pôster apresentado na XXXVII Reunião de Trabalho sobre Física Nuclear no Brasil, setembro 2014.

[93] Dariusz Makowski. The impact of radiation on electronic devices with the special consideration of neutron and gamma radiation monitoring. Tese de doutorado, Technical University of Lódz, 2006.

[94] Fundamentos da Física de Nêutrons. Livraria da Física, 2007.

[95] M. Drosg. Monoenergetic neutron production by two-body reactions in the energy range from 0.0001 to $500 \mathrm{MeV}$.

[96] M.A. Chaudhri, M.N. Chaudri e P. Debo. 13C(p,n) reaction as a new source of fast neutrons, especially for therapy. In F. Marti, editor, Cyclotrons and their applications. AIP, 2001.

[97] M.E. Capoulat, M.S. Herrera, D.M. Minsky, S.J. González e A.J. Kreiner. 9Be $(\mathrm{d}, \mathrm{n}) 10 \mathrm{~B}-$ based neutron sources for BNCT. Applied radiation and isotopes, 88:190-194, 2014.

[98] V. Gressier, J.F. Guerre-Chaley, V. Lacoste, L. Lebreton, G. Pelcot, J.L. Pochat, T. Bolognese-Milstajn e D. Champion. AMANDE: a new facility for monoenergetic neutron fields production between $2 \mathrm{keV}$ and $20 \mathrm{MeV}$. Radiation Protection Dosimetry, 110(1-4):49-52, 2004.

[99] J. Davis, G.M. Petrov, T. Petrova, L. Willingale, A. Taksimchuk e K. Krushelnick. Neutron production from $7 \mathrm{Li}(\mathrm{d}, \mathrm{xn})$ nuclear fusion reactions driven by highintensity laser-target interactions. Plasma physics and controlled fusion, 52:1-15, 2010. 
[100] H.J. Brede, G. Dietze, K. Kudo, U.J. Schrewe, F. Tancu e C. Wen. Neutron yields from thick be targets bombarded with deuterons or protons. Nuclear Instruments and Methods in Physics Research A, 274:332-344, 1989.

[101] L. Schmieder, D. Hilscher, H. Rossner, U. Jahnke, M. Lehmann e K. Ziegler. Neutron yields of $6,7 \mathrm{Li}$-induced reactions on thick $7 \mathrm{Li}, 9 \mathrm{Be}, 12 \mathrm{C}$ and natCutargets. Nuclear Instruments and Methods in Physics Research A, 256:457-464, 1987.

[102] M. Lebois, J.N. Wilson, P. Halipré, B. Leniau, I. Matea, A. Oberstedt e D. Verney. Development of a kinematically focused neutron source with the $\mathrm{p}(7 \mathrm{Li}, \mathrm{n}) 7 \mathrm{Be}$ inverse reaction. Nuclear Instruments and Methods in Physics Research A, 735:145$151,2014$.

[103] Tufic Madi Filho, Margarida M. Hamada, Fumio Shiraishi e Carlos H. Mesquita. Development of neutron detector using the surface barrier sensor with polyethylene $(\mathrm{n}, \mathrm{p})$ and $10 \mathrm{~B}(\mathrm{n}, \mathrm{a})$ converters. Nuclear Instruments and Methods in Physics Research A, 458:441-447, 2001.

[104] Carlos H. Mesquita, Tufic Madi Filho e Margarida M. Hamada. Development of neutron detector using the PIN photodiode with polyethylene (n,p) converter. IEEE Transactions on Nuclear Science, 50(4):1170-1174, 2003.

[105] Jacobus W. Swart. Semicondutores: Fundamentos, Técnicas e Aplicações. Editora UNICAMP, Campinas, 2008.

[106] Sérgio M. Rezende. Materiais e Dispositivos Eletrônicos. Editora Livraria da Física, 2004.

[107] Clive Maxfield. FPGAs Instante Access. Newnes, 2008. 
[108] James R. Schwank, Marty R. Shaneyfelt e Paul E. Dodd. Radiation hardness assurance testing of microelectronic devices and integrated circuits: Radiaiton environments, physical mechanisms and foundations for hardness assurance. Document 2008-6851P, Sandia National Laboratories, 2008.

[109] J. Barak, M. Murat e A. Akkerman. SEU due to electrons in silicon devices with nanometric sensitive volumes and small critical charge. Nuclear Instruments and Methods in Physics Research B, 2012.

[110] Simone Gerardin. SEE and TID testing: Theoretical and practical aspects. Shortcourse on Radiation Effects on Electronic Devices - WERICE 2013, October 2013.

[111] F.B. McLean e T.R. Oldham. Charge funneling in n- and p-type Si substrates. IEEE Transactions on Nuclear Science, 1982.

[112] F.B. McLean T.R. Oldham e J.M. Hartman. Revised funnel calculations for heavy particles with high $\mathrm{dE} / \mathrm{dx}$. IEEE Transactions on Nuclear Science, 1986.

[113] Jizhe Liu, Sha Yan, Jianming Xue e Yugang Wang. Comparison of ionization track structure models for electronic devices of different sizes. Nuclear Instruments and Methods in Physics Research B, 444:43-49, 2019.

[114] L.D. Edmonds. Electric currents through ion tracks in silicon devices. IEEE Transactions on Nuclear Science, 1998.

[115] R.M. Gilbert, G.K. Ovrebo e J.Schifano. Plasma screening of funnel fields. IEEE Transactions on Nuclear Science, 1985.

[116] J.R. Ahlbin, M.J. Gadlage, N.M. Atkinson, B. Narasimham, B.L. Bhuva, A.F. Witulski, W.T. Holman, P.H. Eaton e L.W. Massengill. Effect of multiple-transistor charge collection on single-event transient pulse widths. IEEE Transactions on Device and Materials Reliability, 11(3), 2011. 
[117] L.W. Connell, P.J. McDaniel, A.K. Prinja e F.W. Sexton. Modeling the heavy ion upset cross section. IEEE Transactions on Nuclear Science, 1995.

[118] O. Musseau. Charge collection and SEU mechanisms. Radiation Physics and Chemistry, 1994.

[119] S. Boorboor, S.A.H. Feghhi e H. Jafari. Funneling effect of alpha particles on the charge collection efficiency in $\mathrm{N}$ type silicon surface barrier detector. Nuclear Instruments and Methods in Physics Research B, 325:1-4, 2014.

[120] J. Garcia Lopez, M.C. Jimenez-Ramos, M. Rodrigues-Ramos, J.Forneris e J. Ceballos. An upgraded drift-diffusion model for evaluating the carrier lifetimes in radiation-damaged semiconductor detectors. Nuclear Instruments and Methods in Physics Research B, 371:294-297, 2016.

[121] E.L. Petersen. Single-event data analysis. IEEE Transactions on Nuclear Science, 2008.

[122] Paul E. Dodd. Physics-based simulation of single-event effects. IEEE Transactions on Device and Materials Reliability, 5(3):343-357, september 2005.

[123] G.R. Srinivasan, H.K. Tang e P.C. Murley. Parameter-free, predictive modeling of single event upsets due to protons, neutrons and pions in terrestrial cosmic rays. IEEE Transactions on Nuclear Science, 41(6):2063-2070, 1994.

[124] H.H.K. Tang e Ethan H. Cannon. SEMM-2: A modeling system for single event upset analysis. IEEE Transactions on Nuclear Science, 51(6):3342-3348, 2004.

[125] Y. Li, D. Yu, Q. Zhang, Z. Cai, X. Jia e Y. Wang. Qcrit- independent model method for proton SEU analysis. Microelectronics Reliability, 93:72-80, 2019.

[126] A. Akkerman M. Murat e J. Barak. Electron and ion tracks in silicon: spatial and temporal evolution. IEEE Transactions on Nuclear Science, 2008. 
[127] F. Wrobel, G. Hubert e P. Iacconi. A semi-empirical approach for heavy ion SEU cross section calculations. IEEE Transactions on Nuclear Science, 2006.

[128] A.V. Sogoyan, A.I. Chumakov, A.A. Smolin, A.V. Ulanova e A.B. Boruzdina. A simple analytical model of single-event upsets in bulk CMOS. Nuclear Instruments and Methods in Physics Research B, 400:31-36, 2017.

[129] 3N163 datasheet.

[130] Eduardo L.A. Macchione, Marcilei A.G. Silveira, Nemitala Added, Nilberto H. Medina e Vitor Aguiar (organizadores). Instrumentação nuclear e efeitos de radiação em dispositivos eletrÔnicos. Apostila da XX Escola de Verão Jorge André Swieca de Física Nuclear Experimental, 2018.

[131] Ana Maria Maliska. Microscopia eletrônica de varredura. Universidade Federal de Santa Catarina - Depto de Engenharia Mecânica.

[132] Xilinx unified architecture.

[133] PYNQ-Z1 Board reference manual.

[134] Cepheiden. Back end of line. https://en.wikipedia.org/wiki/Back_end_of_ line\#/media/File:Cmos-chip_structure_in_2000s_(en).svg.

[135] Lucas Antunes Tambara, Fernanda Lima Kastensmidt, Nilberto H. Medina, Nemitala Added, Vitor A. P. Aguiar, Fernando Aguirre, Eduardo L. A. Macchione e Marcilei A. G. Silveira. Heavy ions induced single event upsets testing of the 28 nm Xilinx Zynq-7000 all programmable SoC. 2015 IEEE Radiation Effects Data Workshop (REDW), pages 1-6, 2015.

[136] Kevin M. Warren, Robert A. Weller, Marcus H. Mendenhall, Robert A. Reed, Dennis R. Ball, Christina L. Howe, Brian D. Olson, Michael L. Alles, Lloyd W. 
Massengill, Ronald D. Schrimpf, Nadim F. Haddad, Scott E. Doyle, Dale McMorrow, Joseph S. Melinger e William T. Lotshaw. The contribution of nuclear reactions to heavy ion single event upset cross-section measurements in a highdensity SEU hardened SRAM. IEEE Transactions on Nuclear Science, 52(6), 2005.

[137] David S. Lee, Michael Wirthlin, Gary Swift e Anthony C. Le. Single-Event Characterization of the $28 \mathrm{~nm}$ Xilinx Kintex-7 Field-Programmable Gate Array under Heavy Ion Irradiation. 2014 IEEE Radiation Effects Data Workshop (REDW), 2014 . 


\section{Apêndice A}

\section{Dedução da fórmula de Montenegro}

\section{para o caso geral}

Segundo Meyer [51], chama-se de ângulo de espalhamento reduzido a quantidade definida na Equação 2.21, reproduzida abaixo:

$$
\bar{\theta}=\frac{\epsilon}{2}\left(\frac{A_{1}+A_{2}}{A_{2}}\right) \theta
$$

em que $\epsilon$ é a energia reduzida (Equação 1.11, de modo que, isolando $\theta$ e utilizando $e^{2}=\hbar c / 137$ :

$$
\theta=\bar{\theta} \frac{2 Z_{1} Z_{2} e^{2}}{E a_{L}}=\bar{\theta} \frac{2 Z_{1} Z_{2}\left(Z_{1}^{2 / 3} Z_{2}^{2 / 3}\right)^{1 / 2} \times \hbar c}{E \times 0,8853 \times 0,529 \times 137}
$$

em que $Z_{1,2}$ são os números atômicos do projétil e do alvo e $a_{L}$ o comprimento de blindagem de Lindhard (Equação 1.7). A manipulação desta equação resulta em:

$$
\theta=\bar{\theta} \frac{Z_{1} Z_{2}\left(Z_{1}^{2 / 3} Z_{2}^{2 / 3}\right)^{1 / 2} \times 6,15 \times 10^{-5}}{E}
$$

Segundo Montenegro [54], a uniformidade pode ser expressa em função do ângulo 
$\theta_{1 / 2}$ para o qual a intensidade é metade da intensidade máxima (Equação 2.24, reproduzida abaixo):

$$
\epsilon_{f}=\tanh \left(\frac{1,17 D}{4 R \theta_{1 / 2}}\right)
$$

Combinando as Equações 2.24 e A.2, obtém-se:

$$
\begin{gathered}
\epsilon_{f}=\tanh \left(\left(\frac{1,17^{2}}{4}\right)\left(\frac{D E}{R}\right)^{2} \frac{1}{6,15 \times 10^{-5} \times Z_{1}^{2} Z_{2}^{2}\left(Z_{1}^{2 / 3}+Z_{2}^{2 / 3}\right) \bar{\theta}}\right) \Longrightarrow \\
\epsilon_{f}=\tanh \left(\frac{2,26 \times 10^{7}}{Z_{1}^{2} Z_{2}^{2}\left(Z_{1}^{2 / 3}+Z_{2}^{2 / 3}\right) \bar{\theta}}(D E / R)^{2}\right)
\end{gathered}
$$

$\bar{\theta}_{1 / 2}$, por sua vez, pode ser expresso em termos de duas funções tabeladas por Meyer, $g_{1}(\tau)$ e $g_{2}(\tau):$

$$
\bar{\theta}_{1 / 2}=g_{1}(\tau)+\frac{a^{2}}{r_{0}^{2}} g_{2}(\tau)
$$

em que $a$ é o comprimento de blindagem e $r_{0}$ o raio entre átomos no empacotamento do material. O segundo termo decresce com o aumento do número atômico das espécies envolvidas, de maneira que apenas no caso de feixes e alvos leves representa uma contribuição importante. Mesmo no caso da utilização de feixes de prótons com alvos de ouro, este termo representa uma correção inferior a $0,1 \times g_{2}(\tau)$, função esta que decresce com o aumento de $\tau$, conforme a Figura A.1 a seguir: 


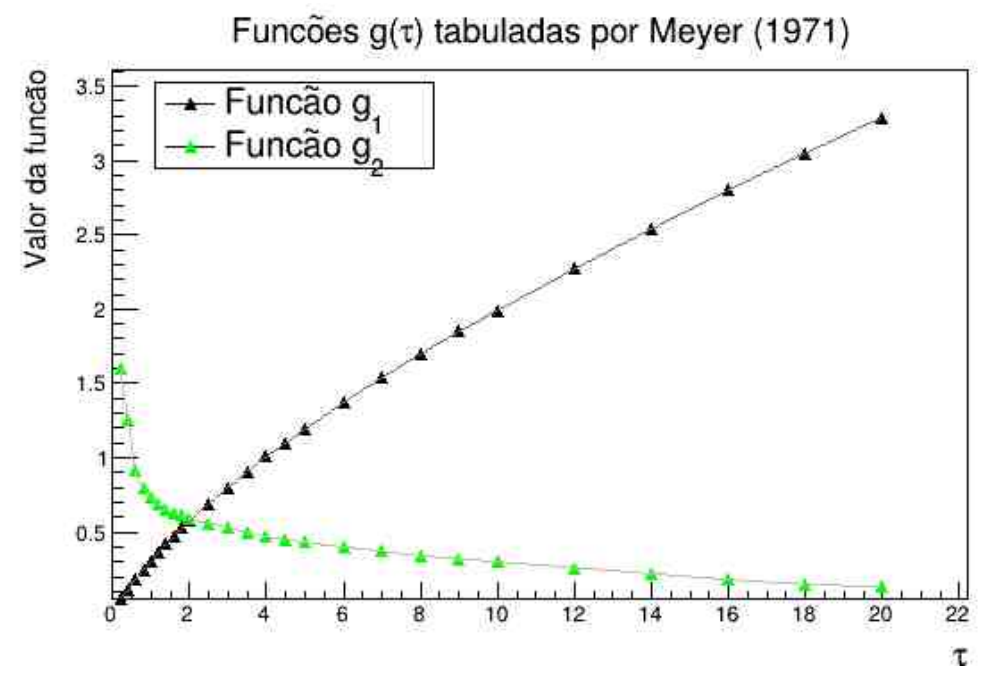

Figura A.1: Funções $g_{1}(\tau)$ e $g_{2}(\tau)$ tabeladas por Meyer [51].

Levando em consideração que o número de colisões sofridas pode variar em decorrência da espessura do material, Meyer demonstra ainda que pode-se aplicar uma segunda correção $\gamma=\frac{\overline{(\tau-\bar{\tau})^{2}}}{\bar{\tau}}$, em que o numerador está relacionado à variância da espessura do alvo. Com essa correção extra, tem-se:

$$
\bar{\theta}_{1 / 2}=g_{1}(\bar{\tau})+\left(\frac{a^{2}}{r_{0}^{2}}-\gamma\right) g_{2}(\bar{\tau})
$$

A espessura $\tau$ do espalhador, conforme o Capítulo 2, representa a espessura reduzida e é definida como:

$$
\tau=\frac{a^{2}}{r_{0}^{2}} \bar{n}=\pi a^{2} N t
$$

em que $n$ representa o número médio de colisões e $N t$ é o número de átomos do alvo por unidade de área. Utilizando o comprimento de blindagem de Lindhard e a espessura $t$ em unidades de $\mathrm{g} / \mathrm{cm}^{2}$ e sendo $A$ a massa atômica do espalhador, obtém-se:

$$
\tau=\frac{41,4}{A\left(Z_{1}^{2 / 3}+Z_{2}^{2 / 3}\right)} t
$$


Desta maneira, a formulação de Montenegro no caso mais geral pode ser escrita da seguinte forma:

$$
\begin{gathered}
\epsilon_{f}=\tanh \left(\frac{2,26 \times 10^{7}}{Z_{1}^{2} Z_{2}^{2}\left(Z_{1}^{2 / 3}+Z_{2}^{2 / 3}\right) \bar{\theta}_{1 / 2}^{2}}(D E / R)^{2}\right) \\
\bar{\theta}_{1 / 2}=g_{1}(\bar{\tau})+\left(\frac{a^{2}}{r_{0}^{2}}-\gamma\right) g_{2}(\bar{\tau}) \\
\tau=\frac{41,4}{A\left(Z_{1}^{2 / 3}+Z_{2}^{2 / 3}\right)} t
\end{gathered}
$$

Todavia, conforme apresentado no Capítulo 2, os cálculos realizados neste trabalho não consideram o termo que envolve a função $g_{2}(\tau)$, uma vez que:

- O uso de colimadores antes do alvo delimita a área do feixe, o que permite, em primeira aproximação, considerar o alvo como homogêneo nesta área;

- A correção pela blindagem torna-se pouco importante no caso de feixes mais pesados que prótons;

- A função $g_{2}(\tau)$ decresce com o valor de $\tau$, sendo importante apenas para valores de espessura do espalhador que seriam, de qualquer forma, impraticáveis para obter os efeitos desejados.

A Figura A.2 ilustra a diferença no cálculo da uniformidade considerando e desprezando o termo $g_{2}(\tau)$ (sem a correção $\gamma$ ) e modificando o comprimento de blindagem segundo a formulação de Ziegler (Equação 1.9), para um feixe de prótons de $10 \mathrm{MeV}$ incidindo em ouro e com plano de medida a 3 metros, e um feixe de ${ }^{28} \mathrm{Si} 60 \mathrm{MeV}$ nas mesmas condições. 


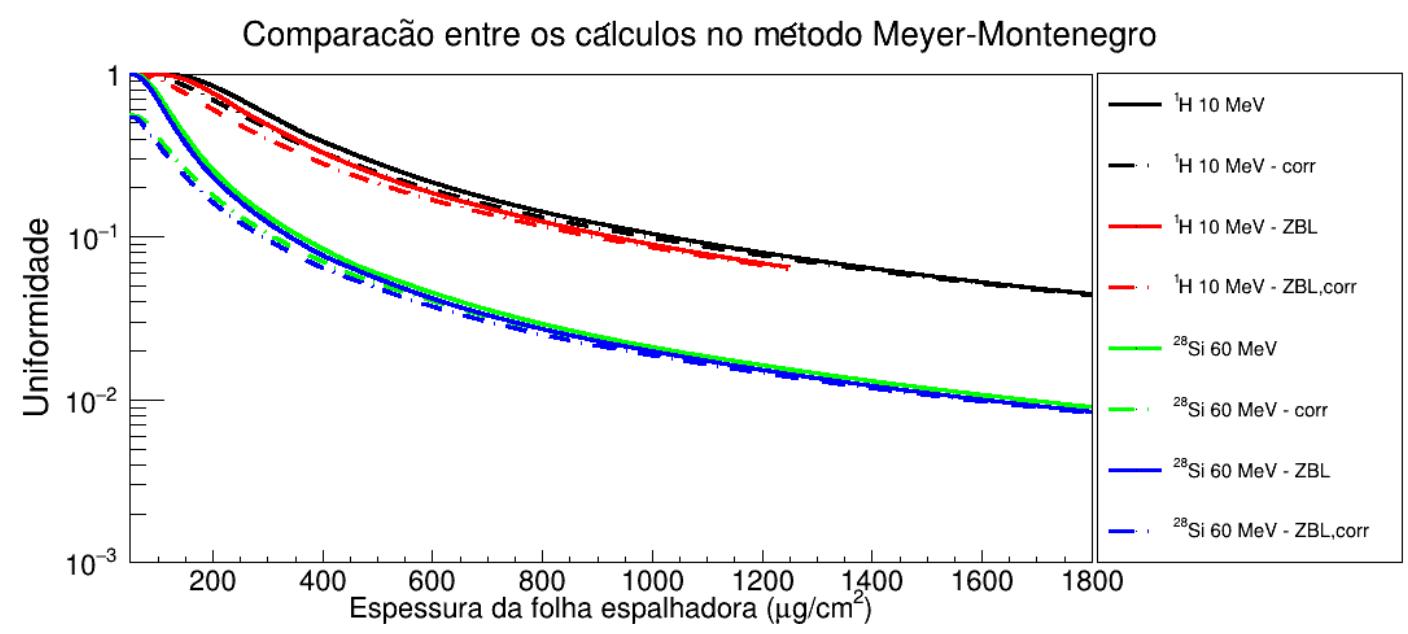

Figura A.2: Comparação dos resultados de uniformidade calculados com diferentes aproximações para feixes de prótons $10 \mathrm{MeV}$ e ${ }^{28}$ Si $60 \mathrm{MeV}$. As condições indicadas por "corr"significam que foi utilizada a correção de blindagem e as condições indicadas por "ZBL"indicam que o comprimento utilizado é o de Ziegler (Equação 1.9)

Como pode ser observado, as correções possuem um efeito mais pronunciado para os feixes mais pesados e alvos finos. No caso de prótons, a utilização do comprimento de blindagem de Ziegler altera os valores até espessuras maiores do alvo. Apesar disso, o efeito das correções é pequeno e pôde ser desconsiderado neste trabalho. 